\title{
SYNTHESIS OF RARE \\ NUCLEOBASES AND ARTIFICIAL \\ NUCLEOTIDES FOR INVESTIGATION \\ OF CATALYTIC ENZYME ACTIVITY
}

\author{
Dissertation
}

for the award of the degree

"Doctor rerum naturalium"

of the Georg-August-Universität Göttingen

within the doctoral program Chemistry

of the Georg-August University School of Science

(GAUSS)

\author{
submitted by \\ Matthias Krull \\ from Göttingen
}

Göttingen, 2019 


\section{Thesis Committee}

Prof. Dr. Ulf Diederichsen

Institute of Organic and Biomolecular Chemistry, University of Göttingen

Prof. Dr. Kai Tittmann

Department of Molecular Enzymology, University of Göttingen

\section{Members of the Examination Board}

Referee:

Prof. Dr. Ulf Diederichsen

Institute of Organic and Biomolecular Chemistry, University of Göttingen

2nd Referee:

Prof. Dr. Kai Tittmann

Department of Molecular Enzymology, University of Göttingen

\section{Further Members of the Examination Board}

Prof. Dr. Manuel Alcarazo

Institute of Organic and Biomolecular Chemistry, University of Göttingen

Prof. Dr. Claudia Steinem

Institute of Organic and Biomolecular Chemistry, University of Göttingen

Dr. Sebastian Kruss

Institute of Physical Chemistry, University of Göttingen

Dr. Michael John

Institute of Organic and Biomolecular Chemistry, University of Göttingen

Date of oral examination: September 25, 2019 
The work described in this thesis was carried out under the supervision of Prof. Dr. Ulf Diederichsen at the Institute of Organic and Biomolecular Chemistry of the Georg-August University of Göttingen between November 2015 and August 2019 in close cooperation with Prof. Dr. Kai Tittmann at the Department of Molecular Enzymology of the Georg-August University of Göttingen.

Parts of Chapter 2 of this thesis have been published as:

S. Johansson, P. Neumann, A. Wulff, L.M. Welp, H.-D. Gerber, M. Krull, U. Diederichsen, H. Urlaub, R. Ficner, "Structural insights into the stimulation of S. pombe Dnmt2 catalytic efficiency by the tRNA nucleoside queuosine", Scientific Reports, 2018, 8:8880.

\section{Declaration of Authorship}

Hereby, I declare that I prepared the doctoral thesis entitled "Synthesis of rare nucleobases and artificial nucleotides for investigation of catalytic enzyme activity" on my own and with no other sources and aids than quoted.

Göttingen, August 2019

MATTHIAS KRULL 

Dedicated to my parents 



\section{Contents}

\begin{tabular}{ll}
\hline Introduction & 1
\end{tabular}

1. Mechanistic studv of orotidine-5'-monophosphate-decarboxylase 5

1.1. Motivation and obiectives ................. . 5

1.2. Orotidine-5'-monophosphate-decarboxylase (OMPD) . . . . . . . . 7

1.2.1. Structure . . . . . . . . . . . . . . . . 7

1.2.2. Substrate bindina . . . . . . . . . . . . . . . . 9

1.3. Possible decarboxvlation mechanisms . . . . . . . . . . . 12

1.4. Synthesis of OMPD Inhibitors . . . . . . . . . . . . . . 15

1.4.1. OMP (1) . . . . . . . . . . . . . . 18

1.4.2. BMP (3) and 6-aza-UMP (4) . . . . . . . . . . . . 20

1.4.3. 6-Amido-UMP (8) . . . . . . . . . . . . . . . . . . 21

1.4.4. 6-Isopropvl-UMP (9) . . . . . . . . . . . . . . . 22

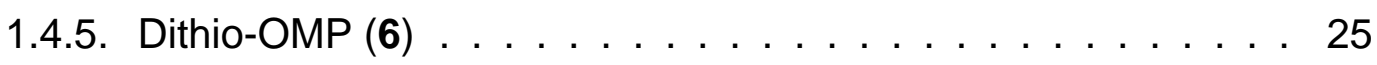

1.4.6. 6-Nitro-UMP (5) . . . . . . . . . . . . . . . 30

1.5. Examination of hOMPD-inhibitor complexes using cryo-crystallography 35

1.5.1. hOMPD-BMP complex. . . . . . . . . . . . 36

1.5.2. hOMPD-6-Aza-UMP complex . . . . . . . . . . . . . 37

1.5.3. hOMPD-6-Amido-UMP complex . . . . . . . . . . . 40

1.5.4. hOMPD-6-Thiocarboxamido-UMP complex . . . . . . . . 42

1.5.5. hOMPD-6-Isopropyl-UMP complex . . . . . . . . . . 44

1.5.6. hOMPD-6-Methyl-UMP complex . . . . . . . . . . . . 46

1.5.7. hOMPD-6-Isopropenyl-UMP complex . . . . . . . . . 48

1.5.8. hOMPD ${ }_{314 \mathrm{Ac}}-\mathrm{OMP}$ complex $\ldots \ldots \ldots \ldots . \ldots 50$

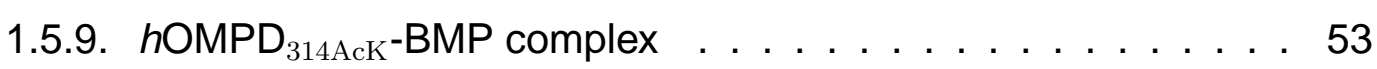

1.6. Discussion . . . . . . . . . . . . . . . . . . . 55

1.6.1. New insights into enzyme substrate interactions . . . . . . 55

1.6.2. Mechanistic implications . . . . . . . . . . . . . . . . . 59

1.7. Summary . . . . . . . . . . . . . . . . . 63

1.8. Outlook . . . . . . . . . . . . . . . . 65 
2. Stimulation of S. pombe Dnmt2 by the micronutrient queuine 67

2.1. Motivation and objectives . . . . . . . . . . . . . . 67

2.2. Dnmt2 . . . . . . . . . . . . . . . . . . . . . . . . . 69

2.3. Queuosine biosvnthesis . . . . . . . . . . . . . . . . 70

2.4. Chemical svnthesis of queuine and queuosine . . . . . . . . 72

2.4.1. Synthetic strateaies for queuosine . . . . . . . . . . . 72

2.4.2. Synthetic strategies for queuine . . . . . . . . . . . . 76

2.4.3. Improved syntheses for the cyclopentylamino building block $63 \quad 78$

2.4.4. Recent synthetic strategies for queuine . . . . . . . . 80

2.5. New synthesis of (1R,2S,3S)-1-bromo-2,3-O-isopropylidene-

cyclopent-4-ene (122) . . . . . . . . . . . . . . . . . . 82

2.6. Stimulation of $S$. pombe Dnmt2 by queuine . . . . . . . . . 89

2.7. Summary . . . . . . . . . . . . . . . . . . . . . . . . 92

3. Experimental section 95

3.1. General Equipment and Methods . . . . . . . . . . . . . . . 95

3.2. Characterization . . . . . . . . . . . . . . . . . 96

3.3. X-rav diffraction data collection and processing . . . . . . . . . . 97

3.4. Svnthesis of orotidine analoques . . . . . . . . . . . . . 98

3.4.1. 2'.3'-O-Isopropylidene-uridine (11) . . . . . . . . . . 98

3.4.2. 5'-O-Tertbutyldimethylsilyl-2',3'-O-isopropylideneuridine (12) . . . . . . . . . . . . . . . . . 99

3.4.3. 5'-O-Tertbutyldimethylsilyl-2',3'-O-isopropylideneorotidine (13) . . . . . . . . . . . . . . 100

3.4.4. Orotidine (14) . . . . . . . . . . . . . . . . 101

3.4.5. Orotidine-5'-monophosphate (1) . . . . . . . . . . . . 102

3.4.6. 2,4,6-tris-trimethylsilyloxy-pyrimidine (16) $\ldots \ldots$. . . . 103

3.4.7. 2', 3',5'-Tri-O-benzoyl-6-hydroxyuridine (18) . . . . . . . . . 104

3.4.8. 6-Hydroxyuridine (19) . . . . . . . . . . . . . . . 105

3.4.9. Barbituric-acid-ribonucleoside-5'-monophosphate (3) . . . . . 106

3.4.10.6-Azauridine-5'-monophosphate (4) . . . . . . . . . . 107

3.4.11.5'-O-Tertbutvldimethvlsilyl-2',3'-O-isopropylideneorotidinemethylester (21) . . . . . . . . . . . . . . . . 108

3.4.12.5'-O-Tertbutyldimethylsilyl-2',3'-O-isopropylidene-

6-amidouridine (22) . . . . . . . . . . . . . . . . . . 109

3.4.13.6-Amidouridine (23) . . . . . . . . . . . . . . . 110

3.4.14.6-Amidouridine-5'-monophosphate (8) . . . . . . . . . . . 111 
3.4.15. Orotidinemethylester (24) . . . . . . . . . . . . . . . 112

3.4.16.5-lodouridine (26) . . . . . . . . . . . . . . 113

3.4.17.5'-O-Tertbutvldimethylsilyl-2',3'-O-isopropylidene-

5-iodouridine (27) . . . . . . . . . . . . . . . . . 114

3.4.18.5'-O-Tertbutvldimethylsilyl-2',3'-O-isopropylidene-

6-cyanouridine $(28 \ldots \ldots \ldots \ldots$

3.4.19.5'-O-Tertbutvldimethvlsilyl-2',3'-O-isopropylidene-

6-isopropyluridine (29) . . . . . . . . . . . . . . 116

3.4.20.6-Isopropyluridine (30) . . . . . . . . . . . . . . . 117

3.4.21.6-Isopropyl-UMP (9) . . . . . . . . . . . . . . . . 118

3.4.22.5'-O-Tertbutvldimethvlsilyl-2'.3'-O-isopropylidenedithioorotidinebenzylester $(35) \ldots . .119$

3.4.23. Dithioorotidinebenzvlester (36) . . . . . . . . . . . . . . 121

3.4.24. Dithioorotidine-5'-monophosphatebenzylester (37) . . . . . . 122

3.5. Synthesis of queuine . . . . . . . . . . . . . . . . . 123

3.5.1. Methvl-6-deoxv-6-iodo-3.4-O-isopropylidene$\alpha$-D-galactopyranoside (139) . . . . . . . . . . . . 123

3.5.2. Methyl-6-deoxy-6-iodo-3,4-O-isopropylidene-2-O-tertbutyldimethylsilyl- $\alpha$-D-galactopyranoside (140) . . . . . . . . . 125

3.5.3. (2R,3S.4S)-3.4-O-Isopropvlidene-2-O-tertbutyldimethylsilyl-hex-5-en-1-al (141) . . . . . . . . . . . 126

3.5.4. (2R.3S.4S)-3.4-O-Isopropylidene-2-O-tertbutyldimethylsilyl-hepta-1,5-diene (142) . . . . . . . . . . . . . 127

3.5.5. (1S.2S.3S)-1-O-tertbutyldimethylsilyl-2,3-O-isopropylidenecyclopent-4-ene (145) . . . . . . . . . . . . . . . . . 128

3.5.6. (2R,3S.4S)-2-Hvdroxy-3,4-O-isopropylidenehepta-1,5-diene (143) . . . . . . . . . . . . . . . . . . . . 129

3.5.7. (1S.2S.3S)-1-Hvdroxv-2,3-O-isopropylidenecyclopent-4-ene (130) . . . . . . . . . . . . . . . . . 130

3.5.8. (1R,2S.3S)-1-Bromo-2,3-O-isopropylidenecyclopent-4-ene (122) . . . . . . . . . . . . . . . . . 131

3.5.9. 2',3'-O-Isopropylidene-queuine (144) . . . . . . . . . . . . 132

3.5.10. Queuine (95) . . . . . . . . . . . . . . . . . . . . 133

3.5.11. Benzyl- $\beta$-D-galactopyranoside (132) . . . . . . . . . . 134

3.5.12. Benzyl-6-O-tertbutyldimethylsilyl- $\beta$-D-galactopyranoside (133) 135 
$\begin{array}{ll}\text { Appendix } & 145\end{array}$

A. Abbreviations ... . . . . . . . . . . . . . . . . . . . . 145

B. Crystal data collection and refinement data . . . . . . . . . . . . . . 147 


\section{Introduction}

In 1828 Friedrich Wöhler synthesized urea by heating of ammoniumcyanate. This experiment proved that organic compounds can be synthesized in vitro from inorganic materials without the necessity of a vital force (lat. vis vitalis), as it was conviction in those days. Based on this discovery, biochemistry developed from the three disciplines of natural science (physics, chemistry and biology) in the second half of the 19th century. Structure elucidation of biochemical compounds was very expensive, time consuming and often not successful at first. With the development of new methods for structure analysis in the 20th century, biochemistry made a fast development. Two events are especially noteworthy. The finding of desoxyribonucleic acid (DNA) as the carrier of genetic information, as well as the discovery of proteins and enzymes. ${ }^{\text {[1] }}$

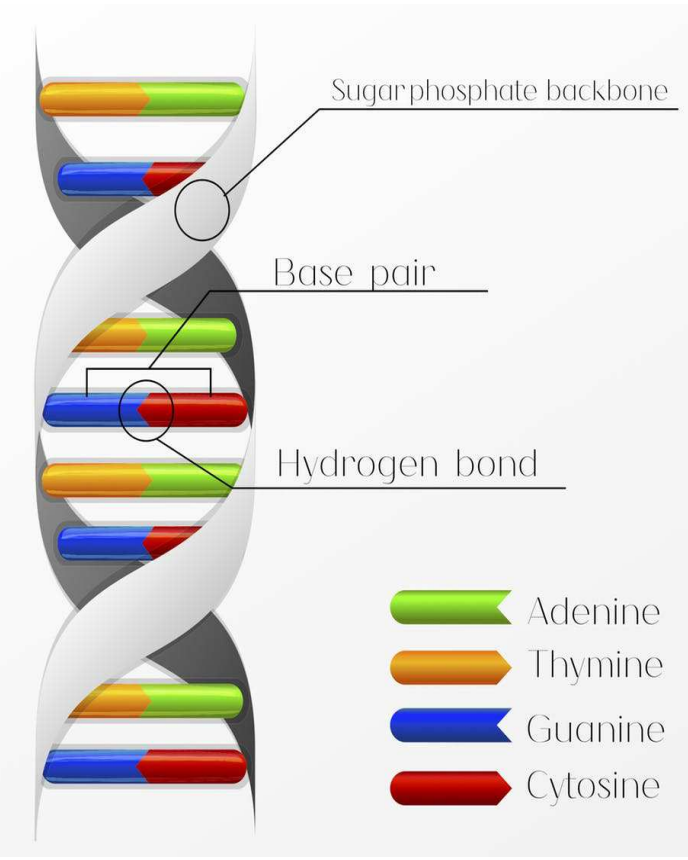

Figure 0.1. Simple model of a DNA double strand. [2]
Nucleic acids are an important class of biomolecules. In 1943 Avery identified the deoxyribonucleic acid (DNA) as the carrier of genetic information. ${ }^{3]}$ In 1953 Watson and Crick decrypted the structure of DNA. They introduced a model of four nucleotides (adenine, guanine, cytosine and thymine) which build up polymers with random sequences. The result of the sequence is a code which contains the genetic information. In pairs of two, each duo is able to form two or three hydrogen bonds between each other. Due to these bonds, two complementary strands can assemble to one double strand and form the well known double helix (figure 0.1 . .4 
Furthermore, base pairing ensures replication of genetic information by synthesizing copies of complementary strands, which enables cell division and transfer of genetic information from mother cells to daughter cells. Moreover, base sequences in DNA can be transcripted into RNA sequences, which act as a templates for amino acid sequences in peptides, enabling the controlled synthesis of proteins via translation. ${ }^{5}$

Beside nucleic acids, proteins have exceptional value in organisms due to their broad range of tasks. They can act as signal transmitters, catalytic active enzymes or form structural stability in cells. This complexity is achieved by the inner structure of proteins. They consist of up to 20 amino acids, which bind together to build up polymers. The variability in the sequence of amino acids result in a huge number of combinatorial possibilities, which lead to their broad range of tasks. With the knowledge that enzymes
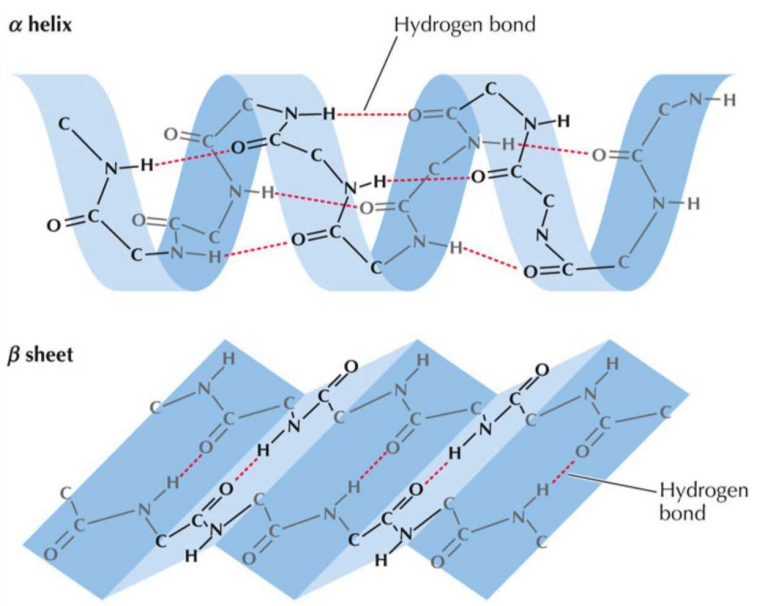

Figure $\mathbf{0 . 2}$. Models of protein secondary structures. 6 . act as bio catalysts researchers took an interest in the mechanisms with which this class of proteins achieves their tasks. The introduction of x-ray diffraction in the 1930's, opened the field of protein analytics as a new discipline in biochemistry. In 1934 Bernal and Hodgkin used this new method to prove that proteins show defined structures in solution. ${ }^{77}$ In 1951 Pauling and Corey identified the $\alpha$-helix and $\beta$-sheet as the central secondary structures in proteins. (figure 0.2 ). ${ }^{[8}$

Enzymes are also involved in replication, transcription and translation of DNA, as well as the synthesis of nucleobases. The roles and mechanisms for many of these enzymes stay broadly unknown until today. The herein presented projects are based on the research of the enzymatic activity of selected enzymes, which are important for the synthesis and modification of nucleobases.

Chapter 1 describes the synthesis of uridine-derivatives for co-crystallization with orotidine-5'-monophosphatedecarboxylase (OMPD). This enzyme catalyzes the last 
step in the de novo biosynthesis of pyrimidine-nucleotides and shows an extreme high catalytic activity. Therefore, investigation of the natural enzyme-substrate complex is impossible with currently available methods. By decreasing the catalytic activity with suitable substrate-derivatives, a targeted investigation of the mechanism should be possible.

Chapter 2 describes the development of a new synthetic route for the rare nucleobase queuine, with focus on the cyclopentadiene part. Via in vitro introduction of queuine into tRNA ${ }^{\text {Asp }}$, the stimulation of $S$. pombe Dnmt2 activity by queuine should be demonstrated. 



\section{Mechanistic study of orotidine-5'- monophosphate-decarboxylase}

\subsection{Motivation and objectives}

Cell division is one of the essential biochemical processes and of exceptional importance for the survival and reproduction of all organisms from protozoic bacterium right up to high developed multicellular animals and humans. To transfer the genetic information from the mother cell to the daughter cell, the DNA has to be duplicated prior to cell division. For this process, large amounts of nucleotides are required, in relation to the rate of division. As for most eukaryotes, humans are able to obtain most of the required nucleotides via a salvage pathway, by degradation of nucleic acids. This is the preferred pathway due to its energetic efficiency. ${ }^{[9]}$ Some cells like hair roots, liver cells and skin cells, but also malignant tumor cells show an extremely high division rate and therefore need more nucleotides than the salvage pathway is able to produce. These cells need to synthesize nucleotides from the ground up via the de novo pathway (scheme 1.1). Inhibition of this pathway might be an interesting target for the development of new therapies against cancer. Like most in vivo syntheses the de novo pathway is a cascade of many single steps. To develop specific therapies it is necessary to understand the mechanism of the de novo pathway in general and the mechanisms of the involved enzymes in particular.

The most interesting enzyme involved in the de novo pathway is orotidine-5'monophosphate-decarboxylase (OMPD (6)), which catalyzes the last step in the de novo synthesis of pyrimidine nucleotides by decarboxylation of orotidine-5'-monophosphate (1) to uridine-5'-monophosphate (2). OMPD shows one of the highest catalytic activities of all known enzymes, especially regarding the fact that it works without metal ions or other co-factors. The decryption of the mechanism of OMPD has been the topic of many studies in past years. However, aside of postulates and proposals, no verified mechanism has been published until today. 


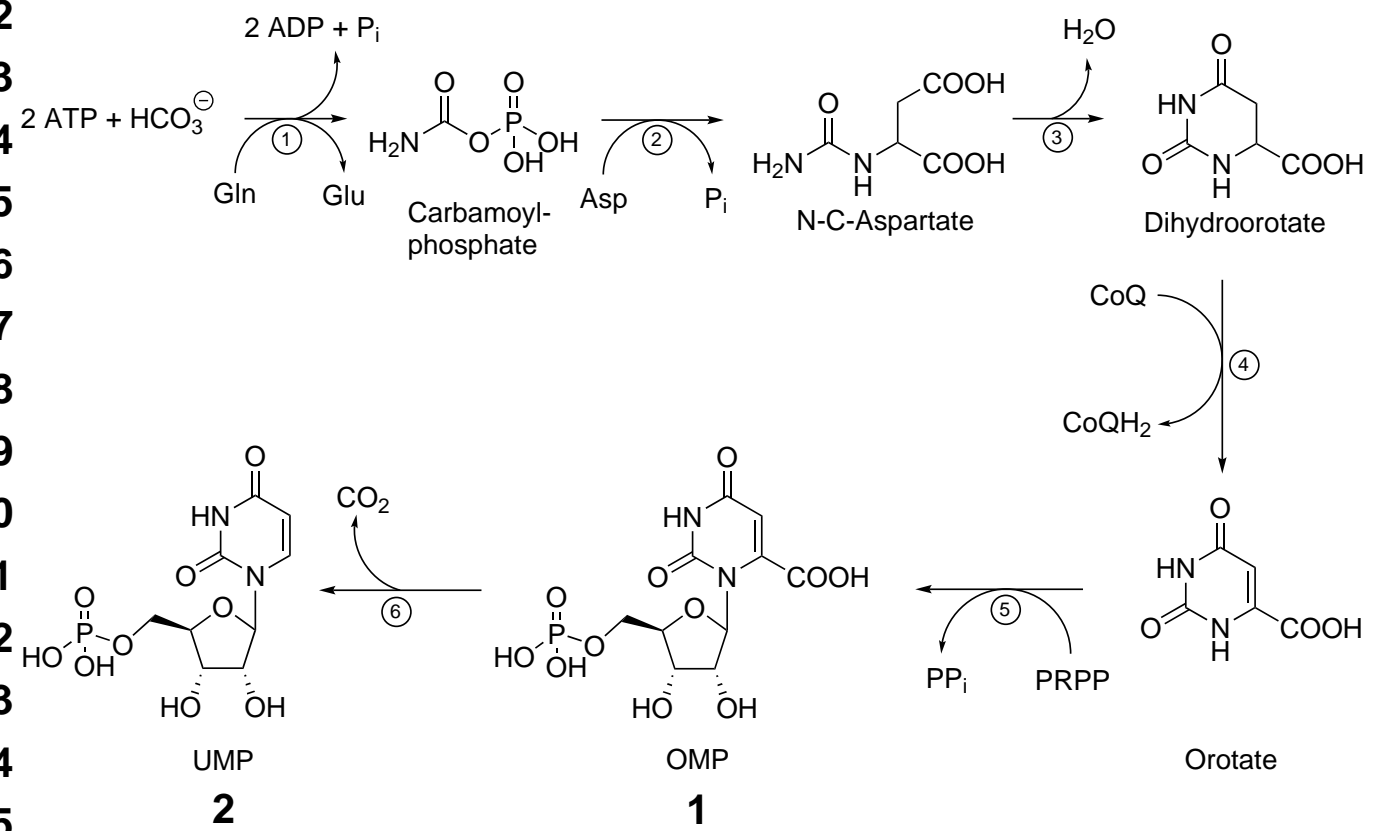

Scheme 1.1. Pathway of the de novo pyrimidine synthesis.

(1) carbamylphosphate synthetase; (2) aspartate transcarbamylase; (3) dihydroorotase; (4) dihydroorotate dehydrogenase; (5) orotate phosphoribosyltransferase; (6) orotidine 5'-monophosphate decarboxylase. 10

As of now, no enzyme-substrate complex structure has been published, due to the extreme acceleration of OMPD catalyzed decarboxylation. To understand how the enzyme is able to be so proficient without usage of metal ions, prosthetic groups or other cofactors, crystal structures are necessary to get more information of substrate binding to the active site. Due to recent improvements of $x$-ray diffraction data collection, much better resolved structures are obtainable these days. Within this thesis, new modified substrates were synthesized to act as inhibitors for OMPD. In order to obtain new information about active site binding these modified substrates and OMPD were cocrystallized and structures were measured via $x$-ray diffraction. All crystallographic experiments were performed in close cooperation with the Tittmann group. 


\subsection{Orotidine-5'-monophosphate-decarboxylase (OMPD)}

\subsubsection{Structure}

In 2000 the first crystal structures of orotidine-5'-monophosphate-decarboxylase from the organism B. subtilis, E. coli, M. thermoautotrophicum and S. cervisiae were published and provided new insights into the general structure of OMPD. ${ }^{[11-[14]}$ Crystal structures of OMPDs from other organisms followed a few years later, including human OMPD.155, 16] This new information lead to better understanding of the enzyme structure. The active OMPD is a homodimeric enzyme, consisting of two identical subunits with two active sites (figure 1.1). 115] Differences between bacteria and eukaryotes were identified. In bacteria OMPD appears in form of a single domain, whereas in eukaryotes OMPD is a part of the bifunctional enzyme complex uridine-5'-monophosphate-synthetase (UMPS). ${ }^{[17}$ Beside OMPD which is located at the C-terminal end, the UMPS complex includes orotate-phosphoribosyl-transferase which is located at the $\mathrm{N}$-terminal end, catalyzing the penultimate step of the de novo synthesis. 15

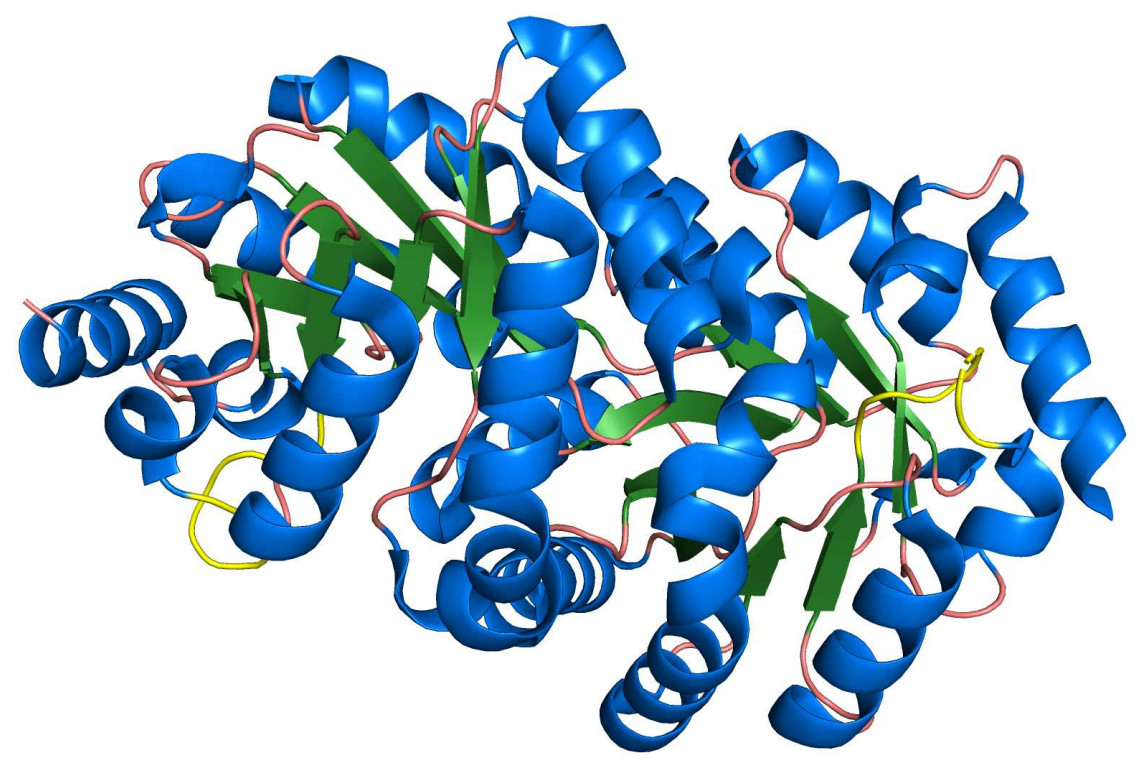

Figure 1.1. Structure of the OMPD dimer from M. thermoautotrophicum complexed with BMP (PDB entry: 4FX8). 18

(BMP is not displayed), $\alpha$-helices and $\beta$-sheets are colored in blue and green, respectively. The phosphate gripper loop is coloured in yellow. 
Each OMPD monomer forms a TIM barrel, which consist of eight parallel aligned $\beta$-sheet structures, forming a $\beta$-barrel and an outer sphere consisting of multiple $\alpha$-helices. ${ }^{19]}$ The $\alpha$ and $\beta$ motifs are connected in an alternating fashion by loop regions (figure 1.2). The exact number of these structures vary among different organisms. The OMPD monomers are stacked at the C-terminal end of the TIM barrels to form the catalytic active OMPD dimer, induced by substrate binding or by addition of $\mathrm{NaCl}$ to the buffer solution. [17, [20--22] Two active sites are formed at the monomer interfaces. Part of the active site pockets is a flexible loop region, which binds to the phosphate and ribose part of OMP. Due to the flexibility of this phosphate gripper loop, binding of the substrate induces a conformational change of the OMPD dimer. ${ }^{12}$ For different organisms, the length of the gripper loop varies in a range from 10 to 20 amino acid residues. The longer the loop, the higher the entropic cost, when the loop closes around the substrate. However, this disadvantage in entropy is offset by higher enthalpic contribution. ${ }^{\text {[23 }}$
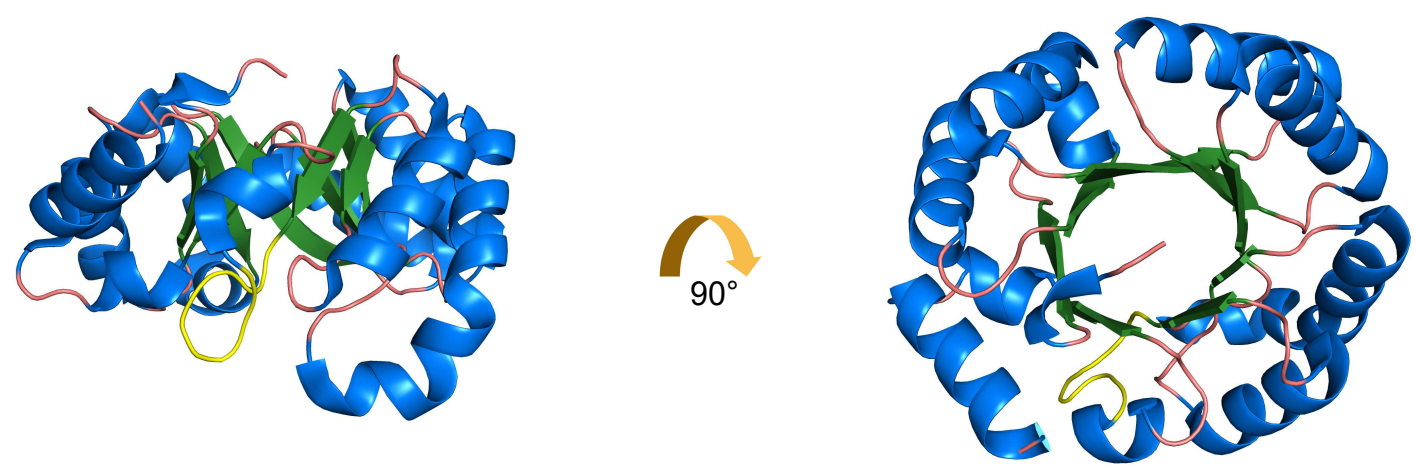

Figure 1.2. Structure of the OMPD monomer from M. thermoautotrophicum (PDB entry: 4FX8). 18 left: side-view, right: top-view, $\alpha$-helices and $\beta$-sheets are colored in blue and green, respectively. The phosphate gripper loop is coloured in yellow.

Opposite of the phosphate gripper loop the active site is located, which looks very similar in all domains of life, ranging from bacteria to higher evolved eukaryotes, like plants and mammals. The amino acid residues, which are part of the active site or are located in close proximity, appear to be highly conserved. 24] The TIM barrels form a rigid framework, which conserves the important catalytic active amino acid residues, while also possess some flexibility due to the loop regions, allowing conformational changes during substrate binding and decarboxylation. 25], 26] The central part of these conserved residues consist of two alternating aspartates and lysines, forming the catalytic tetrad (figure 1.3). Mutation at one of these residues lead to significant loss of catalytic activity. ${ }^{[11]}$ This tetrad is mostly part of one TIM barrel with the exception of Asp' ${ }_{317}$, which belongs to a short loop of the other monomer. ${ }^{[27]}$ The 


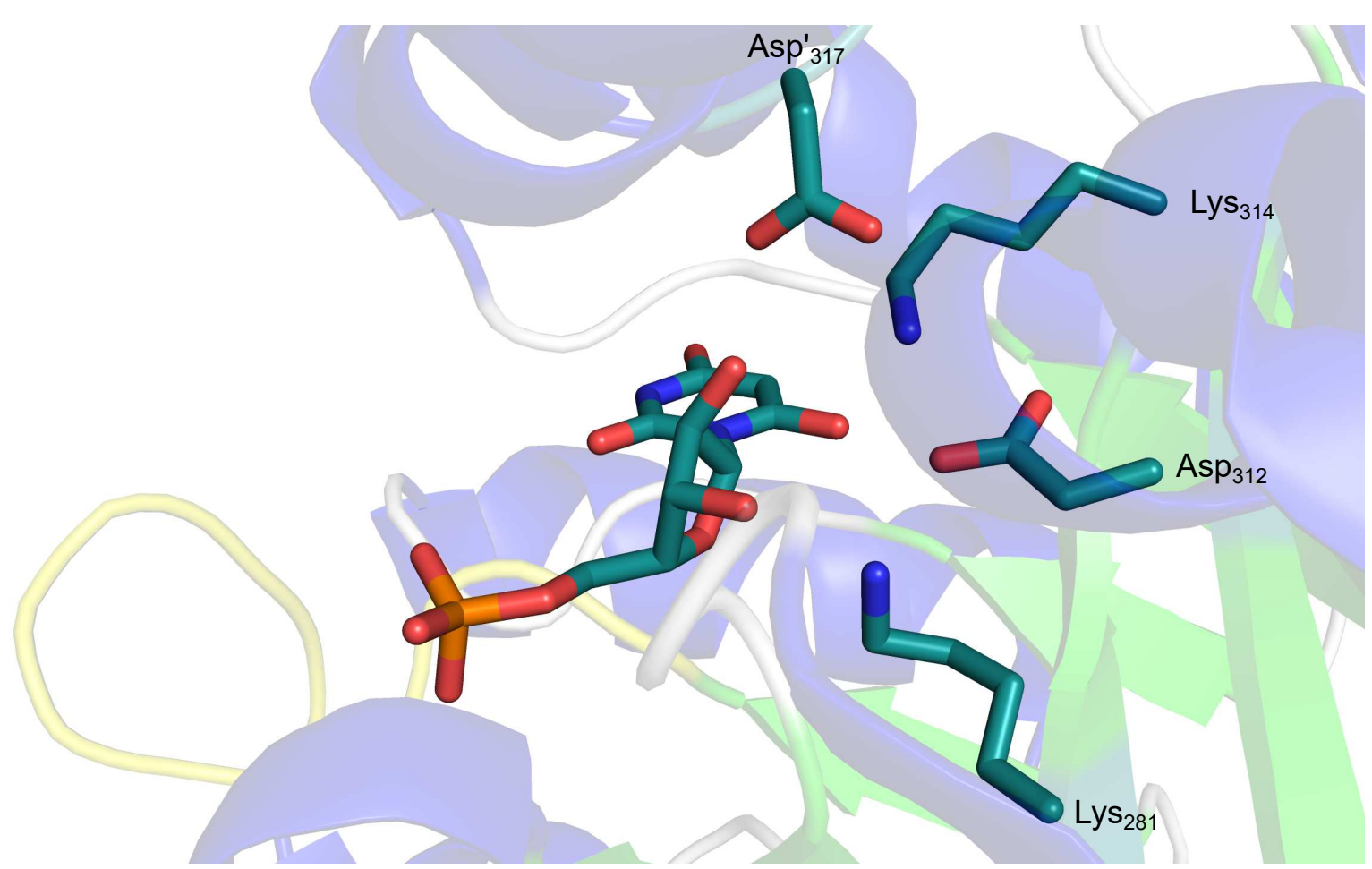

Figure 1.3. Catalytic tetrad from the active site of $M$. thermoautotrophicum complexed with BMP. (PDB entry: 4FX8).

$\alpha$-helices and $\beta$-sheets are colored in blue and green, respectively. The phosphate gripper loop is coloured in yellow.

active site is surrounded by a cage of hydrophobic amino acid residues, shielding it from solvent and keeping it nearly water free after substrate binding. Additionally, a hydrophobic pocket is formed near to the $\mathrm{C} 6$ carboxy group of the substrate. This pocket is considered to harbor the produced carbon dioxide. However, no $\mathrm{CO}_{2}$ could be detected in the pocket yet. ${ }^{[15], 211,28]}$

\subsubsection{Substrate binding}

Substrates are bound to the OMPD active site via a complex network of hydrogen bonds from the phosphate, ribose and pyrimidine part of the substrate to the amino acid side chains from the phosphate gripper loop, the pyrimidine umbrella and the catalytic tetrad of OMPD (figure 1.4). ${ }^{116}$ In human OMPD the phosphate part of substrates forms two hydrogen bonds to $\mathrm{Gly}_{430}$ and $\mathrm{Tyr}_{432}$ of the phosphate gripper loop and four additional bonds to the side chains and the backbone of $\operatorname{Arg}_{451}$ and $\mathrm{Gly}_{450}$. The ribose part is bound to $\mathrm{Asp}_{259}, \mathrm{Ser}_{257}$, Thr' ${ }_{321}$, as well as $\mathrm{Lys}_{281}$ and $\mathrm{Asp}_{317}$ of the catalytic tetrad by six hydrogen bonds. Finally, the substrate pyrimidine is bound to $\mathrm{Ser}_{372}$ from the pyrimidine umbrella at $\mathrm{O} 4$ and N3 and to $\mathrm{Gln}_{430}$ from the phosphate 


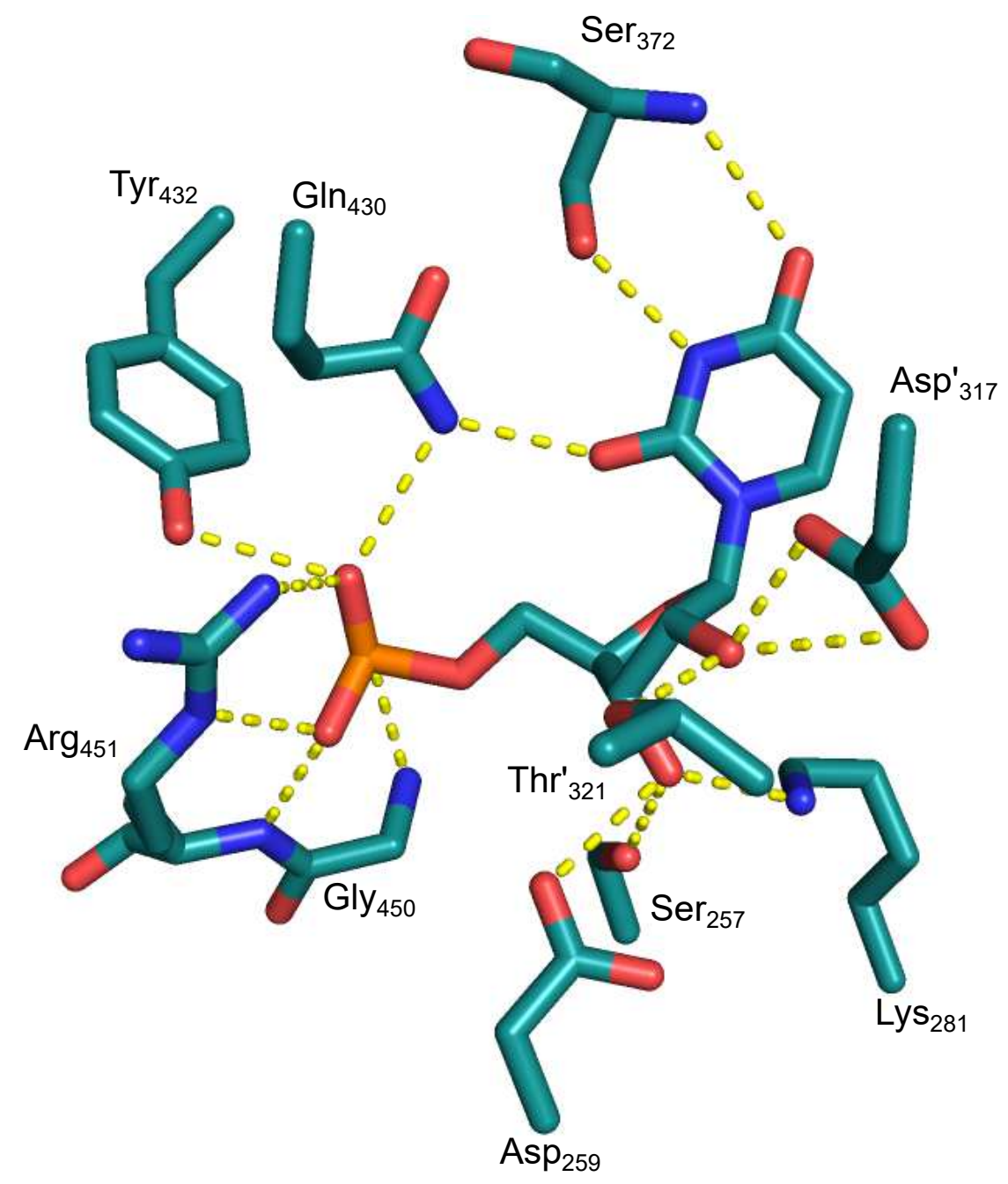

Figure 1.4. Binding of UMP to the active site of human OMPD (PDB entry: 3EX1).16 Hydrogen bonds are depicted as dashed yellow lines.

gripper loop at $\mathrm{O} 2$. Via coordination to the amino acid residues the pyrimidine ring is forced into the energetically unfavored syn conformation, aligning C6 substituents toward the catalytic tetrad. ${ }^{[11, \text { [29] }}$

However, the active site is considered rather small regarding the space needed by the substrate bound in syn conformation. This results in a clash of the $\mathrm{C} 6$ substituent with $\mathrm{Asp}_{312}$ of the catalytic tetrad. In the case of OMP being the substrate, Wu et al. assumed that ground state destabilization due to electrostatic repulsion is a part of the decarboxylation mechanism. The repulsion leads to distortions at the $\mathrm{C} 6$ substituent, showing rotation around the $\mathrm{C} 6-\mathrm{C} 7$ axis and bending out of the pyrimidine plane. ${ }^{[15}$, 16, [30, 31] Nonetheless, C6 substrate distortion do not seem to originate of electrostatic repulsion exclusively. In $\mathrm{Asp}_{312}$ mutants substrate distortion 

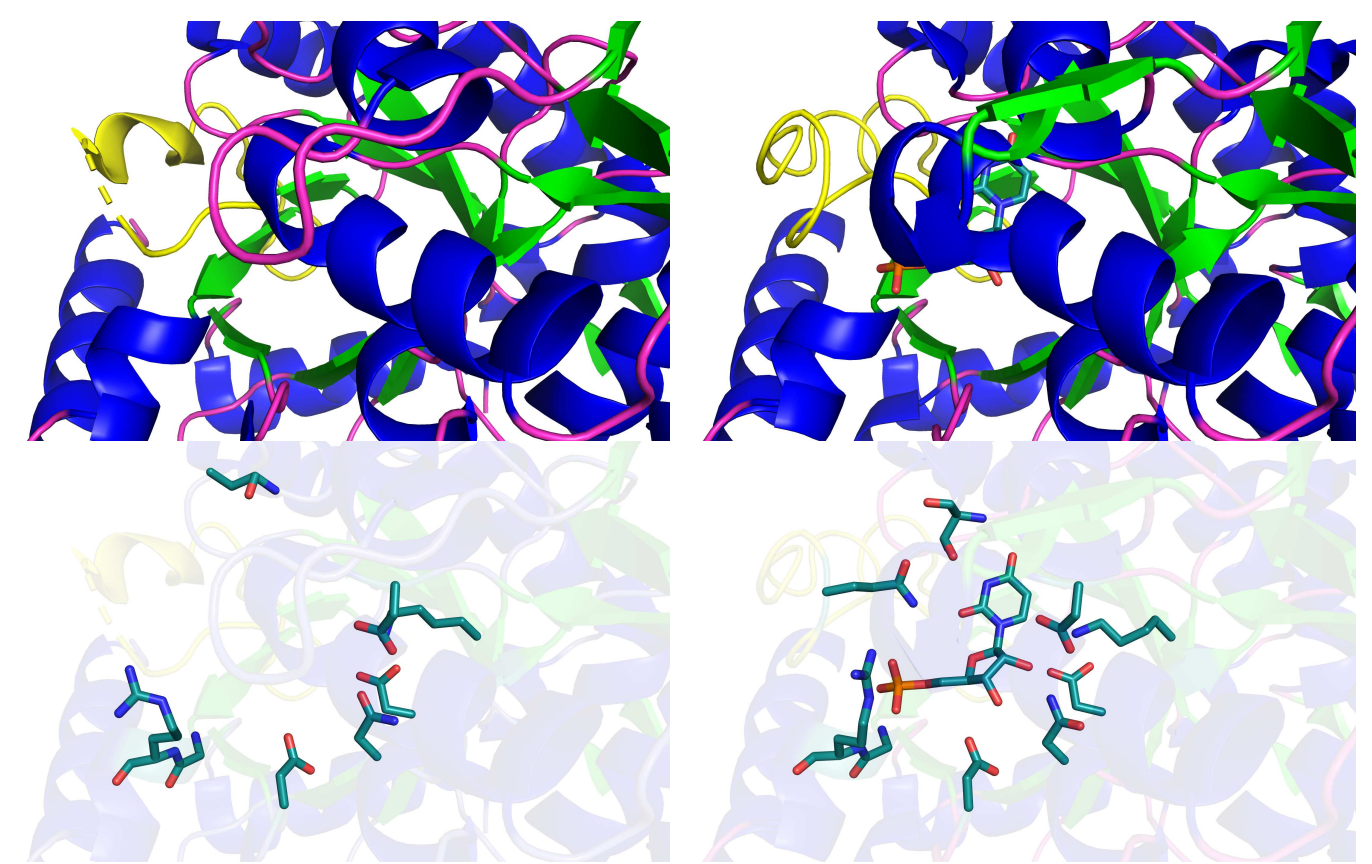

Figure 1.5. Conformational change of OMPD from $P$. falciparum induced by ligand binding. (PDB entries: 2ZA2, 2ZA3) $)^{34}$

$\alpha$-helices and $\beta$-sheets are colored in blue and green, respectively. The phosphate gripper loop is coloured in yellow.

was also observed. [30, [32] The necessary energy to force the syn conformation is gained by phosphate and ribose binding. ${ }^{\text {[3] }}$

Upon substrate binding OMPD undergoes some conformational changes around the active site. An open form, without bound substrate and a closed form with substrate in the active site can be differentiated (figure 1.5). Mainly, the phosphate gripper loop is moving towards the active site, caused by hydrogen bonding of $\mathrm{Gl}_{430}$ to the pyrimidine part of the ligand, closing the active site and resulting in exclusion of solvent molecules. ${ }^{[14,}$, [35] Additionally, movement of some $\alpha$-helices closer the active site causing rearrangement of some amino acid residues involved in substrate binding as well as a minor rearrangement of the catalytic tetrad.

Like mutations at the catalytic tetrad residues, mutations at the binding regions also reduce catalytic activity, though in much lesser severity. Exchange of residues involved in pyrimidine binding may enable the ligand to adopt anti conformation, flipping the C6 substituent away from the catalytic tetrad. ${ }^{[27, \text {, 36] }}$ A similar effect was observed for the ribose binding residues. Failures in the hydrogen bond network are assumed to cause more flexibility of the ligand, which enables the $\mathrm{C} 6$ substituent to evade the catalytic tetrad. 37 


\subsection{Possible decarboxylation mechanisms}

The mechanism of OMPD catalyzed decarboxylation is a topic of discussion for almost 40 years now. 29], [38- -40$]$ Regarding the enormous efficiency of OMPD, it is very difficult to obtain suitable data. NMR spectroscopy is not viable due to the size of the enzyme. Moreover, the method is too slow for the reaction timescale. IR spectroscopy is able to provide data but the results are very difficult to interpret. 41] However, OMPD shows good expressibility and can be crystallized reliably. Therefore, $x$-ray diffraction is the best suited method, although the reaction remains too fast to be directly observable. To get insights into substrate binding, OMPD mutants and substrate analogs were used and are the basis of the following mechanistic proposals, alongside kinetic measurements. The possible mechanisms are manifold and ranging from covalent bound intermediates, over concerted reactions to spontaneous decarboxylation (scheme 1.2). [11, [38], [42]-[45]

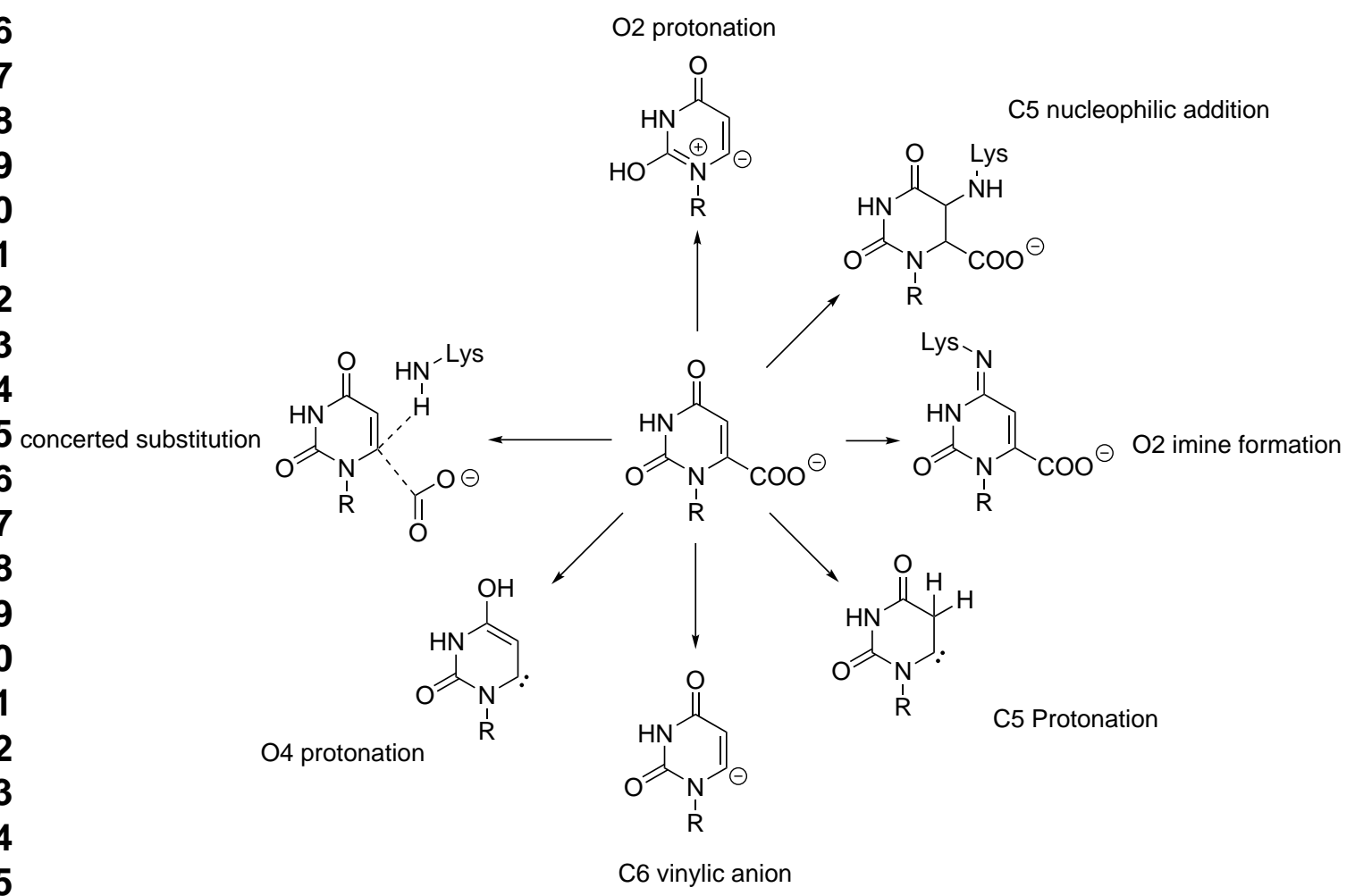

Scheme 1.2. Overview of proposed mechanisms of OMPD catalyzed decarboxylation. 29, (45, ,46]

The first possible mechanism was proposed by Beak and Siegel. They suggested a protonation at $\mathrm{O} 2$ leading to yilide formation and a positive charge located at N1 (scheme 1.3). Decarboxylation would lead to formation of a zwitterionic intermedi- 
ate which is stabilized by tautomerism. Their proposal is supported by observations of an $10^{8}$-fold increase of uncatalyzed decarboxylation velocity in $\mathrm{C} 2$ methylated 1methylorotate compared to unmodified 1-methylorotate. 43, 47] Additionally, Shostak and Jones observed a significant loss of activity using 2-Thio-OMP and 4-Thio-OMP as substrate analogs. However, it remains unclear if this effect is due to lower protonation at $\mathrm{C} 2$ and $\mathrm{C} 4$ position or worse fixation of the pyrimidine ring as a result of weaker hydrogen bonding to the thiocarbonyl groups. [44, [48, [49] A similar mechanism was proposed by Lee and Houk. They reported a protonation at $\mathrm{O} 4$ which gets stabilized as a carbene at C6, following decarboxylation. However, no proton donor amino acid residues were found near $\mathrm{O} 4$ and $\mathrm{O} 2.33$, 38]

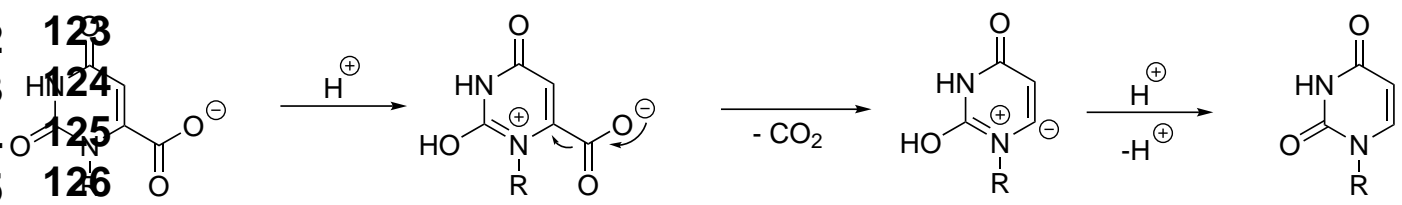

Scheme 1.3. Nitrogen-yilide mechanism postulated by Beak and Siegel. $\stackrel{43}{ }$

Silverman and Groziak proposed a covalent mechanism, although this reaction type is very rare in enzyme catalysis. ${ }^{42}$ In this proposal Lys ${ }_{314}$ acts as a nucleophile attacking $\mathrm{C} 5$ of the pyrimidine ring in a Micheal-addition, followed by elimination of $\mathrm{CO}_{2}$ with $\mathrm{Lys}_{314}$ as the leaving group (scheme 1.4). This mechanism is supported by the finding that any mutation at Lys ${ }_{314}$ leads to almost complete loss of activity, which can be regained by renaturation (Smiley and Jones). [20] However, Lys ${ }_{314}$ may be the most important amino acid residue in other mechanisms as well. Therefore, loss of activity does not support covalent mechanisms exclusively.
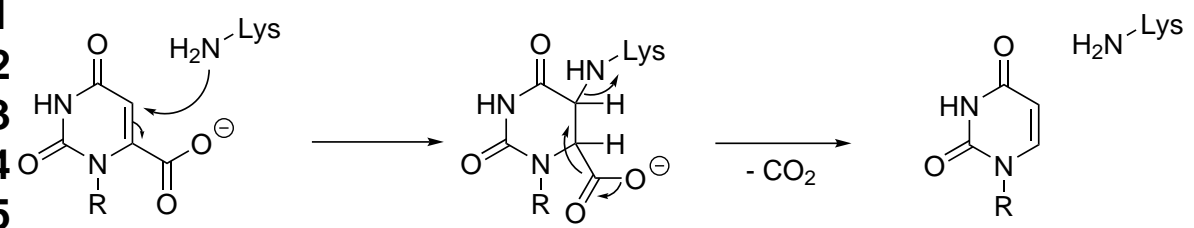

Scheme 1.4. Covalent mechanism postulated by Silverman and Groziak. 42

Kollman et al. proposed a protonation-elimination mechanism at C5 with a carbene intermediate at $\mathrm{C} 6$ (scheme 1.5). This mechanism is supported by out of plane distortion of the $\mathrm{C} 6-\mathrm{C} 7$ bond, indicating a change of geometry at $\mathrm{C} 5$ by switch-

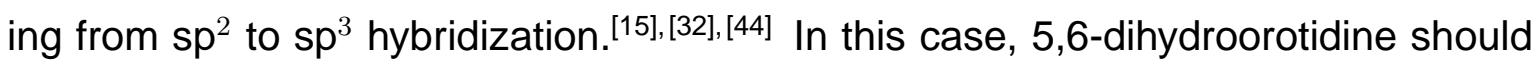
be a strong inhibitor for OMPD. Yet, kinetic studies revealed 5,6-dihydroorotidine 
to bind very poorly to OMPD. Moreover, no crystal structures complexed with 5,6dihydroorotidine could be obtained. .50

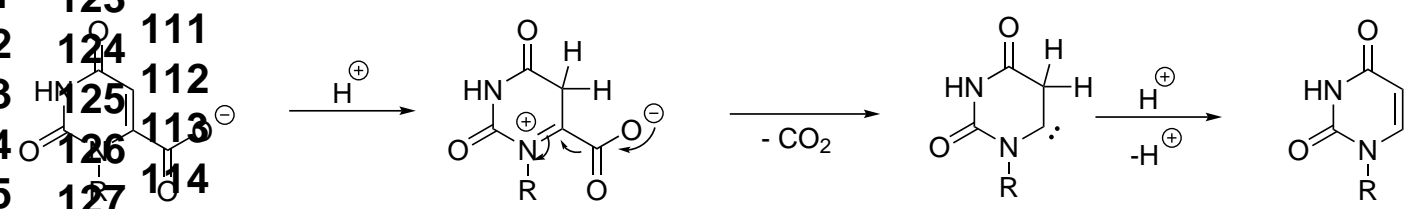

Scheme 1.5. C5 protonation mechanism postulated by Kollman et al. 44

A concerted mechanism with release of $\mathrm{CO}_{2}$ and simultaneous protonation was proposed by Appleby et al. (scheme 1.6) The reaction proceeds without change of geometry at $\mathrm{C} 6$. Support for this proposal comes from computations suggesting no geometrical change at N1, C5 and C6. Additionally, no secondary isotope effect was observed. [11], [51-[53] However, if the reaction is concerted the product UMP should be $100 \%$ protonated in $50: 50 \mathrm{v} / \mathrm{v} \mathrm{H}_{2} \mathrm{O}, \mathrm{D}_{2} \mathrm{O}$ due to the fact that protonation should be done by Lys ${ }_{314}$ exclusively.

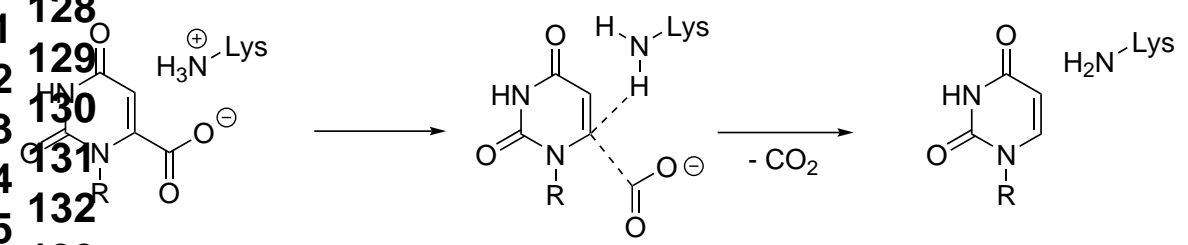

Scheme 1.6. Concerted mechanism postulated by Appleby et al.11]

Another possible mechanism was proposed by Wolfenden et al., suggesting a spontaneous decarboxylation facilitated via ground state destabilization by electrostatic repulsion (scheme 1.7). The resulting negative charge remains located at $\mathrm{C6}$ and is stabilized by protonated $\mathrm{Lys}_{314}$ residue until protonation. [12, [37]

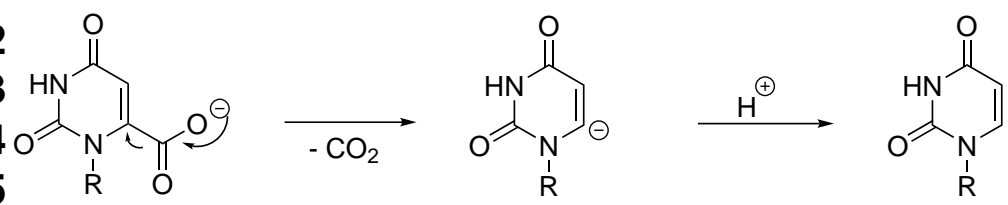

Scheme 1.7. Direct decarboxylation mechanism postulated by Wolfenden et al. ${ }^{37}$ 


\subsection{Synthesis of OMPD Inhibitors}

To get more insight into the mechanism of OMPD catalyzed decarboxylation, crystal structures are a very useful tool. To obtain these structures, the substrate get soaked into the precrystallized resting state enzyme and is then measured via $x$-ray diffraction. Unfortunately, the decarboxylation is too fast in the OMP-OMPD complex to obtain crystal structures using current methods. To get structural information, two options are available. First, OMPD mutants can be used, which show decreased or no activity. The other option to gain information is usage of substrate analogues, which are similar to OMP in terms of geometry and electronic structure. Another option, are transition state analogues, trapping the enzyme at the energy minimum. However, the information gained by both options might belong to artificial structures and are prone to be misinterpreted. In this work new substrate- and transition state analogues were synthesized, which were designed to gain specific information about the structure of the active site and its interactions with the substrate. Additionally, some known inhibitors were synthesized in order to reevaluate published results with higher resolved structures.

Studies from Miller and Wolfenden with the competitive inhibitor BMP (3) demonstrated highly effective inhibition characteristics. ${ }^{[39]}$ They proposed a deprotonation at the C6-hydroxy group, forming a C6-hydroxylate anion, which mimics the C6 anion transition state and results in trapping the enzyme at the energy minimum. This hypothesis should be verified using modern methods of crystallization and $\mathrm{x}$ ray diffraction to obtain new high resolution structures of the OMPD-BMP complex. Therefore BMP should be synthesized following known protocols. Moreover, 6-azaUMP (4) was a synthetic target to evaluate the possibility of a carbene intermediate at $\mathrm{C6}$, which may result from shift of the negative charge to the $\mathrm{O} 4$ oxygen. In this case the electron lone pair of the N6 nitrogen would mimic the carbene lone pair, which should result in detectable interactions with the active site.

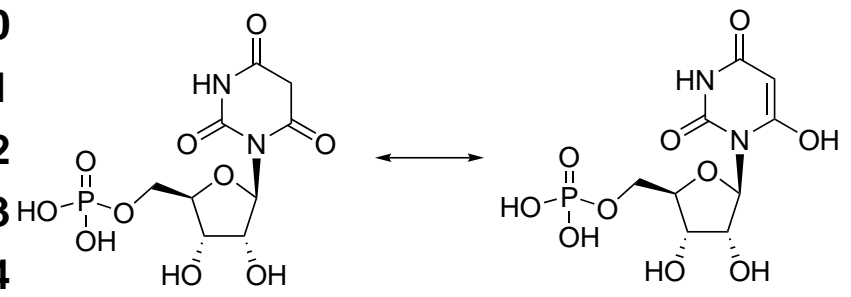

3

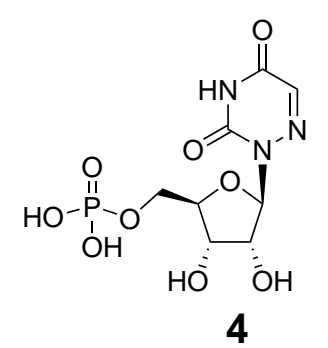

4

Scheme 1.8. Transition state analogues: left: BMP (3); right: 6-aza-UMP (4) 
Earlier studies from Pai et al. revealed an out of plane distortion of the $\mathrm{C} 6-\mathrm{C} 7$ axis from the pyrimidine ring plane. ${ }^{32, \text {, 33] }}$ The reason for this distortion could not be verified exactly and remains unclear until today. In research community an electrostatic repulsion between the carboxylate group at $\mathrm{C} 6$ and $\mathrm{Asp}_{312}$ of the catalytic tetrad is the favored reason for this out of plane distortion. However, aside from OMPD mutants, no OMP-OMPD-structure is known so far to support the electrostatic repulsion hypothesis. The synthesis of OMP analogues, which are isoelectronic to OMP (1) and posses identical geometric properties, should help to evaluate the interactions of the catalytic tetrad with the $\mathrm{C} 6$ carboxy group. For this purpose new substrate analogues should be synthesized (scheme 1.9). Best suitable are 6-nitro-UMP (5) and 6-dithiocarboxy-UMP (6), which are isoelectronic and geometric identical to OMP (1). Other geometric suitable analogues are 6-boryl-UMP (7) and 6-amidoUMP (8). The latter should be synthesized to detect possible attractive interactions, in case that the OMP-C6 carboxy group remains protonated. To evaluate the OMPD active site with respect to steric tolerance and to determine how non-electrostatic interactions contribute to the out of plane distortion, 6-isopropyl-UMP (9) should be synthesized.

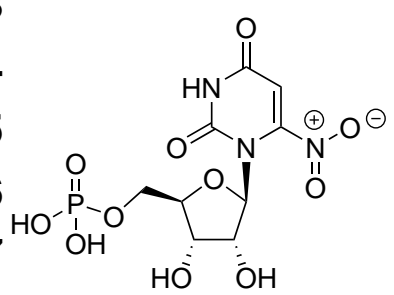

5

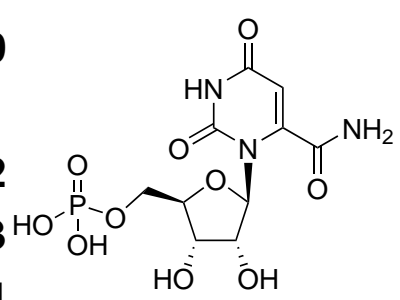

8

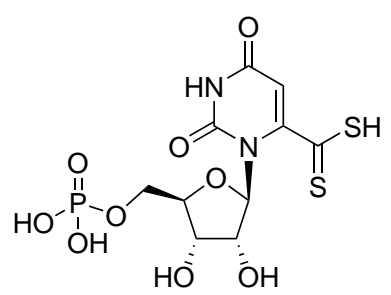

6<smiles>CC(C)c1cc(=O)[nH]c(=O)n1C1OC(O)C(O)C1COP(=O)(O)O</smiles>

9

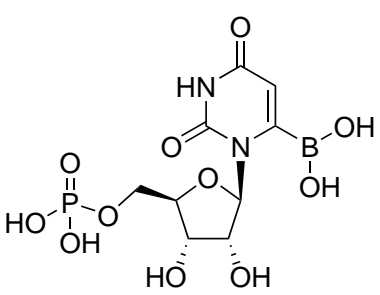

7

Scheme 1.9. Substrate analogues: isoelectronic: 6-nitro-UMP (5), 6-dithiocarboxy-UMP (6); geometric identical: 6-boryl-UMP(7), 6-amido-UMP (8); sterically demanding: 6-isopropyl-UMP (9).

Overall, modifications at $\mathrm{C} 6$ position are best tolerated by the active site, evidenced by relatively low $K_{\mathrm{d}}$ values of $\mathrm{C} 6$ modified UMP derivatives. Modifications at $\mathrm{O} 2$ and $\mathrm{O} 4$, as well as at the phosphate result in much higher $K_{\mathrm{d}}$ values and poor binding affinity to OMPD. Especially phosphate modification lead to signifi- 
cant loss of catalytic activity. In case of $S$. cervisiae the activity is decreased by $10^{9}$, when 1-orotidyl- $\beta$-D-erythrofuranoside and phosphite anions are used as substrate. ${ }^{391,[54,[55]}$ Moreover, co-crystallization experiments failed completely, when nucleosides and phosphite were used instead of the corresponding well crystalizable nucleotide inhibitors. ${ }^{56}$

For modifications at the pyrimidine, electrophilic aromatic substitution is suitable, due to the aromatic character of the pyrimidine heterocycle. However, the double bond between $\mathrm{C} 5$ and $\mathrm{C} 6$ possesses significant olefin character, enabling electrophilic addition and, because of the conjugation to the $\mathrm{O} 4$ carbonyl, Michael addition. For aromatic heterocycles an alternating electron density at the carbon-atoms is common. In the case of pyrimidine the $\mathrm{C} 6$ carbon possesses significant less electron density compared to the $\mathrm{C} 5$ carbon. This enables polarity inversion at $\mathrm{C} 6$ via lithiation with strong bases, followed by reaction with electrophiles as another synthetic strategy. An overview of suitable reactions is displayed in scheme 1.10 ,

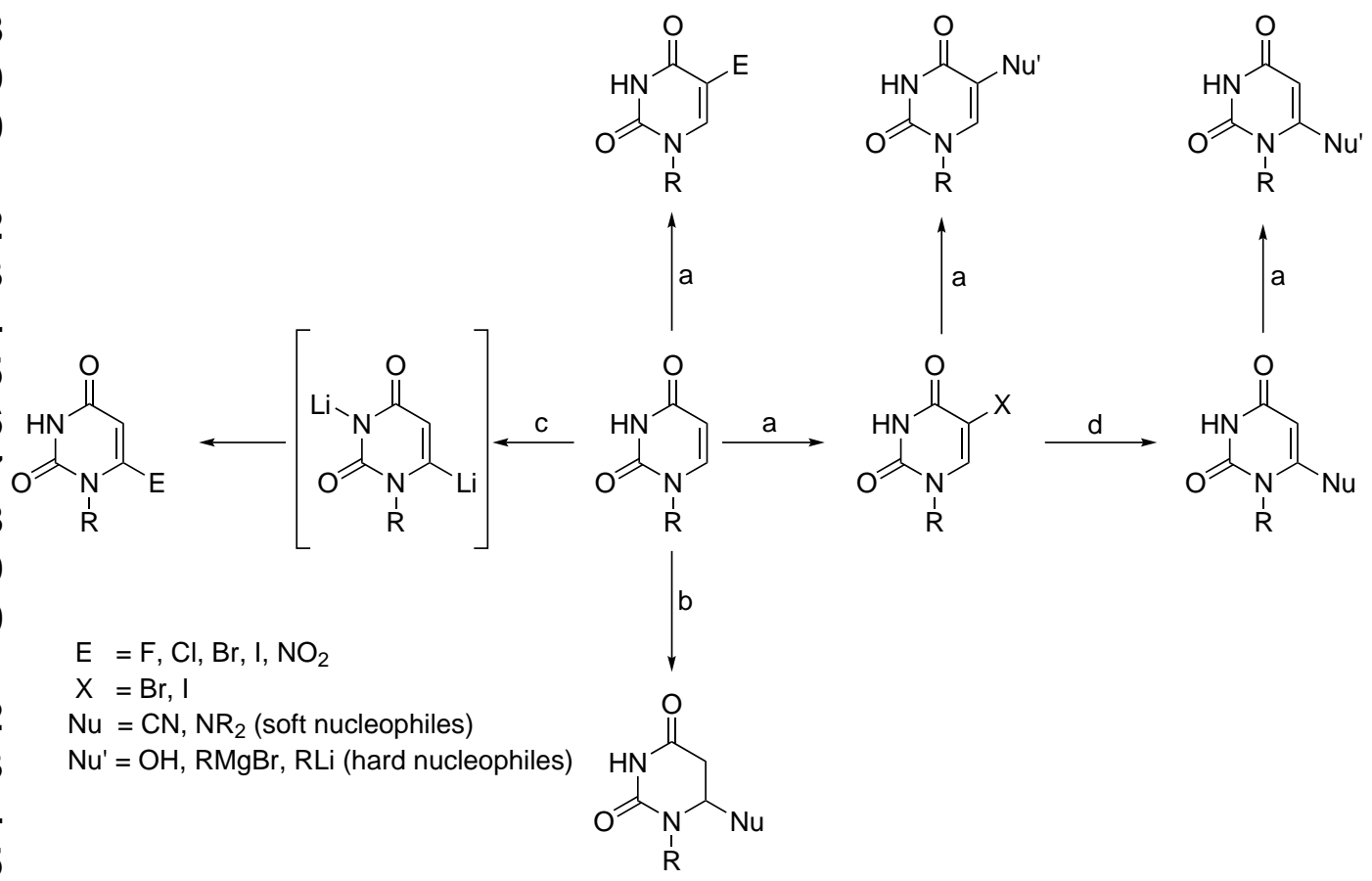

Scheme 1.10. Suitable synthetic strategies for uridine functionalisation.

a) electrophilic aromatic substitution; b) electrophilic addition; c) polarity inversion at C6 and subsequent reaction with an electrophile; d) Michael addition at $\mathrm{C} 6$ followed by elimination at $\mathrm{C} 5$.50]

In order to avoid any side reactions at the ribose unit during pyrimidine modification, the hydroxy groups at C2', C3' and C5' had to be protected prior to C6 functionalisation. Suitable protecting groups need to be stable under harsh basic 
conditions and should be cleavable under slightly acidic conditions. Starting from uridine (10) full protection was achieved in two steps (scheme 1.11). Due to the syn configuration of the hydroxy groups at C2' and C3' an isopropylidene protecting group was chosen, which can be attached easily by reaction with acetone under slightly acidic conditions. The resulting C2'-C3' protected uridine $\mathbf{1 1}$ was used in the next step after chromatographic purification. The remaining hydroxy group at C5' was protected using tert-butyldimethylsilylchloride (TBDMSCI) and imidazole in DMF. After purification by column chromatography the fully protected uridine $\mathbf{1 2}$ was obtained with $85 \%$ yield over two steps in multi gramm scale and was used as the starting material for further $\mathrm{C} 6$ functionalisation in most cases.

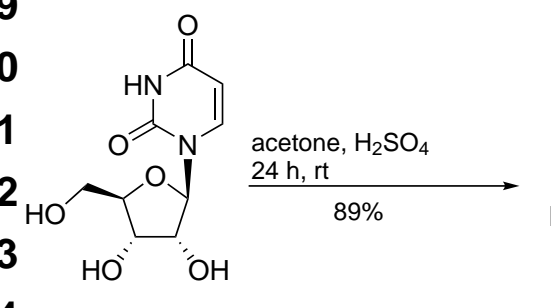

10

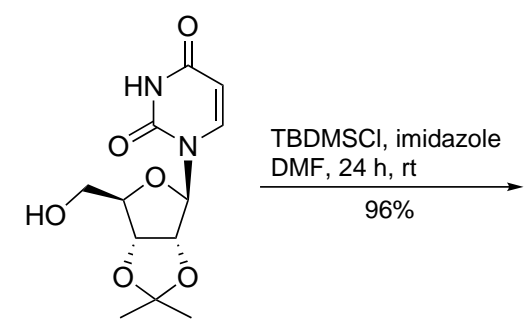

11

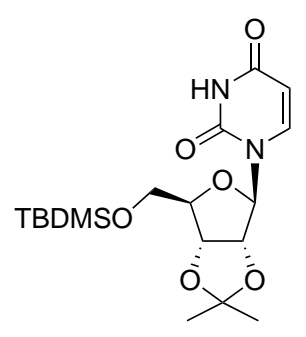

12

Scheme 1.11. Protection of uridine (10) to obtain compound 12.

\subsubsection{OMP (1)}

In order to test the overall reaction conditions for protection and deprotection, as well as phosphorylation and purification of the crude nucleotides, OMP (1) was synthesized following the protocol from $D$. Heinrich. ${ }^{[50]}$ To apply a shorter synthesis sequence and purification by HPLC, the reaction process was modified. Aside from testing conditions the synthesized OMP (1) was used by the Tittmann group as the ligand for the human OMPD mutant 314AcK and to optimize soaking condition with wild type OMPD.

Starting from fully protected uridine 12, polarity inversion and lithiation at $\mathrm{C} 6$ was applied by slow addition of two equivalents of LDA in THF at $-78{ }^{\circ} \mathrm{C}$ to avoid unwanted deprotonation at C5. Two equivalents of LDA were necessary, due to the acidic proton at N3. However, the resulting deprotonated N3 nitrogen is not nucleophilic enough to cause any side reactions with most electrophiles. Following deprotonation, $\mathrm{CO}_{2}$ gas was introduced as the electrophile to obtain protected orotidine 13. After purification via column chromatography, deprotection was applied 
by stirring 13 in a mixture of TFA and water $(50: 50 \mathrm{v} / \mathrm{v})$ for $2 \mathrm{~h}$. The resulting orotidine (14) was phosphorylated with $\mathrm{POCl}_{3}$ in $(\mathrm{MeO})_{3} \mathrm{PO}$. Removal of the solvent yielded crude OMP (1), containing significant amounts of $(\mathrm{MeO})_{3} \mathrm{PO}$ and phosphate as impurities. The synthesis is displayed in scheme 1.12 .

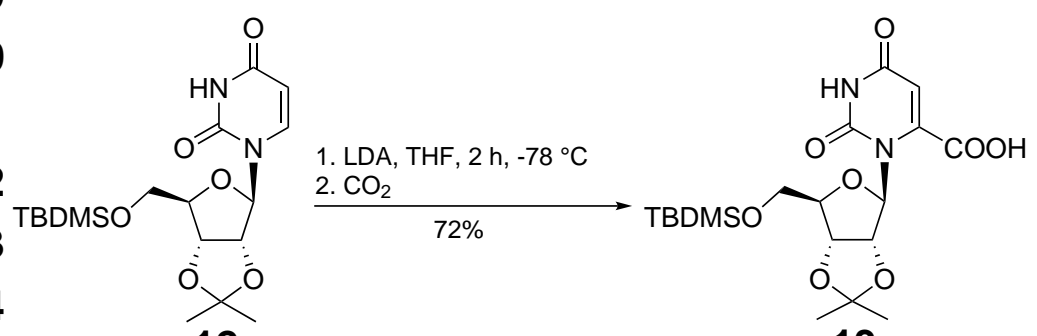

12

13

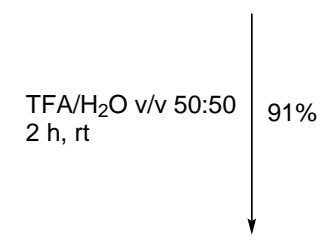

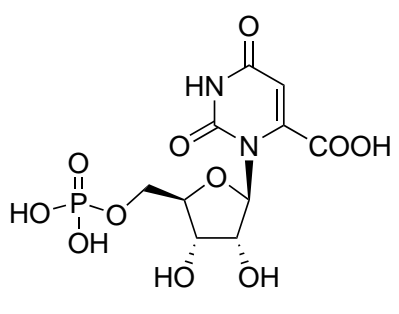

1

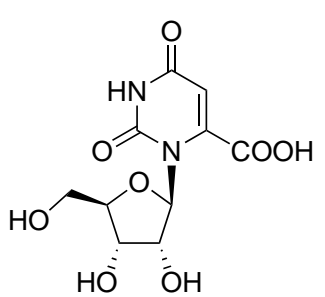

14

Scheme 1.12. Synthesis of OMP (1) starting from compound 12.

Due to the strong affinity of the phosphate group to silica, standard column chromatography with silica gel is not applicable for purification of nucleotides. Following the purification procedure of D. Heinrich, using DEAE-Sephadex GL-25 ionexchange gel yielded unsatisfying results in regard of remaining $(\mathrm{MeO})_{3} \mathrm{PO}$ impurities. In order to improve the purification high pressure liquid chromatography (HPLC) was applied. Attempts to apply reversed phase chromatography failed completely. Both water/acetonitrile and $1 \mathrm{M}$ TEAA buffer/acetonitrile gradients provided no separation of the nucleotide from any impurities. However, successful purification of OMP (1) was achieved by using strong anion binding ion exchange chromatography applying a water/0.5 M TEAA buffer gradient. Remaining excess of buffer could be removed by lyophilization multiple times. The pure OMP (1) was obtained as the triethylammonium salt. 


\subsubsection{BMP (3) and 6-aza-UMP (4)}

In order to reevaluate the crystal structures of OMPD complexed with BMP (3) and 6-aza-UMP (4) by high resultion structures, these inhibitors were synthesized (scheme 1.13). For BMP (3) synthesis the silyl-Hilbert-Johnson reaction was applied, which is also known as Vorbruggen nucleosidation. Here, a preactivated heterocyclic base is connected to a Lewis acid activated sugar derivative, which acts as an electrophile. Activation of the heterocycle is done by silylation. ${ }^{57}$ Barbituric acid (15) and a catalytic amount of TMSCI were stirred in HMDS under reflux to obtain tris-TMS activated pyrimidine 16, which was bound to $\mathrm{SnCl}_{4}$ activated 1-OAcetyl-2,3,5-tri-O-benzoyl- $\beta$-D-ribofuranose (17) via stereochemical controlled nucleophilic substitution to obtain benzoyl protected hydroxyuridine 18.<smiles>O=C1CC(=O)NC(=O)N1</smiles>

15

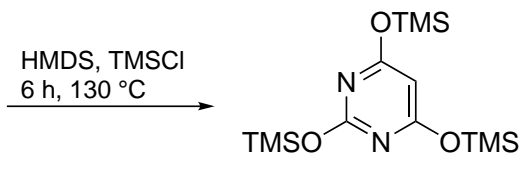

16

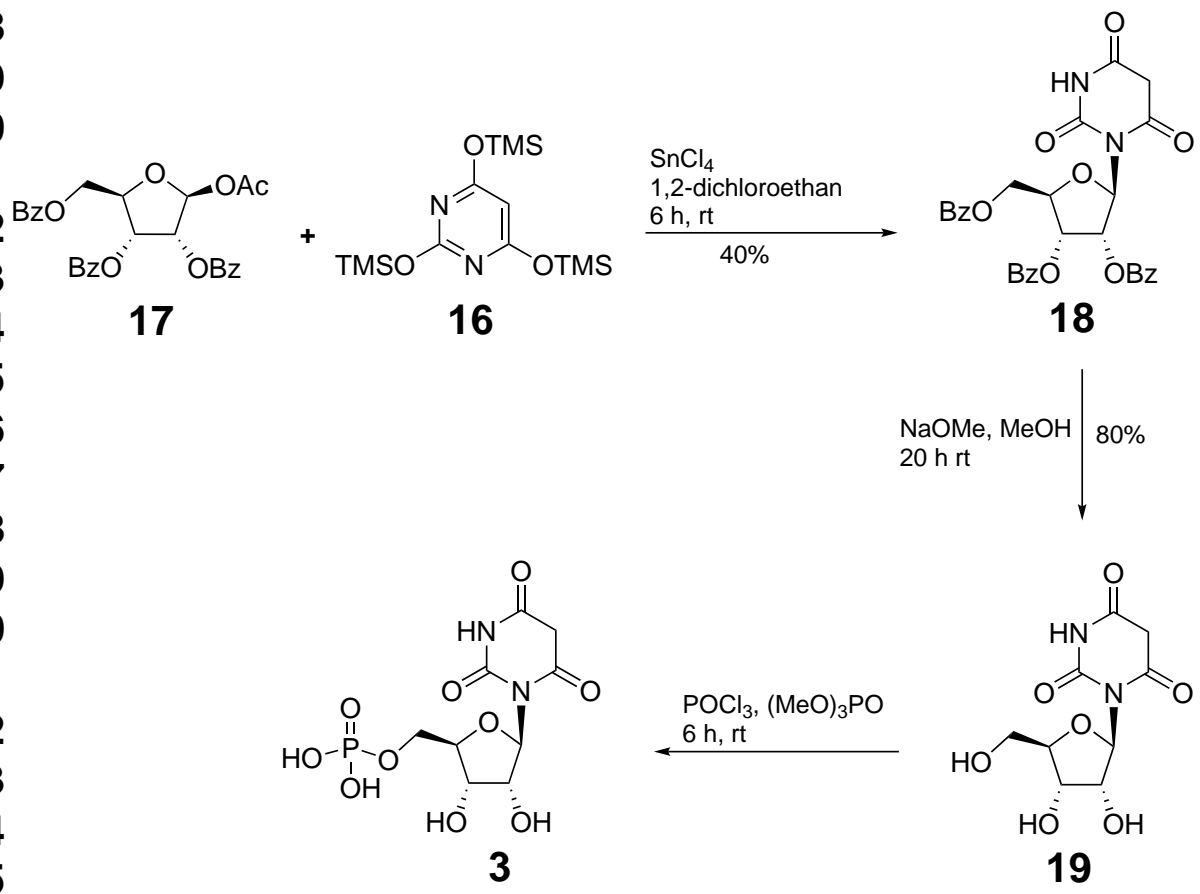

Scheme 1.13. Synthesis of BMP (3) using Vorbruggen nucleosidation.

Due to the symmetry of barbituric acid (15) regioselectivity of N1 and N3 can be neglected. However, double nucleosidation at N1 and N3 occur with high sugar concentration. Saponification of benzoyl groups with $\mathrm{NaOMe}$ in methanol yielded 6hydroxyuridine (19), which was phosphorylated with $\mathrm{POCl}_{3}$ in trimethylphosphate to 
obtain BMP (3). Similar phosphorylation method was applied to convert commercial available 6-azauridine (20) into 6-aza-UMP (4) (scheme 1.14). Purification was done using ion exchange chromatography, with a water/0.5 M TEAA buffer gradient.

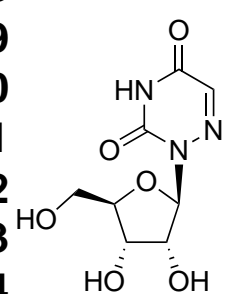

20

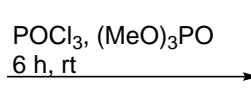
$6 \mathrm{~h}, \mathrm{rt}$

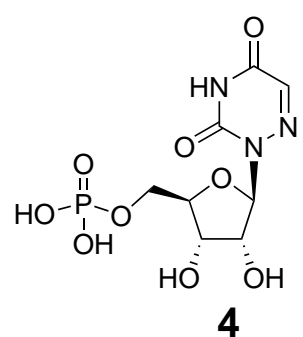

4

Scheme 1.14. Phosphorylation of 6-azauridine (20).

\subsubsection{6-Amido-UMP (8)}

To evaluate the possibility of attractive interactions between the active site and protonated OMP (1), 6-Amidouridine was synthesized as an substrate analogue representing protonated OMP. In a first approach protected orotidine 13 was synthesized by deprotonation of protected uridine 12 and subsequent reaction with $\mathrm{CO}_{2} .13$ should then be activated by either isobutyl-chloroformate or thionylchloride in the presence of $\mathrm{NEt}_{3}$ to neutralize developing $\mathrm{HCl}$. Reaction with ammonia solution in THF should yield protected 6-amidouridine (22) (scheme 1.15). Unfortunately, no reaction could be detected and protected orotidine $\mathbf{1 3}$ was re-isolated, as indicated by NMR spectroscopy and massspectrometry.

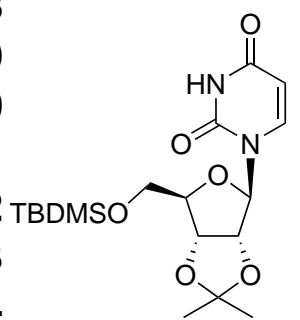

12

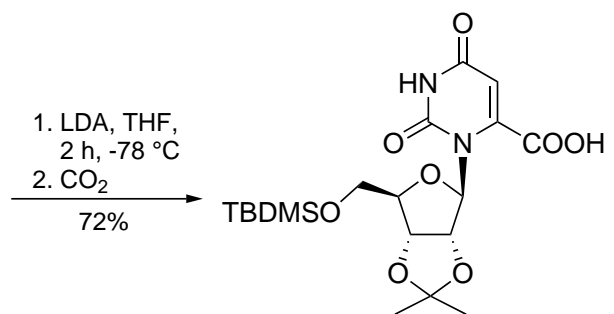

13

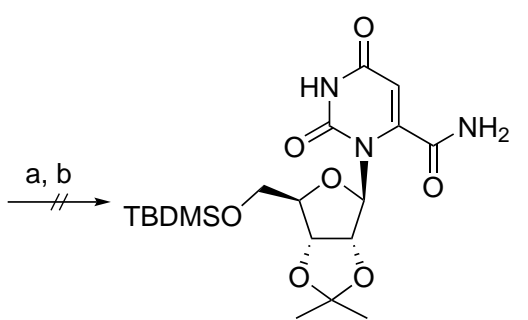

22

Scheme 1.15. First approach to synthesize 6-amidouridine (22) by activation of orotidine 13.

a) 1. isobutyl-chloroformate, $\mathrm{NEt}_{3}, 45 \mathrm{~min},-78^{\circ} \mathrm{C}, 2 . \mathrm{NH}_{3}, \mathrm{THF}, 2 \mathrm{~h}, \mathrm{rt}$;

b) $1 . \mathrm{SOCl}_{2}, \mathrm{NEt}_{3}, 1 \mathrm{~h}, \mathrm{rt}, 2 . \mathrm{NH}_{3}, \mathrm{THF}, 2 \mathrm{~h}$, rt.

In a second approach, 6-amidouridine (23) was synthesized successfully, via aminolysis of protected orotidinemethylester $\mathbf{2 1}$. Starting from protected uridine $\mathbf{1 2}$, protected orotidinemethylester $\mathbf{2 1}$ was obtained via deprotonation with LDA and subsequent reaction with methyl-chloroformate. Stirring of 21 in $7 \mathrm{~m}$ methanolic ammo- 
nia solution for $20 \mathrm{~h}$ yielded protected 6 -amidouridine (22) which was deprotected in $0.5 \mathrm{M}$ methanolic hydrogenchloride solution to obtain 6-amidouridine (23). However, phosphorylation failed using $\mathrm{POCl}_{3}$ in trimethylphosphate. Changing conditions to a mixture of $\mathrm{POCl}_{3}$, pyridine and water in acetonitrile worked out, yielding 6-amidoUMP (8) after purification by ion exchange chromatography. The full synthesis is shown in scheme 1.16
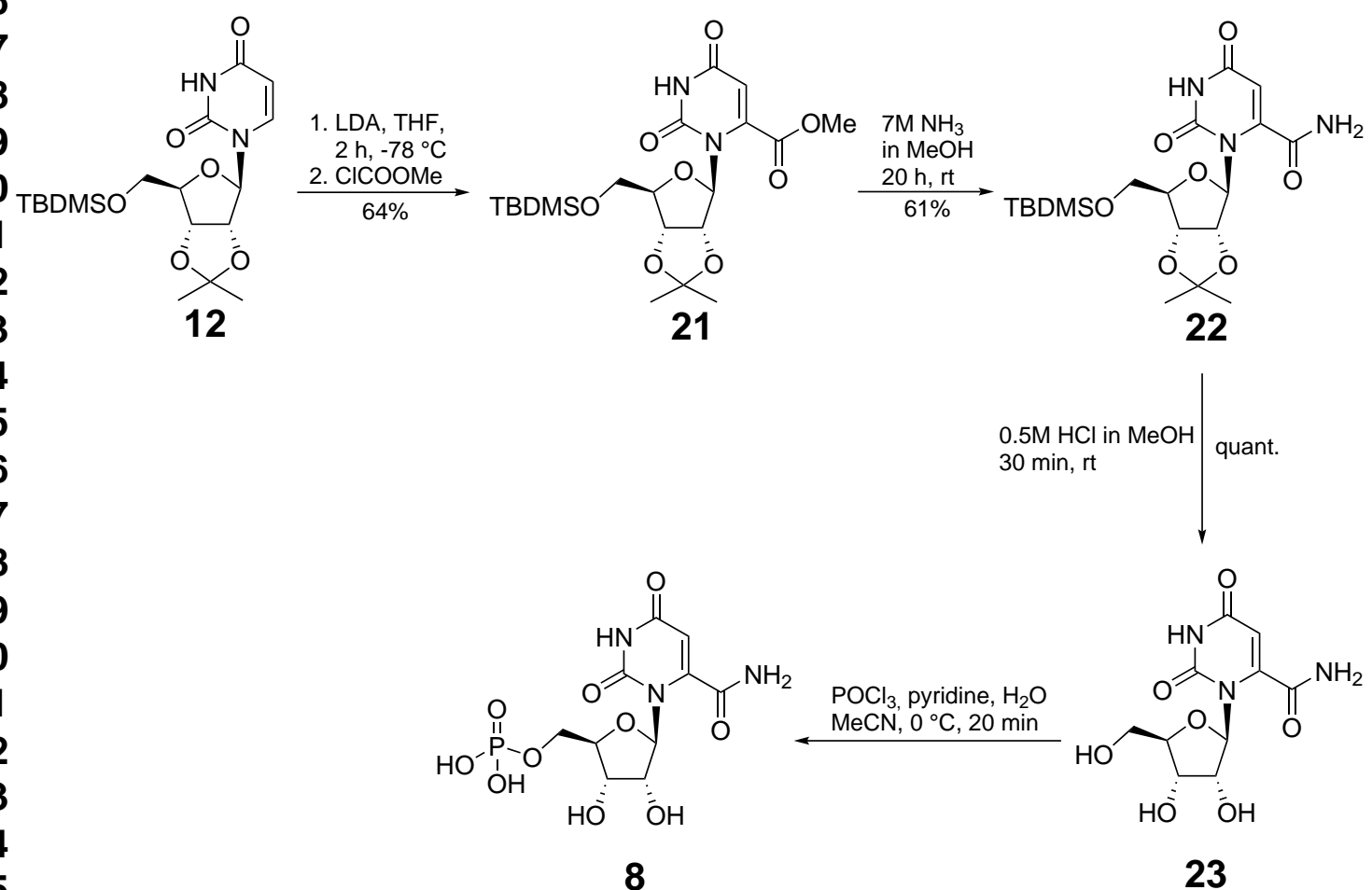

Scheme 1.16. Successful synthesis of 6-amido-ump (8) via aminolysis of orotidinemethylester 21.

The successful synthesis of protected orotidinemethylester $\mathbf{2 1}$ made methyl-OMP (25) another appealing substrate analogue, which should be easily available by deprotection and phosphorylation. However, both $\mathrm{POCl}_{3}$ in trimethylphosphate and the mixture of $\mathrm{POCl}_{3}$, pyridine and water in acetonitrile failed to synthesize methylOMP (25) (scheme 1.17). OMP (1) was obtained in both attempts, indicating ester hydrolysis is the problem preventing a successful synthesis. Because methylOMP (25) was no prioritized target no further attempts were done.

\subsubsection{6-Isopropyl-UMP (9)}

To evaluate how other than electrostatic interactions play a role in ground state destabilization and substrate distortion, 6-isopropyl-UMP (9) was synthesized. Although, the $\mathrm{C} 7$ carbon is $\mathrm{sp}^{3}$ hybridized, which lead to a slightly deviated geometry 


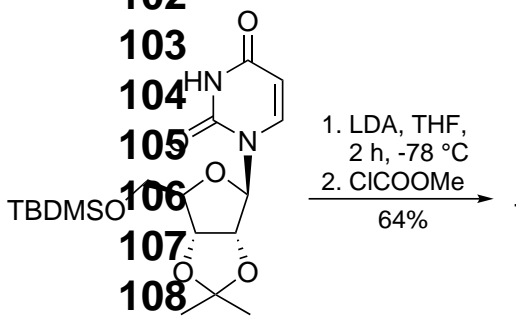

12

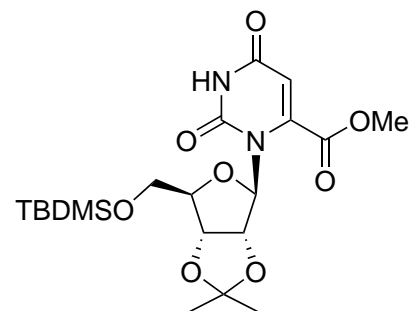

21

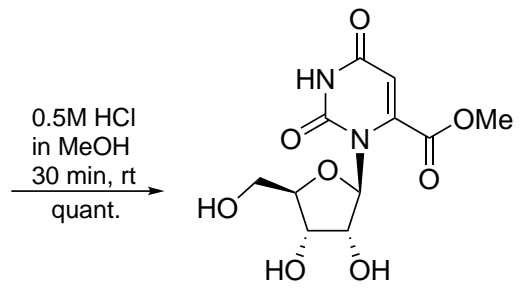

24<smiles>COC(=O)c1cc(=O)[nH]c(=O)n1[C@@H]1O[C@H](COP(=O)(O)O)[C@@H](O)[C@H]1O</smiles>

25

Scheme 1.17. Synthesis of orotidinemethylester 21. Phosphorylation failed due to ester hydrolysis.

a) $\mathrm{POCl}_{3}$, trimethylphosphate, $6 \mathrm{~h}, 0{ }^{\circ} \mathrm{C}$

b) $\mathrm{POCl}_{3}$, pyridine, $\mathrm{H}_{2} \mathrm{O}$, acetonitrile, $20 \mathrm{~min}, 0^{\circ} \mathrm{C}$

compared to OMP (1) this analogue is an interesting target to investigate sterical contribution to the catalytic mechanism.

In a first approach, the isopropyl group should be attached at 6-position via electrophilic addition to $\mathrm{C} 6$ deprotonated uridine 12. Following the standard procedure for deprotonation with LDA, polarity inversion at $\mathrm{C} 6$ was achieved. Subsequent addition of isopropyliodide should yield protected 6-isopropyluridine 29 (scheme 1.18). However, only starting material $\mathbf{1 2}$ was isolated from the reaction mixture. Presumably, isopropyliodide is not electrophilic enough, due to the relatively good stabilization of positive charge at the central carbon atom. Sterical repulsion, due to the

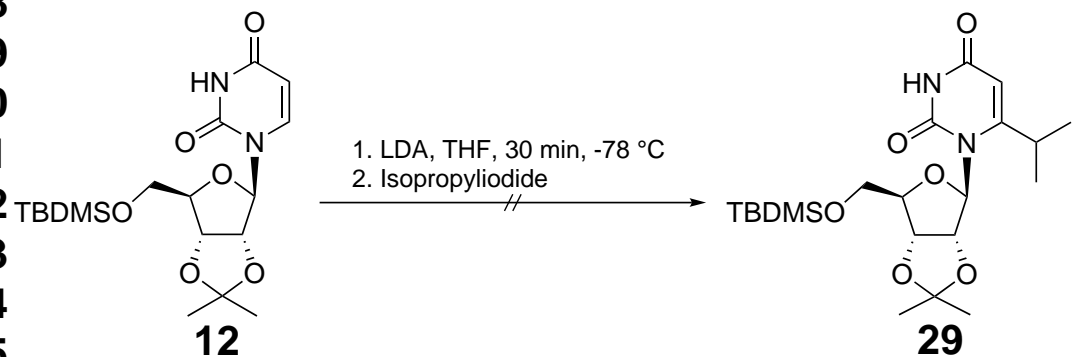

Scheme 1.18. First approach to synthesize 6-isopropyluridine 29 via lithiation and reaction with isopropyliodide. 
bulky character of the isopropyl group might be another problem, which prevent successful conversion.

Due to the weak electrophilicity of the isopropyl group, the reaction was done with strong nucleophilic Grignard reagent isopropylmagnesiumbromide in the second approach. Applying a protocol from Chien et al., nucleophilic substitution of protected 6-cyanouridine 28 should yield compound 29.58 Compound 28 was synthesized following modified protocols from Fujihashi and Torrence.59, 60] Starting from uridine (10), 5-iodouridine 26 was obtained by reaction with NIS in DMF. The product 26 was protected at the hydroxy groups with acetone in acidic media and subsequently

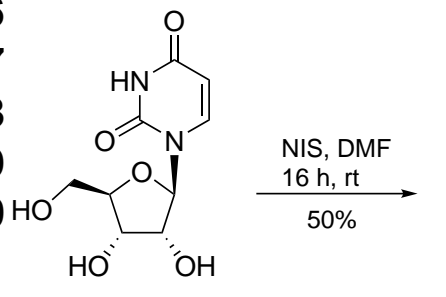

10<smiles></smiles>

26
1. acetone, $\mathrm{H}_{2} \mathrm{SO}_{4}$ $3 \mathrm{~h}, \mathrm{rt}$ 2. TBDMSCI, Imidazole, DMF, $16 \mathrm{~h}$, rt $59 \%$<smiles></smiles>

27<smiles>CC(C)COC[C@H]1OC2OC(C)(C)O[C@@H]2N1c1cc(=O)[nH]c(=O)n1C(C)C</smiles>

29 $0.5 \mathrm{M} \mathrm{HCl}$ in THF
$4 \mathrm{~h}, \mathrm{rt}$<smiles>CC(C)c1cc(=O)[nH]c(=O)n1[C@@H]1O[C@H](CO)[C@@H](O)[C@H]1O</smiles>

30

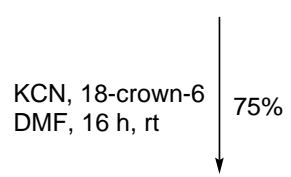<smiles></smiles>

28

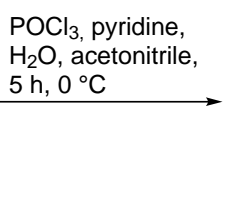

$\mathrm{H}_{2} \mathrm{O}$, acetonitrile,$$
\mathrm{H}
$$

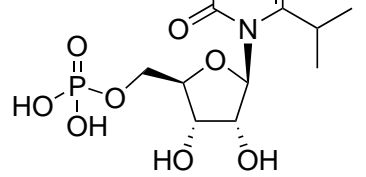

9

Scheme 1.19. Synthesis of 6-isopropyl-UMP (9) via nucleophilic substitution of 6-cyanouridine 28 with isopropylmagnesiumbromide. 
with TBDMSCl in the presence of imidazole to yield protected 5 -iodouridine 27. After purification, $\mathbf{2 7}$ was converted to protected 6-cyanouridine $\mathbf{2 8}$ via Michael addition of $\mathrm{KCN}$ in DMF and subsequent elimination of KI. To enhance the solubility of KCN in DMF, 18-crown-6 was added as a potassium chelating agent. Nucleophilic substitution of the cyano group with isopropylmagnesiumbromide in THF yielded protected 6-isopropyluridine 29. Addition of catalytic amounts of $\mathrm{ZnCl}_{2}$ enhance the reactivity of 6-cyanouridine $\mathbf{2 8}$ for nucleophilic substitution by activating the carbonyl group at C4. 6-Isopropyl-UMP (9) was obtained by deprotection with $0.5 \mathrm{M}$ methanolic $\mathrm{HCl}$ solution and phosphorylation with $\mathrm{POCl}_{3}$, pyridine and water in acetonitrile. The complete synthetic sequence is shown in scheme 1.19.

\subsubsection{Dithio-OMP (6)}

In order to synthesize an OMPD inhibitor with nearly identical steric and electronic properties as OMP (1), dithio-OMP (6) was a promising target as it is identical to OMP except substitution of the carboxylic oxygen atoms against sulfur. In a first approach the synthesis was designed similar to the synthesis of OMP, but $\mathrm{CO}_{2}$ was exchanged by $\mathrm{CS}_{2}$ as the electrophile. However, dithioacid $\mathbf{3 1}$ turned out to be unstable in acidic media producing only unidentifiable products upon deprotection in both TFA/water and $0.5 \mathrm{M} \mathrm{HCl}$ in methanol (scheme 1.20).

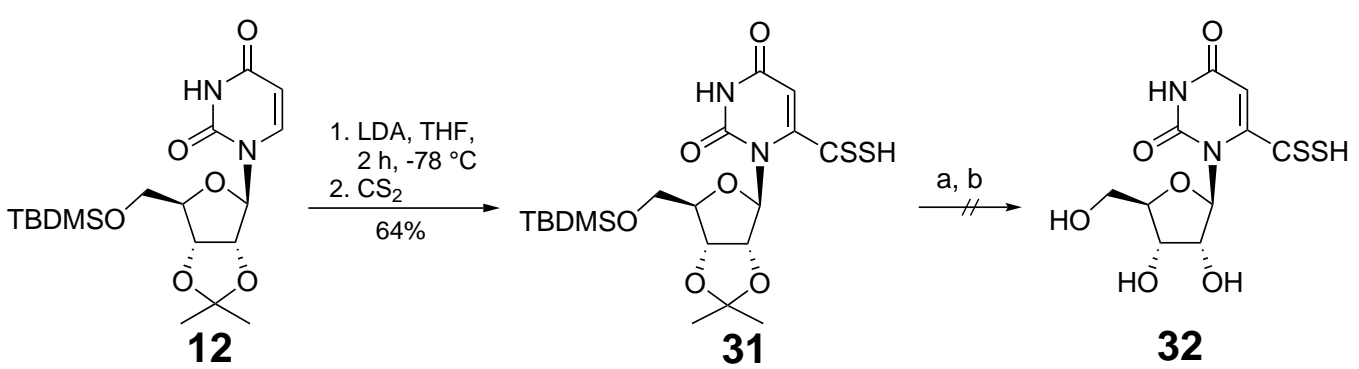

Scheme 1.20. Approach to synthesize dithioorotidine (32). Dithioacid 31 decomposes in acidic media.

a) TFA/water 50:50, v/v, $2 \mathrm{~h}, \mathrm{rt}$

b) $0.5 \mathrm{M} \mathrm{HCl}$ in methanol, $30 \mathrm{~min}$, rt

To avoid acidic conditions during deprotection, the isopropylidene group was exchanged by two additional silyl ether groups. Protection of uridine (10) with 4 equivalents of TBDMSCl and 5-fold excess of imidazole in DMF provided tris-TBDMSuridine $\mathbf{3 3}$ in excellent yield. However, subsequent electrophilic substitution with $\mathrm{CS}_{2}$ showed no conversion of the starting material. Steric hindrance was assumed 
to be an issue. In order to reduce the size of the silyl groups, tris-TES protected uridine $\mathbf{3 4}$ was synthesized, applying the same reaction conditions used for TBDMS protection. However, no conversion was observed during electrophilic substitution with $\mathrm{CS}_{2}$ (scheme 1.21), excluding steric hindrance to be the main issue.

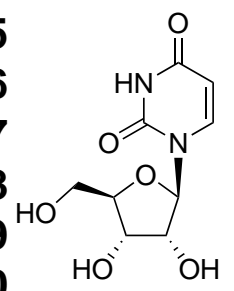

10

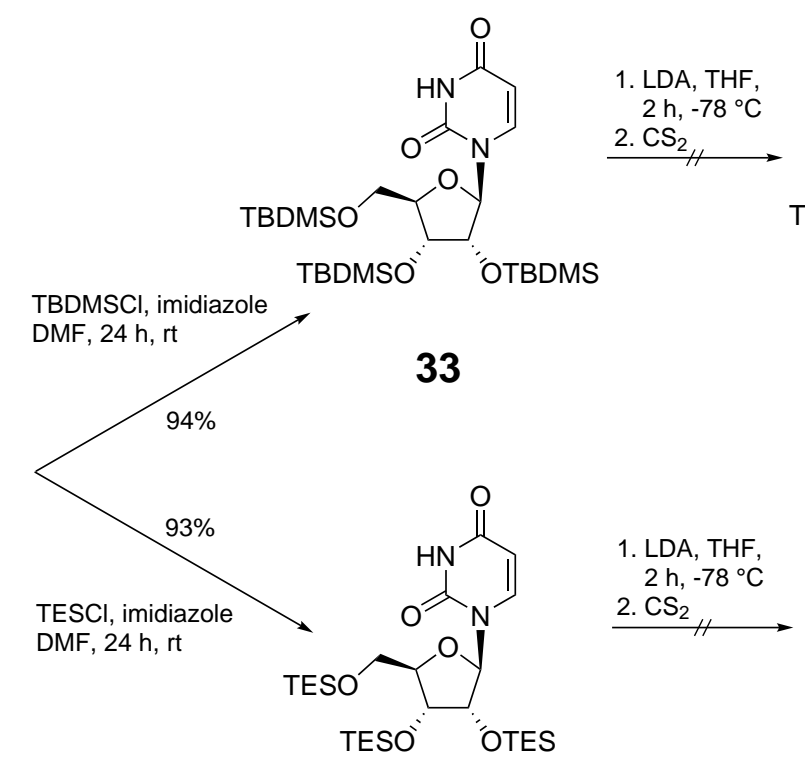

34

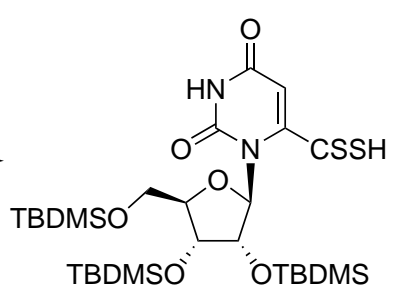

38

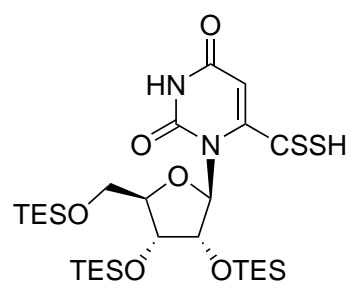

39

Scheme 1.21. Synthesis of tris-silyl ether protected uridines 33 and 34 . Electrophilic substitution with $\mathrm{CS}_{2}$ was unsuccessful in both cases.

To stabilize the dithiocarboxy group against acidic conditions, the acid was protected as a dithiobenzylester, which is more stable against aqueous media and acids. Cleavage of the benzyl group should be achieved by selective catalytic hydrogenation of the benzyl position (scheme 1.22). Synthesis of dithioorotidinebenzylester $\mathbf{3 5}$ was achieved similar to dithioacid $\mathbf{3 1}$ by lithiation at $\mathrm{C} 6$ and reaction with $\mathrm{CS}_{2}$, followed by quenching with benzylbromide. After purification, deprotection of $\mathbf{3 5}$ to dithioester $\mathbf{3 6}$ was achieved successfully in TFA/water 50:50 v/v without any decomposition. Subsequent phosphorylation with $\mathrm{POCl}_{3}$ in trimethylphosphate delivered pure dithio-OMP-benzylester $\mathbf{3 7}$ after ion exchange chromatography. Although, the syntheses of $\mathbf{3 7}$ was proven to be successful, cleavage of the benzyl group provided major problems. Originally considered catalytic hydration with palladium on carbon turned out to produce no conversion at atmospheric $\mathrm{H}_{2}$ pressure as well as higher pressure up to 5 bar. Using $\mathrm{Pd}(\mathrm{OH})_{2}$ on carbon and palladium on $\mathrm{CaCO}_{3}$ provided the same results. The reason might be coordination of palladium by the resulting dithioacid, which lead to intoxication of the catalyst. Another expla- 


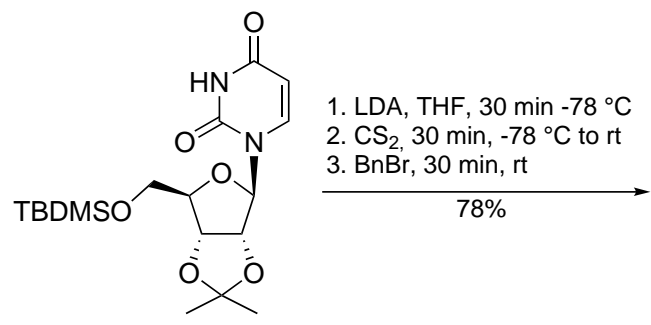

12

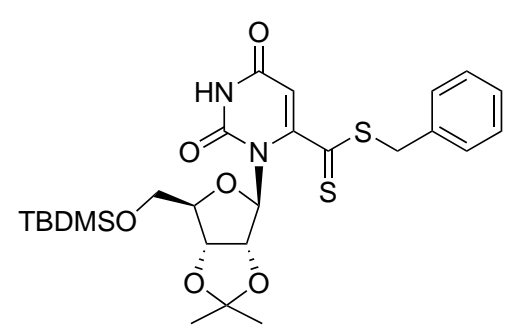

35<smiles>O=c1cc(C(=S)SCc2ccccc2)n([C@@H]2O[C@H](COP(=O)(O)O)[C@@H](O)[C@H]2O)c(=O)[nH]1</smiles>

37
$\mathrm{POCl}_{3},(\mathrm{MeO})_{3} \mathrm{PO}$

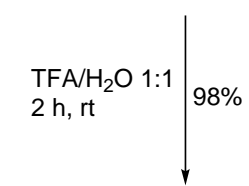

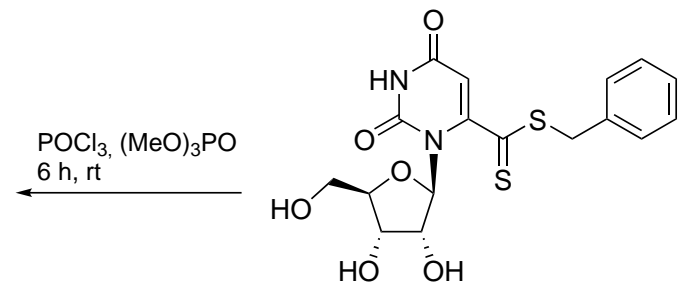

36

$\mathrm{Pd}(\mathrm{OH})_{2} / \mathrm{C}, 5$ bar $\mathrm{H}_{2}$ $\mathrm{MeOH}, 20 \mathrm{~h}, \mathrm{rt}$<smiles>O=c1cc(C(=S)S)n([C@@H]2O[C@H](COP(=O)(O)O)[C@@H](O)[C@H]2O)c(=O)[nH]1</smiles>

6

Scheme 1.22. Synthesis of dithio-OMP-benzylester 37. Cleavage of the benzyl group was unsuccessful.

nation could be that the benzyl position reacts in another way compared to common carbon-acid benzylesters. Either way the benzyl group turned out to be not suitable as a protecting group for the dithioacid.

Another attempt to protect the dithioacid was to synthesize the dithioacidmethylester 38. Deprotection should be performed via ester thiolysis with potassium hydrogensulfide in water free media (scheme 1.23). Because dithiobenzylester 35 proved to be stable under acidic deprotection conditions and during phosphorylation it was assumed that is also the case for other dithioesters. Therefore cleavage of the methylester was tested using $\mathbf{3 8}$ without prior deprotection and phosphorylation. Synthesis of $\mathbf{3 8}$ was performed similar to $\mathbf{3 5}$ using methyliodide instead of 


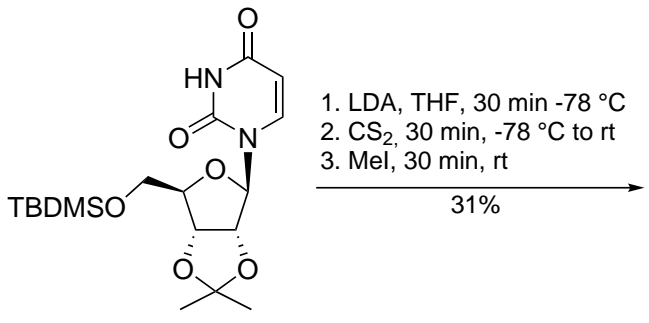

12

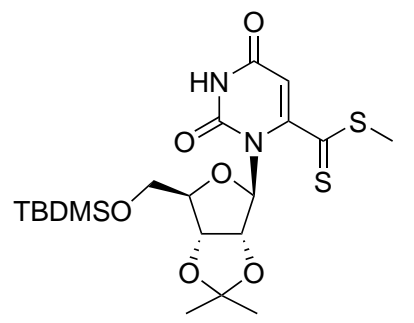

38

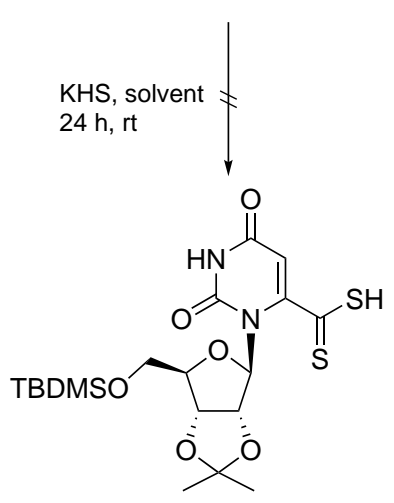

31

Scheme 1.23. Synthesis of dithioorotidinemethylester 38. Thiolysis failed in DCM, THF, DMF, DMSO and $\mathrm{MeOH}$.

benzylbromide. Ester thiolysis was tested using 6-fold excess of KHS in various solvents and stirring the mixtures for $24 \mathrm{~h}$. However, no reaction could be observed in any mixture. Obviously, dithioesters are more stable than expected, protecting the dithioacid well against decomposition but are hardly cleavable.

In order to facilitate dithioester thiolysis, dithiophenylester $\mathbf{3 9}$ was tested in another attempt. Due to the higher pKa value, compared to thiobenzylalcohol and thiomethanol, thiophenol should provide a better leaving group. Synthesis of $\mathbf{3 9}$ was not performable similar to dithiobenzylester $\mathbf{3 5}$ and dithiomethylester $\mathbf{3 8}$ because unlike benzylbromide and methyliodide, phenylbromide does not undergo nucleophilic substitution. Therefore, a synthesis similar to orotidinemethylester 24 was chosen, using phenyl-chlorodithioformate as the electrophile. The resulting dithiophenylester 39 was stirred with 5 -fold excess of KHS in DMF for $24 \mathrm{~h}$. The dithiophenylester turned out to be reactive against thiolysis, leading to complete cleavage of thiophenol. However, the resulting dithioacid $\mathbf{3 1}$ undergoes nucleophilic substitution in the presence of KHS yielding 6-thio-BMP $\mathbf{4 0}$ as the final product (scheme 1.24), which was proven by NMR spectroscopy and ESI massspectrometry. 


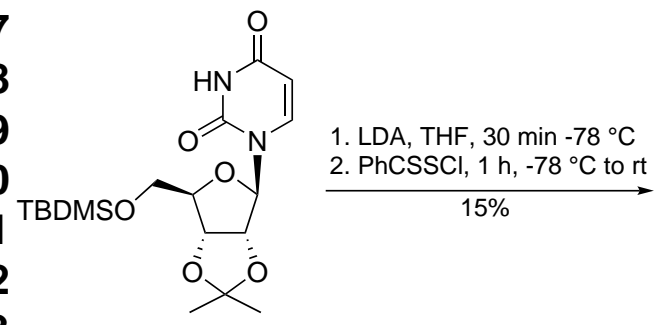

12

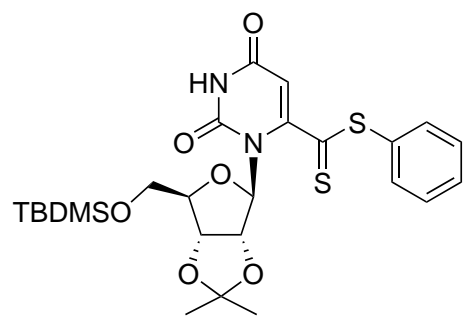

39

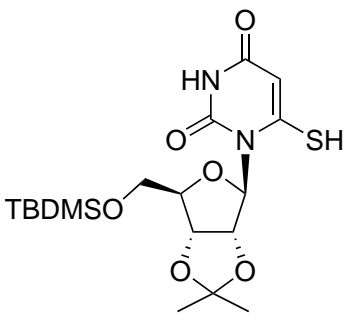

40
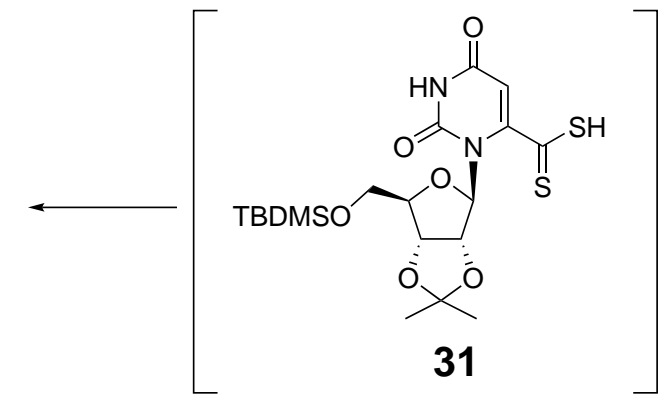

Scheme 1.24. Synthesis of dithiophenylester 39. Thiolysis yielded 6-thio-BMP 40 instead of dithioorotidine 31 .

Another possible strategy is using photolabile protecting groups, which can be cleaved via irradiation by light of certain wavelength. By using this strategy no further reagents are necessary to deprotect the dithioacid, which minimize possible side reactions. However, all following steps have to be done under exclusion of light to avoid any undesired cleavage of the protecting group. For esters ortho-nitrobenzylesters are known to be cleavable by light irradiation in the UV range (350-400 nm), enabling the established synthesis of dithioesters to be applicable for the photocleavable protecting strategy. ${ }^{61}$ However, in case of using ortho-nitrobenzylbromide to obtain dithio-ortho-nitrophenylester $\mathbf{4 1}$ only unidentified side products were formed (scheme 1.25).

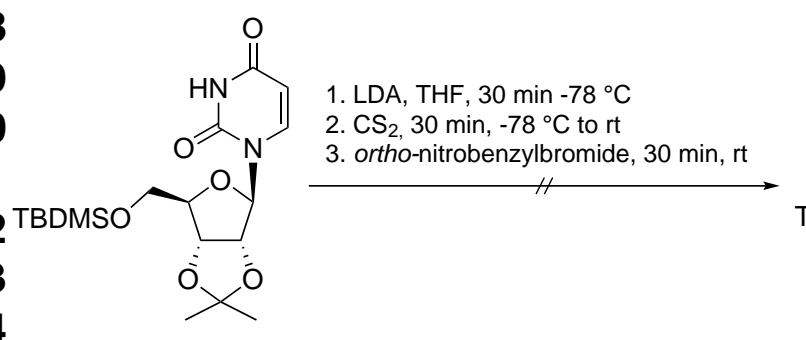

12

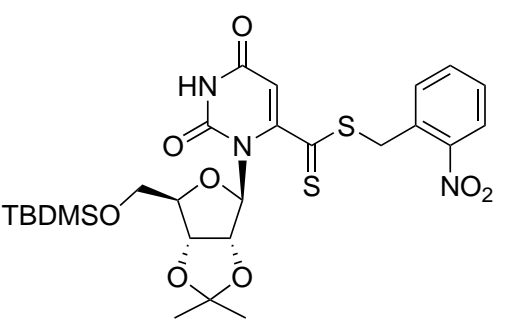

41

Scheme 1.25. Failed synthesis of dithio-ortho-nitrobenzylester $\mathbf{4 1 .}$ 
Another possibility to stabilize dithiocarboxylic acids is to oxidize them to obtain dithiocarboxylic acids disulfides, which can be reduced later on to gain back the dithiocarboxylic acid. In order to obtain dithioacid-disulfide $\mathbf{4 2}$ the dithioacid was synthesized via lithiation and reaction with $\mathrm{CS}_{2}$ as previously described. Subsequent oxidations with either oxygen and iodine were applied but failed to produce in both cases (scheme 1.26).

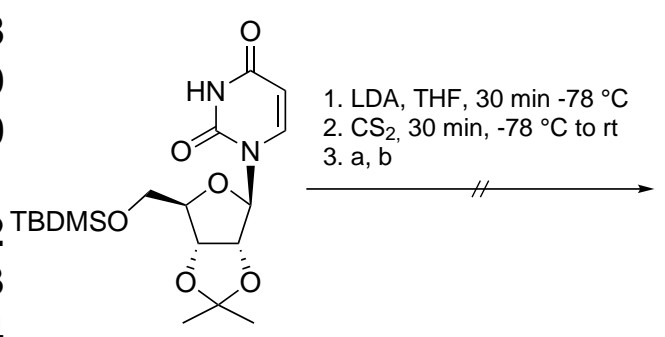

12

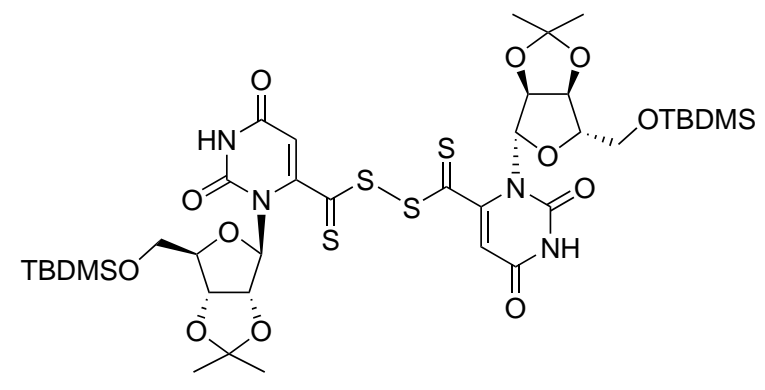

42

Scheme 1.26. Attempted synthesis of dithioacid-disulfide 42.

a) $\mathrm{O}_{2}, 24 \mathrm{~h}, \mathrm{rt}$; b) $\mathrm{I}_{2}, \mathrm{AcOH}, 2 \mathrm{~h}, \mathrm{rt}$

\subsubsection{6-Nitro-UMP (5)}

Another isoelectronic and isosteric OMP analogue is 6-nitro-UMP (5). First synthetic attempts were made by Daniel Heinrich and Julian Strohmeier. These attempts followed the strategy to oxidize 6-aminouridine 43 to obtain 6-nitrouridine 44 , which would then be converted to 6 -nitro-UMP 5 by standard deprotection, phosphorylation procedure. Several oxidants were tested, but all failed to produce the desired product. Ozone on solid support, as well as in solution produced unidentified side products, likely due to oxidation of the double bond. The same results were obtained when $\mathrm{OsO}_{4}, \mathrm{KMnO}_{4}$ and DMDO were used. On the other hand, TBHP and $m \mathrm{CPBA}$ were to mild and only starting material was recovered (scheme 1.27). [50, ,62]

An alternative to the oxidation of 6 -aminouridine $\mathbf{4 3}$ might be well established C6 lithiation, followed by subsequently reaction with an electrophile. While this methods works very well for most electrophiles, in case of nitronium kations some issues occur. First, nitronium ions are highly unstable and therefore are generated in situ by mixing concentrated nitric and sulfonic acid. In the case of $\mathrm{C} 6$ lithiation the addition of acids would reprotonate at $\mathrm{C} 6$. Fortunately, nitronium ions can be stabilized by forming $\mathrm{NO}_{2} \mathrm{BF}_{4}$ and $\mathrm{NO}_{2} \mathrm{PF}_{6}$ salts. Another barrier for using nitronium ions are 


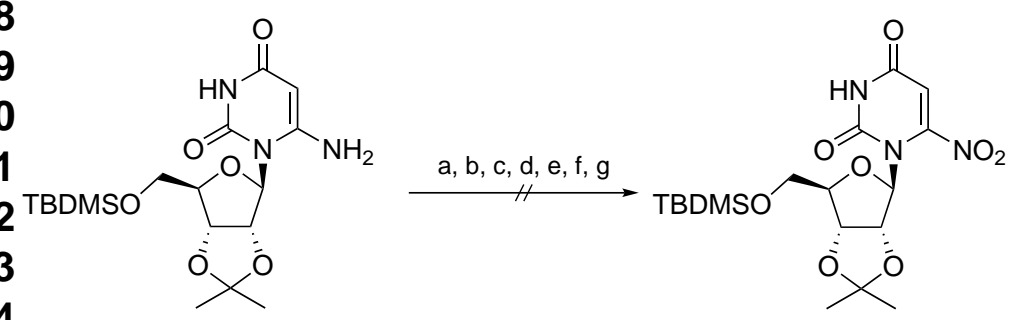

43

44

Scheme 1.27. Attempted oxidations of 6 -aminouridine 43 by Heinrich and Strohmeier. [50, 62] a) $\mathrm{O}_{3}$ on $\mathrm{SiO}_{2}, 5 \mathrm{~min},-78^{\circ} \mathrm{C}$; b) $\mathrm{O}_{3}, \mathrm{DCM}, 2 \mathrm{~min},-78^{\circ} \mathrm{C}$; c) $\mathrm{OsO}_{4}{ }^{*} \mathrm{THF}, \mathrm{DCM}, 1 \mathrm{~h},-78^{\circ} \mathrm{C}$; d) $\mathrm{KMnO}_{4}$, $\mathrm{DCM}, 30 \mathrm{~min},-78{ }^{\circ} \mathrm{C}$; e) DMDO, DCM, $1 \mathrm{~h}, 0{ }^{\circ} \mathrm{C}$; f) TBHP, $\mathrm{Zr}\left(\mathrm{O}^{t} \mathrm{Bu}\right)_{4}$, DCM, 4 Å molecular sieves, $20 \mathrm{~h}, \mathrm{rt} ; \mathrm{g}) \mathrm{mCPBA}, \mathrm{DCM}, 22 \mathrm{~h}, 0^{\circ} \mathrm{C}$

their high reactivity, which lead to reactions with most solvents. Testing the lithiation method with standard procedure, following change of solvent for the nitration step with $\mathrm{NO}_{2} \mathrm{BF}_{4}$ lead to reaction with solvent in case of $\mathrm{THF}, \mathrm{Et}_{2} \mathrm{O}$ and $\mathrm{DCM}$ or to no reaction at all in DMF, DMA and MeCN (scheme 1.28).

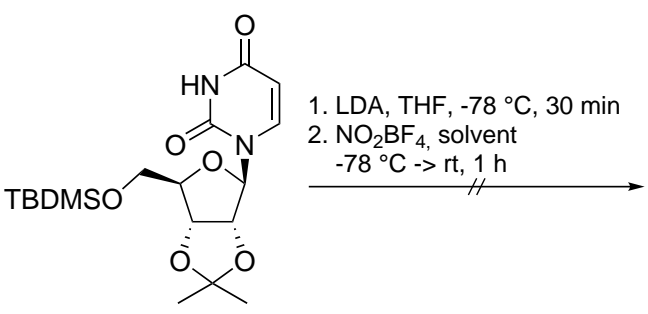

12

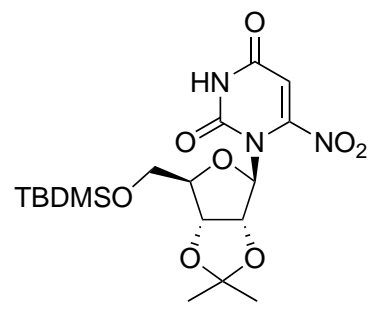

44

Scheme 1.28. Testing direct of lithiation nitration method with $\mathrm{NO}_{2} \mathrm{BF}_{4}$ in $\mathrm{THF}, \mathrm{Et}_{2} \mathrm{O}, \mathrm{DCM}, \mathrm{DMF}$, DMA and MeCN.

In an attempt to stabilize the nitronium ion a method developed by Cupas and Pearson was applied. ${ }^{63}$ In this method, the nitronium ion is bound to pyridine by an $\mathrm{N}-\mathrm{N}$ bond delocalizing the positive charge in the aromatic plane. $\mathrm{N}$-nitro-pyridiniumtetrafluoroborate (46) was obtained by reaction of $\mathrm{NO}_{2} \mathrm{BF}_{4}$ with pyridine (45) in acetonitrile. Unfortunately, addition of $\mathrm{N}$-nitro-pyridinium-tetrafluoroborate (46) to lithiated uridine 12 lead to no reaction again (scheme 1.29).

Another possibility to obtain aromatic nitro compounds is ipso-nitration of suitable 6-nitrouridine $\mathbf{4 4}$ precursors. Prakash and Mathew developed a catalytic method to convert aryl halides into nitro aryls. ${ }^{64]}$ The reaction is done via palladium catalyst and the BRETTPHOS ligand. Although being a reliable method for aryl halides, no experimental data for heteroaryls are available. To evaluate if this reaction is suitable 


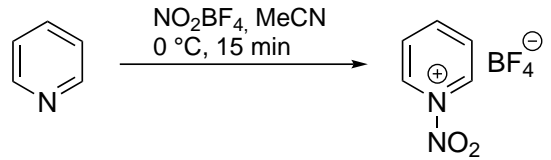

45
46

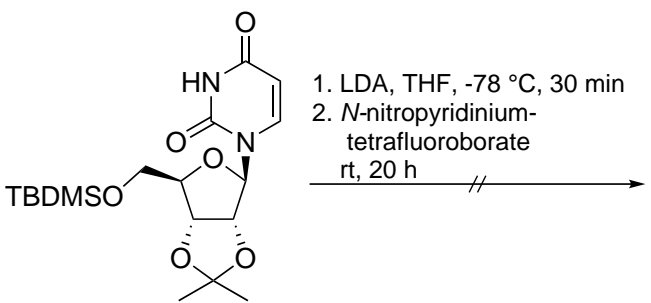

12

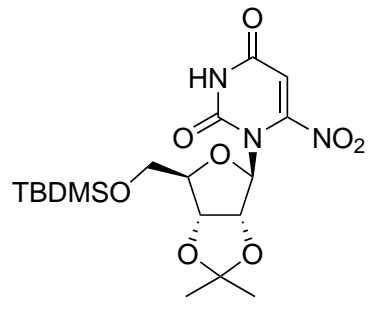

44

Scheme 1.29. Attempted stabilization of $\mathrm{NO}_{2}{ }^{+}$in form of $N$-nitro-pyridinium-tetrafluoroborate (46) and subsequent reaction with lithiated uridine 12.

for uridine, 6-iodouridine $\mathbf{4 7}$ was synthesized from protected uridine $\mathbf{1 2}$ by lithiation and subsequent reaction with iodine. Catalytic ipso-nitration via nucleophilic substitution was attempted following the protocol from Prakash. ${ }^{64]}$ Unfortunately no reaction was observed and the starting material was recovered (scheme 1.30).

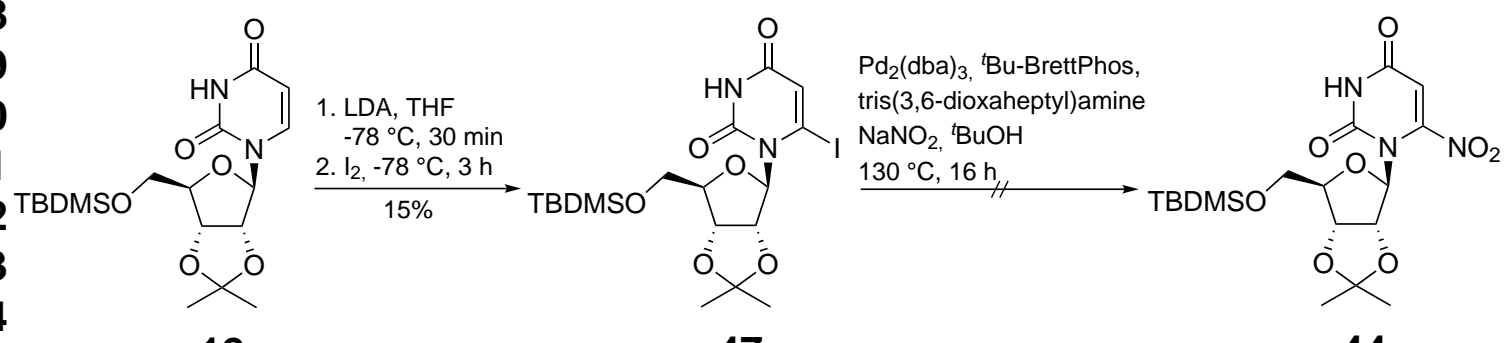

12
47
44

Scheme 1.30. Attempted catalytic ipso-nitration of 6-iodouridine 47.

The main problem might occur from the significantly lower electron density at the uracil C6 position compared to the aryl compounds converted in the work of Prakash. In order to evaluate this assumption and to enhance the electron density, 6-chloro-2,4-dimethoxy-pyrimidine (48) was chosen as a suitable model compound. Same reaction conditions for the palladium mediated ipso-nitration were applied in order to obtain 6-nitro-2,4-dimethoxy-pyrimidine (49) (scheme 1.31). Unfortunately, again only starting material was recovered from the reaction mixture, indicating a more general problem using this nitrating method for heterocyclic compounds. 


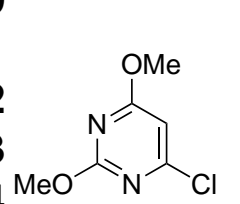

48
$\mathrm{Pd}_{2}(\mathrm{dba})_{3},{ }^{t} \mathrm{Bu}-$ BrettPhos

tris(3,6-dioxaheptyl)amine

$\mathrm{NaNO}_{2},{ }^{t} \mathrm{BuOH}$

$130^{\circ} \mathrm{C}, 16 \mathrm{~h}$

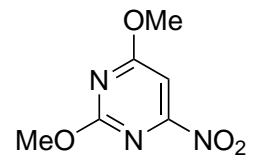

49

Scheme 1.31. Attempted catalytic ipso-nitration of model compound 6-chloro-2,4-dimethoxypyrimidine (48).

Another method to synthesize nitro compounds is conversion of $\alpha$-carboxy-olefins into $\alpha$-nitro-olefins by decarboxylation-nitration mechanism. One possibility is to achieve decarboxylation in the presence of a catalytic amount of silver carbonate, which was discovered by Natarajan et al.[65] The resulting anion at $\mathrm{C} 6$ would then react with $\mathrm{NO}_{2} \mathrm{BF}_{4}$ in DMA. While, the silver catalyzed decarboxylation was successful no reaction of the intermediate anion with $\mathrm{NO}_{2}{ }^{+}$was observed. Instead, protonation upon aqueous workup was achieved. Additionally, deprotection of the silylether seem to be a side reaction, providing acetal protected uridine $\mathbf{1 1}$ as the only product (scheme 1.32). Silylether cleavage might be the reason for the protonation as well. In this case the resulting hydroxy group would provide the proton.

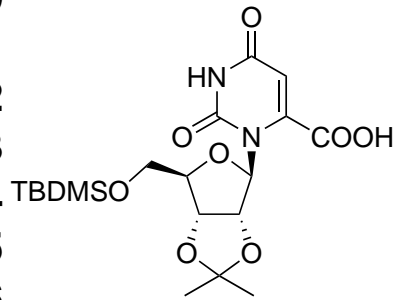

13

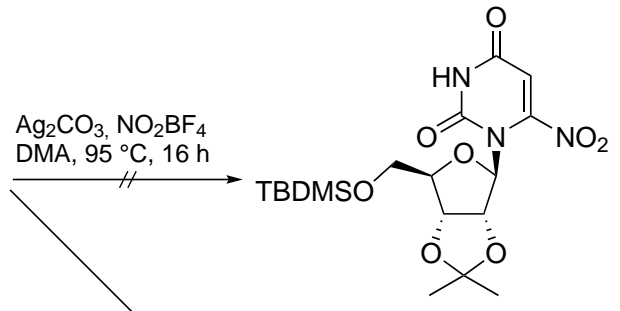

44

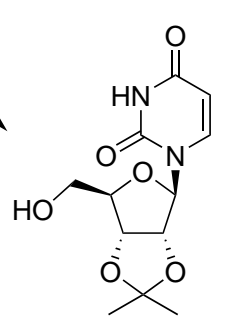

11

Scheme 1.32. Silver catalyzed decarboxylation of protected orotidine $\mathbf{1 3}$ to acetal protected uridine 11. No reaction of the intermediate anion with $\mathrm{NO}_{2}+$ was observed.

A second mechanism for decarboxylation-nitration is the nitro-Hunsdieker reaction, which was invented by Das et al. 66 Here, the decarboxylation is done via a radical mechanism, started by AIBN. The resulting acyloxy radical is attacked by a 
$\mathrm{NO}_{2}$ radical, resulting in the nitro product. However, in case of orotidine 13 only unidentified side products were formed. (scheme 1.33).

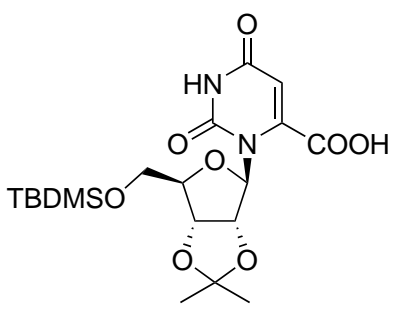

13

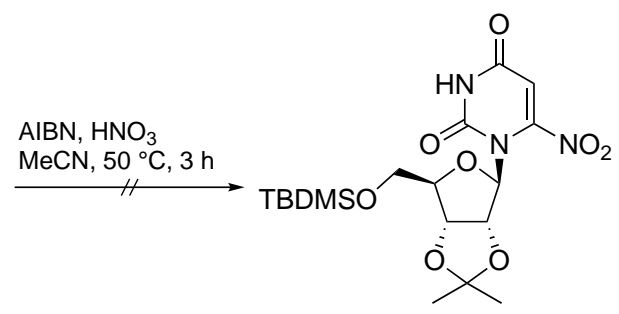

44

Scheme 1.33. Attempted nitro-hunsdieker reaction to obtain 6-nitrouridine 44. 


\subsection{Examination of hOMPD-inhibitor complexes using cryo-crystallography}

In order to obtain more insights into the structure of the hOMPD-substrate complex, enzyme-inhibitor structures were measured, using the in section 1.4 successfully synthesized OMP analogues BMP (3), 6-aza-UMP (4), 6-amido-UMP (8) and 6-isopropyl-UMP (9), which were soaked into precrystallized hOMPD resting state crystals.

To compare the obtained structures with similar analogues, 6-thiocarboxamido-UMP (50) and 6-methyl-UMP (51), which were synthesized by Tobias Schmidt as part of his Ph.D. work and 6-isopropylene-UMP (52), which was synthesized by Moritz von Geyso in his bachelor thesis (scheme 1.34), were soaked into hOMPD resting state crystals and the resulting enzyme-inhibitor structures were detected using $\mathrm{x}$ ray diffraction.

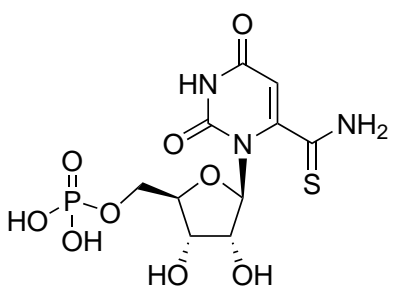

50

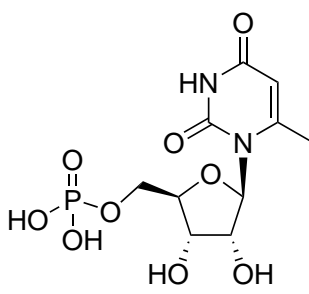

51

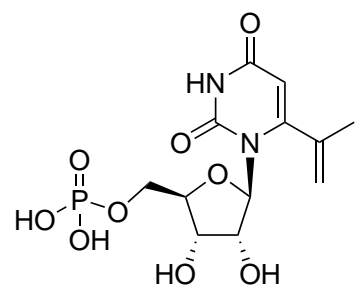

52

Scheme 1.34. 6-thiocarboxamido-UMP (50), 6-methyl-UMP (51) and 6-isopropylene-UMP (52), which were synthesized and provided by Tobias Schmidt and Moritz von Geyso.

The work concerning protein expression and purification as well as crystallization and x-ray diffraction was done by our close cooperation partner Sören Rindfleisch from the Tittmann group $11 \mathrm{His}_{6}$-GST-hOMPD was expressed in E.coli strain SoluBL21. Purification was achieved via Ni-affinity chromatography and the $\mathrm{His}_{6}{ }^{-}$ GST-tag was cleaved by protein protease ULP1, followed by a second Ni-affinity chromatography. hOMPD crystals were obtained using the hanging drop method from Wittmann et al., which was improved by Sören Rindfleisch. [15], 24], 67] Crystallization was done in ammonium sulfate buffer in the presence of gluthation, providing hOMPD resting state crystals at a resolution of $0.95 \AA$ in space group $C 222_{1}$ with one monomer in the asymmetric unit.

${ }^{1}$ AG Prof. K. Tittmann, Georg-August-Universität Göttingen, Dept. of Molecular Enzymology 


\subsection{1. hOMPD-BMP complex}

The hOMPD-BMP complex was obtained by co-crystallization of BMP and hOMPD via the hanging drop method. Diffraction data of the crystals were obtained with the same resolution like the resting state crystals at $0.95 \AA$. The data were processed in space group $\mathrm{C} 222_{1}$ with one monomer in the asymmetric unit. The model was built and refined to fit the experimental data with $R_{\text {work }}=9.9 \%$ and $R_{\text {free }}=11.2 \%$.

The enzyme was found to be in closed conformation completely with the phosphate gripper loop closing the active site. The catalytic tetrad is arranged in the known alternating arrangement, with Lys $_{314}$ being the center of a hydrogen bond network involving Asp' ${ }_{317}$, Asp $_{312}$, Lys $_{281}$ and $\mathrm{O} 6$ of BMP. The diffraction data indicate no alternative positions for the catalytic tetrad residues (figure 1.6).

Due to its extremely high binding affinity with $K_{d}=9 \cdot 10^{-12} \mathrm{M}$, BMP is expected to be a transition state analogue of the OMPD-OMP complex. 68], 69] This analogue is believed to be formed via deprotonation of the C6 hydroxy group resulting in an O6 oxyanion, which mimics the C6 carbanion formed as the intermediate in the proposed mechanism from Wolfenden et al.12], 37] This assumption is supported by the fact that the enol form is the thermodynamically favored tautomer and the $\mathrm{p} K_{a}$ value of barbituric acid being approximately 4.5 enabling for easy deprotonation. 68], [70]

However, the experimental data obtained via x-ray diffraction of the hOMPD-BMP complex dissent the formation of an $\mathrm{O} 6$ oxyanion. The electron density map with higher contour level show equivalent delocalized electron densities for the $\mathrm{C2}-\mathrm{O} 2$, C4-O4 and $\mathrm{C} 6-\mathrm{O} 6$ bonds, indicating the existence of carbonyl double bonds. The bond length were determined at $1.24 \pm 0.01 \AA, 1.26 \pm 0.01 \AA$ and $1.25 \pm 0.01 \AA$ for the $\mathrm{C} 2-\mathrm{O} 2, \mathrm{C} 4-\mathrm{O} 4$ and $\mathrm{C} 6-\mathrm{O} 6$ bond respectively. These length further support a carbonyl bond between $\mathrm{C6}-\mathrm{O} 6$ instead of a hydroxylate, which should show localized electron density and a C-O distance around $1.45 \AA$. Likewise, localized electron density at C5 indicates a single bond between C5-C6 and $\mathrm{sp}^{3}$ hybridized $\mathrm{C} 5$, which is in contradiction to an enolate tautomer and further support the existence of a carbonyl bond between C6-06. Side view of the BMP nucleobase in close distance to the catalytic tetrad show an out of plane distortion of the C6-O6 carbonyl bond by $4.9^{\circ}$ (figure 1.7). 


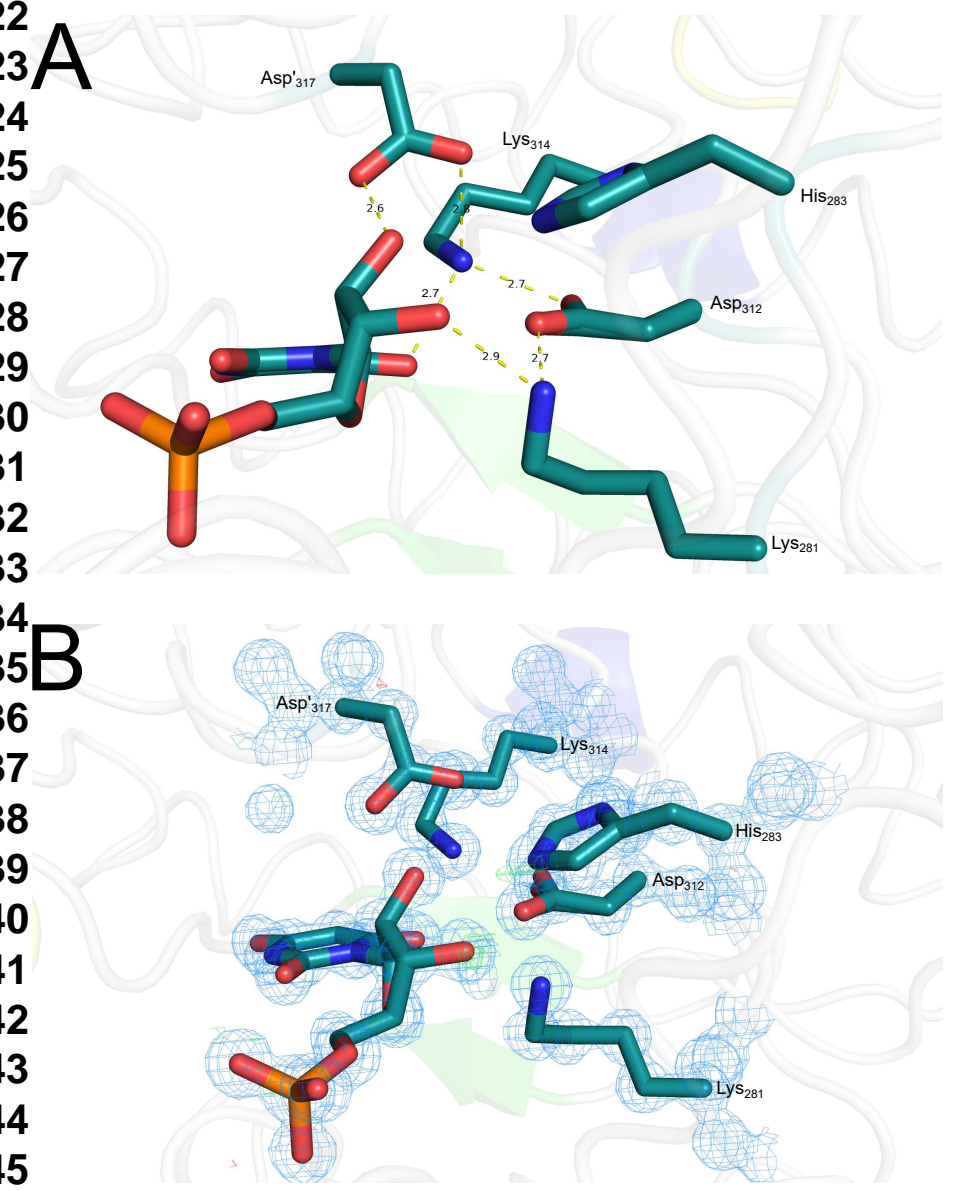

Figure 1.6. Structure of the hOMPD-BMP complex.

A: Binding of BMP at the active site of $h O M P D$ with focus on the interactions with the catalytic tetrad and $\mathrm{His}_{283}$. The structure is determined at a resolution of $0.95 \AA$. Possible hydrogen bonds are indicated as dashed yellow lines with distances of maximal $3.0 \AA$.

B: $2 m \mathrm{~F}_{\mathrm{O}}-D \mathrm{~F}_{\mathrm{C}}$ electron density map (blue meshes) and $m \mathrm{~F}_{\mathrm{O}}-D \mathrm{~F}_{\mathrm{C}}$ difference electron density maps (pos: green meshes, neg: red meshes) with a contour level of 1.5 and $\pm 3.0 \sigma$, respectively.

\subsection{2. hOMPD-6-Aza-UMP complex}

Another good inhibitor for OMPD is 6-aza-UMP (4) with a $K_{d}$ value of $6 \cdot 4 \cdot 10^{-9} \mathrm{M}$, which is used as an anticancer drug. $\left.{ }^{[69,}, 71\right]$, 72] Due to the strong binding affinity 6-aza-UMP might also mimic the transition state. Two different conformers can be transition state analogues for two types of mechanism. The syn-conformation was found in OMPD from E. coli and M. thermoautotrophicum. [32, [33, 35] In this conformer the carbene lone pair, which occurs as the intermediate of the $\mathrm{O} 4$ protonation mechanism from Kollmann et al., is exchanged by the lone pair of the N6 nitrogen. In the anti-conformation, which was found in S. cerevisiae, ${ }^{351}$ the pyrimidine ring is rotated by $180^{\circ}$, exposing the $\mathrm{C} 2-\mathrm{O} 2$ carbonyl to the catalytic tetrad. This causes an environment, similar to the OMPD-BMP complex. 


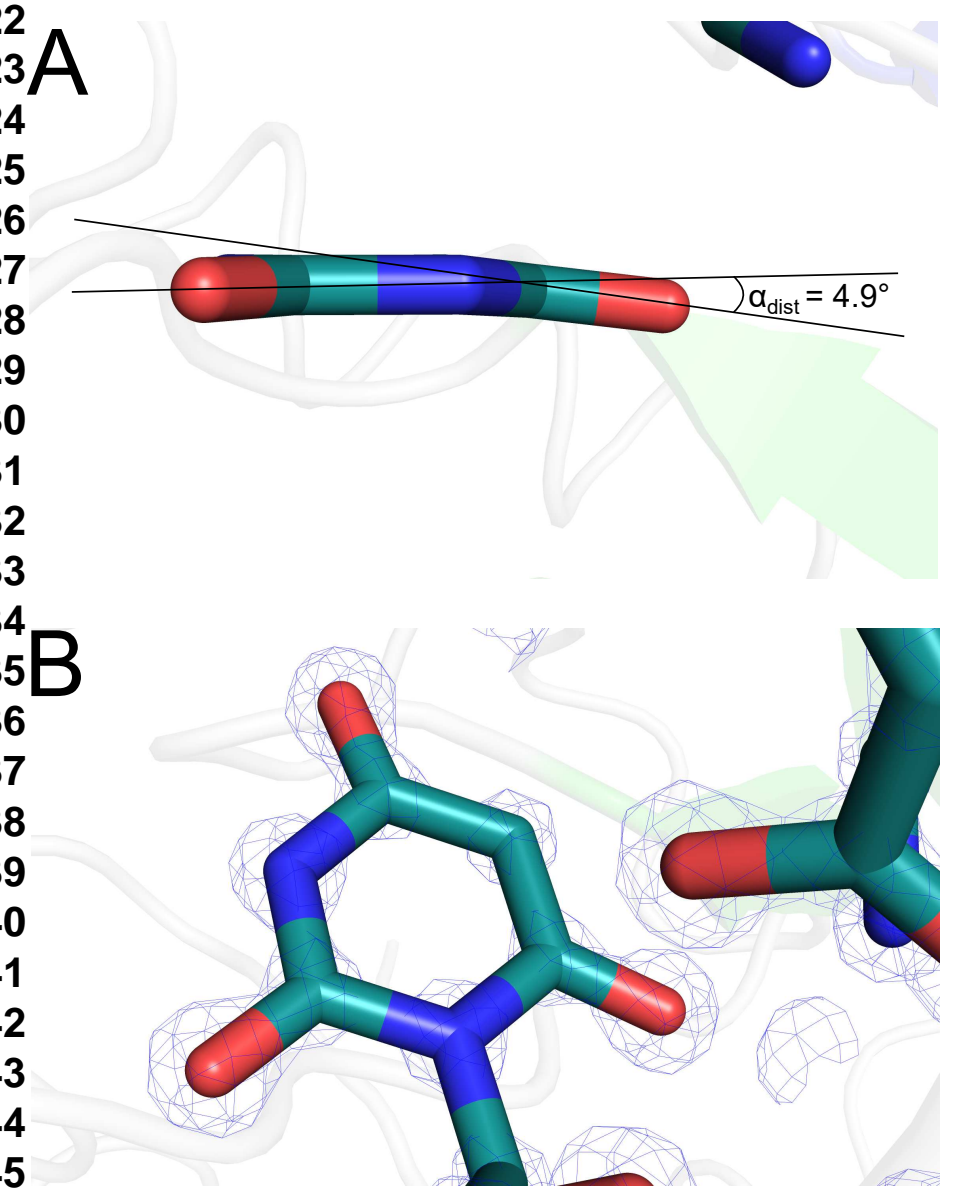

Figure 1.7. Out of plane distortion and focused electron density map of the hOMPD-BMP complex. A: Side view of the BMP nucleobase. Ribose-phosphate is not displayed for better clarity. B: $2 m \mathrm{~F}_{\mathrm{O}}-D \mathrm{~F}_{\mathrm{C}}$ electron density map (gray meshes) with a contour level of $4 \sigma$.

The hOMPD-6-aza-UMP complex was obtained via soaking of 6-aza-UMP into hOMPD resting state crystals. Diffraction data were measured at a resolution of $1.0 \AA$ in space group $\mathrm{C}_{22} 22_{1}$ with one monomer in the asymmetric unit. The model was built and refined to fit the experimental data with $R_{\text {work }}=11.7 \%$ and $R_{\text {free }}=13.4 \%$.

The enzyme was found to be in closed conformation completely with the phosphate gripper loop closing the active site. The catalytic tetrad residues and $\mathrm{His}_{283}$ are in similar position like in the hOMPD-BMP complex. 6-Aza-UMP occupies the active site in the anti-conformation, leading to the formation of a hydrogen bond network, similar to the BMP complex with Lys $_{314}$ in the center, forming bonds to Asp' ${ }_{317}$, $\mathrm{Asp}_{312}, \mathrm{Lys}_{281}$ and $\mathrm{O} 2$ of 6 -aza-UMP (figure 1.8). The rotation of the pyrimidine ring causes loss of interactions to $\mathrm{Gln}_{430}$ and $\mathrm{Ser}_{372}$, which are substituted by hydrogen bonds to water molecules. 


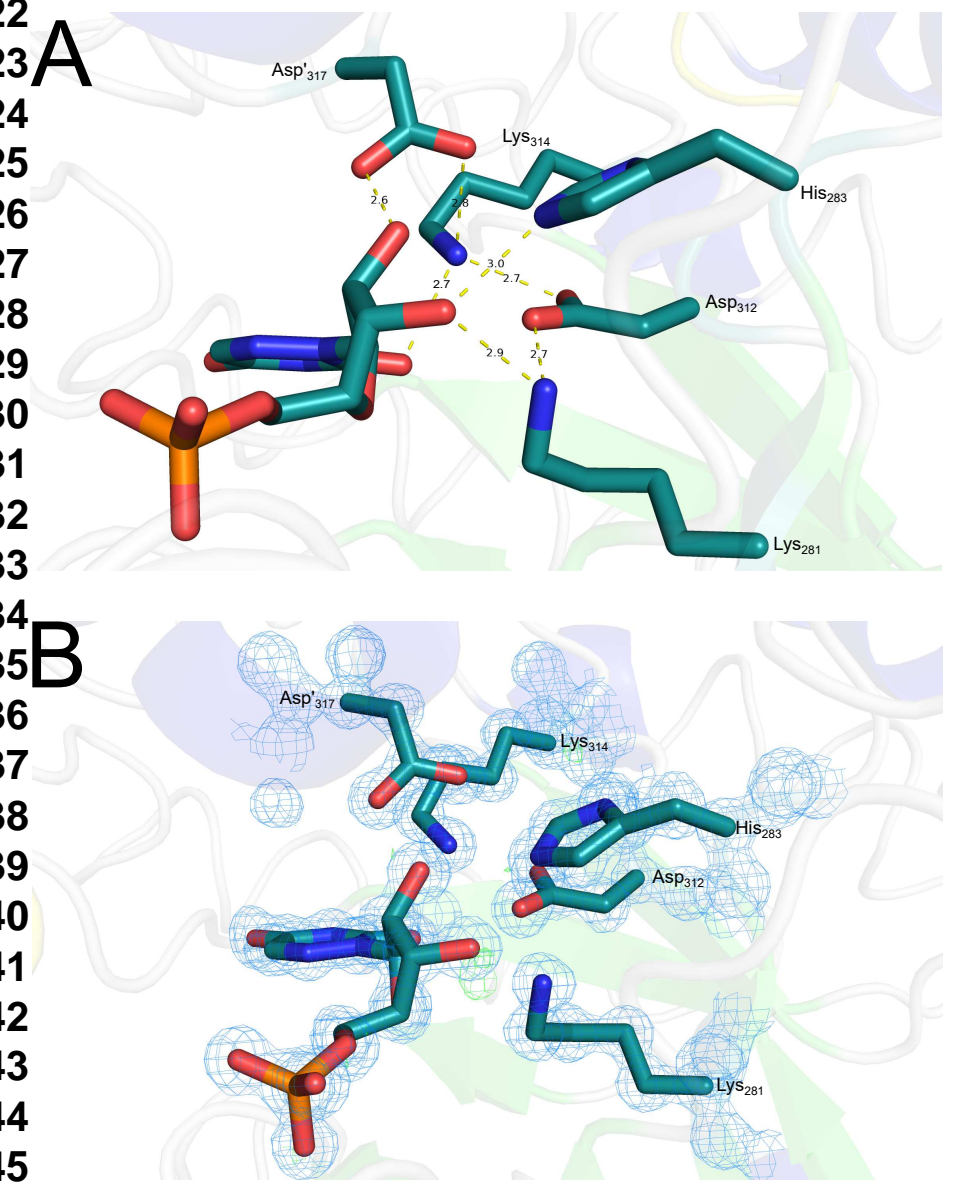

Figure 1.8. Structure of the $h O M P D-6-a z a-U M P$ complex.

A: Binding of 6-aza-UMP at the active site of $h$ OMPD with focus on the interactions with the catalytic tetrad and $\mathrm{His}_{283}$. The structure is determined at a resolution of $1.0 \AA$. Possible hydrogen bonds are indicated as dashed yellow lines with distances of maximal $3.0 \AA$.

B: $2 m \mathrm{~F}_{\mathrm{O}}-D \mathrm{~F}_{\mathrm{C}}$ electron density map (blue meshes) and $m \mathrm{~F}_{\mathrm{O}}-D \mathrm{~F}_{\mathrm{C}}$ difference electron density maps (pos: green meshes, neg: red meshes) with a contour level of 1.5 and $\pm 3.0 \sigma$, respectively.

In difference to the hOMPD-BMP complex, examination of the bond length of the $\mathrm{C} 2-\mathrm{O} 2$ bond and the $\mathrm{C} 4-\mathrm{O} 4$ bond revealed different distances, indicating non equal binding. While the $\mathrm{C} 2-\mathrm{O} 2$ bond has a length of $1.24 \pm 0.01 \AA$ and shows delocalized electron density in the electron density map with higher contour level, the C4-O4 bond has a length of $1.31 \pm 0.01 \AA$ and more localized electron density. This indicates clearly a carbonyl bond at $\mathrm{C} 2-\mathrm{O} 2$, whereas the $\mathrm{C} 4-\mathrm{O} 4$ bond has both carbonyl and single bond character. Side view of the 6-aza-UMP nucleobase in close distance to the catalytic tetrad show a slight out of plane distortion of the $\mathrm{C} 2-\mathrm{O} 2$ carbonyl bond by $4.3^{\circ}$ (figure 1.9). 


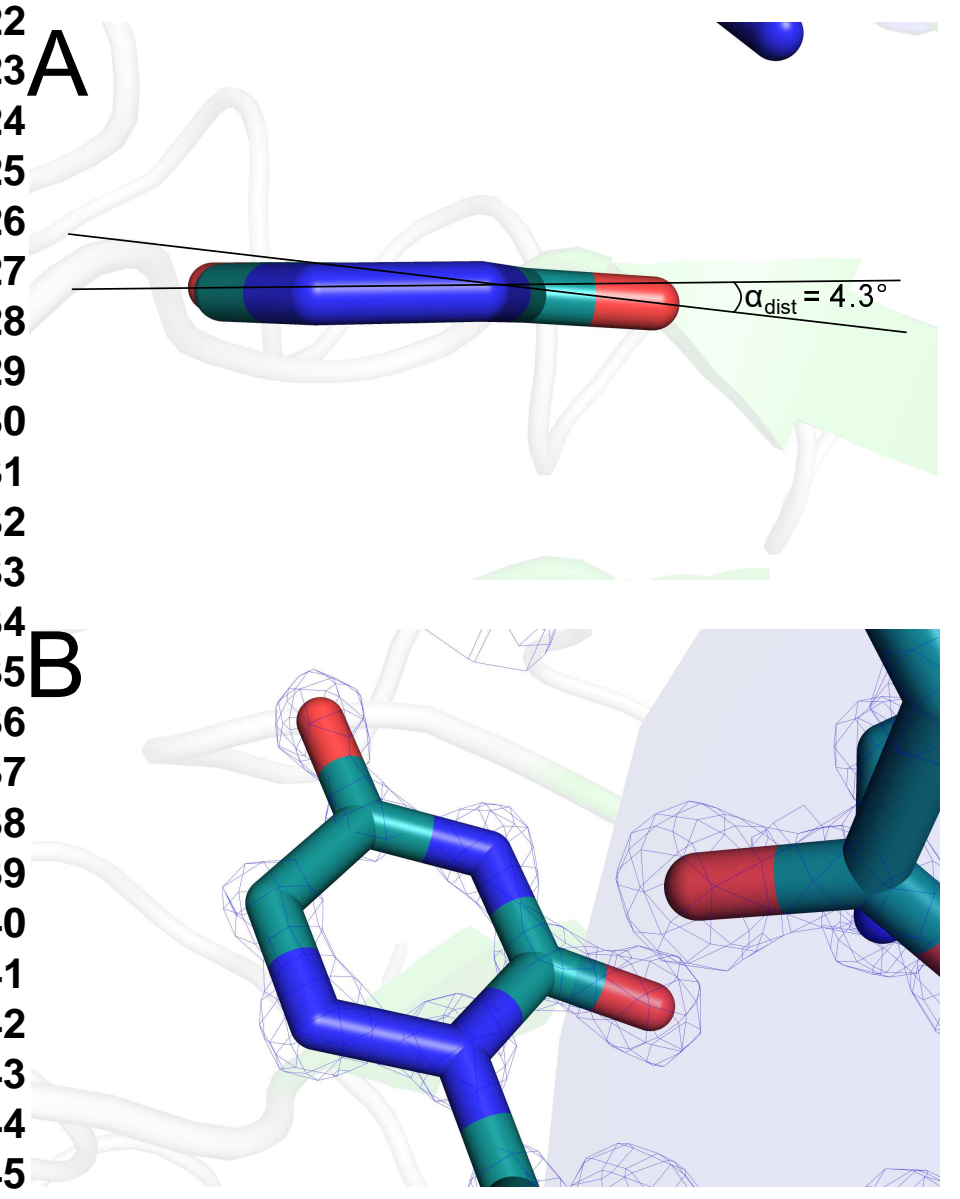

Figure 1.9. Out of plane distortion and focused electron density map of the hOMPD-6-aza-UMP complex.

A: Side view of the 6-aza-UMP nucleobase. Ribose-phosphate is not displayed for better clarity.

B: $2 m \mathrm{~F}_{\mathrm{O}}-D \mathrm{~F}_{\mathrm{C}}$ electron density map (blue meshes) with a contour level of $4 \sigma$.

\subsection{3. hOMPD-6-Amido-UMP complex}

In order to gain more insight into the hOMPD-substrate complex, the isosteric substrate analogue 6-amido-UMP was used to examine interactions with the active site, assuming OMP is bound in protonated $\mathrm{C} 6-\mathrm{COOH}$ form. The protonated C6-carboxy group is mimicked by the C6-amido group, being a proton donor for potential hydrogen bonds.

The hOMPD-6-amido-UMP complex was obtained via soaking of 6-amido-UMP into $h O M P D$ resting state crystals. Diffraction data were measured at a resolution of $1.2 \AA$ in space group $C 222_{1}$ with one monomer in the asymmetric unit. The model was built and refined to fit the experimental data with $R_{\text {work }}=11.9 \%$ and $R_{\text {free }}=14.7 \%$. 


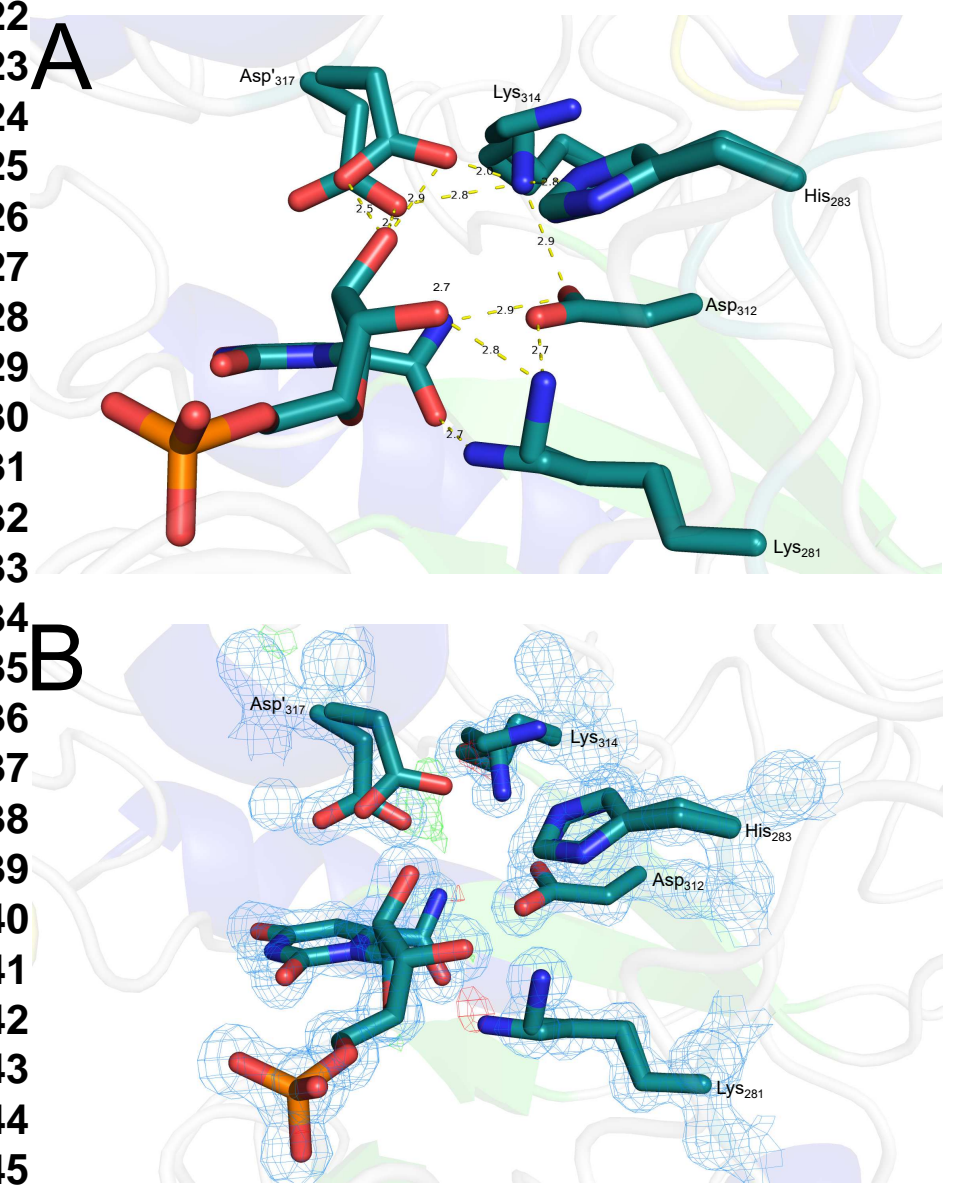

Figure 1.10. Structure of the hOMPD-6-amido-UMP complex.

A: Binding of 6 -amido-UMP at the active site of $h$ OMPD with focus on the interactions with the catalytic tetrad and $\mathrm{His}_{283}$. The structure is determined at a resolution of $1.2 \AA$. Possible hydrogen bonds are indicated as dashed yellow lines with distances of maximal $3.0 \AA$.

B: $2 m \mathrm{~F}_{\mathrm{O}}-D \mathrm{~F}_{\mathrm{C}}$ electron density map (blue meshes) and $m \mathrm{~F}_{\mathrm{O}}-D \mathrm{~F}_{\mathrm{C}}$ difference electron density maps (pos: green meshes, neg: red meshes) with a contour level of 1.5 and $\pm 3.0 \sigma$, respectively.

The enzyme was found to be in closed conformation completely with the phosphate gripper loop closing the active site. 6-Amido-UMP is bound in syn-conformation, exposing the amido group to the catalytic tetrad, which was found to be present in a slightly different arrangement, compared to the BMP and 6-aza-UMP complexes. Lys ${ }_{314}$ adopts another position, sliding out from between Asp' ${ }_{317}$ and $A s_{312}$. The new position is located between Asp' $_{317}$ and $\mathrm{His}_{281}$. The latter is rotated by $180^{\circ}$ in order to enable potential hydrogen bonds from Lys $\mathrm{s}_{314}$ towards both residues. Except for $\mathrm{Asp}_{312}$ all catalytic tetrad residues occupy a second conformation by about $30 \%$. Lys 314 is pointing into the water channel which interconnects both active sites. Asp' ${ }_{317}$ moves slightly towards the pyrimidine ring and Lys $_{281}$ adopts a conformation, oriented towards the amido-carbonyl, potentially enabling a hydrogen bond. The amido protons forms a second hydrogen bond to $\mathrm{Asp}_{312}$. The amido 
group show an out of plane distortion by $8.9^{\circ}$ and a torsion angle with respect to the pyrimidine ring plane of $59.2^{\circ}$ (figures $1.10,1.11$ )

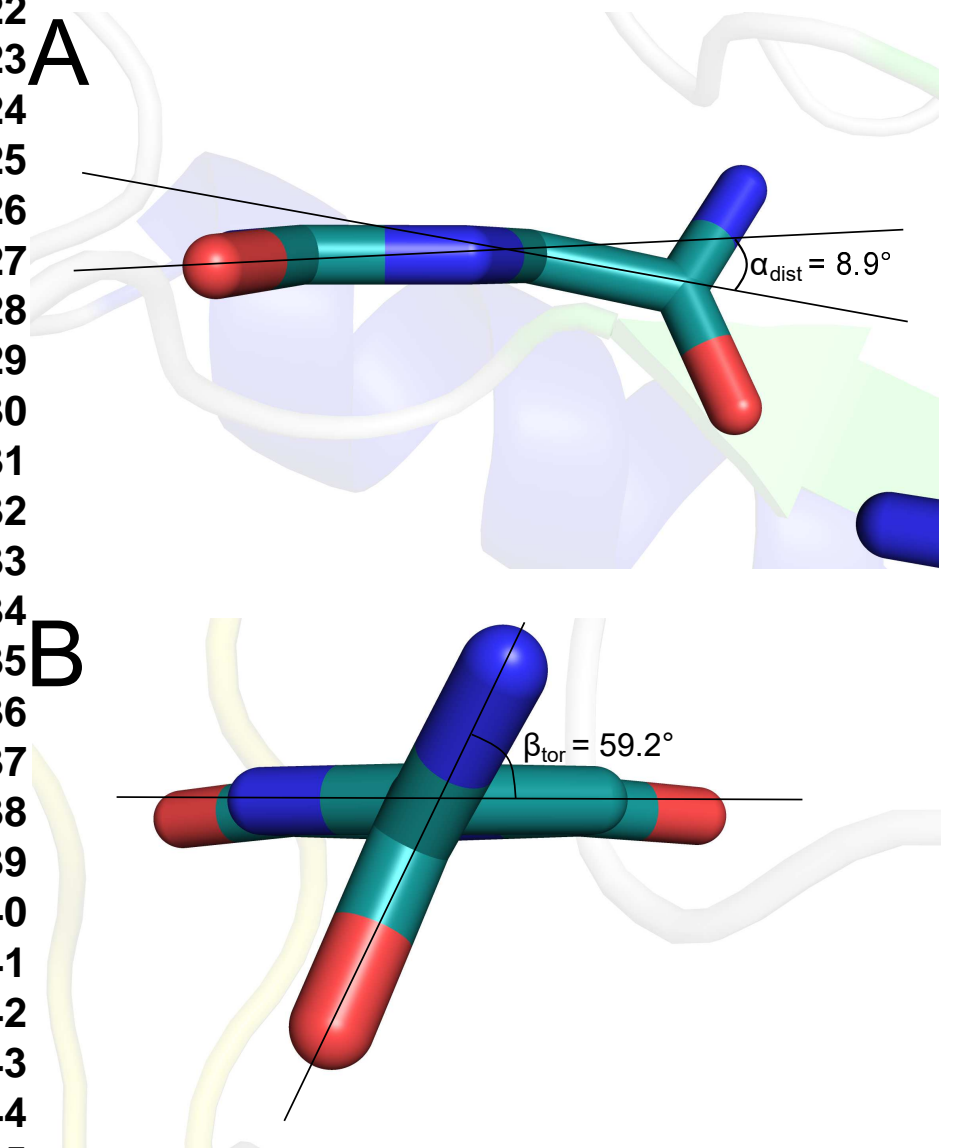

Figure 1.11. Out of plane distortion and torsion of the amido group of the hOMPD-6-amido-UMP complex.

A: Side view of the 6-amido-UMP nucleobase. Ribose-phosphate is not displayed for better clarity.

B: Torsion of the amido group with respect to the pyrimidine ring plane.

\subsection{4. hOMPD-6-Thiocarboxamido-UMP complex}

To further evaluate the structure of the hOMPD-6-amido-UMP complex, the structural similar inhibitor 6-thioamido-UMP (provided by Tobias Schmidt) was soaked into $h$ OMPD resting state crystals to obtain the hOMPD-6-thioamido-UMP complex. Diffraction data were measured at a resolution of $1.2 \AA$ in space group $\mathrm{C} 222_{1}$ with one monomer in the asymmetric unit. The model was built and refined to fit the experimental data with $R_{\text {work }}=12.1 \%$ and $R_{\text {free }}=15.2 \%$. 


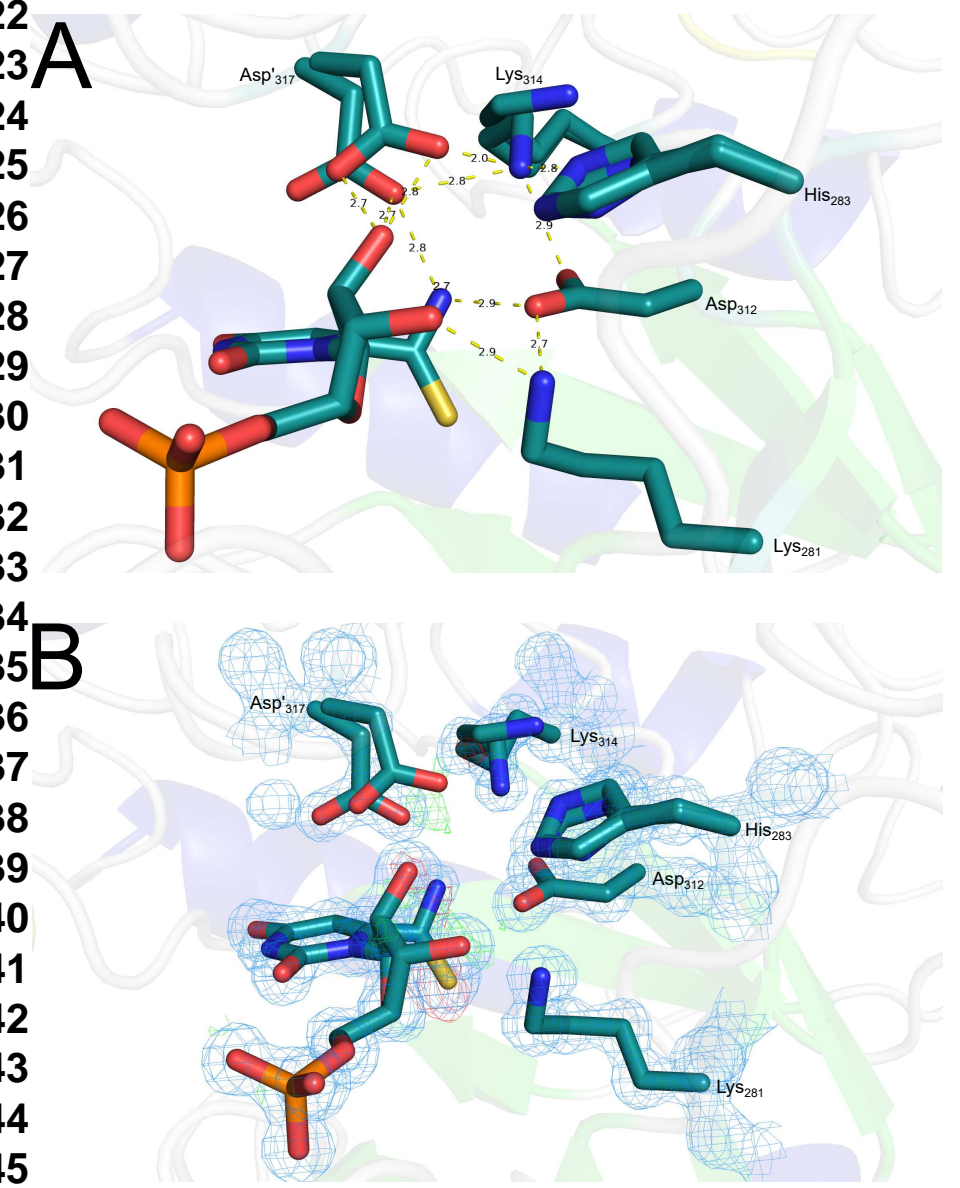

Figure 1.12. Structure of the hOMPD-6-thioamido-UMP complex.

A: Binding of 6-thioamido-UMP at the active site of $h$ OMPD with focus on the interactions with the catalytic tetrad and $\mathrm{His}_{283}$. The structure is determined at a resolution of $1.2 \AA$. Possible hydrogen bonds are indicated as dashed yellow lines with distances of maximal $3.0 \AA$.

B: $2 m \mathrm{~F}_{\mathrm{O}}-D \mathrm{~F}_{\mathrm{C}}$ electron density map (blue meshes) and $m \mathrm{~F}_{\mathrm{O}}-D \mathrm{~F}_{\mathrm{C}}$ difference electron density maps (pos: green meshes, neg: red meshes) with a contour level of 1.5 and $\pm 3.0 \sigma$, respectively.

As expected, the enzyme was found in a similar situation like it was measured for the hOMPD-6-amido-UMP complex, being in closed conformation completely, with the phosphate gripper loop closing the active site and the ligand positioned in synconformation, exposing the $\mathrm{C} 6$ substituent to the active site. The hydrogen bond network between Asp' ${ }_{317}$, Lys $_{314}$, Asp $_{312}$, Lys $_{281}$ and His Hig3 $_{28}$ remains almost the same like in the hOMPD-6-amido-UMP complex with a few exceptions. First, the hydrogen bond between the thioamido-amine and $\mathrm{Asp}_{312}$ is formed to the other oxygen atom of the $\mathrm{Asp}_{312}$ carboxylate, making the bond slightly shorter at $2.86 \AA$ compared to the 6-amido-UMP bond at $2.93 \AA$. An additional bond between the thioamidoamine and Asp' ${ }_{317}$ is formed. Second, The additional conformer of Lys $\mathbf{s}_{281}$, which is bound the amido-carbonyl in the hOMPD-6-amido-UMP complex does not exist in the hOMPD-6-thioamido-UMP complex. Occupancy of both conformations remains 
like in the hOMPD-6-amido-UMP complex at about 70\% for the higher occupied conformation and about $30 \%$ for the lower conformation. The thioamido group show an out of plane distortion by $7.2^{\circ}$ and a torsion angle with respect to the pyrimidine ring plane of $73.7^{\circ}$ (figures $1.12,1.13$ )

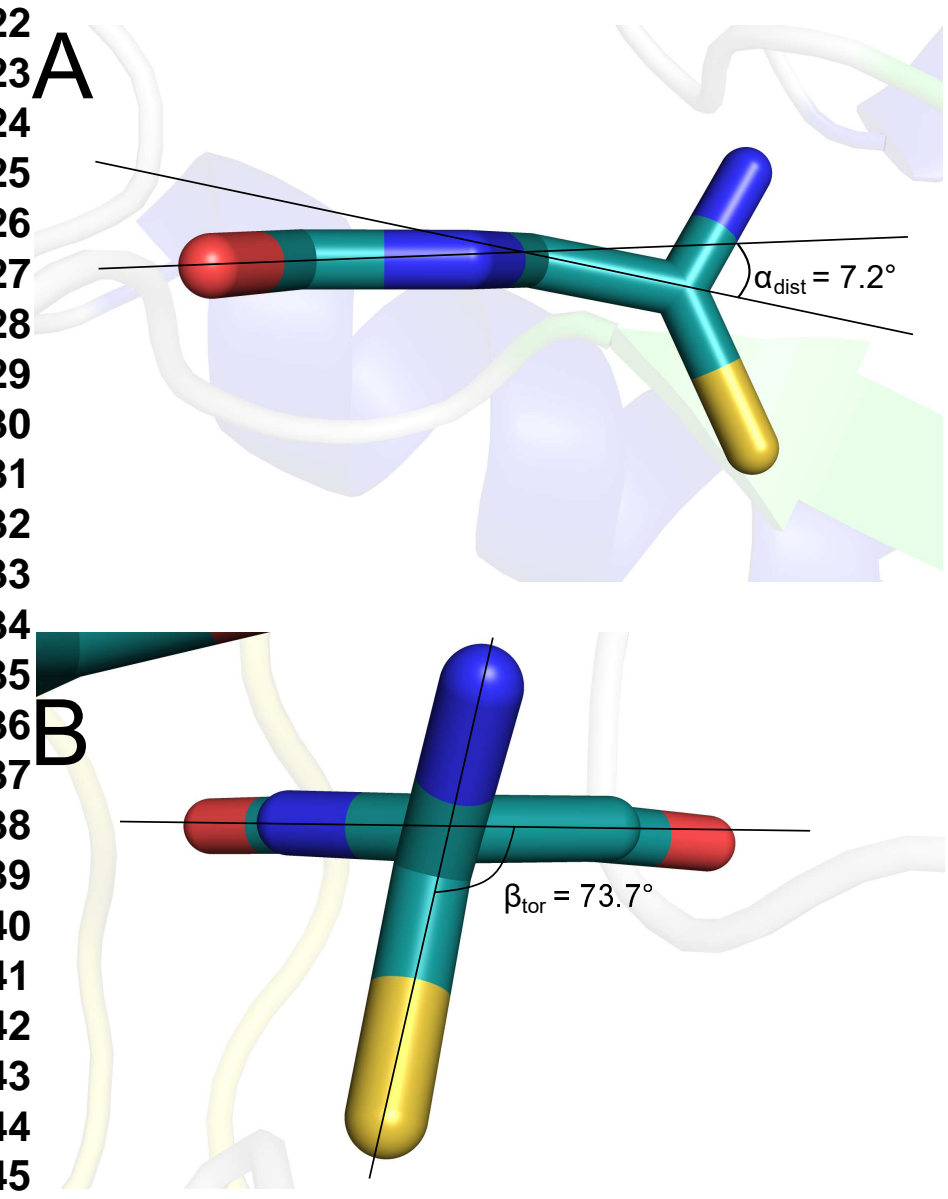

Figure 1.13. Out of plane distortion and torsion of the thioamido group of the hOMPD-6-thioamidoUMP complex.

A: Side view of the 6-thioamido-UMP nucleobase. Ribose-phosphate is not displayed for better clarity.

B: Torsion of the thioamido group with respect to the pyrimidine ring plane.

\subsection{5. hOMPD-6-Isopropyl-UMP complex}

In order to evaluate, how hOMPD reacts if no electrostatic or polar interactions with the C6-substituent are possible the hOMPD-6-isopropyl-UMP complex was investigated. The isopropyl group resemble the carboxylate group in its steric properties, while being completely hydrophobic. The complex was obtained via soaking of 6 isopropyl-UMP into resting state hOMPD crystals. Diffraction data were measured 
at a resolution of $1.3 \AA$ in space group $\mathrm{C} 222_{1}$ with one monomer in the asymmetric unit. The model was built and refined to fit the experimental data with $R_{\text {work }}=14.2 \%$ and $R_{\text {free }}=17.3 \%$.

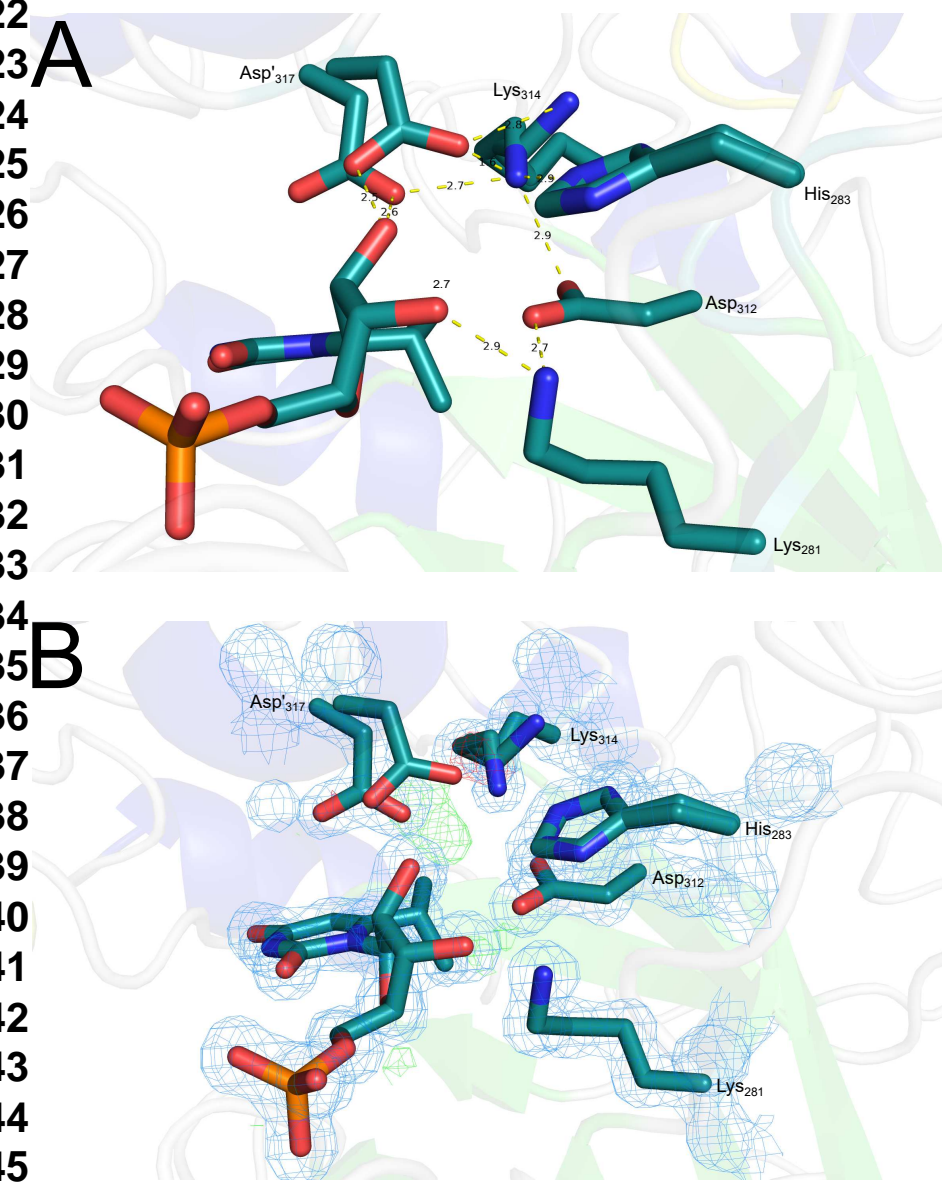

Figure 1.14. Structure of the hOMPD-6-isopropyl-UMP complex.

A: Binding of 6-isopropyl-UMP at the active site of $h$ OMPD with focus on the interactions with the catalytic tetrad and $\mathrm{His}_{283}$. The structure is determined at a resolution of $1.3 \AA$. Possible hydrogen bonds are indicated as dashed yellow lines with distances of maximal $3.0 \AA$.

B: $2 m \mathrm{~F}_{\mathrm{O}}-D \mathrm{~F}_{\mathrm{C}}$ electron density map (blue meshes) and $m \mathrm{~F}_{\mathrm{O}}-D \mathrm{~F}_{\mathrm{C}}$ difference electron density maps (pos: green meshes, neg: red meshes) with a contour level of 1.5 and $\pm 3.0 \sigma$, respectively.

Like in the 6-amido and 6-thioamido complexes, the phosphate gripper loop is fully closed, indicating high ligand occupancy in the active site. 6-isopropyl-UMP is bound in syn-conformation, exposing the isopropyl group to the catalytic tetrad. The positioning of the catalytic tetrad residues resembles the positioning found in 6amido-UMP and 6-thiocarboxamido-UMP complexes. Lys $_{314}$ occupies the position between Asp' $_{317}$, Asp $_{312}$ and flipped $\mathrm{His}_{281}$ forming hydrogen bonds to each residue. Asp' $_{317}$ is dragged towards the pyrimidine ring. Alternative conformations were found for $\mathrm{Asp}^{\prime}{ }_{317}, \mathrm{Asp}_{312}$ and $\mathrm{His}_{281}$ with occupancy of approximately $30 \%$. The isopropyl 
group is rigidly positioned with the methyl groups pointing away from the ribose toward a hydrophobic pocket. No indication for rotation was found. No hydrogen bonds to the isopropyl group are possible, which is mainly due to its hydrophobic character but also because $\mathrm{Asp}_{312}$ is not positioned close enough towards the methyl groups. The isopropyl group show almost no out of plane distortion or distortion at the tetrahedral angle. Measured distortions might be due to modeling errors (figures 1.14, 1.15)

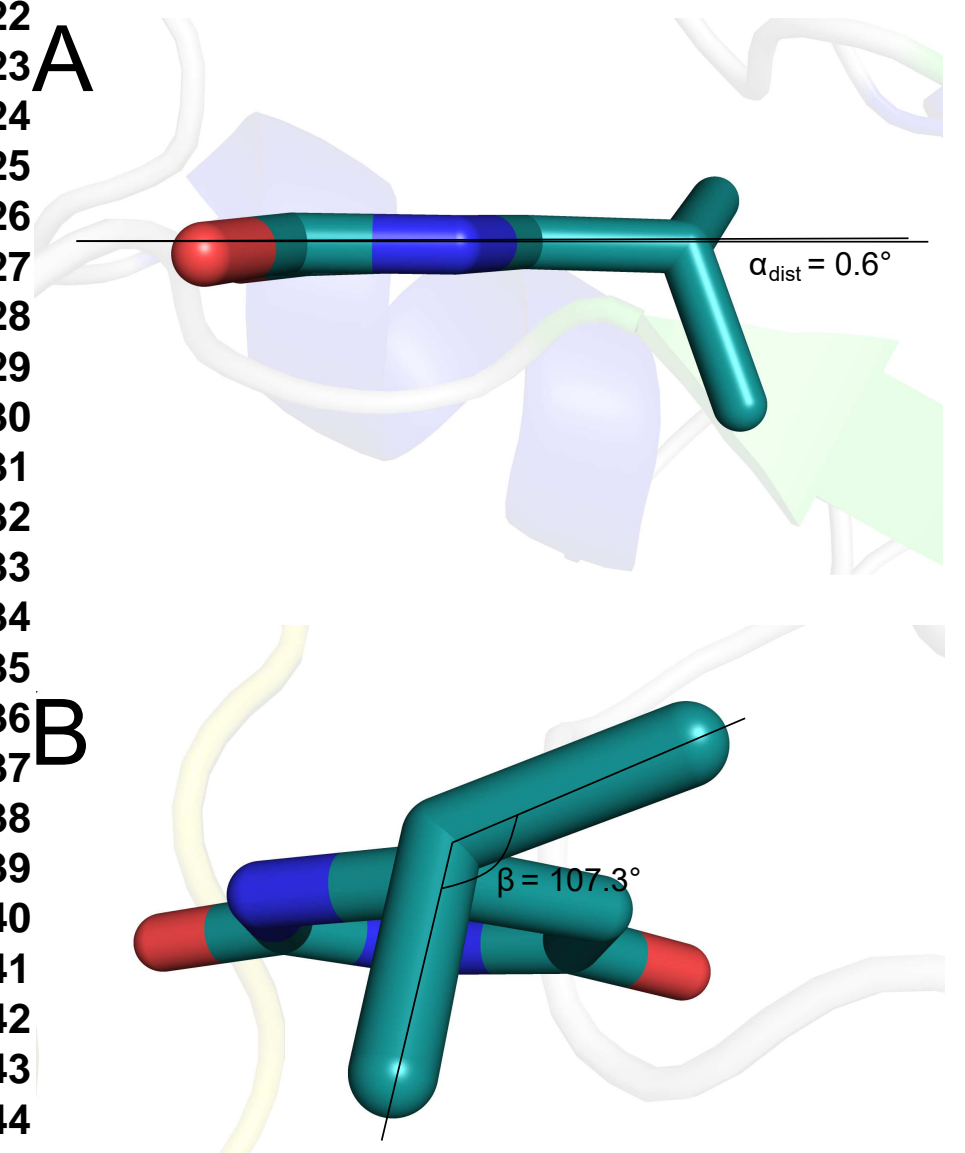

Figure 1.15. Out of plane distortion and tetrahedral angle of the isopropyl group of the hOMPD-6isopropyl-UMP complex.

A: Side view of the 6-isopropyl-UMP nucleobase. Ribose-phosphate is not displayed for better clarity.

B: Angle between the methyl groups of the isopropyl substituent.

\subsection{6. hOMPD-6-Methyl-UMP complex}

To check how the enzyme reacts if the unpolar C6 substituent is smaller, the hOMPD6-Methyl-UMP complex was obtained via soaking of 6-methyl-UMP, which was pro- 
vided by Tobias Schmidt, into $h$ OMPD resting state crystals. Diffraction data were measured at a resolution of $1.4 \AA$ in space group $\mathrm{C} 222_{1}$ with one monomer in the asymmetric unit. The model was built and refined to fit the experimental data with $R_{\text {work }}=13.4 \%$ and $R_{\text {free }}=17.1 \%$.

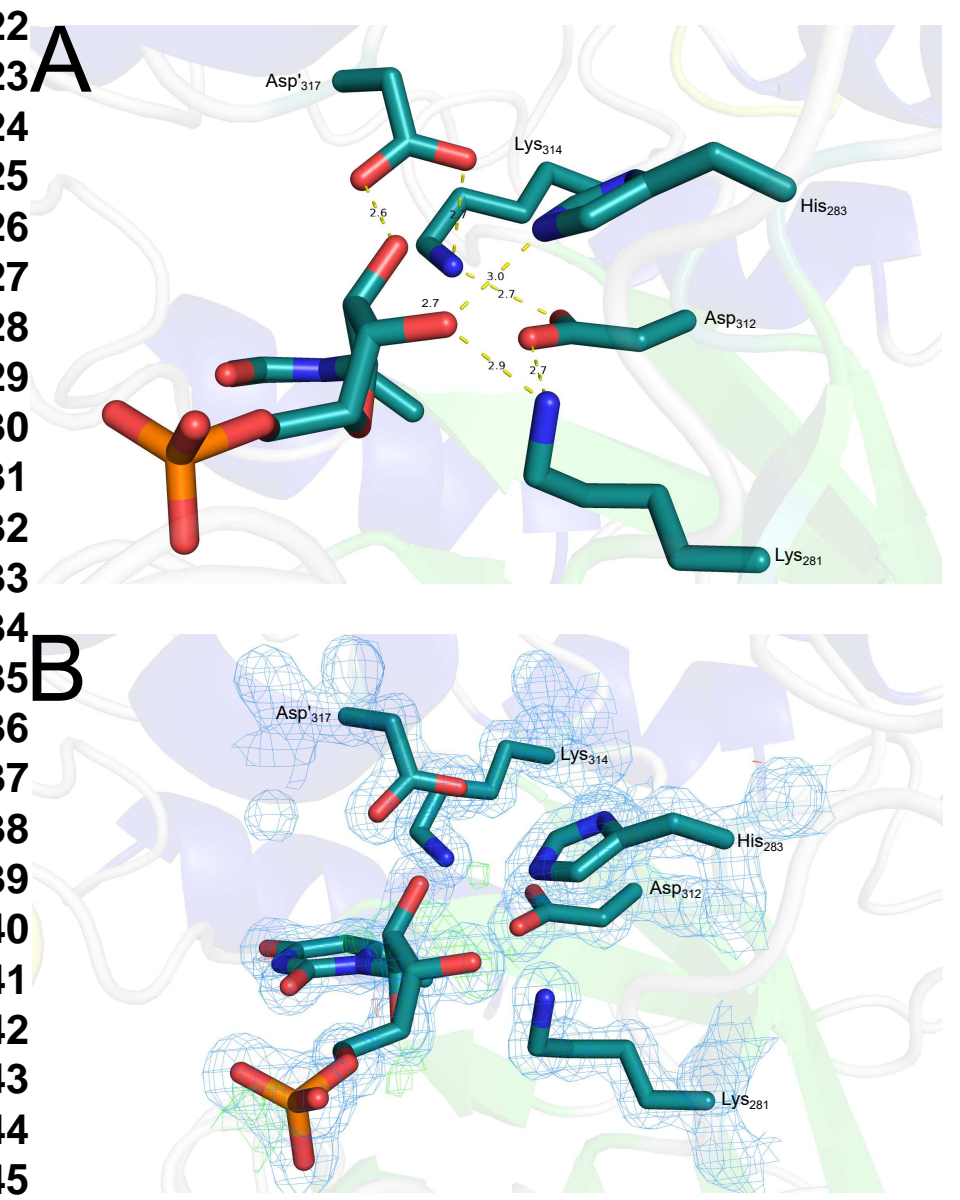

Figure 1.16. Structure of the hOMPD-6-methyl-UMP complex.

A: Binding of 6-methyl-UMP at the active site of $h$ OMPD with focus on the interactions with the catalytic tetrad and $\mathrm{His}_{283}$. The structure is determined at a resolution of $1.4 \AA$. Possible hydrogen bonds are indicated as dashed yellow lines with distances of maximal $3.0 \AA$.

B: $2 m \mathrm{~F}_{\mathrm{O}}-D \mathrm{~F}_{\mathrm{C}}$ electron density map (blue meshes) and $m \mathrm{~F}_{\mathrm{O}}-D \mathrm{~F}_{\mathrm{C}}$ difference electron density maps (pos: green meshes, neg: red meshes) with a contour level of 1.5 and $\pm 3.0 \sigma$, respectively.

As it is the case for the previous described inhibitors, the phosphate gripper loop appears to be fully closed, which indicates a high occupancy of 6-methyl-UMP in the active site. The arrangement of the catalytic tetrad residues resemble the arrangement in the BMP- and 6-aza-UMP complexes. Lys $_{314}$ is centered between Asp' ${ }_{317}$ and $\mathrm{Asp}_{312}$, forming hydrogen bonds to both residues. $\mathrm{Asp}_{312}$ is further connected to Lys $s_{281}$ by a second hydrogen bond, formed by the other oxygen. No alternative residue positions are present. Like in the 6-isopropyl complex, no polar interactions 
are observable to the $\mathrm{C} 6$ substituent. While the hydrophobic character exclude any polar interactions, it would be also out of range from any residue to form potential bonds. This wide distance is caused by an extreme out of plane distortion by $22.7^{\circ}$ (figures 1.16, 1.17).

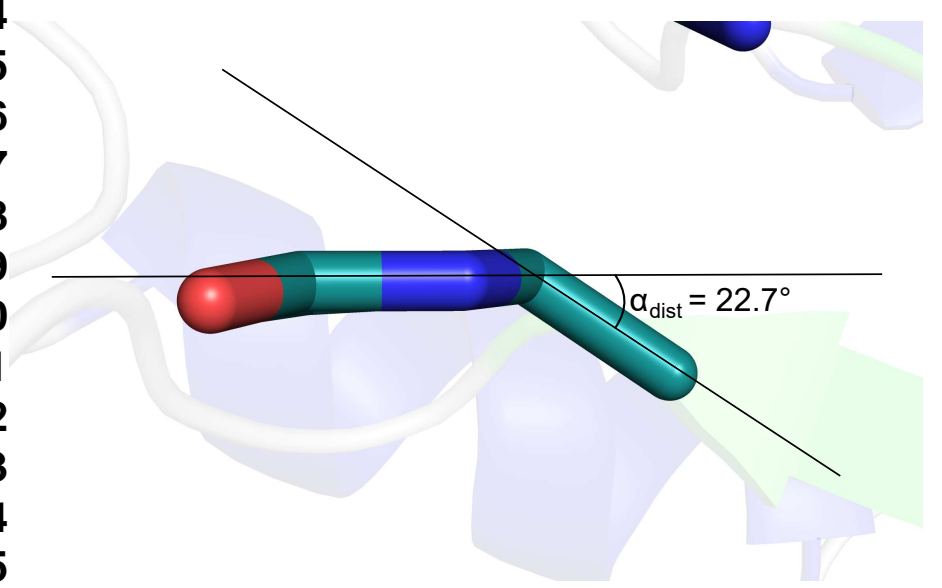

Figure 1.17. Out of plane distortion of the hOMPD-6-methyl-UMP complex.

Side view of the 6-methyl-UMP nucleobase. Ribose-phosphate is not displayed for better clarity.

\subsection{7. hOMPD-6-Isopropenyl-UMP complex}

In order gather more information about sterical similar but unpolar inhibitors the hOMPD-6-isopropenyl-UMP complex was investigated. The inhibitor was synthesized and provided by Moritz von Geyso as part of his bachelor thesis. The isopropenyl group is isosteric the carboxylate group with its central $\mathrm{sp}^{2}$ hybridized carbon. The complex was obtained via soaking of 6-isopropenyl-UMP into resting state hOMPD crystals. Diffraction data were measured at a resolution of $1.2 \AA$ in space group P21 with the dimer in the asymmetric unit. The model was built and refined to fit the experimental data with $R_{\text {work }}=13.6 \%$ and $R_{\text {free }}=15.7 \%$.

The electron density map revealed two ligand configurations bound to the active site. In both cases the positioning of the catalytic tetrad residues is similar to the arrangement found in the 6-amido 6-thioamido and isopropyl-UMP complexes, with Lys $_{314}$ centered between Asp' ${ }_{317}, \mathrm{Asp}_{312}$ and $\mathrm{His}_{283}$. Alternative arrangements for Asp' $_{317}$ and $\mathrm{Lys}_{314}$ were also found, but no indication for inversion of $\mathrm{His}_{283}$, which in result has no polar interactions with Lys $_{314}$. The high occupied first ligand conformer 


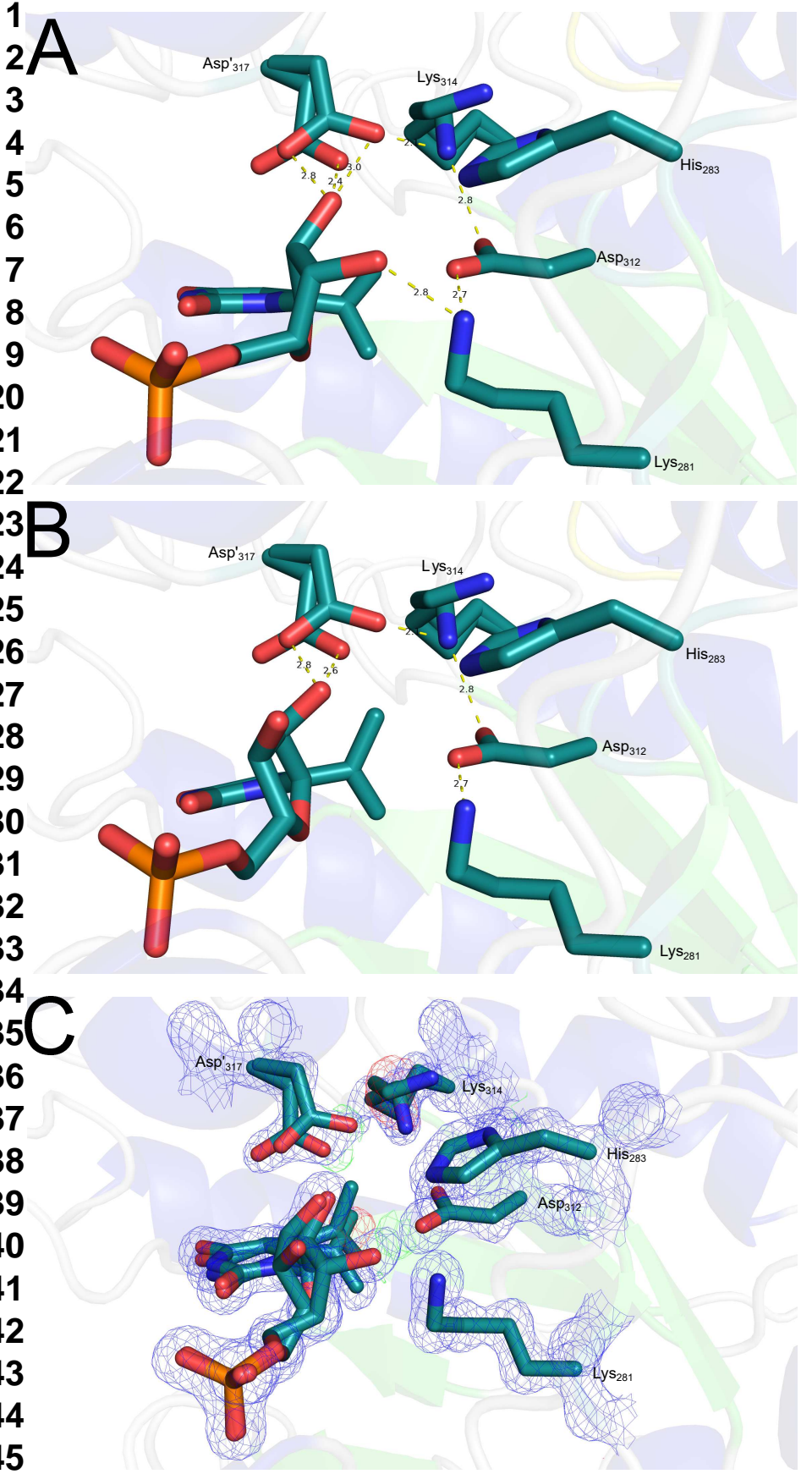

Figure 1.18. Structure of the hOMPD-6-isopropenyl-UMP complex.

A+B: Binding of two potential conformers of 6 -isopropenyl-UMP at the active site of $h O M P D$ with focus on the interactions with the catalytic tetrad and $\mathrm{His}_{283}$. The structure is determined at a resolution of $1.3 \AA$. Possible hydrogen bonds are indicated as dashed yellow lines with distances of maximal $3.0 \AA$.

C: $2 m F_{\mathrm{O}}-D \mathrm{~F}_{\mathrm{C}}$ electron density map (blue meshes) and $m \mathrm{~F}_{\mathrm{O}}-D \mathrm{~F}_{\mathrm{C}}$ difference electron density maps (pos: green meshes, neg: red meshes) with a contour level of 1.5 and $\pm 3.0 \sigma$, respectively.

is in the same position like the other inhibitors, showing a slight out of plane distortion by $4.2^{\circ}$ and a torsion angle with respect to the pyrimidine ring plane of $73.7^{\circ}$ 
(figures $1.18 \mathrm{~A}, 1.19 \mathrm{~A}, \mathrm{~B}$ ). The second ligand conformer adopts a more relaxed structure, with the ribose refolded and a small tilt of the pyrimidine plane. The isopropenyl group shows almost no out of plane distortion, but nearly twice the torsion angle compared to the first conformer (figures $1.18 \mathrm{~B}, 1.19 \mathrm{C}, \mathrm{D}$ ).
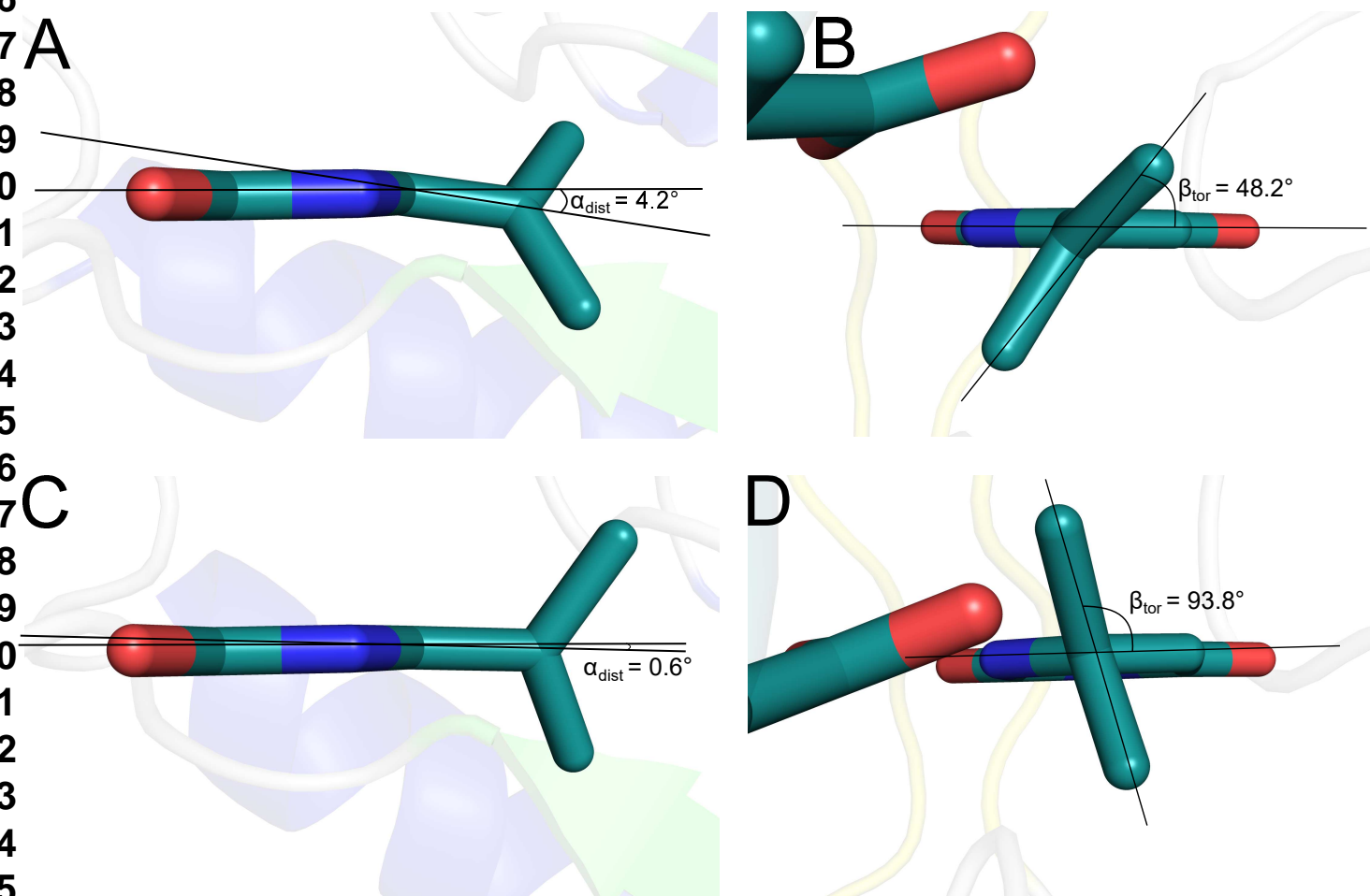

Figure 1.19. Out of plane distortions and torsion angles of the isopropenyl group of the hOMPD-6isopropenyl-UMP complex conformers.

A: Side view of the 6-isopropenyl-UMP nucleobase of the first conformer. Ribose-phosphate is not displayed for better clarity.

B: Torsion of the isopropenyl group of the first conformer with respect to the pyrimidine ring plane.

C: Side view of the 6-isopropenyl-UMP nucleobase of the second conformer. Ribose-phosphate is not displayed for better clarity.

D: Torsion of the isopropenyl group of the second conformer with respect to the pyrimidine ring plane.

\subsection{8. hOMPD $_{314 \mathrm{AcK}}-\mathrm{OMP}$ complex}

For evaluate how the original substrate interacts with the catalytic tetrad the mostly inactive mutant $h \mathrm{OMPD}_{314 \mathrm{AcK}}$ was expressed by Sören Rindfleisch and the complex was obtained via soaking of OMP into $h \mathrm{OMPD}_{314 \mathrm{AcK}}$ resting state crystals. Diffraction data were measured at a resolution of $1.2 \AA$ in space group P222 ${ }_{1}$ with one monomer in the asymmetric unit. The model was built and refined to fit the experi- 
mental data with $R_{\text {work }}=13.2 \%$ and $R_{\text {free }}=15.8 \%$.

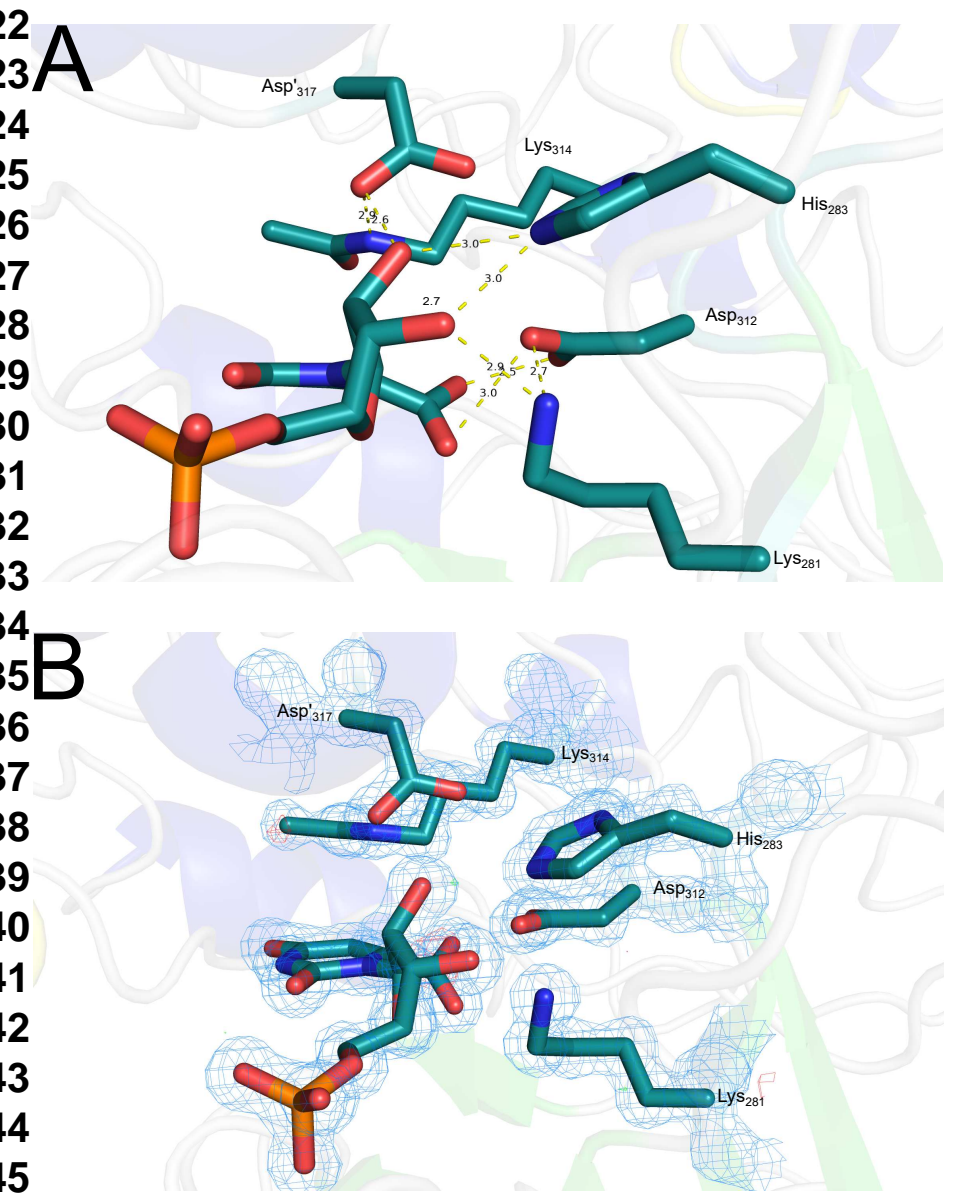

Figure 1.20. Structure of the $h \mathrm{OMPD} \mathrm{D}_{314 \mathrm{AcK}}-\mathrm{OMP}$ complex.

A: Binding of OMP at the active site of $h O M P D_{314 \mathrm{AcK}}$ with focus on the interactions with the catalytic tetrad and $\mathrm{His}_{283}$. The structure is determined at a resolution of $1.2 \AA$. Possible hydrogen bonds are indicated as dashed yellow lines with distances of maximal $3.0 \AA$. .

B: $2 m \mathrm{~F}_{\mathrm{O}}-D \mathrm{~F}_{\mathrm{C}}$ electron density map (blue meshes) and $m \mathrm{~F}_{\mathrm{O}}-D \mathrm{~F}_{\mathrm{C}}$ difference electron density maps (pos: green meshes, neg: red meshes) with a contour level of 1.5 and $\pm 3.0 \sigma$, respectively.

Like in the wild type enzyme complexes the phosphate gripper loop appeared to be fully closed, indicating a high inhibitor occupancy for the $h O M P D_{314 \mathrm{AcK}}-\mathrm{OMP}$ complex as well. The OMP is bound in syn-conformation, forcing the carboxy group in close proximity to $\mathrm{Asp}_{312}$ of the catalytic tetrad. The arrangemant of the catalytic tetrad is similar to the $h \mathrm{OMPD}_{\mathrm{wt}}$-inhibitor complexes, except for acetylated Lys $\mathrm{s}_{314}$, which adopts a new position beside Asp' ${ }_{317}$ with the acetyl group above the pyrimidine ring plane. The distance of the OMP C6-carboxy group and $\mathrm{Asp}_{312}$ at $2.45 \AA$ indicates the formation of a hydrogen bond. Asymmetric electron density at the C6-carboxy group further support the possibility of a bond formation. The electron density map with higher contour level of 4.0 show a clear distinction between a car- 

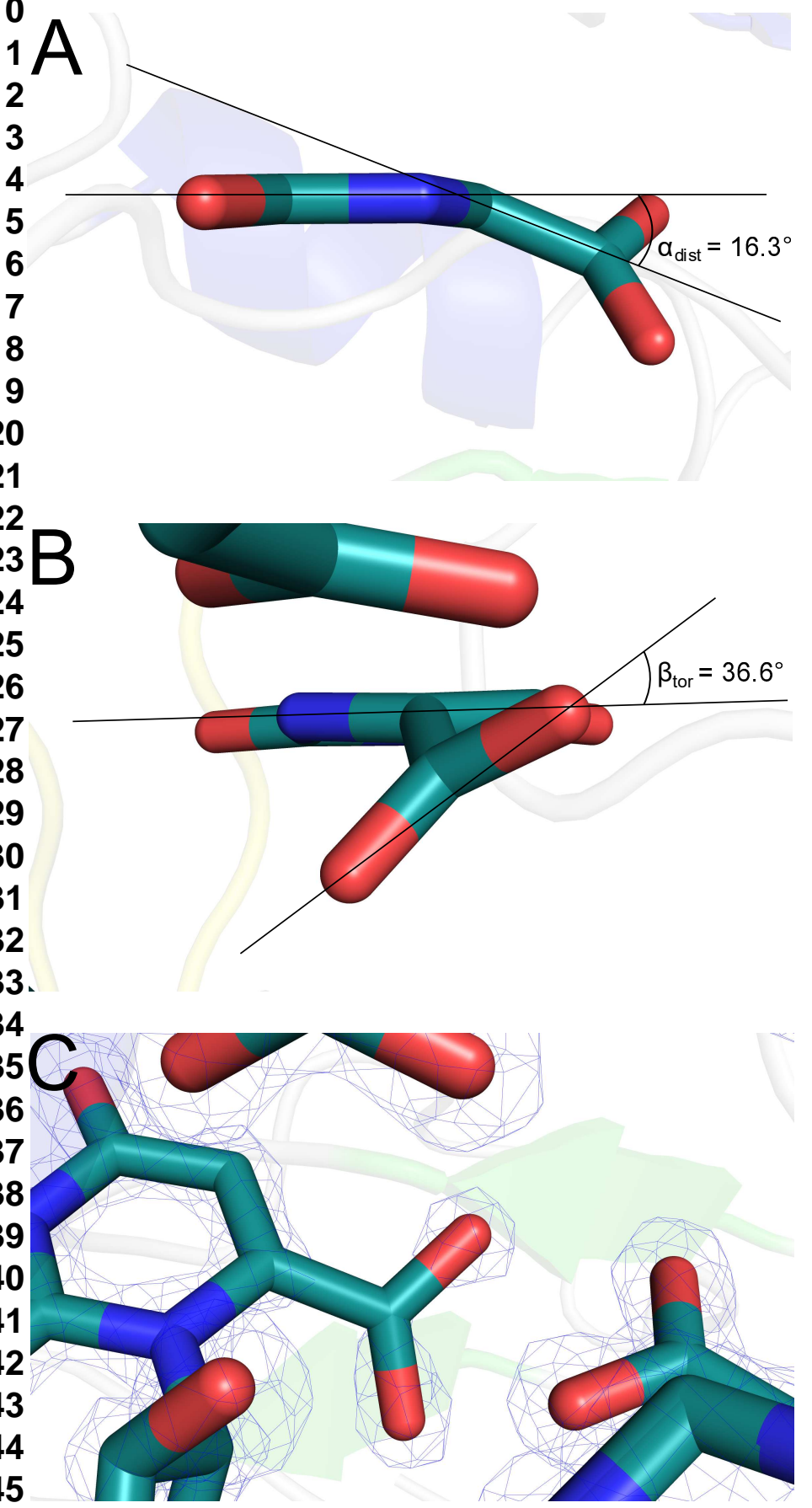

Figure 1.21. Out of plane distortion, torsion, and focused electron density map of the carboxy group of the $h O M P D_{314 \mathrm{AcK}}-\mathrm{OMP}$ complex.

A: Side view of the OMP nucleobase. Ribose-phosphate is not displayed for better clarity.

B: Torsion of the carboxy group with respect to the pyrimidine ring plane.

C: $2 m \mathrm{~F}_{\mathrm{O}}-D \mathrm{~F}_{\mathrm{C}}$ electron density map (blue meshes) with a contour level of $4 \sigma$, focused on the OMP C6-carboxy group.

bonyl bond with delocalized density and a hydroxy group with density only around the second oxygen atom. The carboxy group shows an out of plane distortion by 
$16.3^{\circ}$ and a torsion angle with respect to the pyrimidine ring plane of $36.6^{\circ}$ (figures $1.20,1.21$.

\subsection{9. $h \mathrm{OMPD}_{314 \mathrm{AcK}}-\mathrm{BMP}$ complex}

In order to identify interaction differences of the catalytic tetrad of $h O M P D_{314 A c K}$ and $h O M P D_{w t}$ aside from Lys $_{314}$, the $h O M P D_{314 \mathrm{AcK}}-\mathrm{BMP}$ complex was crystallized and compared with the $h O M P D_{w t}-B M P$ complex. The complex was obtained via soaking of BMP into $h \mathrm{OMPD}_{314 \mathrm{AcK}}$ resting state crystals. Diffraction data were measured at a resolution of $1.1 \AA$ in space group $\mathrm{P} 222_{1}$ with one monomer in the asymmetric unit. The model was built and refined to fit the experimental data with $R_{\text {work }}=10.7 \%$

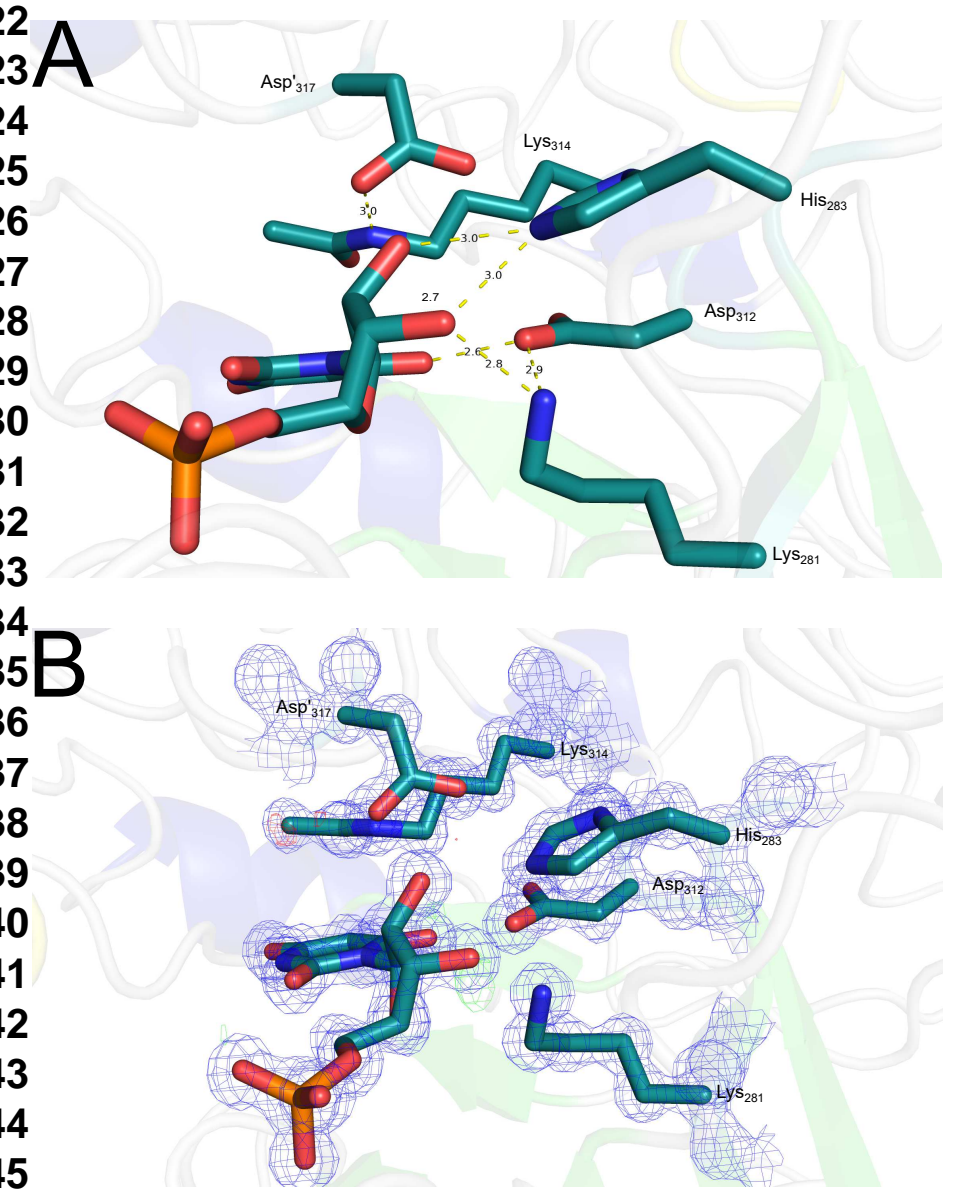

Figure 1.22. Structure of the $h O M P D_{314 A c K}-B M P$ complex.

A: Binding of BMP at the active site of $h \mathrm{OMPD}{ }_{314 \mathrm{AcK}}$ with focus on the interactions with the catalytic tetrad and $\mathrm{His}_{283}$. The structure is determined at a resolution of $1.2 \AA$. Possible hydrogen bonds are indicated as dashed yellow lines with distances of maximal $3.0 \AA$.

B: $2 m F_{O}-D F_{C}$ electron density map (blue meshes) and $m F_{O}-D F_{C}$ difference electron density maps (pos: green meshes, neg: red meshes) with a contour level of 1.5 and $\pm 3.0 \sigma$, respectively. 
and $R_{\text {free }}=12.4 \%$.

Like all other complexes, the $h \mathrm{OMPD}_{314 \mathrm{AcK}}-\mathrm{BMP}$ complex shows high occupancy, by a fully closed phosphate gripper loop. The arrangement of the catalytic tetrade closely resembles the $h O M P D_{314 A c K}-O M P$ complex. Compared to the $h O M P D_{w t}{ }^{-}$ BMP complex no hydrogen bond between $\mathrm{O} 6$ and Lys $_{314}$ is possible as expected. Instead a bond to $\mathrm{Asp}_{312}$ is possible due to moving of BMP towards the catalytic tetrad by approximately $0.5 \AA$. The electron density map with a contour level of $4 \sigma$ shows delocalized density at $\mathrm{C} 2-\mathrm{O} 2, \mathrm{C} 4-\mathrm{O} 4$ and $\mathrm{C} 6-\mathrm{O} 6$, indicating carbonyl bonds like in the $h O M P D_{w t}-B M P$ complex with almost no out of plane distortion for the $\mathrm{C} 6$ carbonyl.

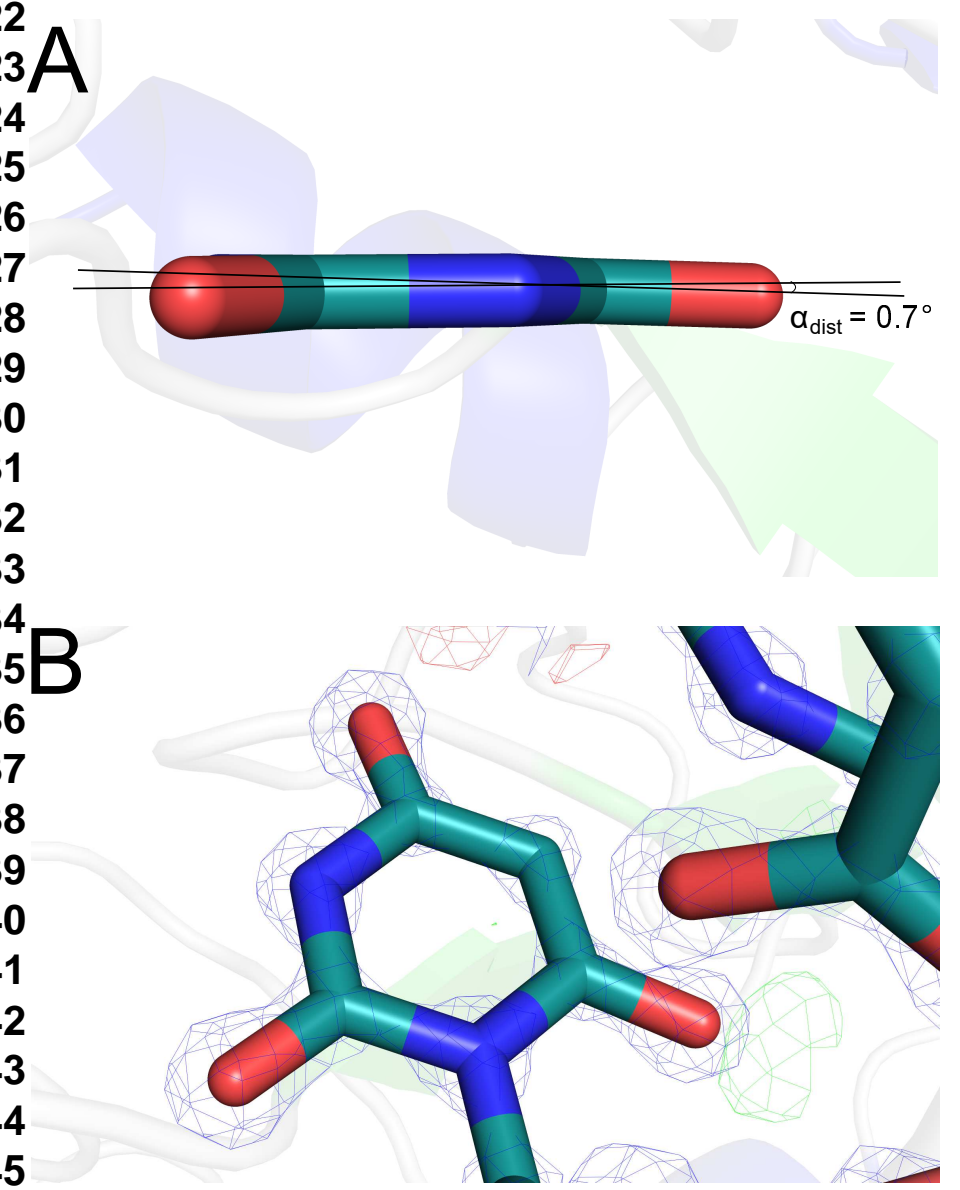

Figure 1.23. Out of plane distortion and focused electron density map of the $h O M P D_{314 \mathrm{AcK}}-\mathrm{BMP}$ complex.

A: Side view of the BMP nucleobase. Ribose-phosphate is not displayed for better clarity.

B: $2 m \mathrm{~F}_{\mathrm{O}}-D \mathrm{~F}_{\mathrm{C}}$ electron density map (gray meshes) with a contour level of $4 \sigma$, focused on the pyrimidine ring. 


\subsection{Discussion}

\subsubsection{New insights into enzyme substrate interactions}

\section{hOMPD favors uncharged species}

The mechanism of OMPD catalyzed decarboxylation is still under discussion, although being investigated for more than 40 years. The scientific community tends to favor the mechanism, first proposed by Wolfenden et al., which involves a carbanion with localized negative charge at C6. ${ }^{[25,},[55,, 73]-[77]$ This intermediate is stabilized and then neutralized by protonated Lys $_{314}$, acting as the proton donor. Proof for this mechanism proposal is the extreme high binding affinity of BMP and 6-aza-UMP to OMPD. These inhibitors are assumed to resemble the carbanion intermediate by either formation of an oxyanion at $\mathrm{O} 6$ in case of BMP or by the N6 lone pair of 6-azaUMP, potentially acting as a hydrogen bond donor to the carbanion stabilizing Lys $\mathbf{s}_{314}$.

However, the herein measured hOMPD-BMP complex did not confirm the formation of charged species. All C-O bonds of the pyrimidine ring are equal, matching the bond length of carbonyl bonds at approximately $1.25 \AA$ and showing evenly electron distribution. This indicates the existence of a carbonyl bond at $\mathrm{C} 6$ instead of an oxyanion, as proposed by Wolfenden et al. The enzyme seems to prefer uncharged species. BMP is bound and stabilized via formation of attractive dipol-dipol interaction and hydrogen bonds as indicated by close distances of the $\mathrm{C} 6$ carbonyl to Lys $_{314}$ and $\mathrm{Asp}_{312}$ of the catalytic tetrad. This binding mode is supported by the hOMPD6-aza-UMP complex. Against expectations, the pyrimidine ring is inverted by $180^{\circ}$ and bound in anti-conformation. Thereby the $\mathrm{C} 2$ carbonyl replaces the $\mathrm{C} 6$ carbonyl in the BMP complex. Due to the ring inversion, the hydrogen bonds of the pyrimidine umbrella, which are formed to the $\mathrm{C} 2$ carbonyl and $\mathrm{N} 3$ in syn-conformation were broken in favor of carbonyl interactions with the catalytic tetrad. This further indicates the preference of uncharged intermediates.

In general, no evidence for $\mathrm{C} 6$ charged transition state intermediates were found. Investigation of the OMP and 6-aza-UMP complexes show strong interactions with uncharged carbonyl bonds, suggesting the formation of a $\mathrm{C} 6$ neutral transition state intermediate.

While a negative charge results from decarboxylation, its whereabouts remains unknown. It might be delocalized in the pyrimidine ring plane and stabilized at $\mathrm{O} 4$. 
The 6-aza-UMP complex reveals a more distinguished electron density at C4-O4 with a slightly elongated bond length compared the the C4 carbonyl in the BMP complex (figure 1.24). This might result from higher electron density in 6-aza-UMP compared to BMP, which possibly mimic delocalized negative charge like it could be exist in the transition state intermediate. This charge seems to be further stabilized at $\mathrm{O} 4$, however no hydrogen bond donor in proximity to $\mathrm{O} 4$ is present. The exact stabilization of the resulting negative charge remains elusive.

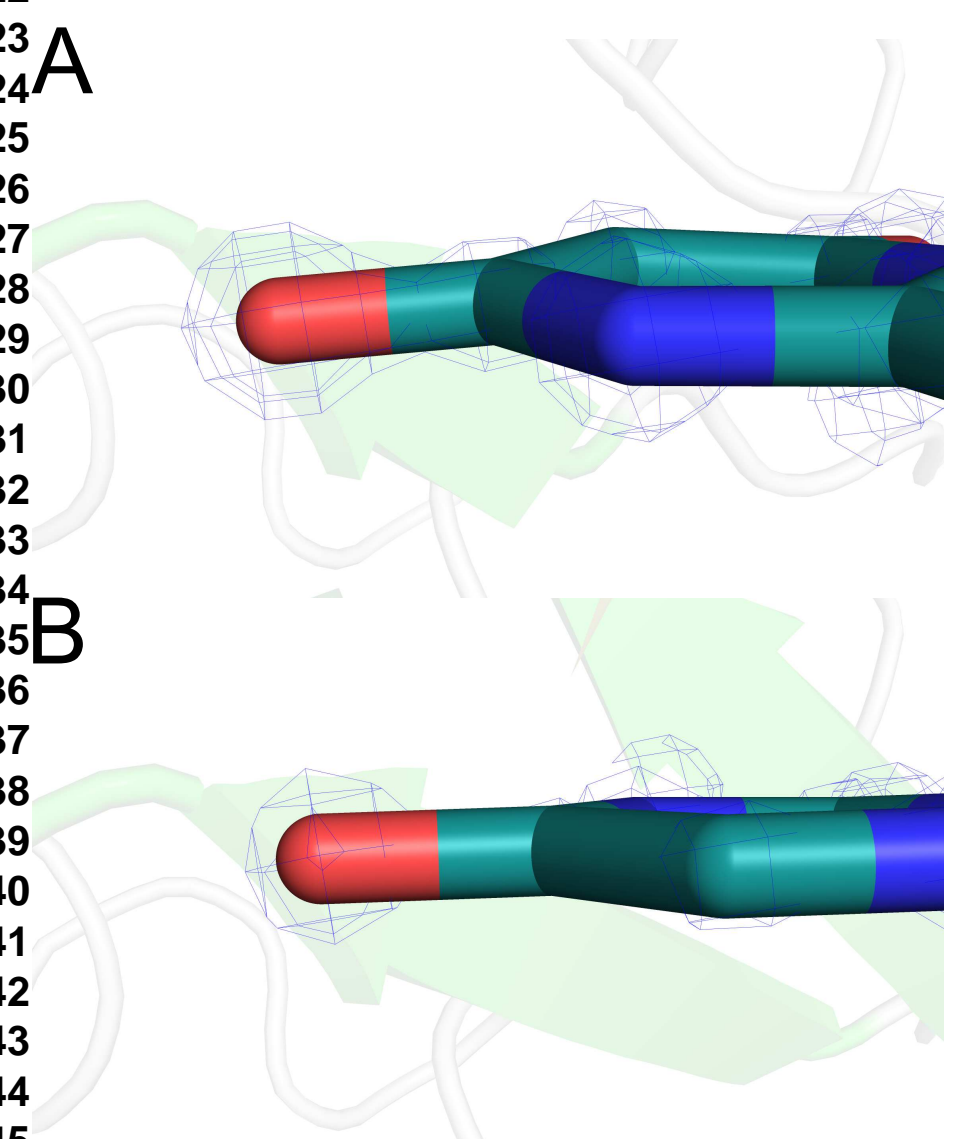

Figure 1.24. Electron density map at $5 \sigma$ of the C4-O4 bond of the hOMPD-BMP complex (A) and hOMPD-6-aza-UMP complex (B), respectively.

In the proposed mechanism from Wolfenden et al. out of plane distortion of C6 substituents is assumed to result mainly from electrostatic repulsion. The negatively charged C6-carboxy group of OMP and Asp $_{312}$ push off each other, resulting in bend of the $\mathrm{C} 6-\mathrm{C} 7$ bond. Against expectations, OMP seems to be protonated and not negatively charged in the $h \mathrm{OMPD}_{314 \mathrm{AcK}}-\mathrm{OMP}$ complex. The electron density map reveals asymmetric density distribution at the C6-carboxy group. While electron density is delocalized at one $\mathrm{C}-\mathrm{O}$ bond, indicating a carbonyl bond, there is 
sharply localized density at the other oxygen, indicating the existence of a hydroxy group. Comparing the distance of the carboxy group to $\mathrm{Asp}_{312}$ with amido-group and thioamido-group distances to $A_{s p_{312}}$ in the respective complexes, similar values were observed. Taking these results into account, repulsive interactions seem unlikely and instead attractive dipole or hydrogen bond formation is more probable.

\section{Size of $\mathbf{C 6}$ substituents is important}

Due to the enormous catalytic proficiency of OMPD, no substrate complex has been obtained until today, regardless of species. In order to gain information about substrate interactions with the active site, stable substrate analogues were synthesized and soaked into $h \mathrm{OMPD}$ resting state crystals. While closely resembling steric properties of OMP, the analogues differ in electronic properties. 6-Amido-UMP and 6-Thioamido-UMP could be bound similar to protonated OMP, acting as a hydrogen bond acceptor. The active site arrangement differ from that observed in the BMP- and 6-aza-UMP complexes. Specifically, Lys $_{314}$ adopts a new position between Asp' ${ }_{317}$ and Asp $_{312}$. Asp' ${ }_{317}$ gets slightly shifted towards the pyrimidine plane in order to make room for Lys $_{314}$. This active site architecture was formerly observed in the mutant $h \mathrm{OMPD}_{D 312 N}$ in complex with 6-hydroxymethyl-UMP. ${ }^{[15]}$ As expected a hydrogen bond is formed between $\mathrm{Asp}_{312}$ and the Amido- and Thioamidogroup, respectively. The new catalytic tetrad arrangement might be induced by a distortion of the hydrogen bond network. In order to exclude non-polar interactions, hOMPD crystal structures in complex with 6-methyl-UMP, 6-isopropyl-UMP and 6isopropenyl-UMP were investigated. All three inhibitors bound interestingly well to the active site, which is indicated by a high occupancy of approximately $90 \%$. Binding interactions seem to occur mainly at the phosphate gripper and the pyrimidine umbrella region. Missing polar interaction did not disturb binding affinity significantly. The inhibitors with unpolar $\mathrm{C} 6$ substituents differ in size and geometry, ranging from 6-methyl-UMP resembling BMP sterically, over 6-isopropenyl-UMP which is similar to OMP and 6-amido-UMP to 6-isopropyl-UMP being the most sterically demanding inhibitor. Interestingly, all three analogue complexes showed the same catalytic tetrad arrangement compared to their sterical matching polar equivalents, indicating that steric interactions being a significant factor for positioning of the tetrad residues (figures 1.25 A, B).

Surprisingly, 6-methyl-UMP shows significantly greater out of plane distortion compared to 6-isopropyl-UMP and 6-isopropenyl-UMP. Expectedly, bulky groups should 


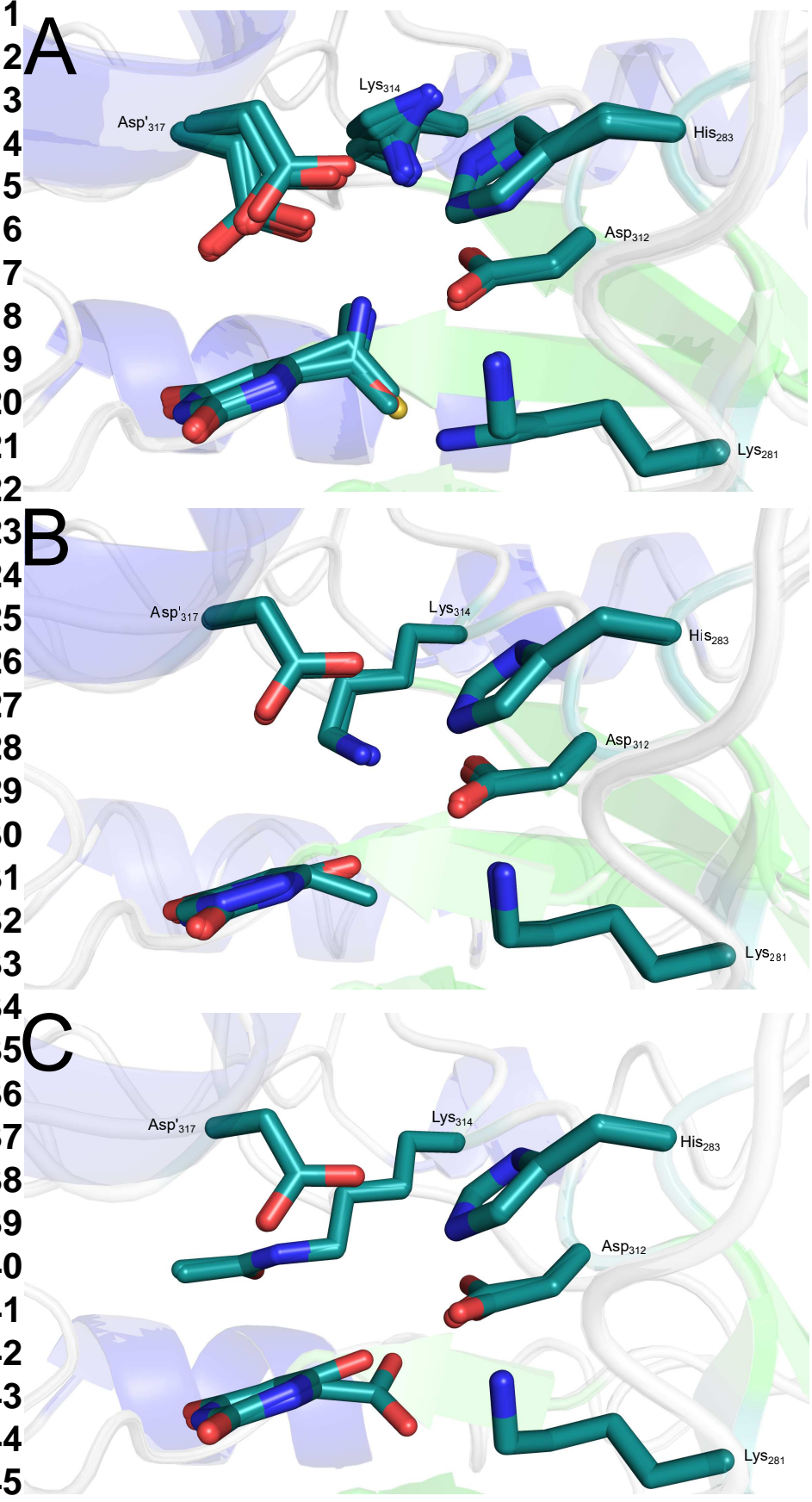

Figure 1.25. Overlay of $h \mathrm{OMPD}$ crystal structures in complex with different inhibitors.

A: 6-amido-UMP, 6-thioamido-UMP, 6-isopropyl-UMP, 6-isopropenyl-UMP

B: BMP, 6-aza-UMP, 6-methyl-UMP

C: $h \mathrm{OMPD}_{314 \mathrm{AcK}}$ in complex with OMP and BMP.

Ribose-phosphate is not displayed for better clarity.

show greater distortion, due to steric hindrance. However, the exact opposite was observed from the crystal structures. Apparently, Lys $_{314}$ is forced out of position, which lead to formation of a new hydrogen bond network by shifting Asp' ${ }_{317}$ and flipping $\mathrm{His}_{283}$. This create space for the substituents. Inhibitors with smaller groups at 
C6 does not seem to be able to force Lys $_{314}$ out of its original position. In this case it might be energetically favorable to bend the $\mathrm{C} 6-\mathrm{C} 7$ bond to avoid steric repulsion. In case of the hOMPD-isopropenyl-UMP complex, a second ligand conformer was observed, which adopts a different arrangement of the ribose, allowing the isopropenyl group to adopt a greater torsion angle. The greater torsion create more space between the isopropenyl group and Lys $_{314}$ to avoid any out of plane distortion. However, in BMP and 6-aza-UMP complexes almost no bending of the C6-O6 and $\mathrm{C} 2-\mathrm{O} 2$ bond respectively was observed, although $\mathrm{Lys}_{314}$ remains in original position. The higher stability of the carbonyl bond might prevent any bending. The formation of a hydrogen bond to Lys $\mathrm{s}_{314}$ further hold the carbonyl bond in plane. Additionally, the a single oxygen atom at $\mathrm{C} 6$ or $\mathrm{C} 2$ in OMP and 6-aza-UMP respectively is significantly smaller than the substituents of the other inhibitors.

Taking the $h \mathrm{OMPD}_{314 \mathrm{AcK}}$ in complex with OMP and BMP into account, the important role of $\mathrm{Lys}_{314}$ becomes even more obvious (figure 1.25 C). The obtained structures further support the assumption that Lys ${ }_{314}$ causes steric repulsion. Comparing the $h \mathrm{OMPD}_{314 \mathrm{Ack}}-\mathrm{BMP}$ complex with the $h \mathrm{OMPD}_{\mathrm{wt}}-\mathrm{BMP}$ complex, both structures appear to be similar except of the Lys $_{314}$ position, proving acylation only affects the concerning residue. Interestingly, the alkyl backbone of Lys $_{314}$ remains nearly in the same position found in the $h O M P D_{w t}-B M P$ complex. Only the acylated $N^{\epsilon}$ adopts a new position above the pyrimidine ring plane. Like the catalytic tetrad, BMP remains in position and show almost no out of plane distortion or different electron density distribution compared to the $h \mathrm{OMPD}_{\mathrm{wt}}-\mathrm{BMP}$ complex. On the other hand, OMP in complex with $h \mathrm{OMPD}_{\mathrm{wt}}$ show significantly greater out of plane distortion compared to $h O M P D_{w t}$ complexes with ligands of similar size and geometry. The only obvious difference in these complexes is the position of Lys $_{314}$, which is arranged closer to the ligand, indicating a direct correlation between Lys $_{314}$ arrangement and distortion of the ligands $\mathrm{C} 6$ substituents (figures 1.26 ).

\subsubsection{Mechanistic implications}

Regarding the observation of attractive interactions between the ligand and $\mathrm{Asp}_{312}$ for 6-amido-UMP and 6-Thioamido-UMP in complex with $h \mathrm{OMPD}_{\mathrm{wt}}$, as well as for OMP in the $h \mathrm{OMPD}_{314 \mathrm{AcK}}$ complex, electrostatic repulsion has to be excluded as the driving force for decarboxylation. Instead, steric interaction concerning the C6substituents and the position of Lys $_{314}$ seem to play a significant role in substrate 


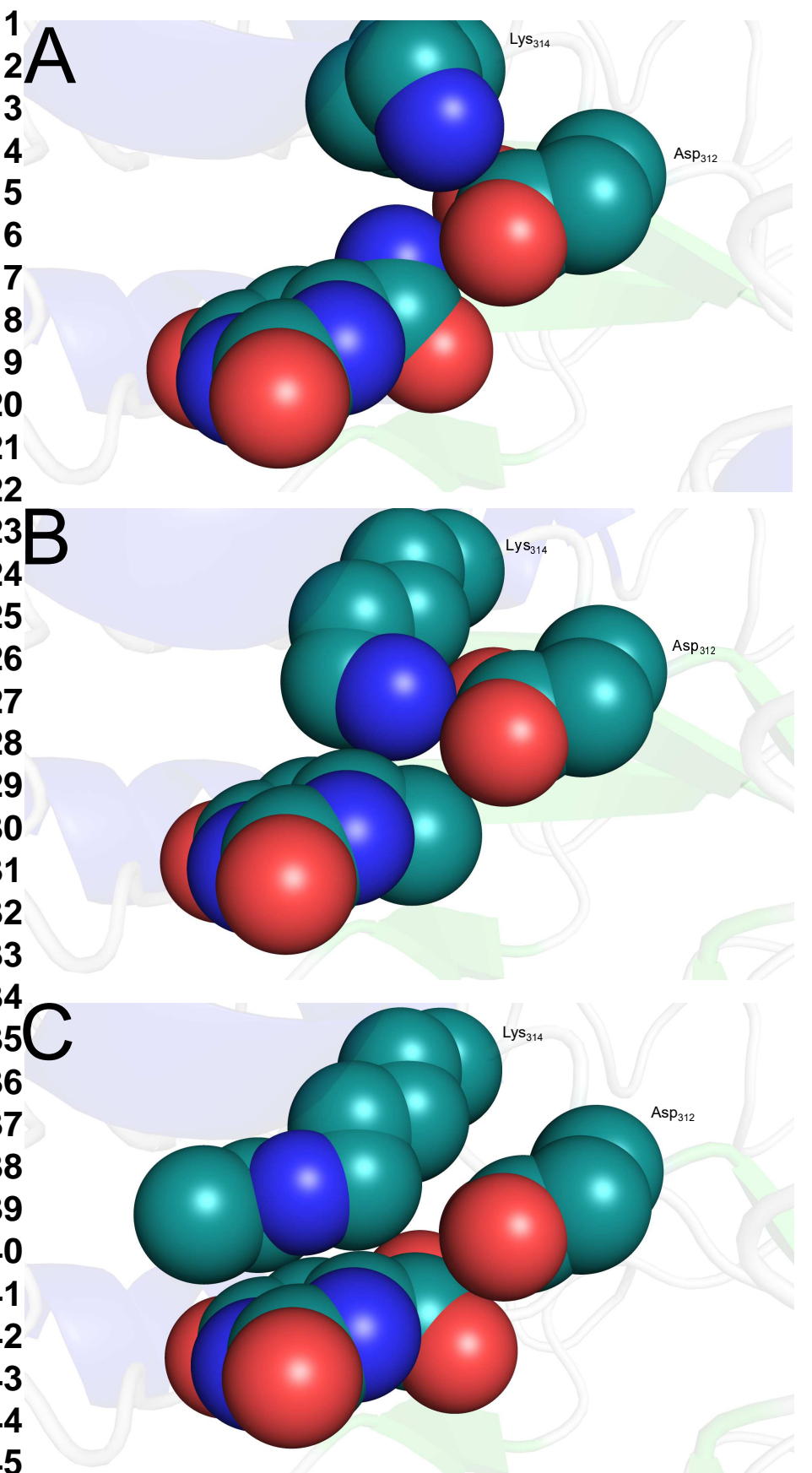

Figure 1.26. Space filling models of $\mathrm{Lys}_{314}$ and $\mathrm{Asp}_{312}$ with 6-amido-UMP, 6-methyl-UMP and OMP, respectively.

A: 6-amido-UMP in complex with $h \mathrm{OMPD}_{\mathrm{wt}}$.

B: 6-methyl-UMP in complex with $h \mathrm{OMPD}_{\mathrm{wt}}$.

C: OMP in complex with hOMPD $314 \mathrm{AcK}$.

Ribose-phosphate is not displayed for better clarity.

distortion, which lead to ground state destabilization. As observed for the best inhibitors BMP and 6-aza-UMP Lys ${ }_{314}$ occupies a position between Asp' ${ }_{317}$ and Asp $_{312}$, which is assumed to be the thermodynamically favored catalytic tetrad arrangement. 
However, upon binding of sterically demanding ligands such as 6-amido-UMP or 6isopropyl-UMP Lys L $_{314}$ is forced out of its favored arrangement into a new conformation. Via pushing Asp' ${ }_{317}$ towards the ligand and flipping of $\mathrm{His}_{283}$, Lys $\mathrm{LS}_{314}$ is stabilized by an alternative hydrogen bond network. Rearrangement of Lys $\mathrm{S}_{314}$ into its original position might be the driving force for substrate destabilization. While Lys $_{314}$ occupies its thermodynamically favored conformation, the OMP-carboxy group get pushed out of the way, leading to $\mathrm{C} 6-\mathrm{C} 7$ bond bending and finally heterocyclic bond fission. The resulting anion intermediate is then quenched by either Lys ${ }_{314}$ or Asp' ${ }_{317}$. However, protonation mechanism remains elusive.

Currently, the proposed mechanisms favor a localized C6 carbanion as the reaction intermediate. ${ }^{201}$, ,73, ,78 However, this localized negative charge would be a very reactive nucleophile with the produced $\mathrm{CO}_{2}$ being a good electrophile in close proximity. ${ }^{79]}$ Assuming similar rates for bond dissociation ans re-association the overall decarboxylation can't be accelerated by the observed rate of $10^{17}$. Computational studies support this assumption. ${ }^{[33],[80]}$ To overcome this limitation other decarboxylases developed specific strategies, like usage of cofactors, solvation or prelocalization of catalytic acids. ${ }^{[81-}$-83] These strategies prevent re-association of $\mathrm{CO}_{2}$, accelerating decarboxylations up to $10^{5}$. ${ }^{84]}$ However, formation of hydrogencarbonate was ruled out for OMPD and the enzyme does not use any cofactors. ${ }^{85]}$ No catalytic acid is prelocalized close to $\mathrm{C} 6$ in the enzyme complexes with OMP sterical similar inhibitors, but $\mathrm{Lys}_{314}$ might change position close to $\mathrm{C} 6$ during the decarboxylation process, enabling it to act as catalytic acid. Another factor to slow down $\mathrm{CO}_{2}$ reassociation might be delocalization of the negative charge by tautomerism, which would reduce the reactivity of the intermediate, enabling the resulting $\mathrm{CO}_{2}$ to leave the active site. However, stabilization of the negative charge could not be elucidated and remains mostly unknown.

\section{Mechanistic proposal}

The catalytic decarboxylation starts with OMP entering the OMPD active site, which triggers phosphate gripper closure and binding to the pyrimidine umbrella, as well as hydrogen bond formation to $\mathrm{Asp}_{312}$. Steric repulsion with the carboxy group forces Lys $_{314}$ out of the energetically favored position between Asp' ${ }_{317}$ and Asp $_{312}$, leading to reorganization of the hydrogen network. Rearrangement to the thermodynamic favored catalytic tetrad positioning lead to bending of the $\mathrm{C} 6-\mathrm{C} 7$ bond, resulting in 
out of plane distortion of the carboxy group and finally heterocyclic bond fission. The carboxy proton remains at $\mathrm{Asp}_{312}$. Upon repositioning of Lys $\mathrm{L}_{314}$ is in suitable distance to protonate the negatively charged reaction intermediate at C6. Stabilization of the negative charge might be achieved by delocalization over the $\mathrm{O} 4$ oxygen as indicated by the hOMPD-6-aza-UMP complex. However, more experiments focusing on the $\mathrm{C} 4-\mathrm{O} 4$ bond are necessary to verify this assumption. Besides, the origin of protons remain unknown. Interconnection of both active sites by a water channel is known. This channel might interchange protons between both active sites. Like for negative charge delocalization, there is no experimental evidence.

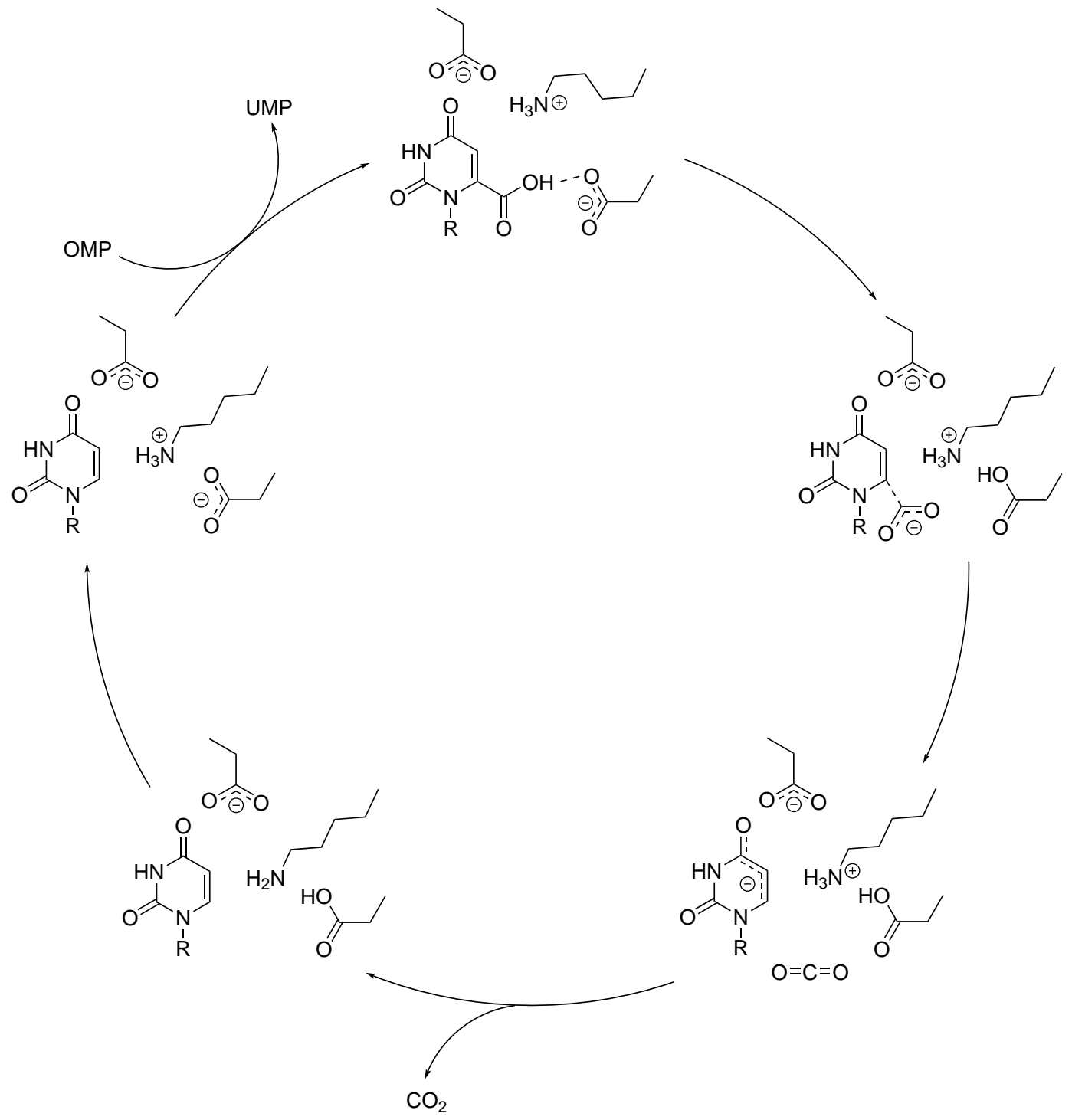

Scheme 1.35. Mechanistic proposal. 


\subsection{Summary}

Orotidine-5'-monophosphate-decarboxylase is a unique enzyme, which accelerates the decarboxylation of orotidine-5'-monophosphate by the factor of $10^{17}$. While being one of the most effective enzymes known, it is able to catalyze the reaction without need for any metals or other cofactors. Although a huge number of crystal structures were resolved from different organism and in complex with different inhibitors, the reaction mechanism could not be identified and still remains under discussion.

In order to obtain new insights into the decarboxylation mechanism new substrate analogues were designed and synthesized. To reveal possible positive interactions between the substrate and the catalytic tetrad residues, 6-amido-UMP was synthesized. Starting from uridine, 6-amido-UMP was obtained via aminolysis of orotidinemethylester over a total of six steps. Additionally, 6-isopropyl-UMP was synthesized to evaluate how the enzyme react to substrates with unpolar C6 substituents, which possess similar size and geometry compared to OMP. Starting from uridine again, 6-isopropyl-UMP was obtained via nucleophilic substitution of 6-cyanouridine. Beside these two inhibitors, the isoelectronic substrate analogues 6-nitro-UMP and dithio-OMP were attempted to synthesize. Unfortunately, all attempts failed. Additionally to the new substrate analogues the natural substrate OMP, as well as the known inhibitors BMP and 6-aza-UMP were synthesized, following known procedures.

The synthesized substrate- and transition state analogues were soaked into precrystallized $h O M P D_{w t}$ resting state crystals or were cocrystallized with $h O M P D_{w t}$. In order to increase the obtained data, 6-thioamido-UMP, 6-methyl-UMP and 6isopropenyl-UMP were cocrystallized additionally 2 The obtained $h$ OMPD-inhibitorcrystals and $h \mathrm{OMPD}_{314 \mathrm{AcK}}-\mathrm{OMP}$-crystals were analyzed via x-ray scattering to obtain structural data 3

Structures of BMP and 6-aza-UMP in complex with $h O M P D_{w t}$ showed no indication for a localized negative charged reaction intermediate. Instead, the structure revealed a carbonyl bond at C6-O6 in the OMP structure and 6-aza-UMP bound in anti-conformation exposing the $\mathrm{C} 2-\mathrm{O} 2$ bond to the catalytic tetrad, which also appear to be a carbonyl. 6-Amido-UMP and 6-thioamido-UMP in complex with

\footnotetext{
${ }^{2}$ Inhibitors were synthesized by Tobias Schmidt and Moritz von Geyso.

${ }^{3}$ Enzyme expression and purification, as well as x-ray scattering was done by Sören Rindfleisch.
} 
$h \mathrm{OMPD}_{\mathrm{wt}}$, as well as OMP in complex with $h \mathrm{OMPD}_{314 \mathrm{AcK}}$ indicated the formation of short hydrogen bonds between the substrates $\mathrm{C} 6$ substituents and $\mathrm{Asp}_{312}$. These results argue against the formation and stabilization of a localized charge at C6 and electrostatic repulsion between the carboxy groups of OMP and $\mathrm{Asp}_{312}$ as the driving force of catalytic decarboxylation.

Comparison of the obtained structures revealed a direct relation of size of the C6 substituents and the arrangement of the catalytic tetrad. Structures with small substituents (BMP, 6-aza-UMP, 6-methyl-UMP) showed Lys si4 $_{314}$ in the expected position between Asp' $_{317}$ and Asp $_{312}$. However, substituents with similar size to OMP (6amido-UMP, 6-thioamido-UMP, 6-isopropyl-UMP, 6-isopropenyl-UMP) seem to force Lys $_{314}$ out of its favored position, inducing a new catalytic tetrad arrangement with Lys $_{314}$ between slightly shifted Asp' ${ }_{317}$ and flipped $\mathrm{His}_{283}$. Interestingly, the smaller substituents show significantly greater out of plane distortion with respect to the pyrimidine ring plane, indicating a direct correlation of the position of Lys $_{314}$ and bending of the $\mathrm{C} 6-\mathrm{C} 7$ bond. $\mathrm{Lsy}_{314}$ forcing back in its favored position seem to push the $\mathrm{C} 6$ substituents, which ultimately lead to heterolytic bond fission. Repositioning of $\mathrm{Lys}_{314}$ might be the main driving force of the reaction. 


\subsection{Outlook}

Substrate analogues are indispensable to get new insights into substrate binding and the reaction mechanism of OMPD. In this work the new analogues 6-amidoUMP and 6-isopropyl-UMP were synthesized successfully. While these analogues resemble the geometry of OMP well or are useful to investigate certain properties of the active site, neither of them mimic the electronic properties of OMP. 6-nitro-UMP or dithio-OMP are suitable synthetic targets but were not synthetically accessible in this work. New developments for nitration and thiolation reactions might enable new synthetic approaches. However, regarding the discovery of hydrogen bond formation between the $\mathrm{C} 6$ substituents and $\mathrm{Asp}_{312} 6$-nitro-UMP might not be a suitable analogue anymore, due to assumed electrostatic repulsion.

An open question remains the distribution and stabilization of the resulting negative charge. New substrate analogues with modifications at C4 and C2 could change electronic situations in the pyrimidine ring. Using electron withdrawing and donating groups might stabilize and destabilize the intermediate negative charge by inducing new mesomeric structures.

A missing key piece for understanding of the decarboxylation mechanism is observation of the natural hOMPD-OMP complex and early stages of the reaction. To obtain these data photocleavable caging groups could be a possibility. Caged substrates may get preorganized into the resting state crystals and bound to the active site upon photoactivation. These groups can be attached at the carboxy group or the phosphate of OMP. An important limitation is the time frame of photoactivated decaging, which has to be in the microsecond range in order to get decaging done some orders of magnitude faster than $\mathrm{x}$-ray scattering is performed. Additionally, the excitation wavelength has to be preferably low energetic to avoid structural damage of the protein crystals. New caging groups would have to be designed and synthesized, matching these requirements.

In the best case scenario, use of photocleavable caging groups might enable insights into active site dynamics via time resolved x-ray scattering. Observation of the process at different time points could generate new information about substrate binding and interconnection of the active site units. Furthermore, the origin of protons and the protonation process of the reaction intermediate could be enlightened. 



\section{Stimulation of S. pombe Dnmt2 by the micronutrient queuine}

\subsection{Motivation and objectives}

In organisms gene regulation plays an important role for the adaption of changing environmental conditions. A part of these regulations is achieved by the chemical modification of nucleobases, to some extend in DNA and in either mRNA or tRNA in particular. The latter is often achieved by methylation and demethylation of cytosine, leading to deactivation and reactivation of gene activity. These processes are related to antibiotic resistance in bacteria. In eukaryotic cells, errors in regulatory processes might play a role in cancer growth. Therefore, insights of these mechanisms on the level of microbiology and biochemistry will be useful in the development of new therapeutic ways to treat diseases. ${ }^{86}$

The addition of methyl groups to DNA and RNA is catalyzed by DNA-methyltransferases (Dnmt) which use $S$-adenosyl-methionine (SAM) as the methyl source. ${ }^{87}$ Dnmt enzymes are expressed by a wide variety of organisms, ranging from mammals over insects to plants. ${ }^{88}$ The proteins are as diverse as their occurence in different organisms. In mammals three major active Dnmts are identified, named Dnmt1, Dnmt3a and Dnmt3b. ${ }^{[89}$ A fourth Dnmt enzyme exists in mammals, which provides barely detectable DNA methylation activity. This enzyme is named Dnmt2 and although sharing a huge sequence homology to other Dnmts, it shows activity in the methylation of tRNA. ${ }^{90}$ It specifically methylates cytosine 38 in tRNA ${ }^{\text {Asp }}$ and is considered to play a role in gene regulation by protecting the tRNA from cleaving enzymes and therefore increases overall translation (figure 2.1A). ${ }^{\text {.90, }}$,91] Until recently, the mechanisms about how Dnmt2 gets activated and silenced was little understood. In 2015 it was discovered that Dnmt2 of the fission yeast Schizosaccharomyces pombe shows an increased in vivo activity, following incorporation of the rare nucleoside and micronutrient queuosine in tRNA ${ }^{\text {Asp }}$ (figure 2.13). ${ }^{.921}$ Incor- 
poration of queuosine was discovered to be done via transglycosylation of guanine to queuine at position 34 by the enzyme tRNA-guanine transglycosylase (TGT). .93

Although it is evident that incorporation of queuine stimulates the methylation of tRNA $^{\text {Asp }}$, until recently no in vitro studies are published excluding other possible stimulating factors. Given that queuine is very rare in organisms, a chemical synthesis is necessary for in vitro studies. While there are some synthetic routes published for the the synthesis of queuosine and queuine, these routes suffer from some disadvantages. In order to establish an in vitro method to proof the dependency of Dnmt2 from queuine and to improve the chemical synthesis of queuine, a new synthetic route should be developed and the synthesized queuine should be used in the in vitro stimulation of Dnmt2 from S. pombe.

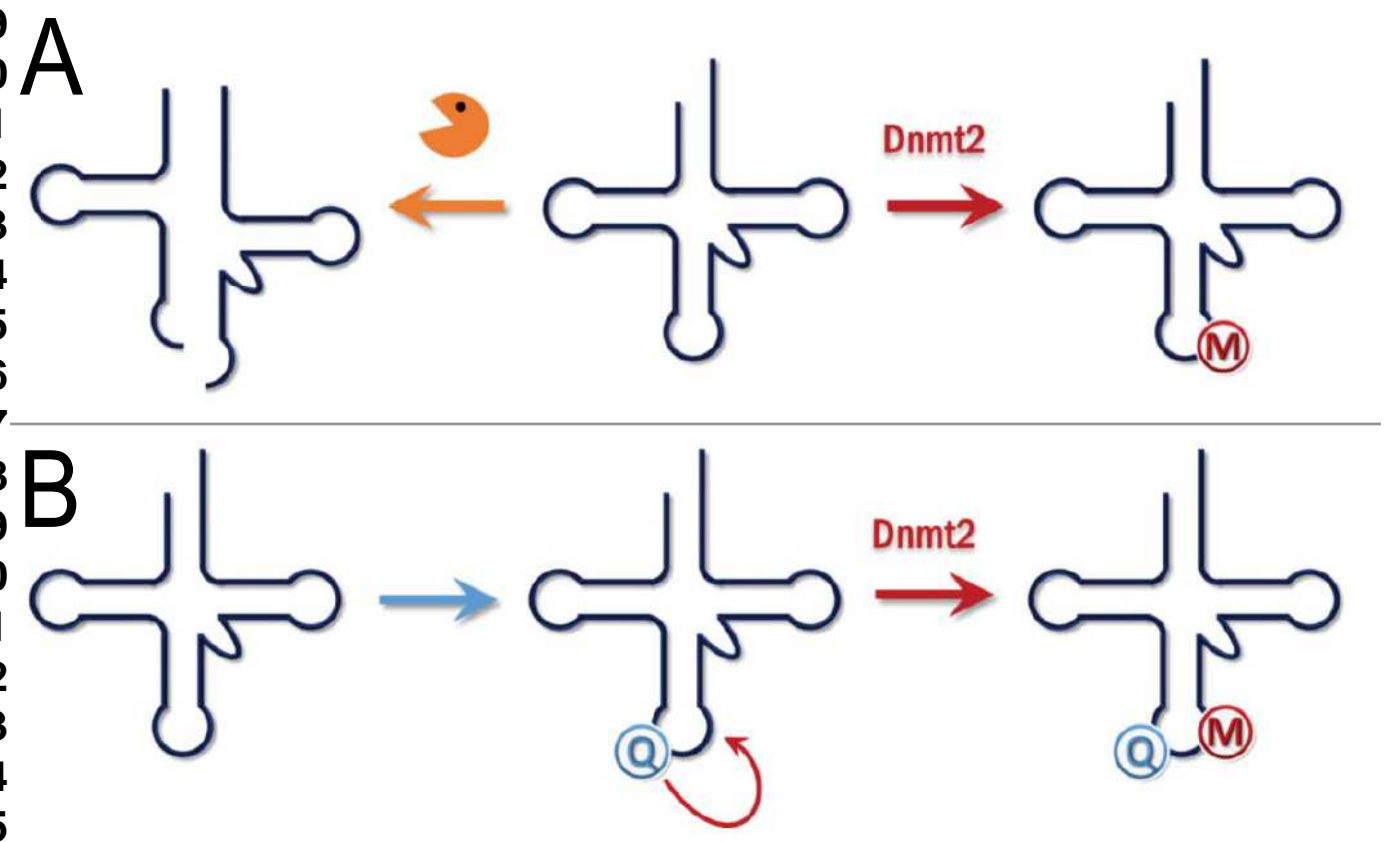

Figure 2.1. Function of Dnmt2.

A) Methylation protects tRNA from cleavage. B) Queuine incorporation stimulates tRNA methylation. 90 


\subsection{Dnmt2}

Dnmt2 enzymes were originally thought to be DNA-methyltransferases, based on their structural similarity compared to other types of DNA-methyltransferases like Dnmt1 or Dnmt3, which methylate cytosine in DNA at 5-position. However, closer studies of Dnmt2 revealed no activity in DNA methylation, but indicated activity for methylation of tRNAs, which was first reported by the Bestor group. They were able to show that Dnmt2 catalyzes the methylation of tRNA ${ }^{\text {Asp }}$ at the cytosine in position 38. ${ }^{911}$ It is assumed that Dnmt2 evolved from a prokaryotic DNA methyltransferase ancestor, which switched substrates from DNA to RNA. ${ }^{[00,}$,94] Clustering analysis support this assumption by showing no evidence for a relationship to other RNA methyltransferases. Moreover, Dnmt2 uses a catalytic mechanism, which is similar to other DNA methylating enzymes. ${ }^{.95}$

To date, several structures of Dnmt2 from different organisms are published. One of the best resolved is the crystal structure of E. histolytica from the groups of Ficner and Ankri (figure 2.2). .96 The crystal structure revealed monomeric enzymes with the active site loop at residues 80 to 100 adopting a $\alpha$-helical structure. Although obtaining structures with good resolutions, no enzyme-substrate complexes could be crystallized. Therefore, the published structures may be stabilized by crystal packing and the enzyme-substrate complex could have other conformations. ${ }^{90}$
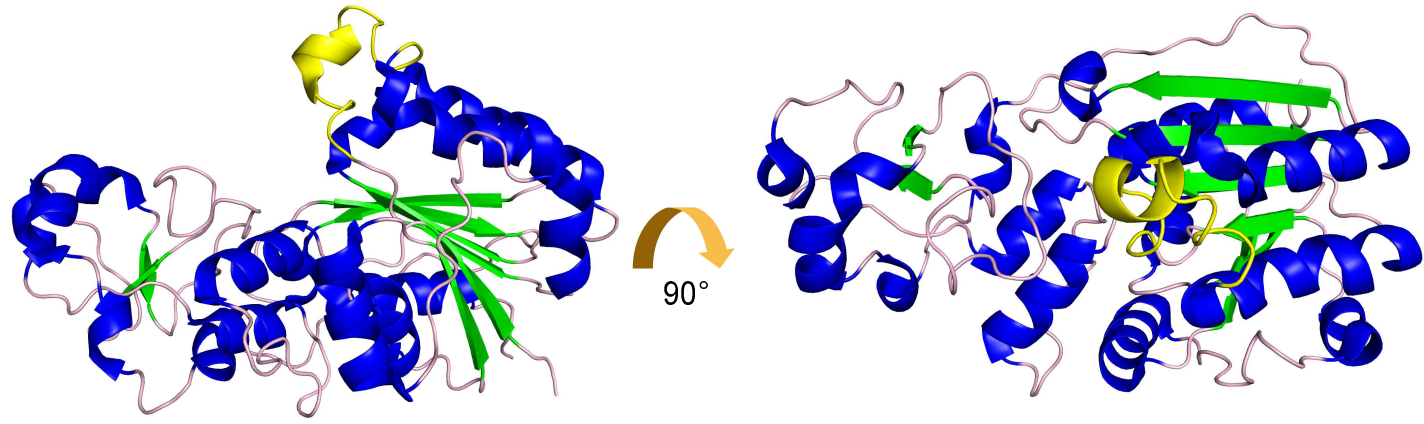

Figure 2.2. Crystal structure of Dnmt2 from E. histolytica.

$\alpha$-helices and $\beta$-sheets are colored in blue and green, respectively. The active site loop and $\alpha$-helix are coloured in yellow. 96

A complex mechanism enables Dnmts to methylate nucleobases at non nucleophilic positions like the C5 carbon in cytosine. Thereby, formation of very stable $\mathrm{C}-\mathrm{C}$ bonds is accessible (scheme 2.1). In the first step the $\mathrm{C} 5$ position gets activated by 1,4 addition of a cytosine residue, working as a helper nucleophile, to create an enamine structure. Thereby, the C5 carbon becomes more nucleophilic 
and can be methylated by SAM. In the last step elimination of the cysteine residue reestablishes the aromatic system, leading to 5-methylated cytosine. 86

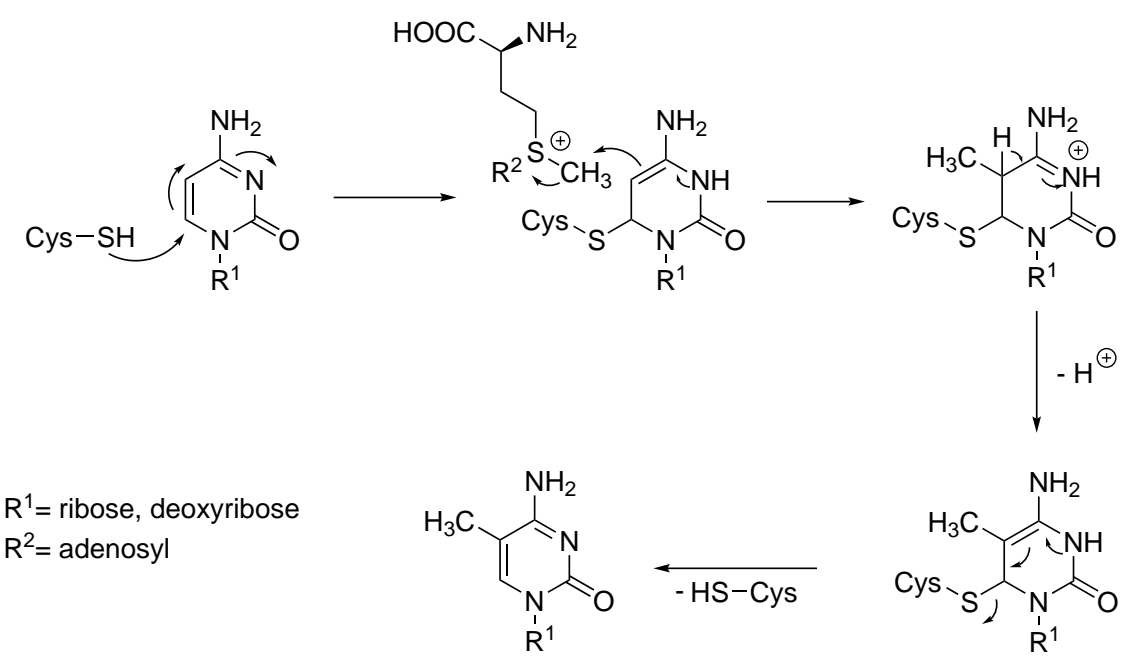

Scheme 2.1. Mechanism of cytosine C5 methylation by Dnmts and SAM. ${ }^{86}$

First hints that Dnmt2 activity might be stimulated by nutrient factors were observed in the Ehrenhofer-Murray group. They detected extreme low Dnmt2 activity, when $S$. pombe cells were grown on minimal medium. ${ }^{92}$ The stimulating nutrient was identified as the rare nucleobase queuine, which upon supplementation to the cell medium increased the methylation of tRNA ${ }^{\text {Asp }}$ from $6 \%$ to quantitative conversion. ${ }^{92]}$ However, the exact mechanism of the stimulation and the question if other factors play a role in increasing Dnmt2 activity remains unclear.

\subsection{Queuosine biosynthesis}

No full queuine or queuosine synthesis has been observed in cytoplasm to date. Instead, $\operatorname{PreQ}_{1}(\mathbf{5 8})$ is synthesized in bacteria, gets incorporated into tRNA and is then functionalized to queuosine (67) (scheme 2.2). 97

First, queuine precursor $\operatorname{PreQ}_{1}(\mathbf{5 8})$ is synthesized in five steps. Starting from guanine-5'-triphosphate $(53), \mathrm{GCH} 1$ cleaves the purine ring at $\mathrm{C} 8$ and the furanose between C2' and C3'. Following, rearrangement and cyclyzation lead to 7,8dihydropterine-triphosphate (54). Next, QueD cleaves acetaldehyde at the triphosphate resulting in 6-carboxy-5,6,7,8-tetrahydropterin (55), which undergoes ring contraction, catalyzed by QueE to generate 7-deaza-7-carboxyguanine (56). 7-deaza- 
7-carboxyguanine (56) is then converted into $\operatorname{PreQ}_{0}(\mathbf{5 7})$. This step is catalyzed by QueC, converting the carboxy group into a nitrile using ammonia as the nitrogen source. PreQ ${ }_{0}(\mathbf{5 7})$ is then reduced to $\operatorname{PreQ}_{1}(\mathbf{5 8})$ by QueF. After incorporation of PreQ $_{1}(\mathbf{5 8})$ into tRNA by TGT, QueA catalyzes a reaction cascade resulting in the formation of epoxy-queuosine-tRNA 60, which is reduced in the last step by QueG to generate the final queuosine nucleotide $(61) .98$

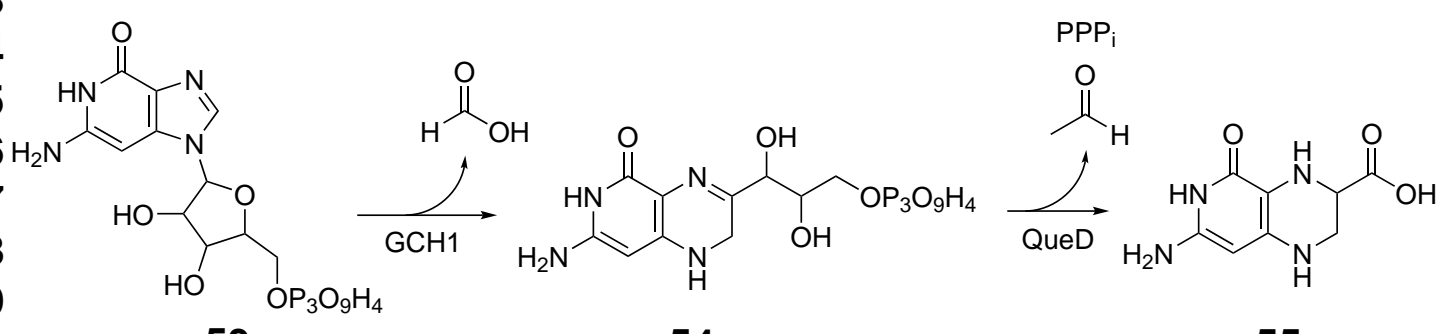<smiles>NCc1c[nH]c2cc(N)[nH]c(=O)c12</smiles>

58

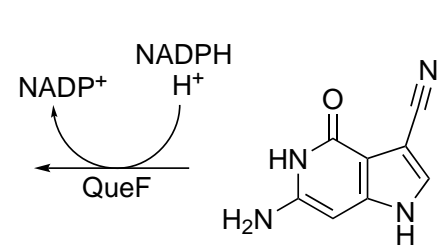

57

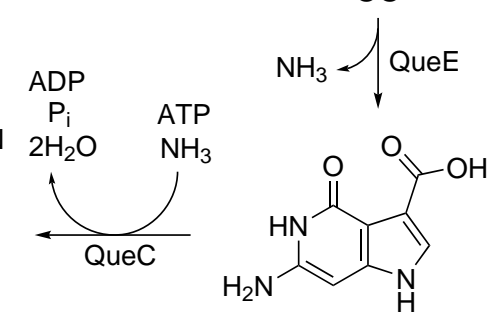

56

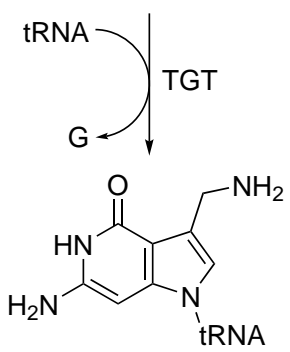

59

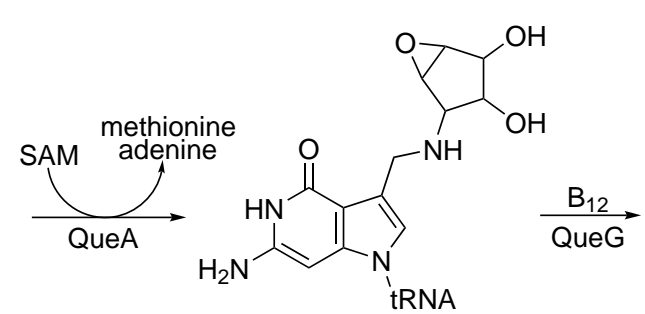

60

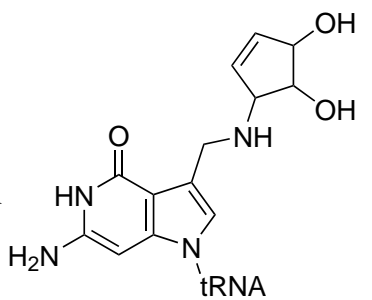

61

Scheme 2.2. Biosynthesis of queuosine. 98 


\subsection{Chemical synthesis of queuine and queuosine}

\subsubsection{Synthetic strategies for queuosine}

In 1975 Kasai discovered the structure of queuosine (67). ${ }^{\text {999 }}$ Only a few years later the first chemical synthesis was published. It was developed by Ohgi in 1979 and was achieved by coupling a dibromodeazaguanosine derivative 62 and a cylopentylamino building block 63 by nucleophilic substitution to obtain $\mathbf{6 4}$. 64 was debrominated to 65 and subsequent deprotection under acidic and basic conditions yielded queuosine (67)(scheme 2.3). 100

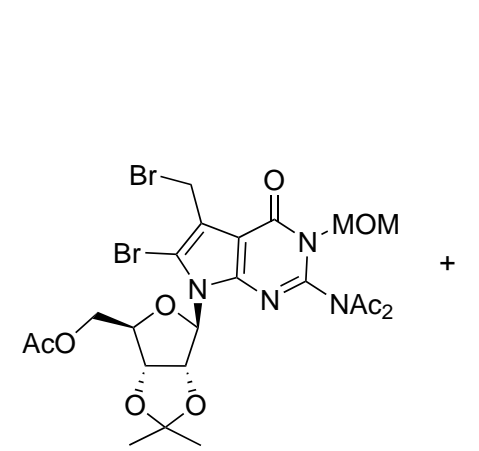

62

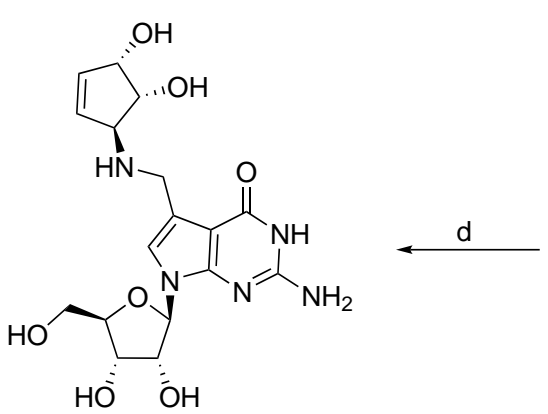

67

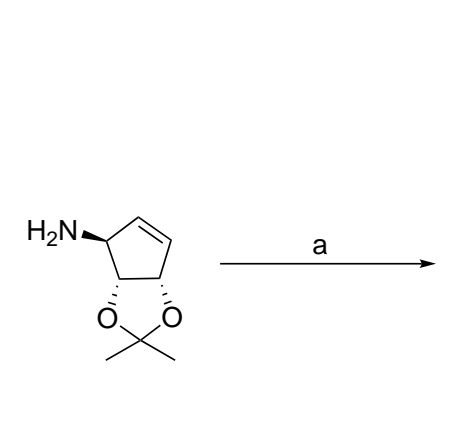

63

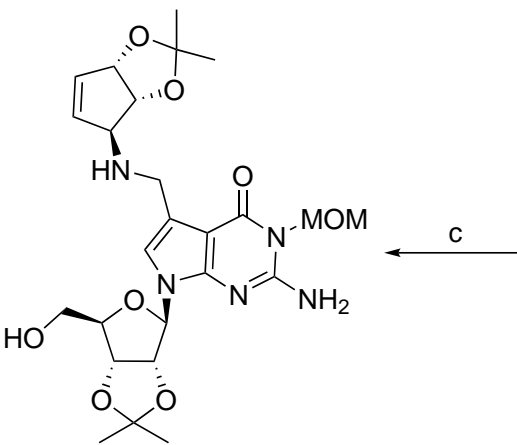

66

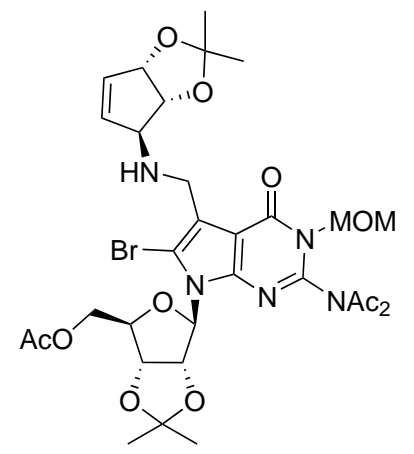

64

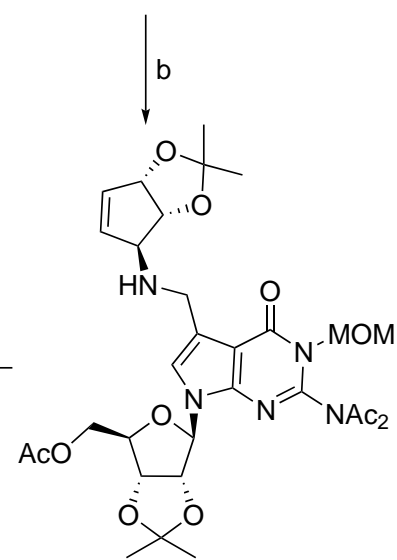

65

Scheme 2.3. First synthesis of queuosine (67) by ohgi et al. ${ }^{[100}$

a) diisopropylethylamine, benzene; b) $\mathrm{Zn} / \mathrm{CuCl}_{2}$, dioxane; c) $\mathrm{NH}_{4} \mathrm{OH}$, methanol; d) $2 \mathrm{~N} \mathrm{HCl}$

The dibromodeazaguanosine derivative $\mathbf{6 2}$ was synthesized following protocols developed by Kondo, Ohgi and Goto (schemes 2.4, 2.5), 100, 1011 starting from cyanoacetale 68 . In the first step, 68 was condensed with thiourea in the presence of sodium ethoxide to obtain 2-methylthio-7-methyl-7-desazahypoxanthin (69). 69 was then chlorinated with phosphorusoxychloride and the resulting product 70 was sub- 
stituted with sodium methoxide to $\mathbf{7 1}$. Coupling of $\mathbf{7 1}$ to the benzyl protected chlorosugar $\mathbf{7 2}$ using Königs-Knorr nucleosidation yielded benzyl protected nucleoside $\mathbf{7 3}$ as a mixture of $\alpha$ and $\beta$ anomeres in a 1:1 ratio.

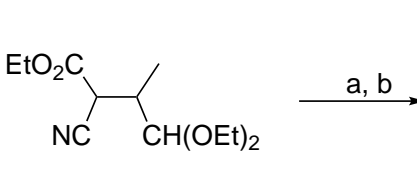

68

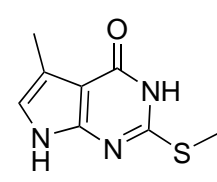

69
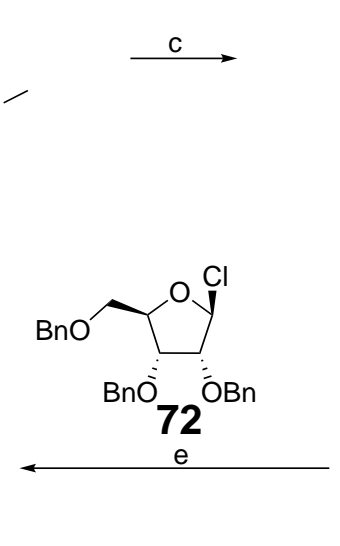

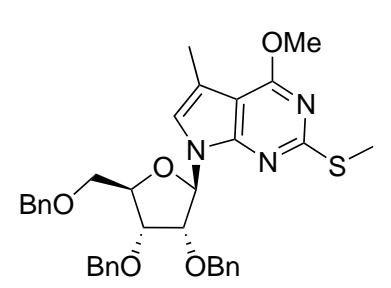

73
70<smiles>CSc1nc(Cl)c2c(C)c[nH]c2n1</smiles>

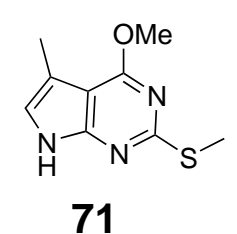

Scheme 2.4. Synthesis of dibromodeazaguanosine derivative 62 part 1.101

a) thiourea, $\mathrm{NaOEt}$, ethanol; b) $\mathrm{NaOH}, \mathrm{Mel}$, methanol; c) $\mathrm{POCl}_{3}, N, N$-dimethylaniline; d) $\mathrm{NaOMe}$, methanol, reflux; e) $\mathrm{NaH}$

Nucleoside $\mathbf{7 3}$ was demethylated under acidic conditions in the presence of a radical inhibitor to avoid oxidation of the mercaptoether and protected with MOM afterwards to compound 74. The mercaptoether was substituted with acetamide to produce deazaguanosine $\mathbf{7 5}$. To avoid side reactions, the benzyl protecting groups were changed to acetyl and isopropylidene groups, producing deazaguanosine $\mathbf{7 7}$. Bromination with an excess of NBS delivered the dibromodeazaguanosine derivative 62 over two steps.

The cylopentylamino building block 63 for both synthetic routes was produced following protocols developed by Gaoni, Posternak, Goto and Ohgi (scheme 2.6). Starting from cyclopentadiene (78), dibenzoyl cyclopentene $\mathbf{7 9}$ was synthesized by electrophilic addition of silverbonzoate in diethylether. 79 was then brominated by NBS in allylic position to yield $\mathbf{8 0}$. The bromine was then substituted by an azide group to yield $\mathbf{8 1}$, which was deprotected under basic conditions and reprotected with acetone under acidic condition to $\mathbf{8 2}$. In the last step the azide was reduced in the presence of $\mathrm{CrCl}_{2}$ to yield 63 .

Due to poor reproducibility of this synthetic procedure, an improved version was published in 1986. In this version deazaguanine aldehyde $\mathbf{8 3}$ was coupled to the 
<smiles>COc1nc(SC)nc2c1c(C)cn2C1OC(COCc2ccccc2)C(OCc2ccccc2)C1OCc1ccccc1</smiles>

73<smiles>CON1C(NC(C)C)=Nc2c(c(C)cn2[C@@H]2O[C@H](COCc3ccccc3)[C@@H](OCc3ccccc3)[C@H]2O)C(=O)N1C</smiles>

74
75

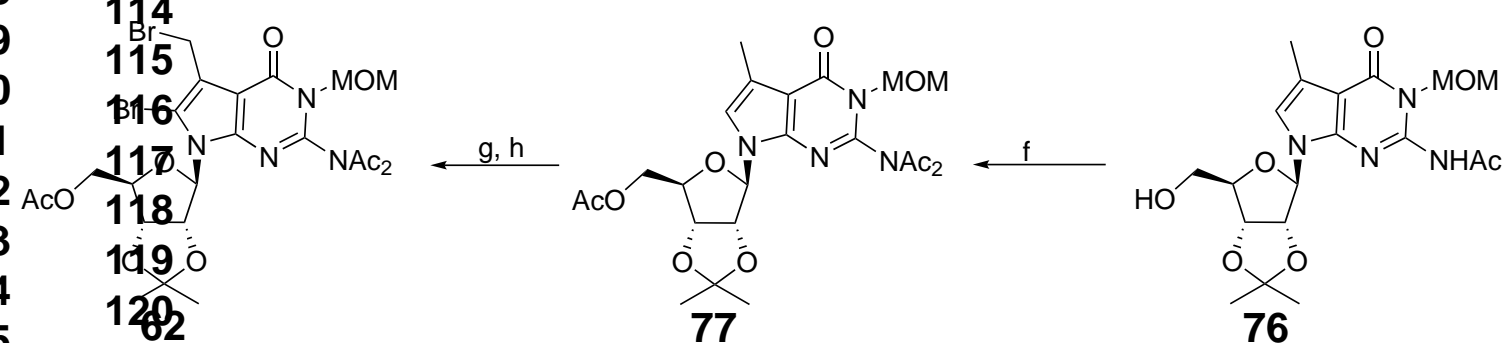

Scheme 2.5. Synthesis of dibromodeazaguanosine derivative 62 part 2. 100

a) $0.5 \mathrm{~N} \mathrm{HCl}$, dioxane; b) $\mathrm{NaH}$, MOMCl, dimethoxyethane; c) $\mathrm{NaH}$, acetamide; d) $\mathrm{Pd} / \mathrm{C}, \mathrm{H}_{2}$, methanol; e) acetone, 2,2-dimethoxypropane, $D, L$-camphorsulfonic acid; f) $\mathrm{Ac}_{2} \mathrm{O}$, pyridine; g) NBS, kat. benzoylperoxide, benzene; h) NBS, kat. benzoylperoxide, $\mathrm{K}_{2} \mathrm{CO}_{3}, \mathrm{CCl}_{4}$, reflux

cylopentylamino building block 63 by reductive amination to obtain isopropylidene and MOM protected queuosine 66. Acidic deprotection lead to queuosine (67) (scheme 2.7).

The deazaguanine aldehyde $\mathbf{8 3}$ was synthesized from 2-methylthio-7-methyl-7desazahypoxanthin (69), with dibromodeazaguanosine 62 as an intermediate, fol-

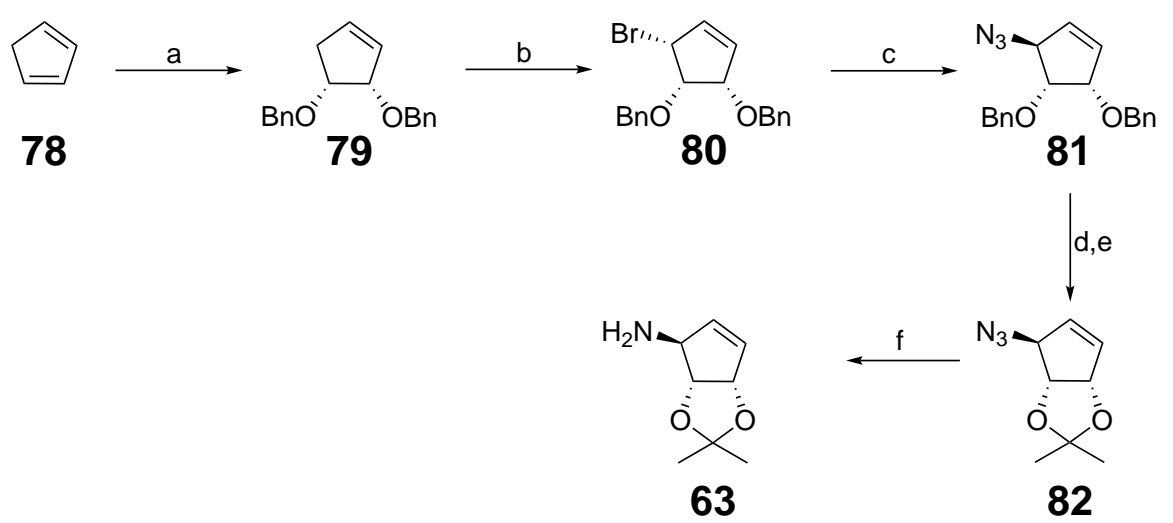

Scheme 2.6. Synthesis of the cylopentylamino building block 63. 100

a) $\mathrm{AgOBn}, \mathrm{Et}_{2} \mathrm{O}$; b) NBS; c) $\mathrm{LiN}_{3}$, DMF; d) NaOMe, methanol; e) acetone, 2,2-dimethoxypropane, $\mathrm{H}^{+}$; f) $\mathrm{CrCl}_{2}$ 


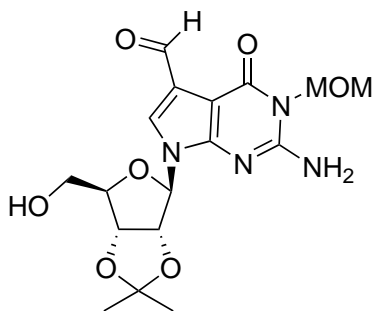

83

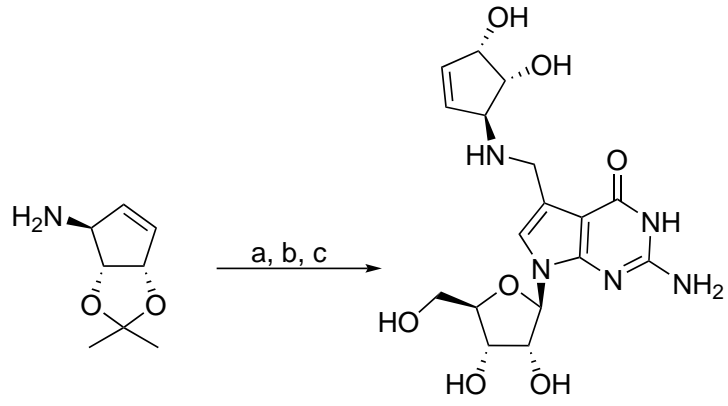

67

Scheme 2.7. Improved synthesis of queuosine 67. 102

a) benzene; b) $\mathrm{NaBH}_{4}$, ethanol; c) $2 \mathrm{~N} \mathrm{HCl}$, methanol

lowing a shorter protocol (scheme 2.8). ${ }^{100}$ In the first step 2-methylthio-7-methyl-7desazahypoxanthin (69) was deprotonated with $n$-BuLi and protected with $\mathrm{MOMCl}$ to obtain 3-methoxymethyl-2-methylthio-7-methyl-7-desazahypoxanthin (84). 84 was coupled to trityl- and isopropylidene protected chlorosugar 85 using Königs-Knorr nucleosidation. The product nucleoside $\mathbf{8 6}$ was obtained as a mixture of $\alpha$ and $\beta$ anomeres in a 1:2 ratio. Substitution of the mercaptomethyl group with acetamide was performed prior to separation of anomers to obtain 87. 87 was detrylated with $\mathrm{HBr}$ and reprotected with acetanhydride to avoid side reactions in the following steps, yielding 77 . Bromination with an excess of NBS delivered the dibromodeazaguanosine derivative 62 over two steps.<smiles>CSc1nc2[nH]cc(C)c2c(=O)[nH]1</smiles>

69<smiles>COn1c(SC)nc2[nH]cc(C)c2c1=O</smiles>

84<smiles>CC(C)(C)OC1C2COC(C2)C1CO</smiles>

85

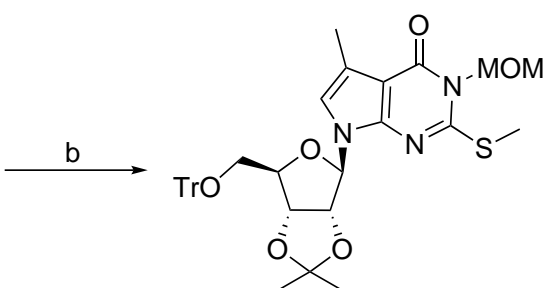

86

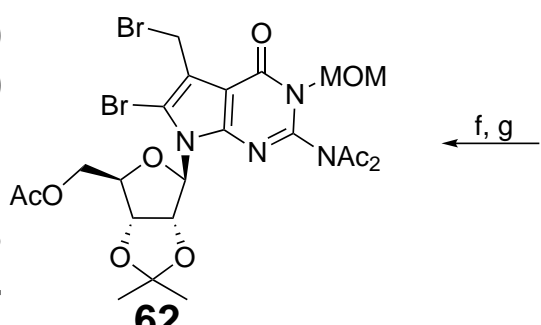

62<smiles>COc1c(C)c2c(=O)n(OC)c([N+](=O)[O-])nc2n1C1CC(OC(C)(C)C)C(COC(C)=O)O1</smiles>

77<smiles>CNc1nc2c(c(I)cn2C2OC(CO)C(OC(C)(C)C)C2O)c(=O)n1O</smiles>

87

Scheme 2.8. Synthesis of deazaguanine aldehyde 83 part 1.102

a) $n \mathrm{BuLi}$, MOMCl, DME; b) $\mathrm{NaBr}$; c) acetamide; d) $\mathrm{HBr}$, DCM; e) $\mathrm{Ac}_{2} \mathrm{O}$, pyridine; f) NBS, kat. benzoylperoxide, benzene; g) NBS, kat. benzoylperoxide, $\mathrm{K}_{2} \mathrm{CO}_{3}, \mathrm{CCl}_{4}$, reflux 
To obtain deazaguanine aldehyde 83, dibromodeazaguanosine derivative 62 was hydrolyzed in the presence of $\mathrm{Ag}_{2} \mathrm{CO}_{3}$ and subsequently debrominated with $\mathrm{Pd} / \mathrm{C}$ and $\mathrm{H}_{2}$ to 89. The primary alcohol was oxidized with $\mathrm{MnO}_{2}$ to form an aldehyde and the product was saponificated to yield $\mathbf{8 3}$ (scheme 2.9).

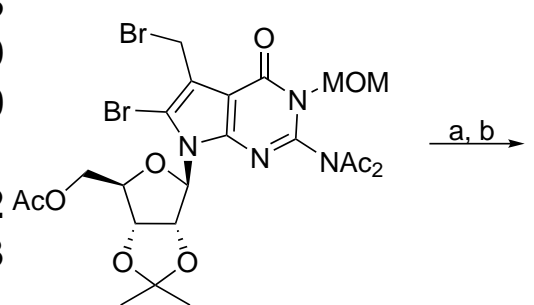

62

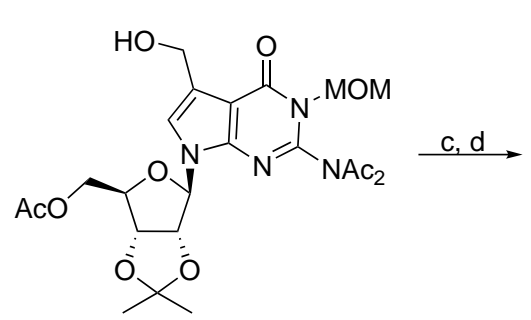

89

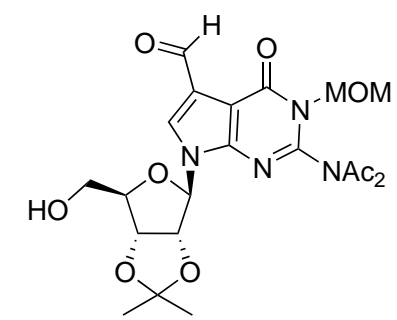

83

Scheme 2.9. Synthesis of deazaguanine aldehyde 83 part 2.102

a) dioxane $/ \mathrm{H}_{2} \mathrm{O}, \mathrm{Ag}_{2} \mathrm{CO}_{3}$; b) $\mathrm{Pd} / \mathrm{C}, \mathrm{H}_{2}$, $\mathrm{AcOK}$, methanol/ $\mathrm{H}_{2} \mathrm{O}$; c) $\mathrm{MnO}_{2}, \mathrm{MeCN}$; d) $\mathrm{NH}_{4} \mathrm{OH}$, methanol

\subsubsection{Synthetic strategies for queuine}

Beside the nucleotide queuosine (67) the corresponding nucleobase queuine (95) was an important synthetic target for the investigation of the role of queuosine in cells. In 1988 Akimoto et al. first published a convergent synthetic route to queuine (95) (scheme 2.10). ${ }^{103}$ The used cylopentylamino building block 63 was synthesized following the protocol of Gaoni, Posternak, Goto and Ohgi (scheme 2.6). Starting from 2,4-diamino-6-hydroxypyrimidin (90), 7-deazaguanine (92) was synthesized by condensation with $\alpha$-chloroacetaldehyde (91) in the presence of sodium methoxide. 7-deazaguanine (92) was acylated with octanoyl chloride at the 2-amino position to compound 93. The acylation affects the electronic properties of the 5carbon, favoring the Mannich-reaction at the 5-position instead of the 6-position, which is favored for the unmodified amino group. Mannich-reaction with formaldehyde and dibenzylamine in $80 \%$ acetic acid yielded aminodeazaguanine 94 . Using bulky amines like dibenzylamine supports regioselective reaction at the 5-position due to steric reasons. The last critical step was an amino substitution reaction with cyclopentylamine 63 in methanol/THF. For this reaction a large excess of 63 (5 eq.) is necessary to gain a satisfactory yield. Subsequently deprotection under basic and mild acidic condition yielded queuine (95).

Another synthetic route to queuine (95) was developed by Barnett et al. in 2000.104 In this route, queuine (95) is built up in a linear synthesis starting from cyclopen- 
<smiles>Nc1cc(=O)[nH]c(N)n1</smiles>

90<smiles>O=CCCl</smiles>

91<smiles>Nc1nc2[nH]ccc2c(=O)[nH]1</smiles>

92

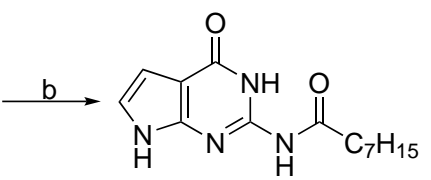

93<smiles>Nc1nc2[nH]cc(CNC3C=CC(O)[C@H]3O)c2c(=O)[nH]1</smiles>

95

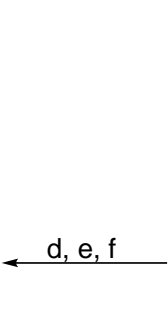

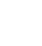

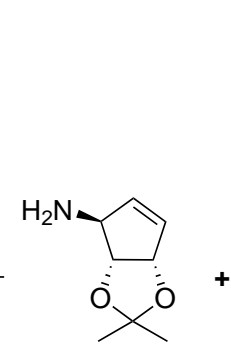

63

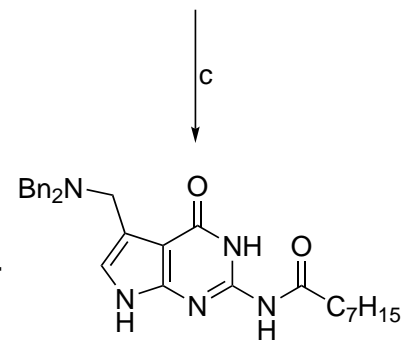

94

Scheme 2.10. Convergent synthesis of queuine (95) by Akimoto et al.103

a) $\mathrm{NaOMe}$, pyridine/ $\mathrm{H}_{2} \mathrm{O}$; b) $\mathrm{ClCOC}_{7} \mathrm{H}_{15}$, pyridine; c) $\mathrm{Bn}_{2} \mathrm{NH}$, formaldehyde, $\mathrm{AcOH}$; d) $\mathrm{MeOH} / \mathrm{THF}$;

e) $\mathrm{KOH}$;) $\mathrm{H}^{+}$

tenol 100. Following a protocol developed by Borchard et al. in 1987 (scheme 2.11),, 105$]$ R-ribose (96) is protected with isopropylidene and methoxy groups to 97 , which is oxidized with a four times excess of PCC. By this oxidation, a C-C cleavage occurs leading to the formation of lactone 98. By an intramolecular Wittig-reaction, the lacton 98 is converted to the cyclopentenone 99 and subsequently reduced with $\mathrm{NaBH}_{4}$ in the presence of $\mathrm{CeCl}_{3}$ to obtain optical pure cyclopentenol 100

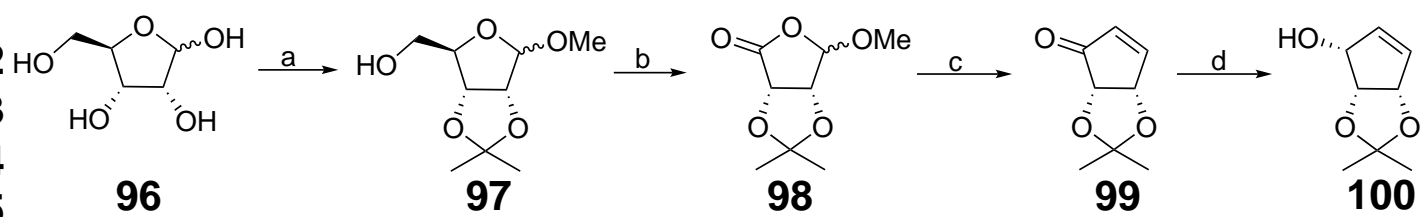

Scheme 2.11. Synthesis of cyclopentenol 100 by Borchard et al. ${ }^{105}$

a) DMP, $\mathrm{HClO}_{4}$ methanol; b) PCC, benzene; c) $(\mathrm{MeO})_{2} \mathrm{POCH}_{2} \mathrm{Li}$; d) $\mathrm{NaBH}_{4}, \mathrm{CeCl}_{3}$, methanol.

Under the conditions of a Mitsunobu-reaction, sulfonamide 101 was coupled to cyclopentenol 100, yielding protected sulfonamide 102. The TBDMS protecting group was cleaved with TBAF und the resulting alcohol 103 was oxidized with TEMPO to obtain aldehyde 104. After condensation of aldehyde 104 with 2,4-diamino-6hydroxypyri- midin (90) protected queuine 105 was obtained. Deprotection yielded the final product queuine (95) (scheme 2.12). 


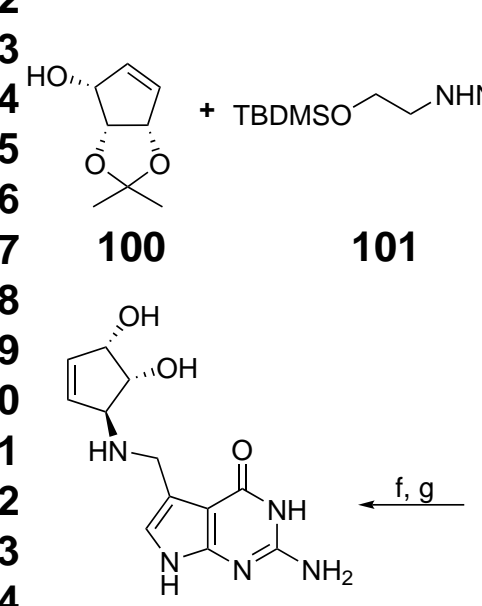

95

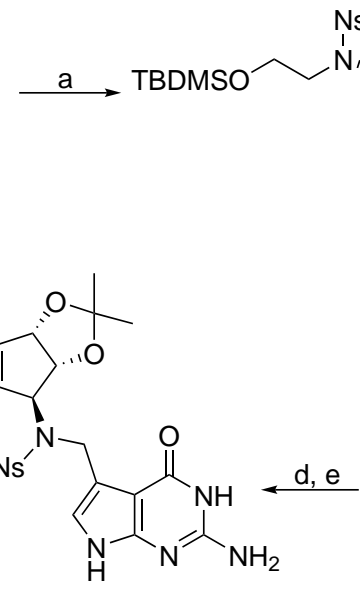

105

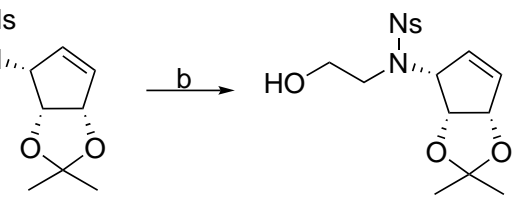

102

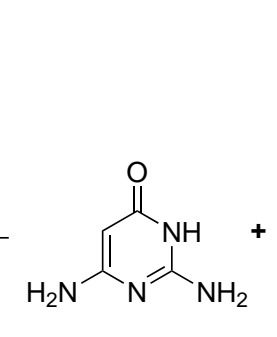

90

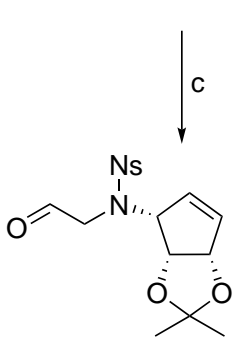

104

Scheme 2.12. Linear synthesis of queuine (95) by Barnett et al.104

a) DIAD, $\mathrm{PPh}_{3}$, THF; b) TBAF, THF; c) TEMPO, NaOCl, KBr, DCM; d) TMSBr, DMSO, MeCN;

e) $\mathrm{NaOAc}, \mathrm{H}_{2} \mathrm{O} / \mathrm{MeCN}$; f) $\mathrm{HSCH}_{2} \mathrm{CH}_{2} \mathrm{OH}$, DBU, DMF; g) $\mathrm{HCl}$, methanol

\subsubsection{Improved syntheses for the cyclopentylamino building block 63}

Since the early 2000's, shorter and more effective syntheses for cyclopentylamine 63 have been published. ${ }^{[106-[109]}$ The main challenge in the synthesis of this molecule is to build up the three stereocenters, with the two hydroxy groups in cis-configuration to each other and the amide function in trans-position to the adjacent hydroxy group.

Trost et al. puplished a six step synthesis in 2003 (scheme 2.13). ${ }^{106}$ Starting from cyclopentadiene (78), epoxide 106 was obtained by epoxidation with peracetic acid. Opening of the epoxide under retention of the configuration was achieved by using the strong lewis acid $\mathrm{BF}_{3} \cdot \mathrm{Et}_{2} \mathrm{O}$. In the presence of acetone, acetal 107 was obtained. Oxidation with $\mathrm{SeO}_{2}$ in boiling dioxane delivered alcohol 108 as a racemic mixture of diastereomers. Conversion of the alcohol $\mathbf{1 0 8}$ to the methyl carbonates 109 occurred with methyl chlorocarbonate and pyridine, setting the stage for the asymmetric allylic alkylation. By a stereoselective palladium catalyzed substitution with the $(R, R)$-DACH-Phenyl Trost-ligand $\mathbf{1 1 0}$ optically pure pthalimide $\mathbf{1 1 1}$ was obtained. Reaction of $\mathbf{1 1 1}$ with ethylenediamine released the primary amine, yielding the cyclopentylamine 63 .

In 1998 Van Boom et al. published a linear synthesis, containing twice as many reaction steps, but after optimization by Leumann et al. the synthesis was feasible in a multi gramm scale. ${ }^{[107,}{ }^{108}$ According to the protocol of Leumann et al., the synthe- 


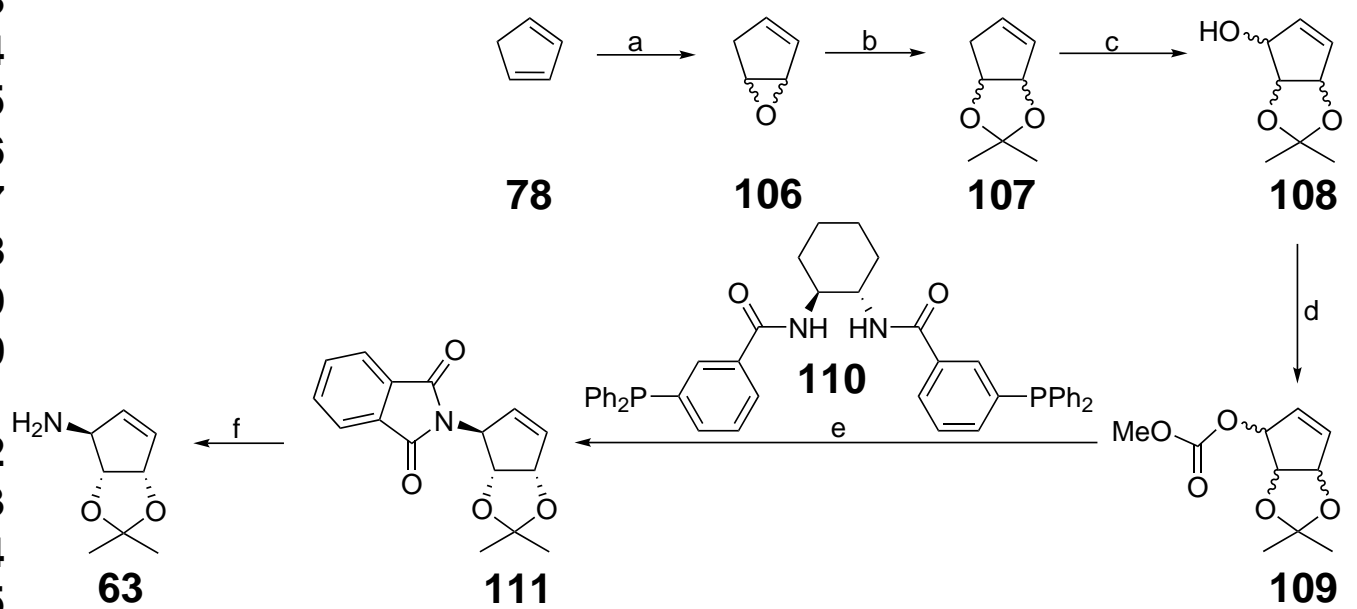

Scheme 2.13. Synthesis of the cylopentylamino building block 63 by Trost et al.106

a) $\mathrm{AcOOH}, \mathrm{Na}_{2} \mathrm{CO}_{3}, \mathrm{DCM}$; b) $10 \mathrm{~mol} \% \mathrm{BF}_{3} \cdot \mathrm{Et}_{2} \mathrm{O}$, acetone; c) $\mathrm{SeO}_{2}, \mathrm{NaHPO}_{4}$, dioxane, reflux; d) CICOOMe, pyridine, DCM; e) potassiumpthalimide, kat. $\mathrm{Pd}_{2} \mathrm{dba}_{2}$, (Hex ${ }_{2} \mathrm{NBr} \mathrm{DCM}$; f) ethylendiamine, phenol, reflux

sis was started from D-mannose (112), which was protected with isopropylidene and acetyl groups to obtain protected mannose 113. The 5,6-isopropylidene group was hydrolyzed and the intermediate $\mathbf{1 1 4}$ was transformed to methyl ortoformate $\mathbf{1 1 5}$ subsequently. Thermal rearrangement of $\mathbf{1 1 5}$ by treatment with neat acetic anhydride at $130{ }^{\circ} \mathrm{C}$ yielded compound 116, which was saponified to yield 117. Wittig reaction furnished diene 118, followed by ring closing metathesis catalyzed by 1st generation Grubb's catalyst to obtain cyclopentenol 119 (scheme 2.14).<smiles>OCC1OC(O)C(O)C(O)C1O</smiles>

112<smiles></smiles>

113<smiles>CC(C)OC1OC(C(O)CO)C2OC(C)(C)OC12</smiles>

114<smiles>COC(C)=O</smiles>

115<smiles>CC1(C)OC2C=CC(O)C2O1</smiles>

119

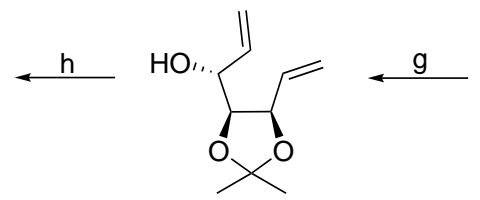

118<smiles>C=CC1OC(O)C2OC(C)(C)OC12</smiles>

117

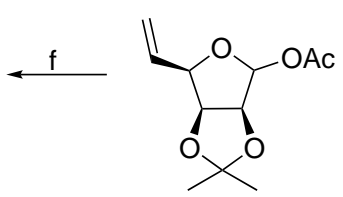

116

Scheme 2.14. Synthesis of cylopentenol 119 by Leumann et al. 108

a) $\mathrm{DMP}, \mathrm{TsOH}$; b) $\mathrm{Ac}_{2} \mathrm{O}$, pyridine; c) $64 \% \mathrm{HOAc}$; d) $\mathrm{HC}(\mathrm{OMe})_{3}$; e) reflux, $\mathrm{Ac}_{2} \mathrm{O}$; f) tertBuOK, $\mathrm{MeOH}$;

g) $\mathrm{NaH}, \mathrm{BrCH}_{2} \mathrm{P}(\mathrm{Ph})_{3}$, DMSO; h) 0.05 mol\% Grubb's 1st gen., DCM

Cyclopentenol 119 was converted into acetimidate 120 by trichloroacetonitrile and 
thermal [3,3]-rearrangement lead to trichloroacetamide 121, which was deprotected under basic conditions to obtain cyclopentylamine 63 (scheme 2.15).

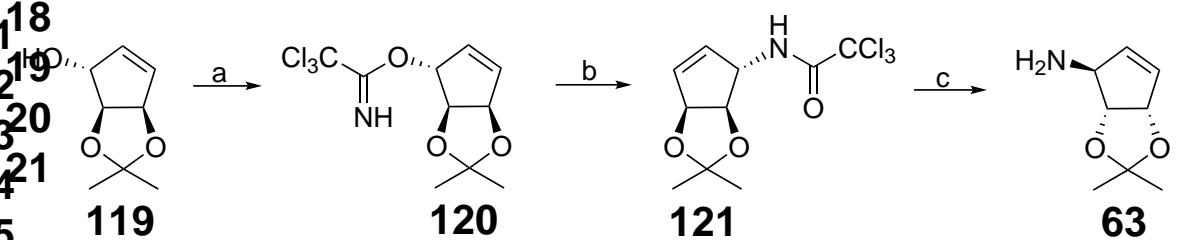

Scheme 2.15. Synthesis of the cylopentylamino building block 63 by Van Boom et al. ${ }^{[107}$ a) trichloroacetonitrile; b) $o$-xylol, $150^{\circ} \mathrm{C}$; c) $\mathrm{NaOH}, \mathrm{MeOH}$

\subsubsection{Recent synthetic strategies for queuine}

In 2012 Gerber and Klebe published a new synthetic route for queuine (95) using the building blocks $\operatorname{PreQ}_{1}(\mathbf{5 8})$ and bromocyclopentene 122 which were connected via nucleophilic substitution under inversion of the chiral center, followed by acidic deprotection (scheme 2.16). 109

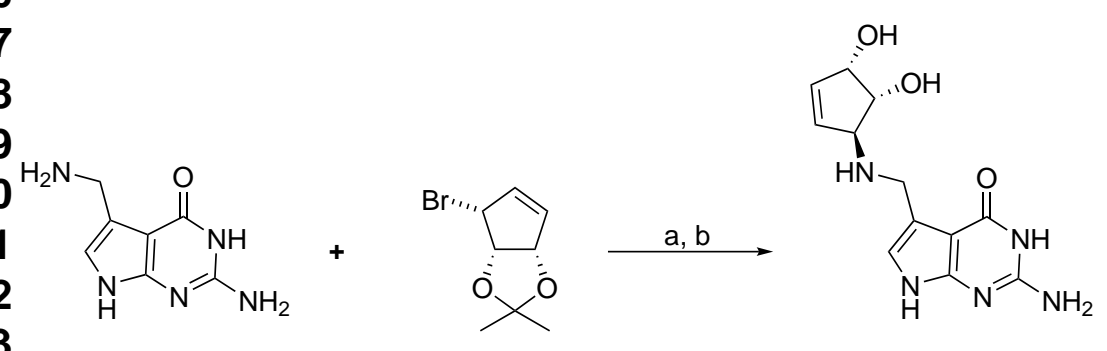

58

122

95

Scheme 2.16. Synthesis of queuine (95) by Gerber and Klebe.109

a) DBU, DMF, $65^{\circ} \mathrm{C}, 5 \mathrm{~h}$; b) $1.25 \mathrm{M} \mathrm{HCl} / \mathrm{MeOH}$, reflux, $5 \mathrm{~h}$

Bromocyclopentene 122 was synthesized starting from ribose (96) following the protocol of Borchard et al. ${ }^{[105}$ to obtain cyclopentenol 100 (scheme 2.11).

To get the right diastereomer of bromocyclopentene 122, the chiral center of the hydroxy group had to be inverted in the next step using Mitsunobu conditions and subsequent saponification to yield the inverted cyclopentenol 124. In the last step a mild bromination following a literature procedure of Diederich et al.110] lead to bromocyclopentene 122. Reinversion of the chiral center during the bromination provided the required diastereomer (scheme 2.17). 


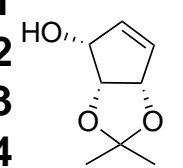

100

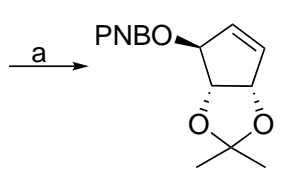

123

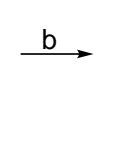<smiles>CC1(C)OC2OCC(O)C2O1</smiles>

124

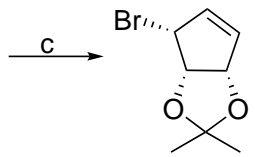

122

Scheme 2.17. Synthesis of bromocyclopentene 122.109

a) PNBA, TPP, DEAD, THF, $55^{\circ} \mathrm{C}, 48 \mathrm{~h}$; b) $\mathrm{NaOH}, \mathrm{MeOH}-\mathrm{H}_{2} \mathrm{O} 5: 1$, rt, $\left.18 \mathrm{~h}, \mathrm{c}\right) \mathrm{Br}_{2}$, TPP, imidazole, $\mathrm{CH}_{2} \mathrm{Cl}_{2},-20{ }^{\circ} \mathrm{C}$ to rt, $1 \mathrm{~h}$

The synthesis of $\operatorname{PreQ}_{1}$ (58) started from phthalimidoacetaldehyde (125). In a first step, $\beta$-nitroalcohol 126 was synthesized by using the Henry reaction, and the product was was dehydrated by reaction with trifluoroacetic anhydride and subsequently elimination of trifluoroacetate to obtain nitroolefin $\mathbf{1 2 7}$ as the trans isomer exclusively. Michael addition of 2,4-diamino-6-hydroxypyrimidin (90) to the nitroolefin 127 yielded the racemic nitroalkyl compound $\mathbf{1 2 8}$, which was converted to phthalamic acid 129 by Nef reaction immediately followed by intramolecular cyclyzation. In the last step the amide was cleaved under acidic conditions to obtain $\operatorname{PreQ}_{1}(\mathbf{5 8})$ as the dihydrochloride salt (scheme 2.18).<smiles>O=CCN1C(=O)c2ccccc2C1=O</smiles>

125<smiles>CC(C)CN1C(=O)c2ccccc2C1=O</smiles>

126

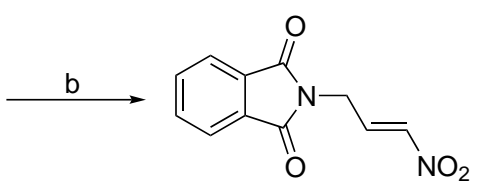

127

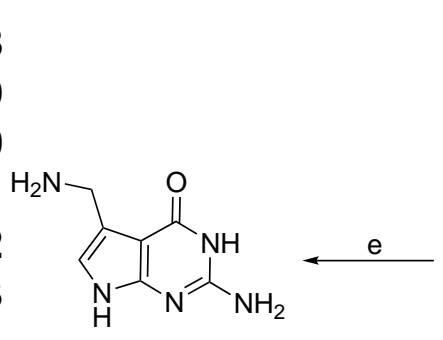

58

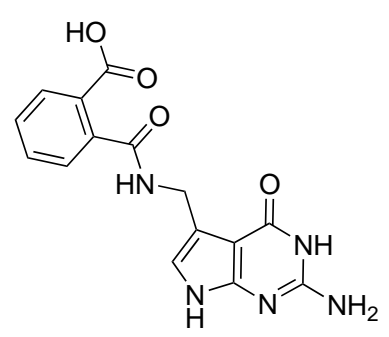

129

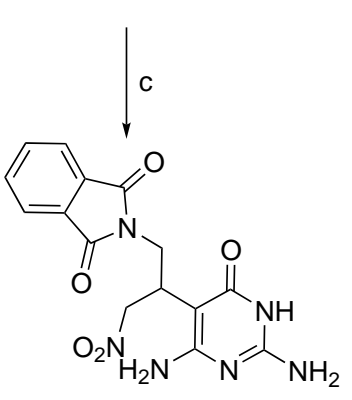

128

Scheme 2.18. Synthesis of $\operatorname{preQ}_{1}$ 58.109

a) $\mathrm{CH}_{3} \mathrm{NO}_{2}$, cat. $\mathrm{KOtBu}$, THF/CH${ }_{3} \mathrm{OH}, 0-20^{\circ} \mathrm{C}, 18 \mathrm{~h}$; b) TFAA, THF, $-5^{\circ} \mathrm{C}, 15 \mathrm{~min}$, then TEA, THF, $-10{ }^{\circ} \mathrm{C}, 5 \mathrm{~min}$; c) 90 , THF/EtOAc/ $\mathrm{H}_{2} \mathrm{O}, 60{ }^{\circ} \mathrm{C}, 4 \mathrm{~h}$; d) $\mathrm{NaOH}, \mathrm{H}_{2} \mathrm{O}, 20{ }^{\circ} \mathrm{C}, 5 \mathrm{~min}$, then $\mathrm{H}^{+}-5^{\circ} \mathrm{C}$ to rt, $18 \mathrm{~h}$; e) $6 \mathrm{M} \mathrm{HCl}$, reflux, $6 \mathrm{~h}$ 


\subsection{New synthesis of (1R,2S,3S)-1-bromo-2,3-O- isopropylidene-cyclopent-4-ene (122)}

In 2012 Gerber and Klebe published a new synthetic route for the synthesis of queuine (95) (see schemes 2.16, 2.17, 2.18). ${ }^{[109]}$ Although being convergent, short and concise, as well as good scalable, this route did still carry some disadvantages. The main problems arose from the synthetic part of $(1 R, 2 S, 3 S)$-1-bromo2,3-O-isopropylidene-cyclopent-4-ene (122) which based on the work of Borchard et al. ${ }^{[105]}$ (see scheme 2.11). It required some expensive reagents and huge excess of toxic pyridinium chlorochromate. Additionally, a diastereoselective reduction was necessary, which provided the exactly wrong diastereomer, due to the already existing stereochemical environment before the reduction. As a result, two more steps were necessary to invert the wrong to the right diastereomer. Furthermore, the purification and storage of the cyclopentenone intermediate 99 was a problem due to its volatility and poor stability.

The new synthesis was designed based on the route published by Gerber and Klebe. Herein, $\operatorname{PreQ}_{1}$ (58) and (1R,2S,3S)-1-bromo-2,3-O-isopropylidene-cyclopent-4-ene (122) are the desired building blocks as well. At the same time, the synthetic route for $\mathbf{1 2 2}$ should be redesigned to avoid the disadvantages of the recent synthesis and to simplify the handling. Thereby, the correct diastereomer has to be synthesized without formation of chiral centers by stereoselective reactions. Additionally, intermediates occurring in the new route should be stable, easy to purify and storable over several weeks. Moreover, all reagents have to be non toxic and if possible inexpensive. In the end, the new synthetic route should not be longer than the original one and should be feasible at a gram scale.

The pivotal goal of the new synthesis was to avoid any stereoselective reactions, which are required to build up chiral centers or to invert diastereomers into each other. Because of that, a suitable starting material had to be found, which already possess all required chiral information in the right arrangement. These chiral information have to be conserved for the synthetic procedure to avoid any loss of them.

In nature most molecules are chiral compounds, which posses numerous chiral centers partly. Especially, the classes of pentoses and hexoses consist of a multitude of different diastereomers. The target molecule allylic alcohol 130 shows 
three cis arranged hydroxy groups, positioned directly next to each other. From all pentoses and hexoses, four aldohexoses, one ketohexose and one aldopentose provide the desired arrangement of chiral centers (scheme 2.19). From these suitable sugars only D-galactose and L-arabinose are naturally occurring in reasonable amounts and therefore are inexpensive starting materials. However, in the case
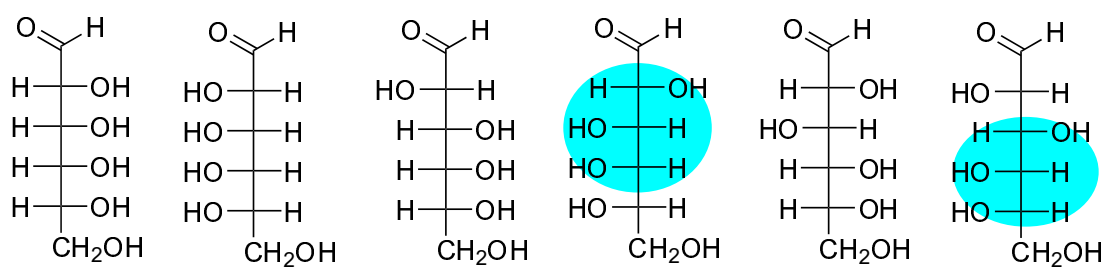

L-Altrose

D-Glucose

L-Glucose
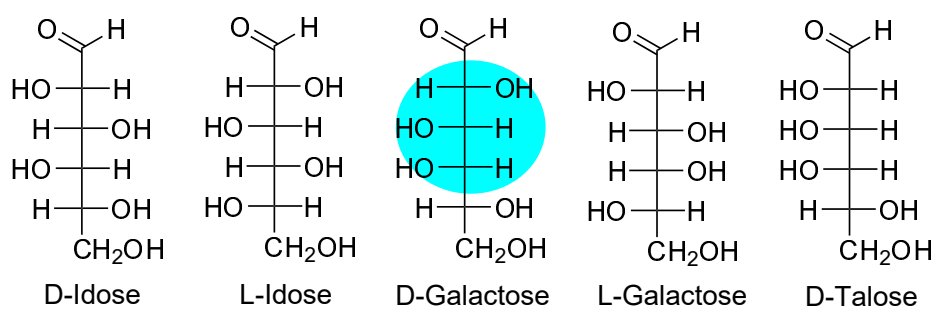

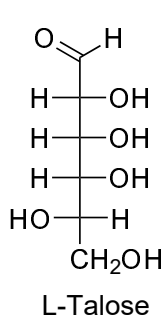

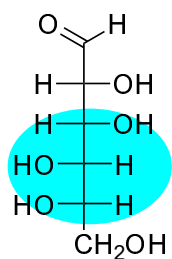

L-Mannose

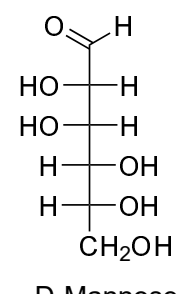

\begin{tabular}{ll}
\multicolumn{2}{c}{$\mathrm{CH}_{2} \mathrm{OH}$} \\
\cline { 2 - 2 }$-\mathrm{O}$ \\
$\mathrm{HO}-\mathrm{H}$ \\
$\mathrm{HO}-\mathrm{H}$ \\
\hline
\end{tabular}

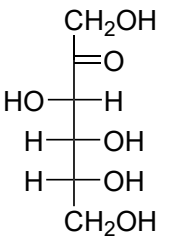

D-Fructose \begin{tabular}{c|c}
\multicolumn{2}{c}{$\mathrm{CH}_{2} \mathrm{OH}$} \\
\cline { 2 - 2 } & $=\mathrm{O}$ \\
$\mathrm{H}$ & $\mathrm{OH}$ \\
$\mathrm{HO}$ & $\mathrm{H}$ \\
$\mathrm{HO}$ & $\mathrm{H}$ \\
$\mathrm{CH}_{2} \mathrm{OH}$
\end{tabular}

L-Fructose

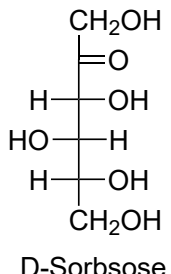

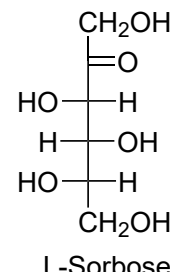
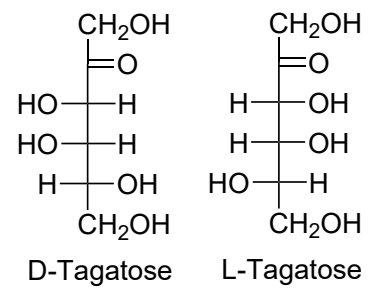

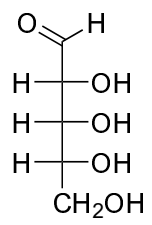

\begin{tabular}{l|l}
$\mathrm{O}$ & $\mathrm{H}$ \\
$\mathrm{HO}$ & $\mathrm{H}$ \\
$\mathrm{HO}$ & $\mathrm{H}$ \\
$\mathrm{HO}$ & $\mathrm{H}$ \\
& $\mathrm{CH}_{2} \mathrm{OH}$
\end{tabular}

D-Ribose

$$
\text { L-Ribose }
$$

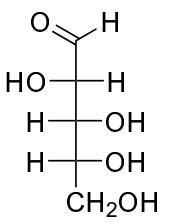

D-Arabinose

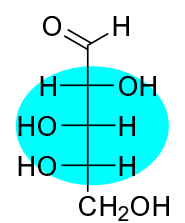

L-Arabinose

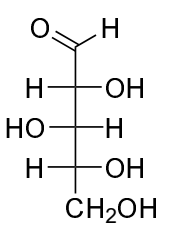

D-Xylose

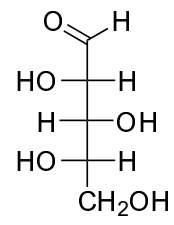

L-Xylose
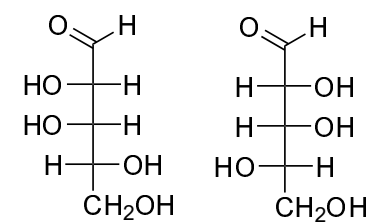

D-Lyxose

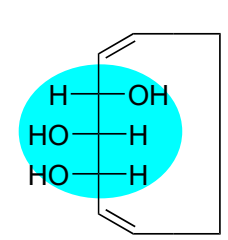

130

Scheme 2.19. Overview of hexoses and pentoses.

Sugars which possess the reacquired chiral information in the right arrangement are highlighted in blue. 


\section{Stimulation of S. pombe Dnmt2 by the micronutrient queuine}

of L-arabinose one of the regarded hydroxy groups is a part of the acetal bond in the pyranose form. This might cause problems during the synthesis. Moreover, L-arabinose is roughly ten times more expensive than D-galactose 1 Due to these facts D-galactose was chosen as the best suited starting material.

Retrosynthetic analysis provided the following steps to convert a hexose into the desired cyclopentenol building block. 1. glycol cleavage of the 5,6-diol to obtain the dialdehyde. 2. Wittig olefination at both ends of the dialdehyde to get the diene. 3. Ring-closing-metathesis. 4. Nucleophilic substitution under $\mathrm{S}_{\mathrm{N}} 2$-conditions to yield the desired bromo-cyclopentene (scheme 2.20).
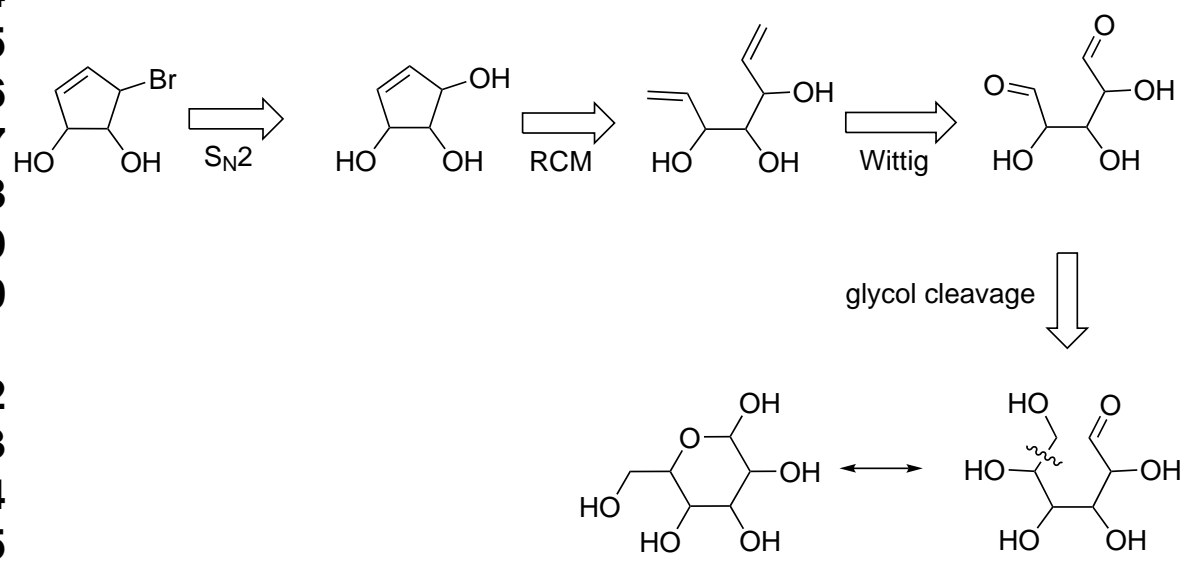

Scheme 2.20. Retro synthesis of the bromocyclopentene building block.

To perform the glycol cleavage exclusively regioselective at the 5,6-diol it is necessary to react all other hydroxy groups with suitable protecting groups. Following a modified protocol developed by Leino et al., $\alpha$-D-galactose should have been protected with an isopropylidene group at $\mathrm{C} 3$ and $\mathrm{C} 4$ and an acetyl group at C2.111] In order to achieve this regioselective protection the anomeric hydroxy group had to be protected as benzylether first. This protecting group can be cleaved selectively by catalytic hydrogenation later on. This first step was done starting from pentaacetylgalactose (131) by substitution of the anomeric acetyl group with ben$\mathrm{zyl}$ alcohol in the presence of $\mathrm{BF}_{3}$ in $\mathrm{DCM}$ at ambient temperature. Afterwards, all remaining acetyl groups were cleaved by saponification with sodium methoxide in methanol to obtain benzylgalactose 132. To acetylate the hydroxy group at $\mathrm{C} 2$ selectively, the $\mathrm{C} 6$ hydroxy group had to be protected with TBDMS temporarily, which gets cleaved in the presence of TBAF later on. The protection was performed with TBDMSCI in DCM at ambient temperature. To avoid any re-

\footnotetext{
${ }^{1}$ The prices are compared from Sigma Aldrich for the $99 \%$ pure products.
} 
action at the C2 hydroxy group, DBU was used as a sterically demanding base to activate the primary alcohol selectively. TBDMS protected benzylgalactose 133 should have been protected in the next step with 2,2-dimethoxypropane with $p$ $\mathrm{TsOH}$ as a catalyst to obtain benzyl-3,4-O-isopropylidene-6-O-tertbutyldimethylsilylgalactose (134). However, the TBDMS group seemed to be unstable in the presence of even catalytic amounts of $p-\mathrm{TsOH}$, leading to cleavage and reaction of the $\mathrm{C} 6$ hydroxy group with 2,2-dimethoxypropane resulting in benzyl-3,4-O-isopropylidene6-methoxyisopropyl-galactose (136) as the only product (scheme 2.21). The successful results from Leino et al. could not be reproduced. ${ }^{[111}$ Not being able to selectively deprotect both hydroxy groups at $\mathrm{C} 1$ and $\mathrm{C} 6$ respectively, the following steps to obtain the $\mathrm{C} 2, \mathrm{C} 3$ and $\mathrm{C} 4$ protected galactose derivative 135 could not be performed and therefore no selective glycol cleavage at C5 and C6 was possible.

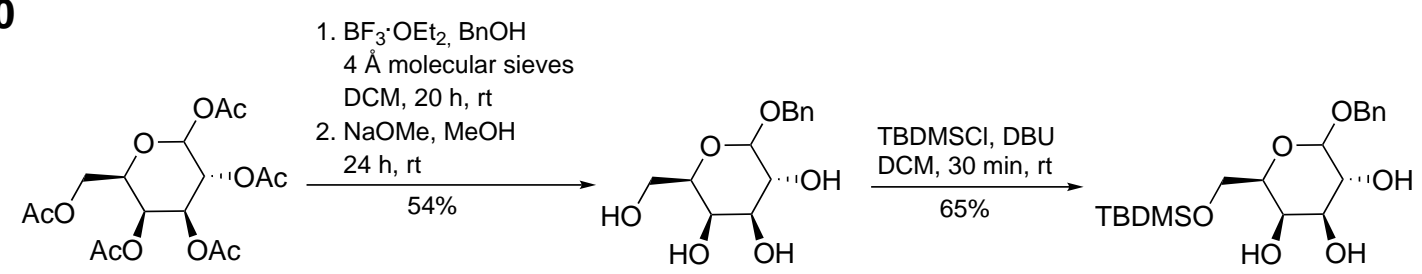

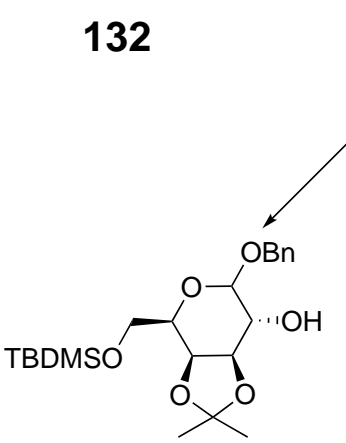

134
133

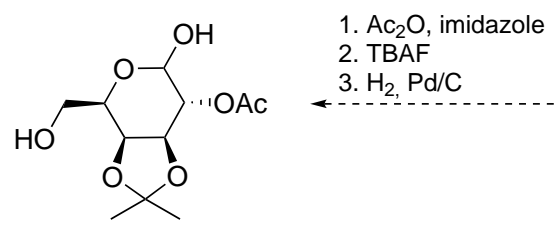

135

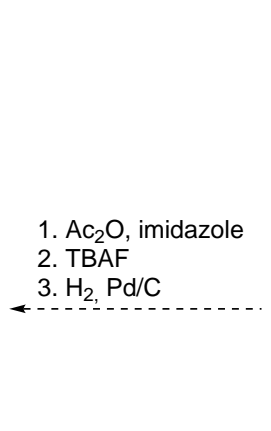

To avoid the loss of the TBDMS group, the protection with an isopropylidene group at $\mathrm{C} 3$ and $\mathrm{C} 4$ should be done before the protection of C6. Although, this strategy goes along with the disadvantage of $\mathrm{C} 2, \mathrm{C} 3, \mathrm{C} 4$, and $\mathrm{C} 6$ as well as $\mathrm{C} 4$ and $\mathrm{C} 6$ protected byproducts, according to Catelani et al. the amount of these byproducts are below $10 \%$, using camphorsulfonic acid instead of $p \mathrm{TsOH}$. 1112]

However, the applicability of this synthetic strategy was not further evaluated. Instead, a more suitable method for the C5 and C6 cleavage was found in the zinc-mediated reductive fragmentation. ${ }^{1113}$ In this process, methyl-6-deoxy-6-iodohexopyranosides are reacted with zinc powder in a THF/water mixture under son- 
ication to generate 5,6-dideoxy-hex-5-enoses, which are useful chiral synthons in organic chemistry (scheme 2.22).

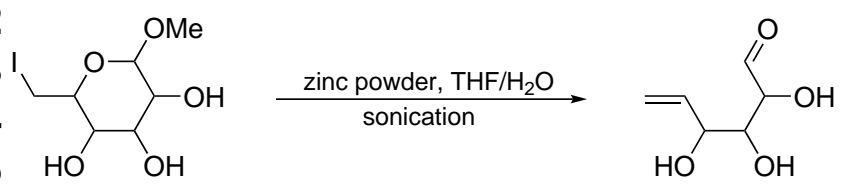

Scheme 2.22. Zinc mediated reductive fragmentation of methyl-6-deoxy-6-iodo-hexopyranosides.

Murphy et al. published a protocol for the zinc mediated reductive fragmentation of mannose, followed by Horner Wittig Emmons olefination to obtain a precursor for C-glycosyl iminosugars. ${ }^{[14}$ This protocol was adapted with some adjustments for the synthesis of 3,4-O-isopropylidene-2-O-tertbutyldimethylsilyl-hex5-enal (141). Methyl-galactopyranoside (137) was chosen as the starting material, which can be synthesized by reaction of galactose with methanol in acetylchloride, but is also commercially available at a reasonable price. ${ }^{[115]}$ Protected 6-iodogalactopyranoside $\mathbf{1 4 0}$ was synthesized in three steps as a precursor for the zincmediated reductive fragmentation (scheme 2.23).

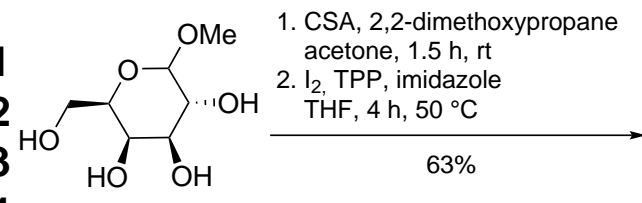

137

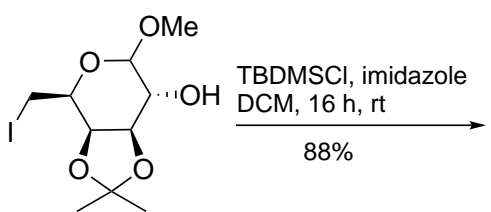

139

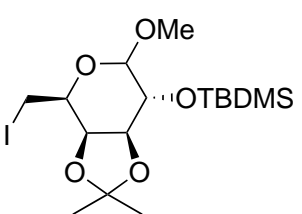

140

Scheme 2.23. Iodination and protection of methyl-galactopyranoside (137) to obtain 140.

First, methyl-galactopyranoside (137) was treated with CSA and 2,2-dimethoxypropane in acetone to protect the hydroxy groups at C3 and C4 by an isopropylidene group. The obtained methyl-4,6-O-isopropylidene-galactopyranoside (138) was iodinated with iodine in the presence of TPP and imidazole directly without previous purification. This reaction is multiple times faster at the primary alcohol compared to the secondary due to steric reasons. By this effect, the iodination takes place at $\mathrm{C} 6$ exclusively. Methyl-6-iodo-3,4-O-isopropylidene-galactopyranoside (139) was obtained in reasonable yield over two steps. As mentioned by Catelani et al. a small amount (below 10\%) of methyl-4,6-O-isopropylidene-galactopyranoside was formed as byproduct during the first reaction step. ${ }^{[12]}$ Following purification, the hydroxy group at $\mathrm{C} 2$ was converted into the TBDMS-ether using TBDMSCl and imidazole in DCM to obtain methyl-6-iodo-3,4-O-isopropylidene-2-O-tertbutyldimethylsilyl- galactopyranoside (140). Protection at $C 2$ is required to avoid racemization after the re- 
ductive fragmentation step.

Methyl-6-iodo-3,4-O-isopropylidene-2-O-tertbutyldimethylsilyl-galactopyranoside (140) was converted into 3,4-O-isopropylidene-2-O-tertbutyldimethylsilyl-hex-5-enal (141) via zinc-mediated reductive fragmentation with zinc powder in a 1:9 mixture of water and THF. The reaction was performed under sonication at $40{ }^{\circ} \mathrm{C}$ and the product 141 was isolated in almost quantitative yield. $\alpha$-hydroxy aldehydes are prone for racemization at the $\alpha$-carbon due to keto-enol tautomerism. This was prevented effectively by conversion of the C2 hydroxy group into the silyl ether. Subsequently, aldehyde 141 should be converted into heptadiene 142 via Wittig olefination. The reaction was performed with $\mathrm{MePPh}_{3} \mathrm{Br}$ and $n$-BuLi in THF at $0{ }^{\circ} \mathrm{C}$. Unfortunately, no desired product was detectable. Only unidentified side products were formed. The acidity of the $\alpha$-proton might be problematic in the presence of $n$-BuLi. To avoid harsh basic conditions, Wittig olefination was changed to Tebbe olefination, which was applied with only Tebbe reagent in THF at $0{ }^{\circ} \mathrm{C}$. In this case reaction conditions are only slightly basic and the desired product 4,5-O-isopropylidene-3O-tertbutyldimethylsilyl-hepta-1,6-diene (142) was isolated in moderate yield after chromatographic purification (scheme 2.24).

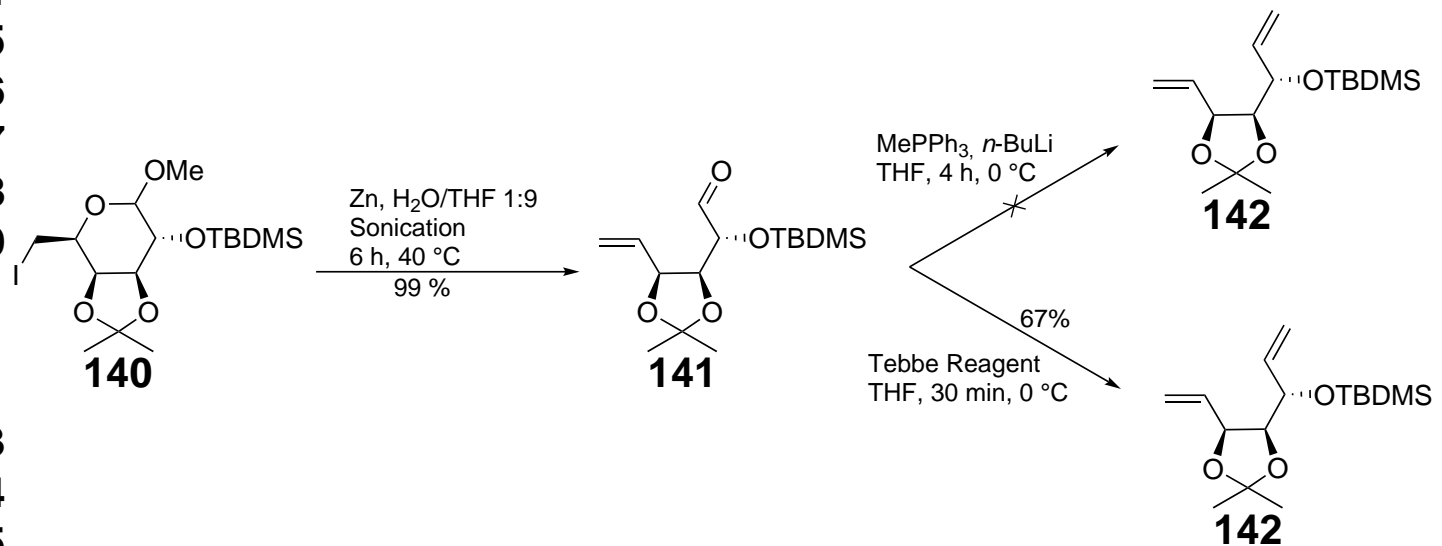

Scheme 2.24. Zinc mediated reductive fragmentation and Tebbe olefination to obtain heptadiene 142.

After conversion of aldehyde 141 into heptadiene 142, the silylether was cleaved by addition of TBAF in THF at ambient temperature in nearly quantitative yield. After chromatographic purification, cyclopentenol 130 was formed by ring-closingmetathesis, following a modified protocol of Smith et al. ${ }^{[16]}$ The ring-closing metathesis has emerged as a powerful and efficient process in the cyclyzation of dienes, which is also advantageous in carbohydrate chemistry. ${ }^{[17}$ Using $5 \mathrm{~mol} \%$ of second generation Grubb's catalyst in THF, the reaction was finished after stirring for two 
hours at $40^{\circ} \mathrm{C}$ with satisfying yield (scheme 2.25).<smiles>C=CC(OCC)C1OC(C)(C)OC1C=C</smiles>

142

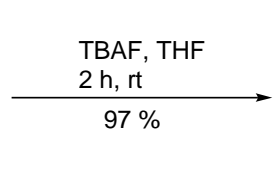<smiles>C=CC1OC(C)(C)OC1C=C</smiles>

143
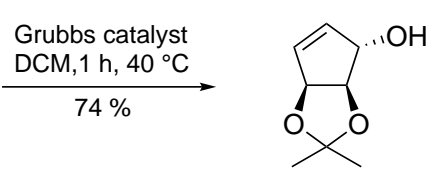

130

Scheme 2.25. Cleavage of the silylether and RCM to obtain cyclopentenol $\mathbf{1 3 0 .}$

The last steps were done similar to the queuine synthesis by Gerber and Klebe. [109] First, the cyclopentenol $\mathbf{1 3 0}$ was converted into cyclopentene bromide $\mathbf{1 2 2}$ by reaction of TPP to the hydroxy group and subsequently nucleophilic substitution under $\mathrm{S}_{\mathrm{N}} 2$ conditions. Thereby, the chiral center at the hydroxy group was inverted to obtain enantiomeric pure cyclopentene bromide 122 in fair yield. Finally, queuine was synthesized by connection of cyclopentene bromide 122 and $\operatorname{PreQ}_{1}$ (58). This was done again via nucleophilic substitution under $\mathrm{S}_{\mathrm{N}} 2$ conditions. The primary amine of PreQ $_{1}$ (58) was activated by the sterically demanding base DBU and cyclopentene bromide 122 was added. Chromatographic purification yielded the isopropylidene protected queuine 144, which was deprotected in refluxing acidic methanol solution to obtain pure queuine (95) as the hydrochloride salt (scheme 2.26).

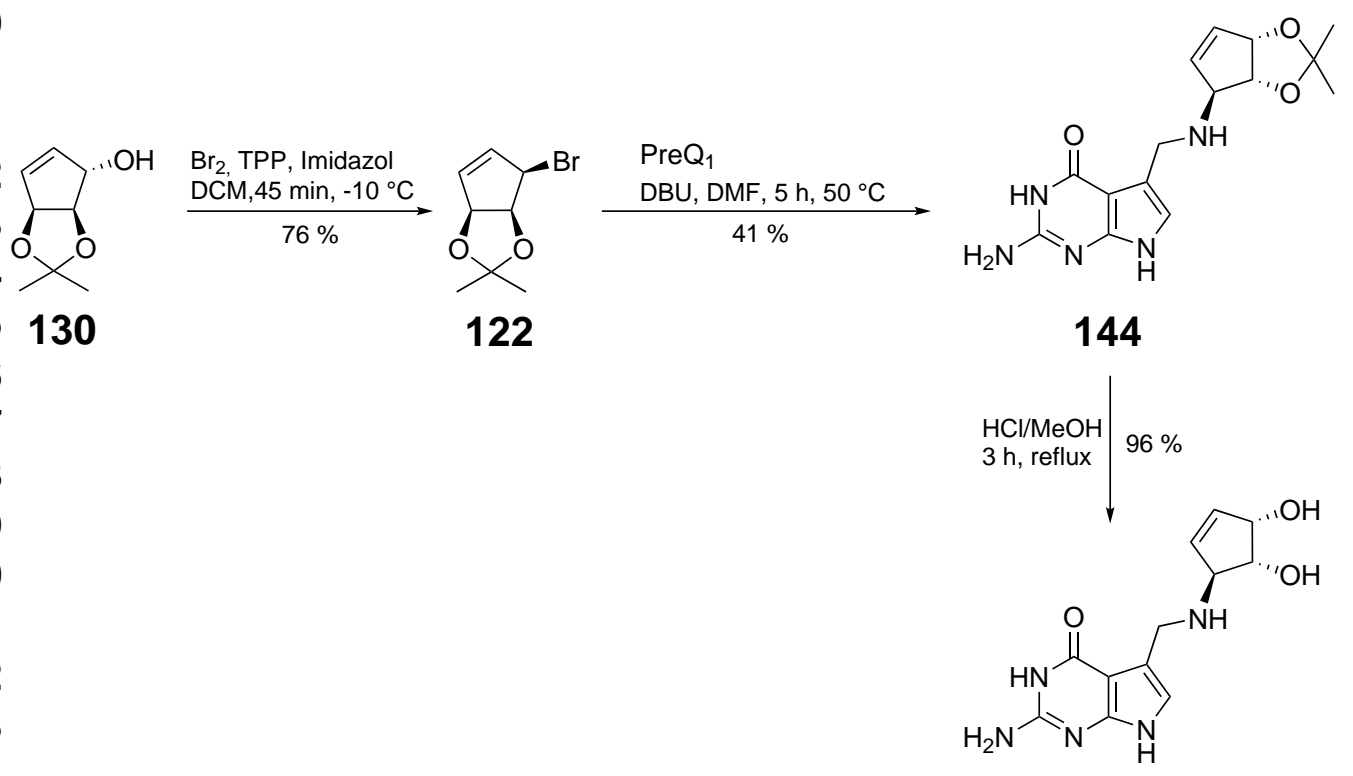

95

Scheme 2.26. Bromination of cyclopentenol 130 and connection of building blocks 122 and $\mathbf{5 8}$ with subsequent deprotection to obtain queuine (95). 


\subsection{Stimulation of $S$. pombe Dnmt2 by queuine}

In order to quantify the catalytic activity of $S$. pombe Dnmt2 (spDnmt2) in dependency of queuine containing tRNA ${ }^{\text {Asp }}$, methyltransferase activity assays and binding affinity assays were performed by Sven Johansson from the Ficner group. A new system was established, working exclusively outside of $S$. pombe to prove, that queuine by itself is able to stimulate the catalytic reaction velocity. 118

Therefore, unmodified tRNA ${ }^{\text {Asp }}$ was converted into queuine containing Q34tRNA ${ }^{\text {Asp }}$ via transglycosylation with human guanine transglycosylase (TGT). Successful transglycosylation was confirmed using a specific electrophoresis band-shift method described by Igloi and Kossel (figure 2.3). [119]

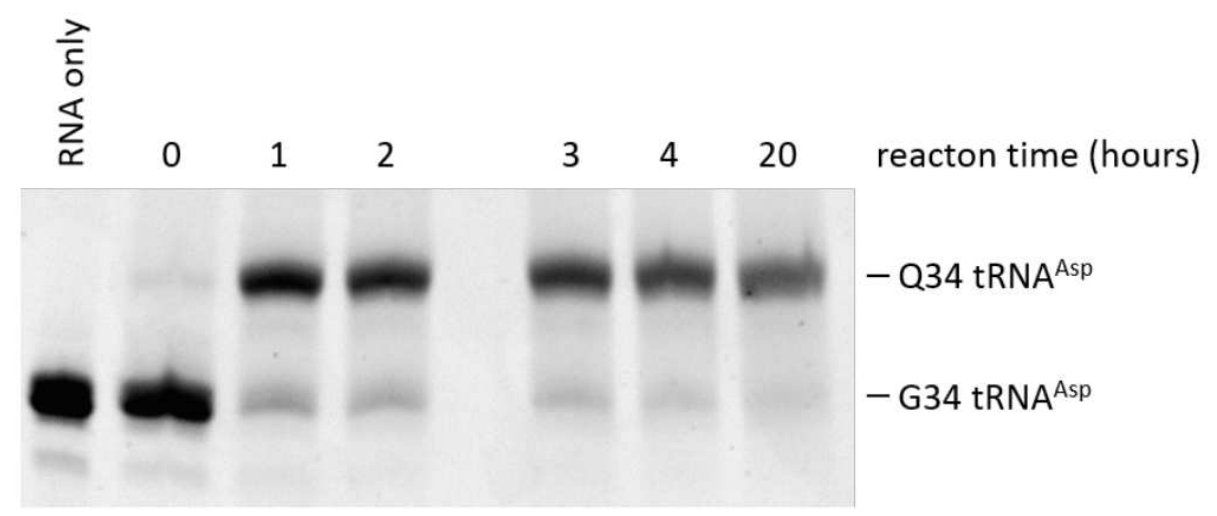

Figure 2.3. Electrophoresis of guanine to queuine transglycosylation in tRNA $A^{\mathrm{Asp}}$ by TGT. Samples were taken from the reaction mixture at the indicated time after addition of TGT. Information provided by S. Johansson. ${ }^{118}$

The methyltransferase assay was performed with an assay kit developed by Dorgan et al. Therein, methyltransferase co-product SAH gets degraded by an enzymatic cascade, finally producing ureate and hydrogen peroxide. The latter oxidizes 3,5-dichloro-2-hydroxybenzenesulfonic acid, resulting in an increased absorbance at $515 \mathrm{~nm}$ which can be monitored via UV-Vis spectroscopy and is directly related to the enzyme activity. The measurements were performed independently with increasing tRNA ${ }^{\text {Asp }}$ and Q34tRNA ${ }^{\text {Asp }}$ concentration respectively. The results are displayed in figure 2.4.

Comparing the efficiency assays of spDnmt2 with G34tRNA ${ }^{\text {Asp }}$ and Q34tRNA ${ }^{\text {Asp }}$ an increased $V_{\max }$ value and a decreased $K_{0.5}$ value were observed for Q34tRNA ${ }^{\text {Asp }}$. $V_{\text {max }}$ was increased from $1.41 \pm 0.01 \mathrm{~min}^{-1}$ to $2.59 \pm 0.11 \mathrm{~min}^{-1}$, while $K_{0.5}$ was decreased from $15.59 \pm 0.29 \mu \mathrm{M}$ to $6.88 \pm 0.58 \mu \mathrm{M}$. These results suggest that gua- 


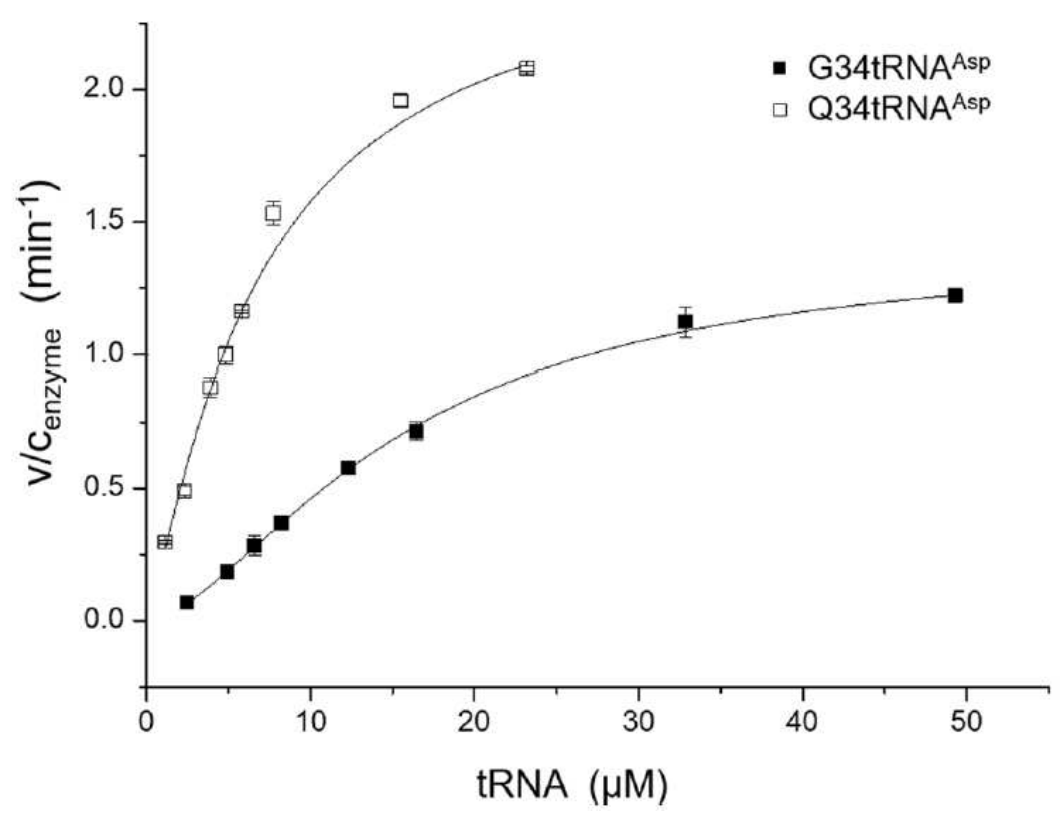

Figure 2.4. Methyltransferase activity assay.

The activity is plotted as substrate conversion per TAT concentration against G34tRNA ${ }^{\text {Asp }}$ and Q34tRNA ${ }^{\text {Asp }}$ concentration respectively. Error bars representing standard deviation. Fitting were performed applying the Hill equation with a free Hill coefficient.

Information provided by S. Johansson. ${ }^{[18]}$

nine/queuine exchange at position 34 in tRNA ${ }^{\text {Asp }}$ directly increase the catalytic efficiency of $s p D n m t 2$. Moreover, spDnmt2 only poorly follows Michaelis-Menten kinetics, but is better described by the Hill equation, with an observed Hill coefficient $n=1.63 \pm 0.02$ and $n=1.19 \pm 0.07$ for G34tRNA ${ }^{\text {Asp }}$ and Q34tRNA ${ }^{\text {Asp }}$ respectively (figure 2.5).

These data suggest the existence of cooperativity for $s p D n m t 2$, although there are no reports that the enzyme is active as a dimer or multimer. However, in some monomeric enzymes some kind of cooperativity was observed, which might be due to several conformations the enzyme takes on while forming the enzyme substrate complex. ${ }^{[120]}$

The affinity assay was done by fluorescence anisotropy measurement using a Fluoromax III flourimeter (HORIBA JOBIN YVON). G34tRNA ${ }^{\text {Asp }}$ and Q34tRNA ${ }^{\text {Asp }}$ were fluorescence labeled with $1 \mathrm{~mm}$ fluorescein-5-thiosemicarbazide in $100 \mathrm{~mm} \mathrm{NaOAc}$ buffer at pH 5.5. Binding of the fluorescent tRNA's to $s p D n m t 2$ was measured by florescence anisotropy with increasing $s p D n m t 2$ concentration (figure 2.6).

The data show a decrease of $\mathrm{K}_{\mathrm{d}}$ from $0.96 \pm 0.05 \mu \mathrm{M}$ for the binding of G34tRNA ${ }^{\text {Asp }}$ 

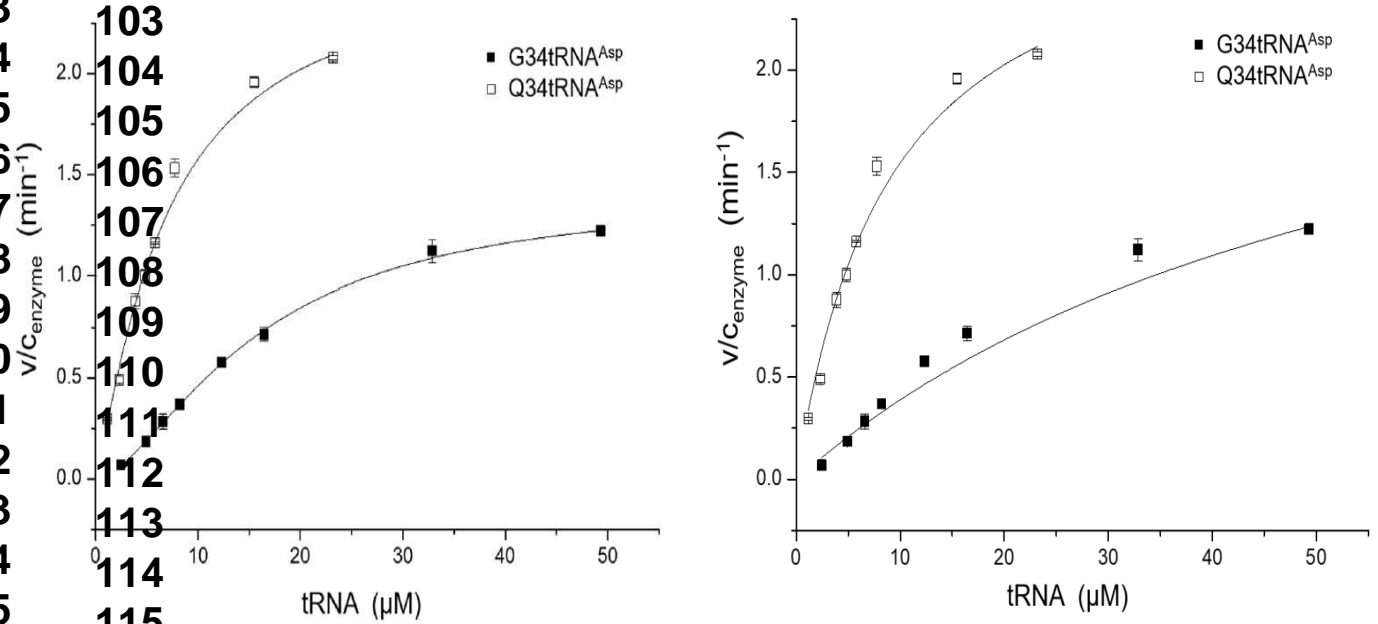

Figure 2.5. Comparison of fitting with the Hill equation (left) and Michaelis-Menten equation (right). Information provided by S. Johansson. $\frac{118}{118}$

to $0.67 \pm 0.003 \mu \mathrm{M}$ for the binding of Q34tRNA ${ }^{\text {Asp }}$. These results are in accordance to the data obtained from the activity assay, showing 1.4 fold stronger binding of queuine incorporated tRNA ${ }^{\text {Asp }}$. However, the increase in binding affinity of Q34tRNA ${ }^{\text {Asp }}$ is not strong enough to explain the observed activity for Q34tRNA ${ }^{\text {Asp }}$ completely.

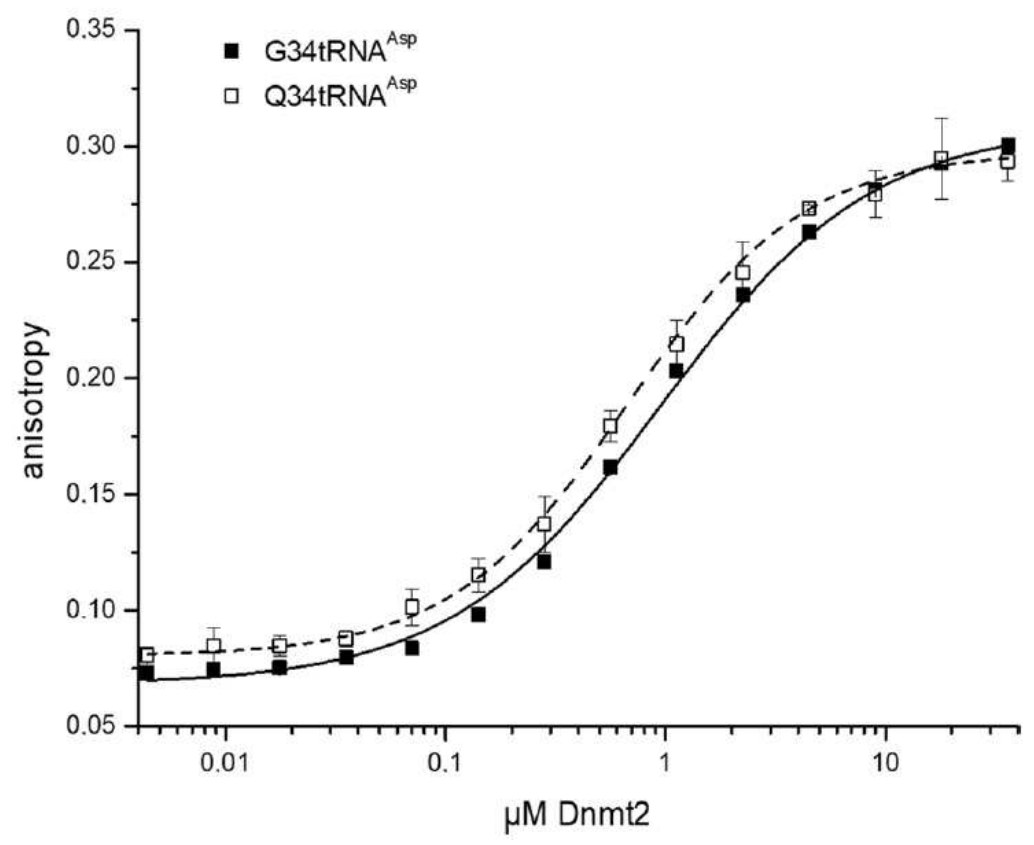

Figure 2.6. Fluorescence anisotropy measurement as binding assay.

Information provided by S. Johansson. $\frac{[118}{}$ 


\subsection{Summary}

Dnmt2 is a family of RNA methyltransferases, which methylate cytosine 38 in tRNA ${ }^{\text {Asp }}$ at $\mathrm{C5}$. In vivo studies suggest that the methylation is stimulated by incorporation of the micronutrient queuosine. However, other factors can not be excluded. Establishing of an in vitro method could proof the dependency of Dnmt2 but require significant amounts of the rare nucleobase queuine.

Although some syntheses for queuine exist, they bear significant disadvantages like usage of toxic reagents, difficult handling and stereoselective reactions. To improve the queuine synthesis a new synthetic route was developed (scheme 2.27). Starting from inexpensive $\alpha$-methyl-galactopyranoside, queuine was obtained in 10 steps with an overall yield of $8 \%$. Key steps in this new synthetic route are zinc mediated reductive fragmentation of methyl-6-iodo-galactopyranoside, Tebbe olefination and ruthenium catalyzed ring closing metathesis. In the process, the stereochemical arrangement of the galactopyranoside was conserved making stereoselective reactions expandable.

The synthesized queuine was used in an in vitro essay developed by Dorgan et al., proving that queuosine directly stimulates Dnmt2 catalyzed methylation (figure 2.4). Theese data are supported by fluorescence anisotropy measurement, showing increased binding affinity of queuosine containing tRNA ${ }^{\text {Asp }}$ to Dnmt2 compared to tRNA $^{\text {Asp }}$ without queuosine (figure 2.6). 


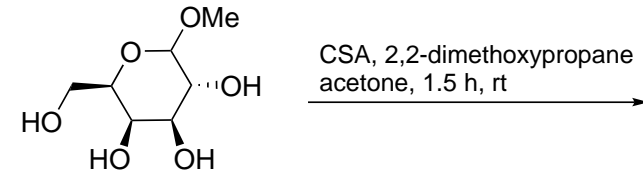

137<smiles>COC1OC(CO)C2OC3(C)OC1C2O3</smiles>

138

12 TPP, imidazole $63 \%$

THF, $4 \mathrm{~h}, 50^{\circ} \mathrm{C} \quad$ over two steps

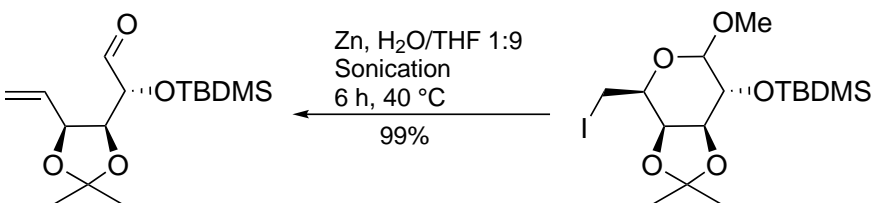

141

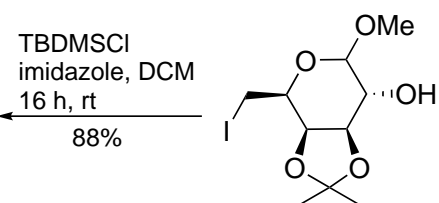

139

$67 \% \downarrow \begin{aligned} & \text { Tebbe Reagent } \\ & \text { THF, } 15 \text { min, } 0{ }^{\circ} \mathrm{C}\end{aligned}$

$=\sum_{>0}^{1 / \cdot \text { OTBDMs }}$

142

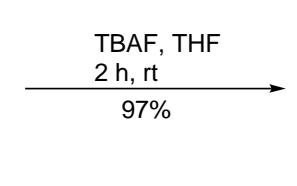<smiles>CC1(C)O[C@H]2C=C[C@H](NCc3c[nH]c4nc(N)[nH]c(=O)c34)[C@H]2O1</smiles>

144<smiles>C=CC(O)C1OC2(C)OC1O2</smiles>

143

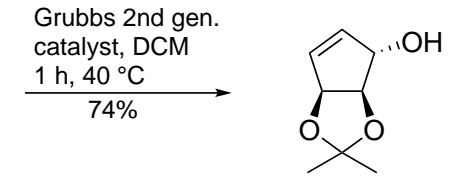

130

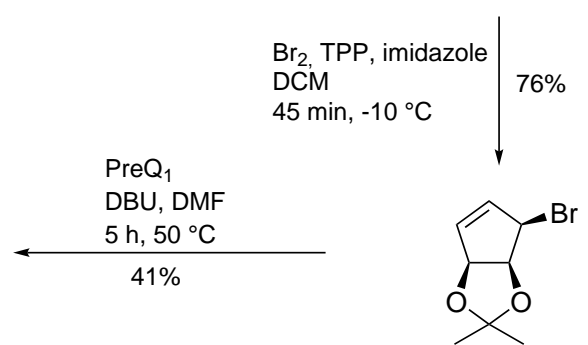

122<smiles>Nc1nc2[nH]cc(CNC3C=C[C@@H](O)[C@H]3O)c2c(=O)[nH]1</smiles>

Scheme 2.27. Complete scheme of queuine synthesis. 



\section{Experimental section}

\subsection{General Equipment and Methods}

\section{General Reagent Information}

All reagents, including anhydrous solvents, were purchased from commercial suppliers (ABCR, Acros-Organics, Alfa Aesar, Fisher Scientific, Merck, Roth, SigmaAldrich, $T C l$ and $V W R$ ) without further purification. Technical solvents were distilled prior to use. Ultrapure water was obtained via purification of demineralized water by an arium mini water purification system by Sartorius.

\section{Moisture sensitive reactions}

Moisture sensitive reactions were performed under an argon (> 99.996\%) atmosphere. The gas was dried over $\mathrm{P}_{2} \mathrm{O}_{5}$ and $\mathrm{KOH}$ prior to use. Glassware was used after heating in a vacuum und subsequent filling with inert gas. This procedure was repeated three times.

\section{Chromatography}

Reactions were monitored by thin-layer chromatography (TLC) carried out on aluminum backed plates of silica gel $60 \mathrm{~F}_{254}$ (layer thickness: $0.20 \mathrm{~mm}$ ) from Merck. Spots were detected by fluorescence quenching at $254 \mathrm{~nm}$ or dying with $\mathrm{KMnO}_{4}$ solution. Purification by flash chromatography was conducted using Merck Silica Gel 60 (particle size: 40-62 $\mu \mathrm{m}$ ). 


\section{Experimental section}

\section{High Performance Liquid Chromatography (HPLC)}

HPLC was performed on the HPLC-system ÄKTA basic 10 by Amersham Pharmacia Biotech equipped with a $P$-900 pump system and a UV-900 UV detection module. It was used an anion exchange column typ Spherisorb SAX OBD 80A 5 $250 \mathrm{~mm} \times 19 \mathrm{~mm}$ from waters with a particle size of $5 \mu \mathrm{m}$. Purification was done at a flow of $10 \mathrm{~mL} / \mathrm{min}$ with a linear gradient of eluent $A$ (ultrapure water) and eluent $B$ $(0.5 \mathrm{M}$ TEAA-buffer at $\mathrm{pH}=7$ ). Nucleotides were detected at $230 \mathrm{~nm}, 260 \mathrm{~nm}$ and $300 \mathrm{~nm}$ if not noted otherwise.

\section{Freeze-Drying}

Nucleotide solutions in TEAA buffer were freezed with liquid nitrogen and the buffer was sublimated under reduced pressure $(<1$ mbar) using an Alpha-2-4-LD plus freeze-dryer from Christ.

\subsection{Characterization}

\section{Nuclear Magnetic Resonance (NMR)}

NMR spectra were recorded at Varian instruments (Mercury 300, Mercury VX 300 , Unity 300, VNMRS-300, Inova-500) and Bruker instruments (Avance III 400, Avance III HD 400) using chloroform- $d$, DMSO- $\mathrm{d}_{6}$, methanol- $d_{4}$ or $\mathrm{D}_{2} \mathrm{O}$ as the internal standard at $298 \mathrm{~K}$. Chemical shifts are quoted in ppm and coupling constants in $\mathrm{Hz}$. Multiplicities are abbreviated as follows: $\mathrm{s}=$ singlet, $\mathrm{s}_{\mathrm{br}}=$ broad singlet, $\mathrm{d}=$ doublet, $\mathrm{dd}=$ doublet of doublets, $\mathrm{t}=$ triplet, $\mathrm{dt}=$ doublet of triplets, sept $=$ septet, $\mathrm{m}=$ multiplet. ${ }^{13} \mathrm{C}-\mathrm{NMR}$ experiments were recorded with proton decoupling.

\section{Mass Spectrometry}

Mass spectrometry was performed using electron spray ionization (ESI). High resolution ESI spectra were obtained using microTOF-Q II or maXis ESI-QTOF-MS instrument from Bruker. The values are given as $\mathrm{m} / \mathrm{z}$ relation. 


\subsection{X-ray diffraction data collection and processing}

\section{Synchrotron X-ray diffraction}

The datasets were measured under cryogenic conditions at the Deutsches Elektronen-Synchrotron (DESY) in Hamburg at the PETRA III storage ring beamlines P13 and P14. For data collection, the protein crystals were exposed to maximal 1 MGy.

\section{Data processing and image generation}

3D crystal structures were processed using COOT, Jligand and SHELXL. Structure images were generated using PyMol. 


\subsection{Synthesis of orotidine analogues}

\subsubsection{2',3'-O-Isopropylidene-uridine (11)}

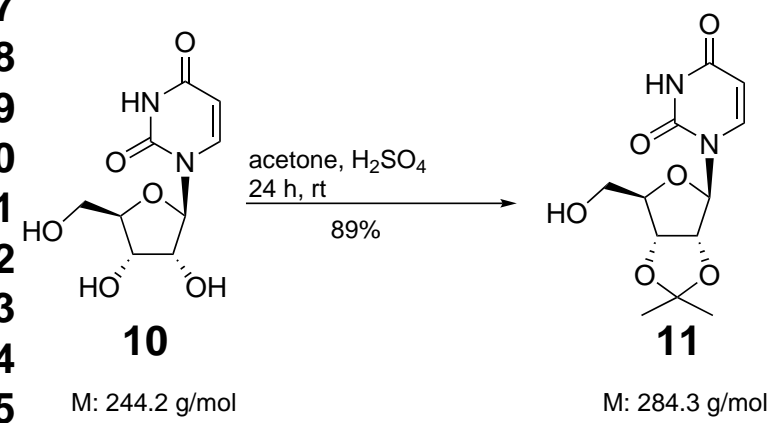

To a stirred suspension of uridine (10) $(6.0 \mathrm{~g}, 24.5 \mathrm{mmol}, 1.0 \mathrm{eq}$.) in acetone (360 $\mathrm{mL}) \mathrm{H}_{2} \mathrm{SO}_{4}(1.5 \mathrm{~mL})$ was added and the resulting solution was stirred at room temperature for $24 \mathrm{~h}$. The mixture was quenched with $\mathrm{NEt}_{3}(4.0 \mathrm{~mL})$ and the solvent was evaporated in vacuo. The crude product was purified by column chromatography on silica gel using DCM/MeOH 9:1. The desired product (11) $(6.19 \mathrm{~g}, 21.8 \mathrm{mmol}$, $89 \%$ ) was obtained as a white solid.

${ }^{1} \mathrm{H}-\mathrm{NMR}\left(300 \mathrm{MHz}, \mathrm{DMSO}-\mathrm{d}_{6}\right): \delta=11.38\left(\mathrm{~s}_{\mathrm{br}}, 1 \mathrm{H}, \mathrm{NH}\right), 7.78(\mathrm{~d}, J=8.1 \mathrm{~Hz}, 2 \mathrm{H}$, $\mathrm{H}-6), 5.82$ (d, J = 2.7 Hz, $\left.1 \mathrm{H}, \mathrm{H}-1^{\prime}\right), 5.56$ (d, J = 8.1 Hz, $\left.1 \mathrm{H}, \mathrm{H}-5\right), 4.89$ (dd, $J=6.3$, $2.7 \mathrm{~Hz}, 1 \mathrm{H}, \mathrm{H}-2$ '), 4.74 (dd, J = 6.3, 3.6 Hz, $\left.1 \mathrm{H}, \mathrm{H}-3^{\prime}\right), 4.08-4.04$ (m, $1 \mathrm{H}, \mathrm{H}-4^{\prime}$ ), 3.63-3.50 (m, $2 \mathrm{H}, \mathrm{H}-5$ '), 1.48 (s, $3 \mathrm{H}, \mathrm{CH}_{3}$ ), 1.28 (s, $\left.3 \mathrm{H}, \mathrm{CH}_{3}\right)$ ppm.

${ }^{13}$ C-NMR (125 MHz, DMSO-d 6 ): $\delta=163.2$ (C-4), 150.4 (C-2), 141.7 (C-6), 113.0 $\left(\mathrm{C}\left(\mathrm{CH}_{3}\right)\right), 101.8$ (C-5), 91.2 (C-1'), 86.5 (C-4'), 83.7 (C-2'), 80.5 (C-3'), 61.3 (C-5'), $27.1\left(\mathrm{CH}_{3}\right), 25.2\left(\mathrm{CH}_{3}\right)$ ppm.

MS (ESI): m/z (\%) = $307.1(100)[\mathrm{M}+\mathrm{Na}]^{+}, 283.1(100)[\mathrm{M}-\mathrm{H}]^{-}$.

HRMS: $m / z$ calc. for $\mathrm{C}_{12} \mathrm{H}_{16} \mathrm{~N}_{2} \mathrm{O}_{6} \mathrm{Na}[\mathrm{M}+\mathrm{Na}]^{+}: 307.0901$, found: 307.0902 . 


\subsubsection{5'-O-Tertbutyldimethylsilyl-2',3'-O-isopropylidene- uridine (12)}

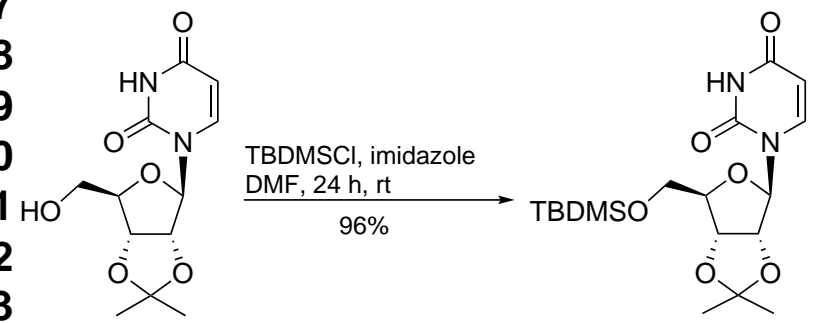

11

12

$\mathrm{M}: 284.3 \mathrm{~g} / \mathrm{mol}$

M: $398.5 \mathrm{~g} / \mathrm{mol}$

Under an argon atmosphere, 11 (6.19 g, $21.8 \mathrm{mmol}, 1.0$ eq.), imidazole (3.7 g, $54.5 \mathrm{mmol}, 2.5$ eq.) and TBDMSCl (4.92 g, $32.7 \mathrm{mmol}, 1.5 \mathrm{eq}$.) were dissolved in dry DMF $(50 \mathrm{~mL})$ and the solution was stirred at room temperature for $24 \mathrm{~h}$. The solvent was evaporated in vacuo and the crude product was purified by column chromatography on silica gel using $\mathrm{DCM} / \mathrm{MeOH}$ 95:5. The desired product (12) $(8.3 \mathrm{~g}$, $20.9 \mathrm{mmol}, 96 \%$ ) was obtained as a white solid.

${ }^{1} \mathrm{H}-N M R\left(300 \mathrm{MHz}\right.$, DMSO-d 6 ): $\delta=11.33\left(\mathrm{~s}_{\mathrm{br}}, 1 \mathrm{H}, \mathrm{NH}\right), 7.68(\mathrm{~d}, J=8.1 \mathrm{~Hz}$, $2 \mathrm{H}, \mathrm{H}-6$ ), 5.80 (d, J = 2.3 Hz, $1 \mathrm{H}, \mathrm{H}-1$ '), 5.57 (d, J = 8.1 Hz, $1 \mathrm{H}, \mathrm{H}-5$ ), 4.90 (dd, $J=6.3,2.3 \mathrm{~Hz}, 1 \mathrm{H}, \mathrm{H}-2$ '), 4.71 (dd, $J=6.3,3.6 \mathrm{~Hz}, 1 \mathrm{H}, \mathrm{H}-3$ '), 4.13-4.09 (m, $1 \mathrm{H}$, $\mathrm{H}-4^{\prime}$ ), 3.83-3.71 (m, $\left.2 \mathrm{H}, \mathrm{H}-5^{\prime}\right), 1.48$ (s, $3 \mathrm{H}, \mathrm{CH}_{3}$ ), 1.29 (s, $3 \mathrm{H}, \mathrm{CH}_{3}$ ), 0.86 (s, $9 \mathrm{H}$, $\left.\mathrm{SiC}\left(\mathrm{CH}_{3}\right)_{3}\right), 0.04\left(\mathrm{~s}, 6 \mathrm{H}, \mathrm{Si}\left(\mathrm{CH}_{3}\right)_{2}\right)$ ppm.

${ }^{13}$ C-NMR (125 MHz, DMSO-d ${ }_{6}$ ): $\delta=163.9$ (C-4), 150.0 (C-2), 141.6 (C-6), 112.8 $\left(\mathrm{C}\left(\mathrm{CH}_{3}\right)\right), 101.4(\mathrm{C}-5), 91.6\left(\mathrm{C}-1\right.$ ') $, 86.5\left(\mathrm{C}-4^{\prime}\right), 83.9$ (C-2'), 80.3 (C-3'), 63.1 (C-5'), $27.0\left(\mathrm{CH}_{3}\right), 25.7\left(\mathrm{SiC}\left(\mathrm{CH}_{3}\right)_{3}\right), 25.2\left(\mathrm{CH}_{3}\right), 17.9\left(\mathrm{SiC}\left(\mathrm{CH}_{3}\right)_{3}\right), 5.5 \mathrm{Si}\left(\mathrm{CH}_{3}\right)_{2}$ ppm.

MS (ESI): m/z (\%) = $399.2(75)[\mathrm{M}+\mathrm{H}]^{+}, 421.2(100)[\mathrm{M}+\mathrm{Na}]^{+}, 397.2(100)[\mathrm{M}-\mathrm{H}]^{-}$.

HRMS: $m / z$ calc. for $\mathrm{C}_{18} \mathrm{H}_{30} \mathrm{~N}_{2} \mathrm{O}_{6} \mathrm{SiNa}[\mathrm{M}+\mathrm{Na}]^{+}:$:21.1765, found 421.1764. 


\subsubsection{5'-O-Tertbutyldimethylsilyl-2',3'-O-isopropylidene- orotidine (13)}

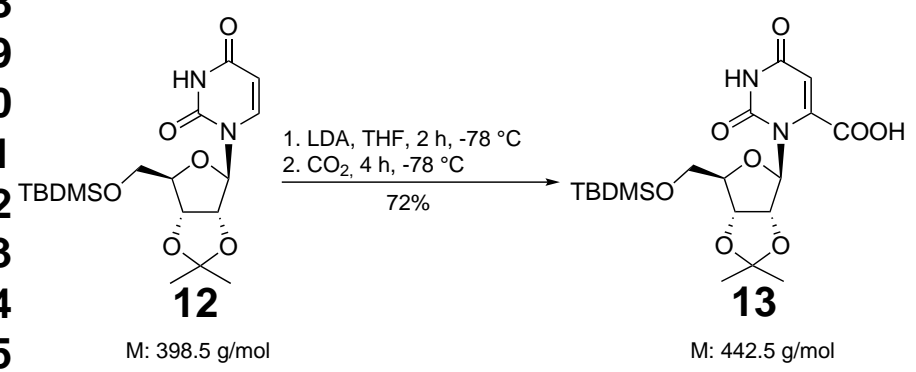

Under an argon atmosphere, $12(1.0 \mathrm{~g}, 2.5 \mathrm{mmol}, 1.0 \mathrm{eq}$.) was dissolved in dry THF (15 mL) and the solution was cooled to $-78{ }^{\circ} \mathrm{C}$. LDA solution ( $2 \mathrm{M}$ in THF, $3.13 \mathrm{~mL}, 6.25 \mathrm{mmol}, 2.5 \mathrm{eq}$.) was added dropwise. The resulting brownish solution was stirred at $-78{ }^{\circ} \mathrm{C}$ for $30 \mathrm{~min}$ and subsequently $\mathrm{CO}_{2}$ was bubbled trough the solution for $4 \mathrm{~h}$. The mixture was quenched by the addition of $\mathrm{HOAc}(1 \mathrm{~mL})$ and the solvent was evaporated in vacuo. The crude product was purified by column chromatography on silica gel using $\mathrm{DCM} / \mathrm{MeOH} 4: 1$. The desired product (13) $(811 \mathrm{mg}$, $1.8 \mathrm{mmol}, 72 \%$ ) was obtained as a white solid.

${ }^{1}$ H-NMR $\left(300 \mathrm{MHz}\right.$, DMSO-d $\left.\mathrm{d}_{6}\right): \delta=6.04(\mathrm{~d}, J=1.1 \mathrm{~Hz}, 1 \mathrm{H}, \mathrm{H}-1$ '), $5.35(\mathrm{~s}, 1 \mathrm{H}$, H-5), 5.11 (dd, $J=6.4,1.1 \mathrm{~Hz}, 1 \mathrm{H}, \mathrm{H}-2$ '), 4.70 (dd, $J=6.4,4.3 \mathrm{~Hz}, 1 \mathrm{H}, \mathrm{H}-3^{\prime}$ ), 3.93-3.85 (m, $\left.1 \mathrm{H}, \mathrm{H}-4^{\prime}\right), 3.78-3.66\left(\mathrm{~m}, 2 \mathrm{H}, \mathrm{H}-5^{\prime}\right), 1.42\left(\mathrm{~s}, 3 \mathrm{H}, \mathrm{CH}_{3}\right), 1.26(\mathrm{~s}, 3 \mathrm{H}$, $\left.\mathrm{CH}_{3}\right), 0.85\left(\mathrm{~s}, 9 \mathrm{H}, \mathrm{SiC}\left(\mathrm{CH}_{3}\right)_{3}\right), 0.02\left(\mathrm{~s}, 3 \mathrm{H}, \mathrm{Si}\left(\mathrm{CH}_{3}\right)\right), 0.01\left(\mathrm{~s}, 3 \mathrm{H}, \mathrm{Si}\left(\mathrm{CH}_{3}\right)\right)$ ppm.

${ }^{13}$ C-NMR (125 MHz, DMSO-d 6 ): $\delta=163.4$ (C-4), $163.1(\mathrm{COOH}), 156.3$ (C-2),

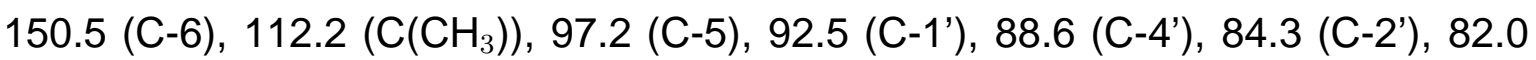
(C-3'), $63.8\left(\mathrm{C}-5^{\prime}\right), 27.1\left(\mathrm{CH}_{3}\right), 25.8\left(\mathrm{SiC}\left(\mathrm{CH}_{3}\right)_{3}\right), 25.2\left(\mathrm{CH}_{3}\right), 18.0\left(\mathrm{SiC}\left(\mathrm{CH}_{3}\right)_{3}\right),-5.2$ $\mathrm{Si}\left(\mathrm{CH}_{3}\right),-5.3 \mathrm{Si}\left(\mathrm{CH}_{3}\right) \mathrm{ppm}$.

MS (ESI): $\mathbf{m} / \mathbf{z}(\%)=441.2(100)[M-H]^{-}$.

HRMS: $m / z$ calc. for $\mathrm{C}_{19} \mathrm{H}_{30} \mathrm{~N}_{2} \mathrm{O}_{8} \mathrm{Si}[\mathrm{M}-\mathrm{H}]^{-}:$441.1699, found: 441.1693 . 


\subsubsection{Orotidine (14)}

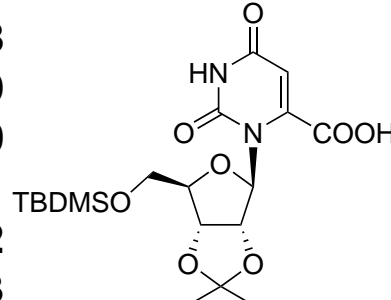

13

M: $442.5 \mathrm{~g} / \mathrm{mol}$

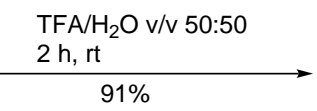

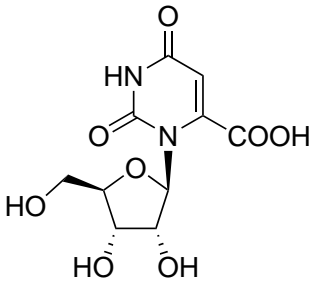

14

$\mathrm{M}: 288.2 \mathrm{~g} / \mathrm{mol}$

13 (811 mg, $1.8 \mathrm{mmol}, 1.0$ eq.) was dissolved in $\mathrm{TFA} / \mathrm{H}_{2} \mathrm{O}(50: 50 \mathrm{v} / \mathrm{v}, 15 \mathrm{~mL})$ and the solution was stirred at ambient temperature for $30 \mathrm{~min}$. The solvents were evaporated in vacuo. The residue was dissolved in water $(5 \mathrm{~mL})$ and washed with EtOAc $(3 \times 5 \mathrm{~mL})$. The solvent was evaporated in vacuo. The desired product (14) (472 mg, $1.64 \mathrm{mmol}, 91 \%$ ) was obtained as a white solid.

$\left.{ }^{1} \mathbf{H}-N M R(300 \mathrm{MHz}, \text { DMSO-d })_{6}\right): \delta=11.09(\mathrm{~s}, 1 \mathrm{H}, \mathrm{COOH}), 8.48\left(\mathrm{~s}_{\mathrm{br}}, 1 \mathrm{H}, \mathrm{NH}\right)$, $5.58\left(\mathrm{~d}, J=3.8 \mathrm{~Hz}, 1 \mathrm{H}, \mathrm{H}-1^{\prime}\right), 5.36(\mathrm{~s}, 1 \mathrm{H}, \mathrm{H}-5), 4.49$ (dd, $J=6.1,3.8 \mathrm{~Hz}, 1 \mathrm{H}$, H-2'), 4.08 (t, J = 6.1 Hz, 1 H, H-3'), 3.70-3.39 (m, 3 H, H-4', H-5') ppm.

MS (ESI): $\mathbf{m} / \mathbf{z}(\%)=287.1(100)[\mathrm{M}-\mathrm{H}]^{-}$.

HRMS: $m / z$ calc. for $\mathrm{C}_{10} \mathrm{H}_{12} \mathrm{~N}_{2} \mathrm{O}_{8}[\mathrm{M}-\mathrm{H}]^{-}:$: 287.0521, found: 287.0524 . 


\subsubsection{Orotidine-5'-monophosphate (1)}

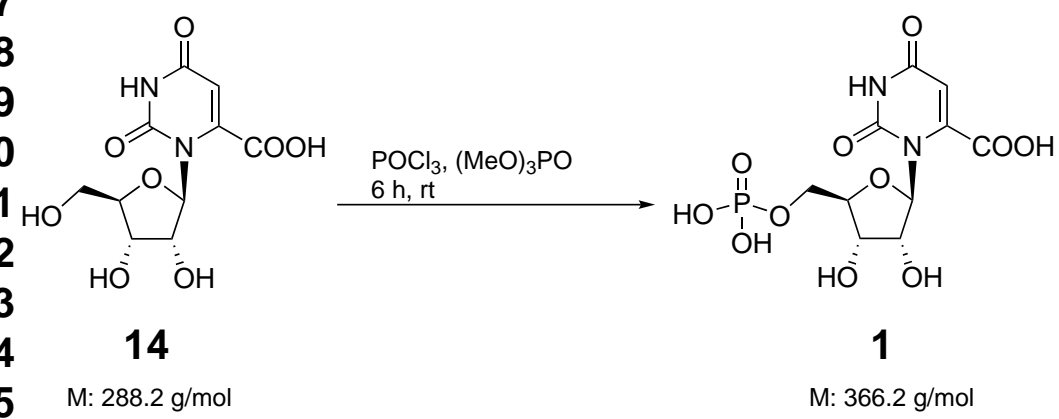

Under an argon atmosphere, orotidine (14) $(500 \mathrm{mg}, 1.73 \mathrm{mmol}, 1.0$ eq.) was suspended in dry trimethylphosphate $(5 \mathrm{~mL})$ and was cooled to $0{ }^{\circ} \mathrm{C}$. Phosphoroxychloride ( $316 \mu \mathrm{L}, 531 \mathrm{mg} 3.47 \mathrm{mmol}, 2.0 \mathrm{eq}$.) was added dropwise and the resulting solution was stirred at $0{ }^{\circ} \mathrm{C}$ for $6 \mathrm{~h}$. The mixture was quenched by the addition of water $(1 \mathrm{~mL})$ and the solvent was evaporated in vacuo. The crude product was purified by ion exchange HPLC using a linear gradient of TEAA in water at $\mathrm{pH}$. The product (1) was obtained as the triethylammonium salt.

${ }^{1} \mathrm{H}-\mathrm{NMR}\left(300 \mathrm{MHz}, \mathrm{D}_{2} \mathrm{O}\right): \delta=5.87(\mathrm{~s}, 1 \mathrm{H}, \mathrm{H}-5), 5.65(\mathrm{~d}, J=3.2 \mathrm{~Hz}, 1 \mathrm{H}, \mathrm{H}-1$ '), 4.88 (dd, $J=6.5,3.2 \mathrm{~Hz}, 1 \mathrm{H}, \mathrm{H}-2^{\prime}$ ), 4.52 (t, $J=6.5 \mathrm{~Hz}, 1 \mathrm{H}, \mathrm{H}-3$ '), 4.30-4.08 (m, $\left.3 \mathrm{H}, \mathrm{H}-4^{\prime}, \mathrm{H}-5^{\prime}\right)$ ppm.

${ }^{13}$ C-NMR $\left(125 \mathrm{MHz}, \mathrm{D}_{2} \mathrm{O}\right): \delta=167.1(\mathrm{C}-4), 166.2(\mathrm{COOH}), 155.3(\mathrm{C}-2), 151.1$ (C-6), 98.7 (C-5), 95.0 (C-1'), 82.5 (C-4'), 71.9 (C-2'), 69.5 (C-3'), 64.6 (C-5') ppm.

${ }^{31}$ P-NMR $\left(25 \mathrm{MHz}, \mathrm{D}_{2} \mathrm{O}\right): \delta=0.46 \mathrm{ppm}$.

MS (ESI): $\mathbf{m} / \mathbf{z}(\%)=367.0(100)[\mathrm{M}-\mathrm{H}]^{-}$.

HRMS: $m / z$ calc. for $\mathrm{C}_{10} \mathrm{H}_{13} \mathrm{~N}_{2} \mathrm{O}_{11} \mathrm{P}[\mathrm{M}-\mathrm{H}]^{-}: 367.0184$, found: 367.0180 . 


\subsubsection{2,4,6-tris-trimethylsilyloxy-pyrimidine (16)}

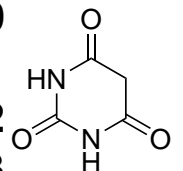

15

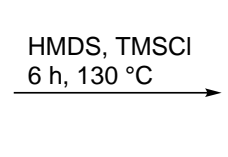

M: $128.1 \mathrm{~g} / \mathrm{mol}$

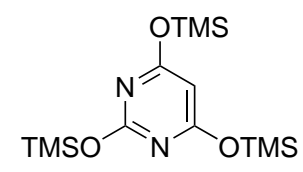

16

$\mathrm{M}: 344.6 \mathrm{~g} / \mathrm{mol}$

Barbituric acid (15) (1.28 g, 10.0 mmol, 1.0 eq.) was suspended in HMDS (30 mL) and TMSCI ( $1 \mathrm{~mL}$ ) was added. The reaction mixture was stirred for $6 \mathrm{~h}$ under reflux. The resulting solution was cooled to ambient temperature and the solvent was evaporated in vacuo. The crude residue was used in the next step without further purification. 


\subsubsection{2',3',5'-Tri-O-benzoyl-6-hydroxyuridine (18)}
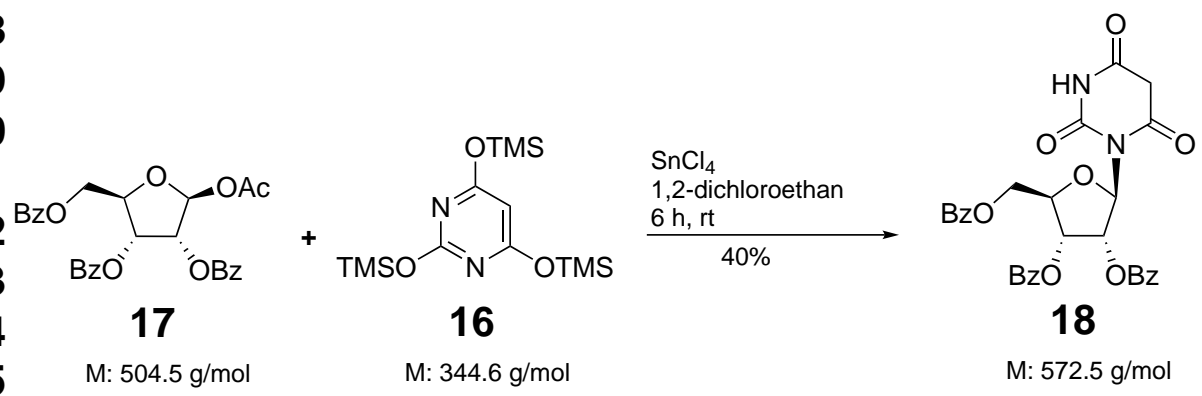

Under an argon atmosphere, 16 (3,45 g, $10.0 \mathrm{mmol}, 1.1 \mathrm{eq}$.) was dissolved in 1,2dichloroethan $(40 \mathrm{~mL})$ and $\mathrm{SnCl}_{4}(1.3 \mathrm{~mL}, 2.86 \mathrm{~g}, 11 \mathrm{mmol}, 1.25 \mathrm{eq}$.) was added. 1-O-Acetyl-2,3,5-tri-O-benzoyl- $\beta$-D-ribofuranose (17) $(4.4 \mathrm{~g}, 8.8 \mathrm{mmol}, 1.0 \mathrm{eq}$.) dissolved in 1,2-dichloroethan $(20 \mathrm{~mL})$ was added dropwise. The resulting solution was stirred for $6 \mathrm{~h}$ at ambient temperature and poured into saturated $\mathrm{NaHCO}_{3}$-solution $(100 \mathrm{~mL})$. The resulting suspension was filtered through a plug of silica gel and the layers were separated. The organic layer was dried over $\mathrm{MgSO}_{4}$ and the solvent was evaporated in vacuo. The crude product was purified by column chromatography on silica gel using DCM/MeOH 9:1. The desired product (18) $(2.0 \mathrm{~g}, 3.5 \mathrm{mmol}, 40 \%)$ was obtained as a yellowish solid.

${ }^{1} \mathrm{H}-\mathrm{NMR}\left(300 \mathrm{MHz}\right.$, DMSO-d $\left.\mathrm{d}_{6}\right): \delta=11.49\left(\mathrm{~s}_{\mathrm{br}}, 1 \mathrm{H}, \mathrm{NH}\right), 8.01-7.27(\mathrm{~m}, 15 \mathrm{H}, \mathrm{Ph}-$ H), 6.49 (d, J = 1.9 Hz, $\left.1 \mathrm{H}, \mathrm{H}^{\prime} \mathbf{1}^{\prime}\right), 6.15-6.05$ (m, $\left.2 \mathrm{H}, \mathrm{H}-2^{\prime}, \mathrm{H}-3^{\prime}\right), 4.72-4.48(\mathrm{~m}, 3 \mathrm{H}$, $\left.\mathrm{H}-4^{\prime}, \mathrm{H}-5^{\prime}\right), 3.72(\mathrm{~s}, 2 \mathrm{H}, \mathrm{H}-5) \mathrm{ppm}$.

${ }^{13}$ C-NMR (125 MHz, DMSO-d $\mathrm{d}_{6}$ ): $\delta=165.2$ (C-6), 164.5 (C-4), 164.3 (COOPh), 150.7 (C-2), 133.6, 133.4, 133.1, 129.1, 129.0, 128.5, 128.4, 128.2 (C-Ph), 85.1 (C-1'), 77.8 (C-4'), 73.8 (C-2'), 70.1 (C-3'), 63.4 (C-5'), 56.2 (C-5) ppm.

MS (ESI): m/z $(\%)=573.2(28)[\mathrm{M}+\mathrm{H}]^{+}, 595.1(100)[\mathrm{M}+\mathrm{Na}]^{+}, 571.1(100)[\mathrm{M}-\mathrm{H}]^{-}$.

HRMS: $m / z$ calc. for $\mathrm{C}_{30} \mathrm{H}_{24} \mathrm{~N}_{2} \mathrm{O}_{10} \mathrm{Na}[\mathrm{M}+\mathrm{Na}]^{+}:$595.1323, found 595.1298. 


\subsubsection{6-Hydroxyuridine (19)}

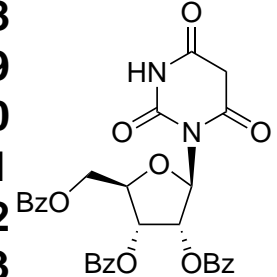

18

M: $572.5 \mathrm{~g} / \mathrm{mol}$

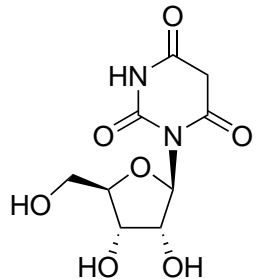

19

M: $260.0 \mathrm{~g} / \mathrm{mol}$

$18(2.0 \mathrm{~g}, 3.5 \mathrm{mmol}, 1.0$ eq.) was dissolved in methanol $(40 \mathrm{~mL})$ and $\mathrm{NaOMe}$ (500 mg) was added. The solution was stirred for $20 \mathrm{~h}$ at ambient temperature. It was neutralized with DOWEX $50 \mathrm{~W}$ ion exchange resin. After filtration the solvent was removed in vacuo and the residue was redissolved in water $(20 \mathrm{~mL})$. The aqueous solution was washed with $\mathrm{Et}_{2} \mathrm{O}(3 \times 30 \mathrm{~mL})$. Removal of the solvent in vacuo yielded the product (19) $(720 \mathrm{mg}, 2.8 \mathrm{mmol}, 80 \%)$ as a yellow solid.

${ }^{1}$ H-NMR $\left(300 \mathrm{MHz}\right.$, DMSO-d $\left.\mathrm{d}_{6}\right): \delta=11.35\left(\mathrm{~s}_{\mathrm{br}}, 1 \mathrm{H}, \mathrm{NH}\right), 5.88(\mathrm{~d}, J=3.2 \mathrm{~Hz}, 1 \mathrm{H}$, $\left.\mathrm{H}-1^{\prime}\right)$, 5.12-5.09 (m, $\left.2 \mathrm{H}, \mathrm{H}-2^{\prime}, \mathrm{H}-3^{\prime}\right), 4.05-3.98$ ( $\left.\mathrm{m}, 3 \mathrm{H}, \mathrm{H}-4^{\prime}, \mathrm{H}-5^{\prime}\right), 3.66$ (s, $\left.2 \mathrm{H}, \mathrm{H}-5\right)$ ppm.

${ }^{13}$ C-NMR (125 MHz, DMSO-d 6 ): $\delta=166.9$ (C-6), 166.2 (C-4), 151.1 (C-2), 88.0 (C-1'), 84.3 (C-4'), 71.6 (C-2'), 70.1 (C-3'), 62.4 (C-5'), 56.2 (C-5) ppm.

MS (ESI): $\mathbf{m} / \mathbf{z}(\%)=283.1(100)[\mathrm{M}+\mathrm{Na}]^{+}, 259.1(100)[\mathrm{M}-\mathrm{H}]^{-}$.

HRMS: $m / z$ calc. for $\mathrm{C}_{9} \mathrm{H}_{12} \mathrm{~N}_{2} \mathrm{O}_{7} \mathrm{Na}[\mathrm{M}+\mathrm{Na}]^{+}:$283.0537, found 283.0535 . 


\subsubsection{Barbituric-acid-ribonucleoside-5'-monophosphate (3)}

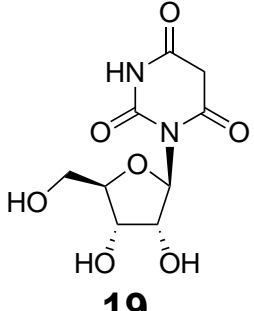

19

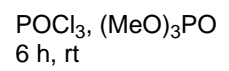
$6 \mathrm{~h}, \mathrm{rt}$

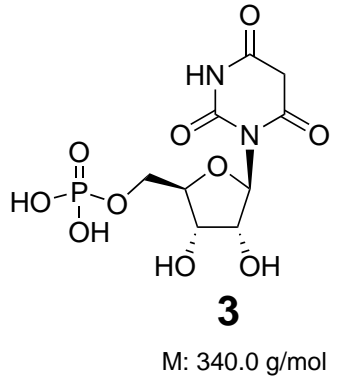

Under an argon atmosphere, 19 (220 mg, $846 \mu \mathrm{mol}, 1.0$ eq.) was dissolved in dry trimethylphosphate $(3 \mathrm{~mL})$ and was cooled to $0{ }^{\circ} \mathrm{C}$. Phosphoroxychloride $(154 \mu \mathrm{L}$, $259 \mathrm{mg} 1.60 \mathrm{mmol}, 2.0 \mathrm{eq}$.) was added dropwise and the resulting solution was stirred at $0{ }^{\circ} \mathrm{C}$ for $6 \mathrm{~h}$. The mixture was quenched by the addition of water $(1 \mathrm{~mL})$ and the solvent was evaporated in vacuo. The crude product was purified by ion exchange HPLC using a linear gradient of $0.5 \mathrm{M}$ TEAA in water at $\mathrm{pH} 7$. The product (3) was obtained as the triethylammonium salt.

MS (ESI): $\mathbf{m} / \mathbf{z}(\%)=339.0(100)[\mathrm{M}-\mathrm{H}]^{-}$.

HRMS: $m / z$ calc. for $\mathrm{C}_{9} \mathrm{H}_{13} \mathrm{~N}_{2} \mathrm{O}_{10} \mathrm{P}[\mathrm{M}-\mathrm{H}]^{-}:$:339.0235, found 339.0237. 


\subsubsection{6-Azauridine-5'-monophosphate (4)}

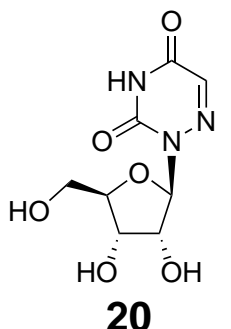

M: $245.2 \mathrm{~g} / \mathrm{mol}$

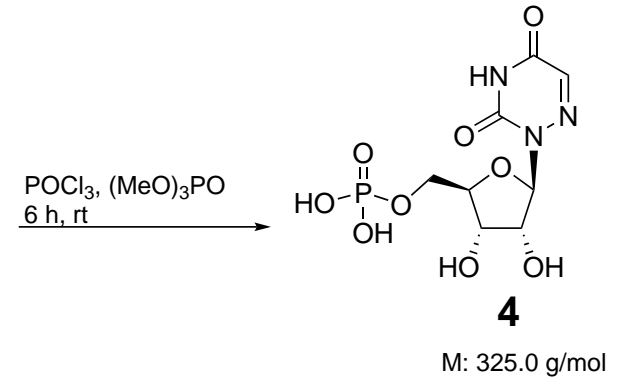

Under an argon atmosphere, 6-azauridine (20) (400 mg, $1.63 \mathrm{mmol}, 1.0$ eq.) was dissolved in dry trimethylphosphate $(4 \mathrm{~mL})$ and was cooled to $0{ }^{\circ} \mathrm{C}$. Phosphoroxychloride (297 $\mu \mathrm{L}, 3.26 \mathrm{mmol}, 2.0$ eq.) was added dropwise and the resulting reaction mixture was stirred at $0{ }^{\circ} \mathrm{C}$ for $6 \mathrm{~h}$. The mixture was quenched by the addition of water $(1 \mathrm{~mL})$ and the solvent was evaporated in vacuo. The crude product was purified by ion exchange HPLC using a linear gradient of $0.5 \mathrm{M}$ TEAA in water at $\mathrm{pH} 7$. The product (4) was obtained as the triethylammonium salt.

MS (ESI): m/z (\%) = $324.0(66)[\mathrm{M}-\mathrm{H}]^{-}$.

HRMS: $m / z$ calc. for $\mathrm{C}_{8} \mathrm{H}_{12} \mathrm{~N}_{3} \mathrm{O}_{9} \mathrm{P}[\mathrm{M}-\mathrm{H}]^{-}:$324.0238, found 324.0237. 


\subsubsection{5'-O-Tertbutyldimethylsilyl-2',3'-O-isopropylidene- orotidinemethylester (21)}

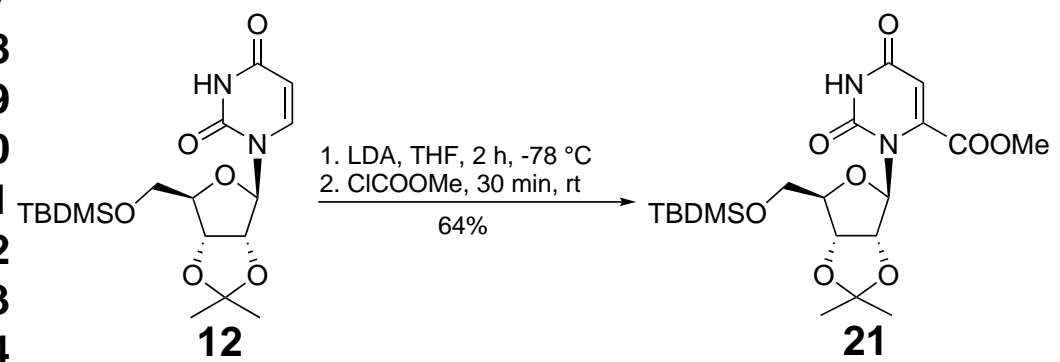

M: $398.5 \mathrm{~g} / \mathrm{mol}$

M: $456.6 \mathrm{~g} / \mathrm{mol}$

Under an argon atmosphere, 12 (2.15 g, $4.86 \mathrm{mmol}, 1.0$ eq.) was dissolved in dry THF $(30 \mathrm{~mL})$ and the solution was cooled to $-78{ }^{\circ} \mathrm{C}$. LDA solution (1.5 $\mathrm{M}$ in THF, $8.1 \mathrm{~mL}, 12.1 \mathrm{mmol}, 2.5 \mathrm{eq}$.) was added dropwise. The resulting brownish solution was stirred at $-78{ }^{\circ} \mathrm{C}$ for $30 \mathrm{~min}$. CICOOMe $(414 \mu \mathrm{L}, 505.1 \mathrm{mg}, 5.35 \mathrm{mmol}, 1.1 \mathrm{eq}$.) was added dropwise at $-78^{\circ} \mathrm{C}$, the solution was warmed to ambient temperature and stirred for $30 \mathrm{~min}$. The mixture was quenched by the addition of HOAc (1 mL) and the solvent was evaporated in vacuo. The crude product was purified by column chromatography on silica gel using pentane/EtOAc 1:1. The desired product (21) (1.4 g, $3.10 \mathrm{mmol}, 64 \%)$ was obtained as a greenish solid.

${ }^{1} \mathrm{H}-\mathrm{NMR}\left(300 \mathrm{MHz}, \mathrm{CDCl}_{3}\right): \delta=8.83\left(\mathrm{~s}_{b r}, 1 \mathrm{H}, \mathrm{NH}\right), 6.08(\mathrm{~s}, 1 \mathrm{H}, \mathrm{H}-5), 5.90(\mathrm{~d}$, $J=2.0 \mathrm{~Hz}, 1 \mathrm{H}, \mathrm{H}-1^{\prime}$ ), 5.18 (dd, $\left.J=6.2,2.0 \mathrm{~Hz}, 1 \mathrm{H}, \mathrm{H}-2^{\prime}\right), 4.73$ (dd, $J=6.2,3.1 \mathrm{~Hz}$, $\left.1 \mathrm{H}, \mathrm{H}-3^{\prime}\right)$, 4.14-4.06 (m, $\left.1 \mathrm{H}, \mathrm{H}-4^{\prime}\right), 3.87-3.71$ (m, $2 \mathrm{H}, \mathrm{H}-5$ '), 1.54 (s, $\left.3 \mathrm{H}, \mathrm{CH}_{3}\right), 1.34$ (s, $\left.3 \mathrm{H}, \mathrm{CH}_{3}\right), 0.88\left(\mathrm{~s}, 9 \mathrm{H}, \mathrm{SiC}\left(\mathrm{CH}_{3}\right)_{3}\right), 0.05\left(\mathrm{~s}, 6 \mathrm{H}, \mathrm{Si}\left(\mathrm{CH}_{3}\right)\right)$ ppm.

${ }^{13}$ C-NMR (125 MHz, $\left.\mathrm{CDCl}_{3}\right): \delta=162.4$ (C-4), 162.1 (COOMe), 150.1 (C-2), 145.3

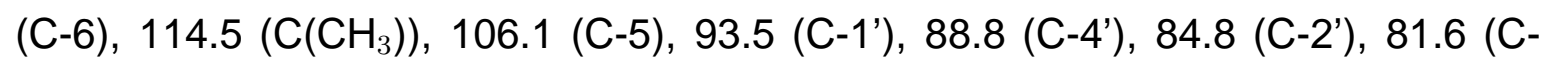
3'), 64.0 (C-5'), 54.5 (COOMe), $27.4\left(\mathrm{CH}_{3}\right), 26.1\left(\mathrm{SiC}\left(\mathrm{CH}_{3}\right)_{3}\right), 25.5\left(\mathrm{CH}_{3}\right), 18.6$ $\left(\mathrm{SiC}\left(\mathrm{CH}_{3}\right)_{3}\right),-5.2 \mathrm{Si}\left(\mathrm{CH}_{3}\right)$ ppm.

MS (ESI): m/z (\%) = $479.2(25)[\mathrm{M}+\mathrm{Na}]^{+}, 455.2(100)[\mathrm{M}-\mathrm{H}]^{-}$.

HRMS: $m / z$ calc. for $\mathrm{C}_{20} \mathrm{H}_{32} \mathrm{~N}_{2} \mathrm{O}_{8} \mathrm{SiNa}[\mathrm{M}+\mathrm{Na}]^{+}:$479.1820, found: 479.1813 . 


\subsubsection{5'-O-Tertbutyldimethylsilyl-2',3'-O-isopropylidene-6- amidouridine (22)}

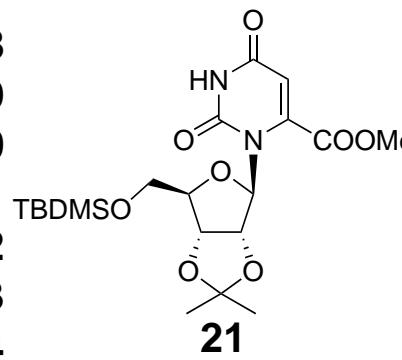

M: $456.6 \mathrm{~g} / \mathrm{mol}$

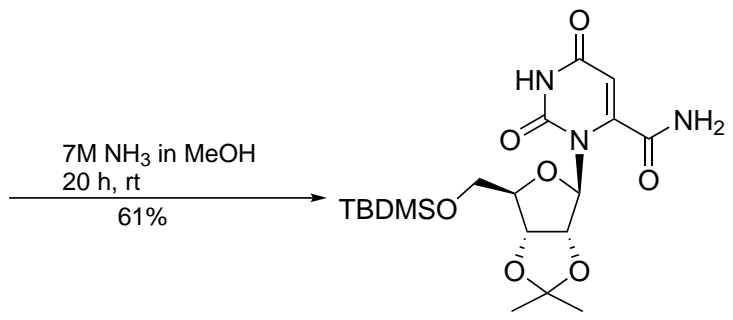

22

21 (1.41 g, $3.1 \mathrm{mmol}, 1.0$ eq.) was dissolved in $7 \mathrm{M} \mathrm{NH}_{3}$ methanolic solution $(50 \mathrm{~mL})$ und the solution was stirred at ambient temperature for $20 \mathrm{~h}$. The solvent was evaporated in vacuo and the crude product was purified by column chromatography on silica gel using pentane/EtOAc 1:1. The desired product (22) $(838 \mathrm{mg}$, $1.9 \mathrm{mmol}, 61 \%$ ) was obtained as a white solid.

${ }^{1} \mathrm{H}-\mathrm{NMR}\left(300 \mathrm{MHz}, \mathrm{CDCl}_{3}\right): \delta=11.62\left(\mathrm{~s}_{b r}, 1 \mathrm{H}, \mathrm{NH}\right), 8.44\left(\mathrm{~s}, 1 \mathrm{H}, \mathrm{NH}_{2}\right), 8.12(\mathrm{~s}$, $\left.1 \mathrm{H}, \mathrm{NH}_{2}\right), 6.69(\mathrm{~s}, 1 \mathrm{H}, \mathrm{H}-5), 5.66(\mathrm{~d}, J=2.0 \mathrm{~Hz}, 1 \mathrm{H}, \mathrm{H}-1$ '), $5.16(\mathrm{dd}, J=6.2,2.0 \mathrm{~Hz}$, $\left.1 \mathrm{H}, \mathrm{H}-2^{\prime}\right), 4.70$ (dd, $\left.J=6.2,3.1 \mathrm{~Hz}, 1 \mathrm{H}, \mathrm{H}-3^{\prime}\right), 3.98-3.92\left(\mathrm{~m}, 1 \mathrm{H}, \mathrm{H}-4^{\prime}\right), 3.76-3.70$ $\left(\mathrm{m}, 2 \mathrm{H}, \mathrm{H}-5^{\prime}\right), 1.44\left(\mathrm{~s}, 3 \mathrm{H}, \mathrm{CH}_{3}\right), 1.27\left(\mathrm{~s}, 3 \mathrm{H}, \mathrm{CH}_{3}\right), 0.85\left(\mathrm{~s}, 9 \mathrm{H}, \mathrm{SiC}\left(\mathrm{CH}_{3}\right)_{3}\right), 0.02$ $\left(\mathrm{s}, 6 \mathrm{H}, \mathrm{Si}\left(\mathrm{CH}_{3}\right)\right) \mathrm{ppm}$.

${ }^{13}$ C-NMR $\left(125 \mathrm{MHz}, \mathrm{CDCl}_{3}\right): \delta=163.2(\mathrm{C}-4), 162.5\left(\mathrm{COONH}_{2}\right), 150.2(\mathrm{C}-2), 149.7$ (C-6), $112.9\left(\mathrm{C}\left(\mathrm{CH}_{3}\right)\right), 101.1$ (C-5), 92.5 (C-1'), 88.7 (C-4'), 84.2 (C-2'), 81.8 (C-3'), $63.5\left(\mathrm{C}-5^{\prime}\right), 27.1\left(\mathrm{CH}_{3}\right), 25.8\left(\mathrm{SiC}\left(\mathrm{CH}_{3}\right)_{3}\right), 25.2\left(\mathrm{CH}_{3}\right), 18.0\left(\mathrm{SiC}\left(\mathrm{CH}_{3}\right)_{3}\right),-5.2 \mathrm{Si}\left(\mathrm{CH}_{3}\right)$ ppm.

MS (ESI): $\mathbf{m} / \mathbf{z}(\%)=464.2(100)[\mathrm{M}+\mathrm{Na}]^{+}$.

HRMS: $\mathrm{m} / z$ calc. for $\mathrm{C}_{19} \mathrm{H}_{31} \mathrm{~N}_{3} \mathrm{O}_{7} \mathrm{SiNa}[\mathrm{M}+\mathrm{Na}]^{+}:$464.1823, found: 464.1797 . 


\subsubsection{6-Amidouridine (23)}

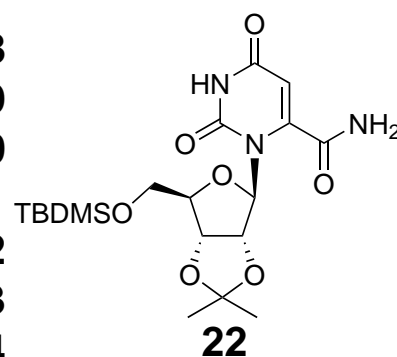

$\mathrm{M}: 441.6 \mathrm{~g} / \mathrm{mol}$

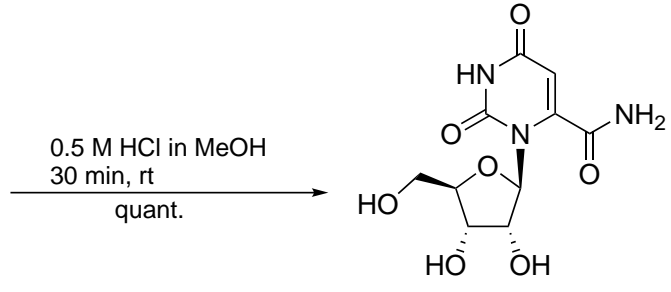

23

M: $287.4 \mathrm{~g} / \mathrm{mol}$

22 (461 mg, $1.04 \mathrm{mmol}, 1.0$ eq.) was dissolved in $0.5 \mathrm{M} \mathrm{HCl}$ in $\mathrm{MeOH}(10 \mathrm{~mL})$ and the solution was stirred at ambient temperature for $30 \mathrm{~min}$. The solvents were evaporated in vacuo. The desired product (23) (371 $\mathrm{mg}, 1.04 \mathrm{mmol}$, quant.) was obtained a greenish solid.

${ }^{1} \mathrm{H}-N M R\left(300 \mathrm{MHz}, \mathrm{CD}_{3} \mathrm{OD}\right): \delta=5.77(\mathrm{~s}, 1 \mathrm{H}, \mathrm{H}-5), 5.53(\mathrm{~d}, J=3.1 \mathrm{~Hz}, 1 \mathrm{H}, \mathrm{H}-1$ '), 4.69 (dd, $J=6.2,3.1 \mathrm{~Hz}, 1 \mathrm{H}, \mathrm{H}-2$ '), 4.28 (dd, J = 6.2, $1.0 \mathrm{~Hz}, 1 \mathrm{H}, \mathrm{H}-3$ '), 3.77-3.68 (m, $\left.3 \mathrm{H}, \mathrm{H}-4^{\prime}, \mathrm{H}-5^{\prime}\right)$ ppm.

${ }^{13}$ C-NMR (125 MHz, CD 3 OD): $\delta=166.1$ (C-4), $165.2\left(\mathrm{COONH}_{2}\right), 152.4(\mathrm{C}-2)$, 151.1 (C-6), 102.5 (C-5), 96.1 (C-1'), 86.5 (C-4'), 73.5 (C-2'), 71.2 (C-3'), 63.6 (C-5') ppm.

MS (ESI): m/z (\%) = $310.1(100)[\mathrm{M}+\mathrm{Na}]^{+}, 286.1(80)[\mathrm{M}-\mathrm{H}]^{-}$.

HRMS: $m / z$ calc. for $\mathrm{C}_{10} \mathrm{H}_{13} \mathrm{~N}_{3} \mathrm{O}_{7} \mathrm{Na}[\mathrm{M}+\mathrm{Na}]^{+}: 310.0646$, found: 310.0646 . 


\subsubsection{6-Amidouridine-5'-monophosphate (8)}

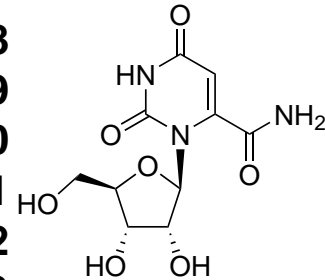

23

$\mathrm{M}: 287.4 \mathrm{~g} / \mathrm{mol}$

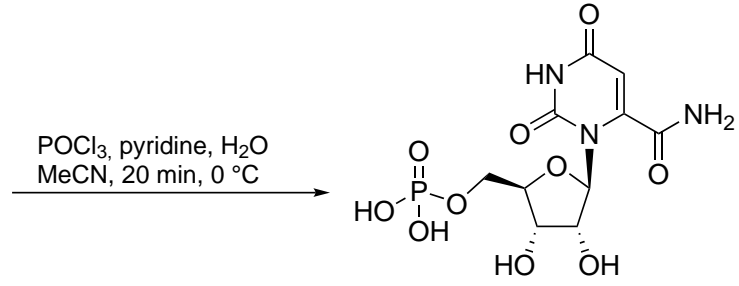

8

$\mathrm{M}: 367.2 \mathrm{~g} / \mathrm{mol}$

$\mathrm{POCl}_{3}(215 \mu \mathrm{L}, 2.30 \mathrm{mmol}, 4.4$ eq.) was dissolved in MeCN (1 mL) and the solution was cooled to $0{ }^{\circ} \mathrm{C}$. Pyridine (186 $\mu \mathrm{L}, 2.30 \mathrm{mmol}, 4.4$ eq.) and water $(20.7 \mu \mathrm{L}$, $1.15 \mathrm{mmol}, 2.2$ eq.) were added and the solution was stirred at $0{ }^{\circ} \mathrm{C}$ for $3 \mathrm{~min} .23$ (150 mg, $522 \mu \mathrm{mol}, 1.0$ eq.) was added and the resulting suspension was stirred at $0{ }^{\circ} \mathrm{C}$ for $20 \mathrm{~min}$. Ice cold water $(20 \mathrm{~mL})$ was added and the solution was stirred for $30 \mathrm{~min}$. The solvents were evaporated in vacuo and the crude product was purified by ion exchange HPLC using a linear gradient of TEAA in water at $\mathrm{pH} 7$. The product (8) was obtained as the triethylammonium salt.

MS (ESI): m/z (\%) = $390.0(25)[\mathrm{M}+\mathrm{Na}]^{+}, 366.0(100)[\mathrm{M}-\mathrm{H}]^{-}$.

HRMS: $m / z$ calc. for $\mathrm{C}_{10} \mathrm{H}_{14} \mathrm{~N}_{3} \mathrm{O}_{10} \mathrm{PNa}[\mathrm{M}-\mathrm{H}]^{-}:$366.0344, found: 366.0338 . 


\subsubsection{Orotidinemethylester (24)}

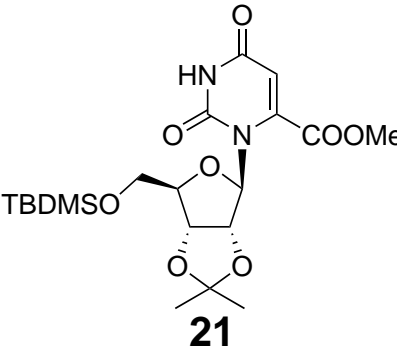

M: $456.6 \mathrm{~g} / \mathrm{mol}$

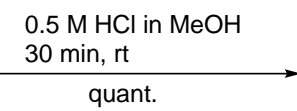

quant.

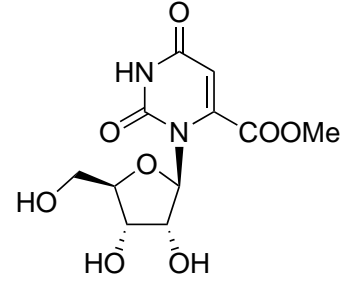

24

$\mathrm{M}: 302.1 \mathrm{~g} / \mathrm{mol}$

21 (207 mg, $453 \mu \mathrm{mol}, 1.0$ eq.) was dissolved in $0.5 \mathrm{M} \mathrm{HCl}$ in $\mathrm{MeOH}(5 \mathrm{~mL})$ and the solution was stirred at ambient temperature for $30 \mathrm{~min}$. The solvents were evaporated in vacuo. The desired product (24) (137 mg, $453 \mu \mathrm{mol}$, quant.) was obtained as a greenish solid.

${ }^{1} \mathrm{H}-N M R\left(300 \mathrm{MHz}, \mathrm{CD}_{3} \mathrm{OD}\right): \delta=6.00(\mathrm{~s}, 1 \mathrm{H}, \mathrm{H}-5), 5.58(\mathrm{~d}, J=4.0 \mathrm{~Hz}, 1 \mathrm{H}, \mathrm{H}-1$ '), 4.64 (dd, $J=6.5,4.0$ Hz, $1 \mathrm{H}, \mathrm{H}-2^{\prime}$ ), 4.19 (t, $J=6.5,1 \mathrm{H}, \mathrm{H}-3$ '), 3.94 (s, $3 \mathrm{H}, \mathrm{CH}_{3}$ ) 3.98-3.74 (m, 3 H, H-4', H-5') ppm.

MS (ESI): m/z (\%) = $325.1(50)[\mathrm{M}+\mathrm{Na}]^{+}, 301.1(45)[\mathrm{M}-\mathrm{H}]^{-}$.

HRMS: $m / z$ calc. for $\mathrm{C}_{11} \mathrm{H}_{14} \mathrm{~N}_{2} \mathrm{O}_{8} \mathrm{Na}[\mathrm{M}+\mathrm{Na}]^{+}: 326.0642$, found: 326.0642 . 


\subsubsection{5-lodouridine (26)}

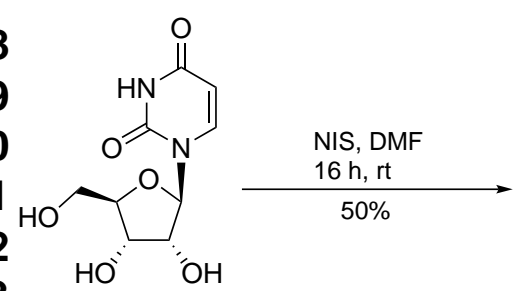

10

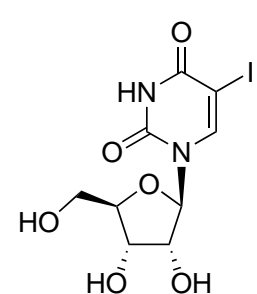

26

M: $244.2 \mathrm{~g} / \mathrm{mol}$

M: $370.1 \mathrm{~g} / \mathrm{mol}$

Under an argon atmosphere, uridine (10) $(10 \mathrm{~g}, 41.0 \mathrm{mmol}, 1.0 \mathrm{eq}$.) was dissolved in dry DMF (15 mL). NIS (11.9 , $49.2 \mathrm{mmol}, 1.2$ eq.) was added and the solution was stirred for $20 \mathrm{~h}$, at ambient temperature. The solvent was removed in vacuo and the resulting crude product was purified by column chromatography on silica gel using $\mathrm{DCM} / \mathrm{MeOH}$ 9:1. The desired product (26) $(7.6 \mathrm{~g}, 20.5 \mathrm{mmol}, 50 \%)$ was obtained as a white solid.

${ }^{1} \mathrm{H}-\mathrm{NMR}\left(300 \mathrm{MHz}, \mathrm{DMSO}-\mathrm{d}_{6}\right): \delta=11.66(\mathrm{~s}, 1 \mathrm{H}, \mathrm{NH}), 8.47(\mathrm{~s}, 1 \mathrm{H}, \mathrm{H}-6), 5.72(\mathrm{~d}$, $\left.J=4.4 \mathrm{~Hz}, 1 \mathrm{H}, \mathrm{H}^{\prime} \mathbf{1}^{\prime}\right), 5.40$ (d, $\left.J=5.2 \mathrm{~Hz}, 1 \mathrm{H}, \mathrm{OH}-2^{\prime}\right), 5.24$ (t, $J=4.6,1 \mathrm{H}, \mathrm{H}-2^{\prime}$ ),

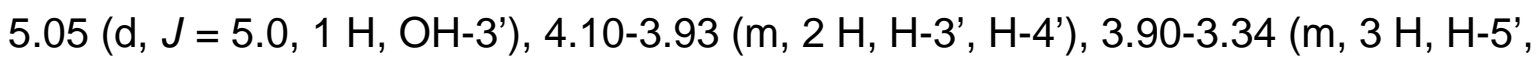
$\left.\mathrm{OH}-5^{\prime}\right) \mathrm{ppm}$.

MS (ESI): $\mathbf{m} / \mathbf{z}(\%)=393.0(38)[\mathrm{M}+\mathrm{Na}]^{+}, 369.0(100)[\mathrm{M}-\mathrm{H}]^{-}$.

HRMS: $m / z$ calc. for $\mathrm{C}_{9} \mathrm{H}_{11} \mathrm{~N}_{2} \mathrm{O}_{6} \mathrm{INa}[\mathrm{M}+\mathrm{Na}]^{+}:$392.9554, found: 392.9554 . 


\subsubsection{5'-O-Tertbutyldimethylsilyl-2',3'-O-isopropylidene-5- iodouridine (27)}

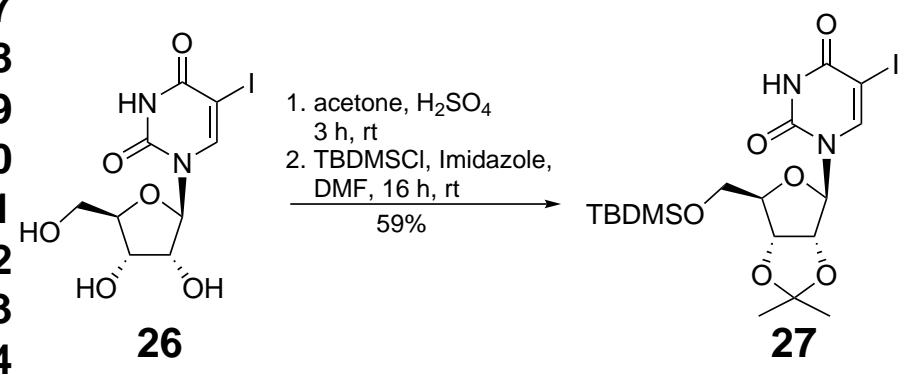

M: $370.1 \mathrm{~g} / \mathrm{mol}$

M: $524.4 \mathrm{~g} / \mathrm{mol}$

To a stirred suspension of 5-iodouridine (26) (7.6 g, $20.5 \mathrm{mmol}, 1.0 \mathrm{eq}$.) in acetone $(350 \mathrm{~mL}) \mathrm{H}_{2} \mathrm{SO}_{4}(1.5 \mathrm{~mL})$ was added and the resulting solution was stirred at room temperature for $4 \mathrm{~h}$. The resulting solution was quenched with $\mathrm{NEt}_{3}(4.0 \mathrm{~mL})$ and the solvent was evaporated in vacuo. The residue was redissolved in dry DMF (50 mL). Imidazole (3.4 g, $51.3 \mathrm{mmol}, 2.5$ eq.) and TBDMSCl (4.63 g, $30.8 \mathrm{mmol}$, 1.5 eq.) were added and the solution was stirred for $3 \mathrm{~h}$ at ambient temperature. The solvent was evaporated in vacuo and the crude product was purified by column chromatography on silica gel using pentane/EtOAc 1:1. The desired product (27) $(6.35 \mathrm{~g}, 12.1 \mathrm{mmol}, 59 \%)$ was obtained as a white solid.

${ }^{1} \mathrm{H}-N M R\left(300 \mathrm{MHz} \mathrm{CDCl}_{3}\right): \delta=8.76(\mathrm{~s}, 1 \mathrm{H}, \mathrm{NH}), 7.94(\mathrm{~s}, 1 \mathrm{H}, \mathrm{H}-6), 5.86(\mathrm{~d}$, $\left.J=2.7 \mathrm{~Hz}, 1 \mathrm{H}, \mathrm{H}-1^{\prime}\right)$, 4.76-4.66(m, $\left.2 \mathrm{H}, \mathrm{H}-2^{\prime}, \mathrm{H}^{\prime} 3^{\prime}\right), 4.41-4.36$ (m, $\left.1 \mathrm{H}, \mathrm{H}-4^{\prime}\right), 3.92$ (dd, $J=11.7 \mathrm{~Hz}, 2.2 \mathrm{~Hz}, 1 \mathrm{H}, \mathrm{H}-5_{a}^{\prime}$ ), 3.80 (dd, $J=11.6 \mathrm{~Hz}, 3.0 \mathrm{~Hz}, 1 \mathrm{H}, \mathrm{H}-5^{\prime}{ }_{b}$ ), 1.59 (s, $\left.3 \mathrm{H}, \mathrm{CH}_{3}\right), 1.36\left(\mathrm{~s}, 3 \mathrm{H}, \mathrm{CH}_{3}\right), 0.91\left(\mathrm{~s}, 9 \mathrm{H}, \mathrm{SiC}\left(\mathrm{CH}_{3}\right)_{3}\right), 0.13\left(\mathrm{~s}, 6 \mathrm{H}, \mathrm{Si}\left(\mathrm{CH}_{3}\right)\right)$ ppm.

${ }^{13}$ C-NMR (125 MHz, $\mathrm{CDCl}_{3}$ ): $\delta=159.9$ (C-4), 149.7 (C-2), 144.7 (C-6), 114.1 $\left(\mathrm{C}\left(\mathrm{CH}_{3}\right)\right), 93.1$ (C-1'), 86.7 (C-4'), 85.4 (C-2'), 80.7 (C-3'), 68.1 (C-5), 63.4 (C5'), $27.2\left(\mathrm{CH}_{3}\right), 26.1\left(\mathrm{SiC}\left(\mathrm{CH}_{3}\right)_{3}\right), 25.3\left(\mathrm{CH}_{3}\right), 18.5\left(\mathrm{SiC}\left(\mathrm{CH}_{3}\right)_{3}\right),-5.0 \mathrm{Si}\left(\mathrm{CH}_{3}\right),-5.3$ $\mathrm{Si}\left(\mathrm{CH}_{3}\right) \mathrm{ppm}$.

MS (ESI): m/z (\%) = $525.1(100)[\mathrm{M}+\mathrm{H}]^{+}, 523.1(100)[\mathrm{M}-\mathrm{H}]^{-}$.

HRMS: $m / z$ calc. for $\mathrm{C}_{18} \mathrm{H}_{30} \mathrm{~N}_{2} \mathrm{O}_{6}$ Sil $[\mathrm{M}+\mathrm{H}]^{+}:$525.0912, found: 525.0911 . 


\subsubsection{5'-O-Tertbutyldimethylsilyl-2',3'-O-isopropylidene-6- cyanouridine (28)}

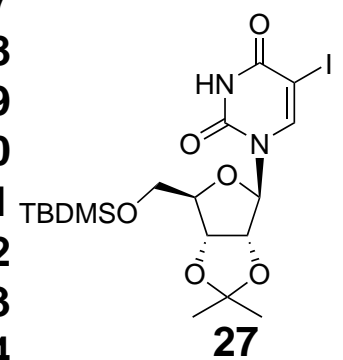

M: $524.4 \mathrm{~g} / \mathrm{mol}$

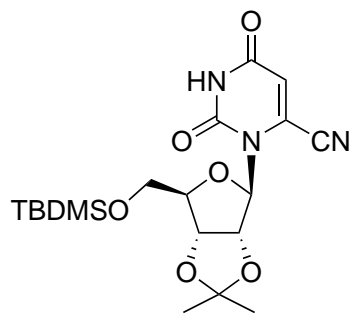

28

M: $309.3 \mathrm{~g} / \mathrm{mol}$

Under an argon atmosphere, 27 (3.0 g, 5,7 mmol, 1.0 eq.) was dissolved in dry DMF (60 mL). KCN (445 mg, $6.84 \mathrm{mmol}, 1.2 \mathrm{eq}$.) and 18-crown-6 (301 mg, $1.14 \mathrm{mmol}, 0.2 \mathrm{eq}$.) were added and the solution was stirred for $20 \mathrm{~h}$ at ambient temperature. The solvent was evaporated in vacuo and the crude product was purified by column chromatography on silica gel using pentane/EtOAc 1:1. The desired product (28) (1.83 g, $4.3 \mathrm{mmol}, 75 \%)$ was obtained as a white solid.

${ }^{1}$ H-NMR $\left(300 \mathrm{MHz}, \mathrm{CDCl}_{3}\right): \delta=9.37(\mathrm{~s}, 1 \mathrm{H}, \mathrm{NH}), 6.31(\mathrm{~d}, J=2.0 \mathrm{~Hz}, 1 \mathrm{H}, \mathrm{H}-5)$, $6.05\left(\mathrm{~d}, J=2.3 \mathrm{~Hz}, 1 \mathrm{H}, \mathrm{H}-1^{\prime}\right.$ ), $5.13(\mathrm{dd}, J=6.7 \mathrm{~Hz}, 2.3 \mathrm{~Hz}, 1 \mathrm{H}, \mathrm{H}-2$ '), 4.78 (dd, $\left.J=6.7 \mathrm{~Hz}, 4.7 \mathrm{~Hz}, 1 \mathrm{H}, \mathrm{H}-3^{\prime}\right), 4.21-4.07$ (m, $\left.1 \mathrm{H}, \mathrm{H}^{\prime} 4^{\prime}\right), 3.89-3.76$ (m, $\left.2 \mathrm{H}, \mathrm{H}-5^{\prime}\right), 1.58$ (s, $\left.3 \mathrm{H}, \mathrm{CH}_{3}\right), 1.35\left(\mathrm{~s}, 3 \mathrm{H}, \mathrm{CH}_{3}\right), 0.89\left(\mathrm{~s}, 9 \mathrm{H}, \mathrm{SiC}\left(\mathrm{CH}_{3}\right)_{3}\right), 0.06\left(\mathrm{~s}, 6 \mathrm{H}, \mathrm{Si}\left(\mathrm{CH}_{3}\right)\right)$ ppm.

${ }^{13}$ C-NMR $\left(125 \mathrm{MHz}, \mathrm{CDCl}_{3}\right.$ ): $\delta=160.5$ (C-4), 148.7 (C-2), 127.9 (C-6), 115.1 ( $\left(\mathrm{CH}_{3}\right)$ ), $113.2(\mathrm{C}-5), 110.9(\mathrm{CN}), 93.8\left(\mathrm{C}-1^{\prime}\right), 88.7$ (C-4'), 83.7 (C-2'), $81.4\left(\mathrm{C}-3^{\prime}\right)$, $63.5\left(\mathrm{C}-5^{\prime}\right), 27.3\left(\mathrm{CH}_{3}\right), 26.1\left(\mathrm{SiC}\left(\mathrm{CH}_{3}\right)_{3}\right), 25.5\left(\mathrm{CH}_{3}\right), 18.6\left(\mathrm{SiC}\left(\mathrm{CH}_{3}\right)_{3}\right),-5.1 \mathrm{Si}\left(\mathrm{CH}_{3}\right)$ ppm.

MS (ESI): $\mathbf{~ m / z ~ ( \% ) ~ = ~} 224.2(95)[\mathrm{M}+\mathrm{H}]^{+}, 446.2(100)[\mathrm{M}+\mathrm{Na}]^{+}, 422.0(100)[\mathrm{M}-\mathrm{H}]^{-}$.

HRMS: $m / z$ calc. for $\mathrm{C}_{19} \mathrm{H}_{29} \mathrm{~N}_{3} \mathrm{O}_{6} \mathrm{SiNa}[\mathrm{M}+\mathrm{Na}]^{+}: 446.1718$, found: 446.1728 . 


\subsubsection{5'-O-Tertbutyldimethylsilyl-2',3'-O-isopropylidene-6- isopropyluridine (29)}

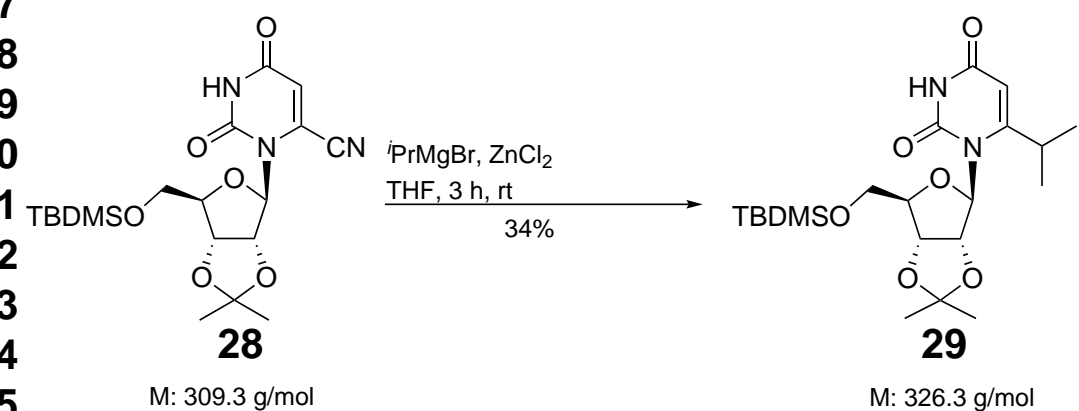

Under an argon atmosphere, 28 (600 mg, $1.41 \mathrm{mmol}, 1.0$ eq.) and $\mathrm{ZnCl}_{2}(97 \mathrm{mg}$, $710 \mu \mathrm{mol}, 0.5$ eq.) were dissolved in dry THF $(15 \mathrm{~mL})$ and the solution was cooled to $0{ }^{\circ} \mathrm{C}$. ${ }^{\mathrm{PrMgBr}}$ (3 M in 2-methyl-THF, $1.42 \mathrm{~mL}, 7.1 \mathrm{mmol}, 3.0$ eq.) was added and the solution was stirred for $3 \mathrm{~h}$ at ambient temperature. The reaction was quenched by addition of saturated $\mathrm{NH}_{4} \mathrm{Cl}$ solution $(15 \mathrm{~mL})$. The layers were separated and the aqueous layer was extracted with THF $(3 \times 10 \mathrm{~mL})$. The combined organic layers were dried over $\mathrm{MgSO}_{4}$ and the solvent was evaporated in vacuo. The crude product was purified by column chromatography on silica gel using pentane/EtOAc 2:1. The desired product (29) (212 mg, $481 \mu \mathrm{mol}, 34 \%)$ was obtained as a white solid.

${ }^{1}$ H-NMR $\left(300 \mathrm{MHz}, \mathrm{CDCl}_{3}\right): \delta=9.16(\mathrm{~s}, 1 \mathrm{H}, \mathrm{NH}), 5.80(\mathrm{~s}, 1 \mathrm{H}, \mathrm{H}-5), 5.64(\mathrm{~s}, 1 \mathrm{H}$, $\left.\mathrm{H}-1^{\prime}\right), 5.19$ (d, $\left.J=6.5 \mathrm{~Hz}, 1 \mathrm{H}, \mathrm{H}-2^{\prime}\right), 4.81$ (t, $\left.J=5.1 \mathrm{~Hz}, 1 \mathrm{H}, \mathrm{H}-3^{\prime}\right), 4.17-4.06(\mathrm{~m}$, $1 \mathrm{H}, \mathrm{H}-4$ '), 3.86-3.78 (m, $\left.2 \mathrm{H}, \mathrm{H}-5^{\prime}\right), 2.97$ (sept, $\left.J=6.7 \mathrm{~Hz}, 1 \mathrm{H}, \mathrm{CH}\left(\mathrm{CH}_{3}\right)_{2}\right), 1.54$ $\left(\mathrm{s}, 3 \mathrm{H}, \mathrm{CH}_{3}\right), 1.33\left(\mathrm{~s}, 3 \mathrm{H}, \mathrm{CH}_{3}\right), 1.28\left(\mathrm{t}, J=7.7 \mathrm{~Hz}, 6 \mathrm{H}, \mathrm{CH}\left(\mathrm{CH}_{3}\right)_{2}\right), 0.87(\mathrm{~s}, 9 \mathrm{H}$, $\left.\mathrm{SiC}\left(\mathrm{CH}_{3}\right)_{3}\right), 0.04\left(\mathrm{~s}, 6 \mathrm{H}, \mathrm{Si}\left(\mathrm{CH}_{3}\right)\right) \mathrm{ppm}$.

${ }^{13}$ C-NMR $\left(125 \mathrm{MHz}, \mathrm{CDCl}_{3}\right): \delta=163.4$ (C-4), 162.7 (C-6), 150.9 (C-2), 113.9 (C( $\left.\mathrm{CH}_{3}\right)$ ), 99.1 (C-5), 91.0 (C-1'), 89.6 (C-4'), 84.7 (C-2'), 82.3 (C-3'), 64.4 (C-5'), $\left.\left.29.7\left(\mathrm{CH}\left(\mathrm{CH}_{3}\right)_{2}\right)\right), 27.4\left(\mathrm{CH}_{3}\right), 26.1\left(\mathrm{SiC}\left(\mathrm{CH}_{3}\right)_{3}\right), 25.5\left(\mathrm{CH}_{3}\right), 22.2\left(\mathrm{CH}\left(\mathrm{CH}_{3}\right)_{2}\right)\right), 21.4$ $\left.\left(\mathrm{CH}\left(\mathrm{CH}_{3}\right)_{2}\right)\right), 18.6\left(\mathrm{SiC}\left(\mathrm{CH}_{3}\right)_{3}\right),-5.1 \mathrm{Si}\left(\mathrm{CH}_{3}\right) \mathrm{ppm}$.

MS (ESI): $\mathbf{m} / \mathbf{z}(\%)=441.3(100)[\mathrm{M}+\mathrm{H}]^{+}, 881.5(95)[2 \mathrm{M}+\mathrm{H}]^{+}, 439.2(100)[\mathrm{M}-\mathrm{H}]^{-}$.

HRMS: $\mathrm{m} / z$ calc. for $\mathrm{C}_{21} \mathrm{H}_{37} \mathrm{~N}_{2} \mathrm{O}_{6} \mathrm{SiNa}[\mathrm{M}+\mathrm{Na}]^{+}: 441.2415$, found: 441.2419 . 


\subsubsection{6-Isopropyluridine (30)}

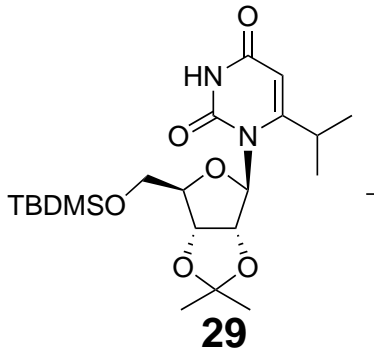

M: $326.3 \mathrm{~g} / \mathrm{mol}$

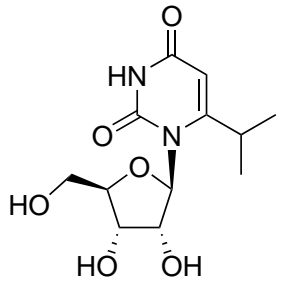

30

M: $286.3 \mathrm{~g} / \mathrm{mol}$

29 (212 mg, $481 \mu \mathrm{mol}, 1.0$ eq.) was dissolved in $0.5 \mathrm{M} \mathrm{HCl}$ in $\mathrm{MeOH}(5 \mathrm{~mL})$ and the solution was stirred at ambient temperature for $4 \mathrm{~h}$. The solvent was evaporated in vacuo. The desired product (30) (138 mg, $481 \mu \mathrm{mol}$, quant.) was obtained a white solid.

${ }^{1} \mathrm{H}-N M R\left(300 \mathrm{MHz}, \mathrm{DMSO}-\mathrm{d}_{6}\right): \delta=4.86(\mathrm{~d}, J=3.8 \mathrm{~Hz}, 1 \mathrm{H}, \mathrm{H}-1$ '), $4.81(\mathrm{~s}, 1 \mathrm{H}$, H-5), 3.92 (dd, $J=6.4 \mathrm{~Hz}, 3.7 \mathrm{~Hz}, 1 \mathrm{H}, \mathrm{H}-2$ '), 3.52 (t, J = 6.3 Hz, $1 \mathrm{H}, \mathrm{H}-3^{\prime}$ ), 3.07 (td, J = 6.0 Hz, 2.9 Hz, $1 \mathrm{H}, \mathrm{H}-4^{\prime}$ ), 2.95-2.81 (m, $2 \mathrm{H}, \mathrm{H}-5^{\prime}$ ), 2.26 (sept, $J=6.7 \mathrm{~Hz}$, $\left.1 \mathrm{H}, \mathrm{CH}\left(\mathrm{CH}_{3}\right)_{2}\right), 0.49\left(\mathrm{~d}, J=6.7 \mathrm{~Hz}, 6 \mathrm{H}, \mathrm{CH}\left(\mathrm{CH}_{3}\right)_{2}\right)$ ppm.

${ }^{13}$ C-NMR (125 MHz, DMSO-d 6 ): $\delta=164.5$ (C-4), 163.4 (C-6), 151.3 (C-2), 98.1 (C-5), 91.7 (C-1'), 84.8 (C-4'), 71.7 (C-2'), 70.0 (C-3'), $62.4\left(\mathrm{C}-5^{\prime}\right), 29.4\left(\mathrm{CH}\left(\mathrm{CH}_{3}\right)_{2}\right)$ ), $\left.\left.21.0\left(\mathrm{CH}\left(\mathrm{CH}_{3}\right)_{2}\right)\right), 20.4\left(\mathrm{CH}\left(\mathrm{CH}_{3}\right)_{2}\right)\right)$ ppm.

MS (ESI): m/z (\%) = $287.1(66)[\mathrm{M}+\mathrm{H}]^{+}, 309.1(60)[\mathrm{M}+\mathrm{Na}]^{+}, 573.3(100)[2 \mathrm{M}+\mathrm{H}]^{+}$, $285.1(57)[\mathrm{M}-\mathrm{H}]^{-}$.

HRMS: $m / z$ calc. for $\mathrm{C}_{12} \mathrm{H}_{18} \mathrm{~N}_{2} \mathrm{O}_{6} \mathrm{Na}[\mathrm{M}+\mathrm{Na}]^{+}:$309.1057, found: 309.1066. 


\subsubsection{6-Isopropyl-UMP (9)}

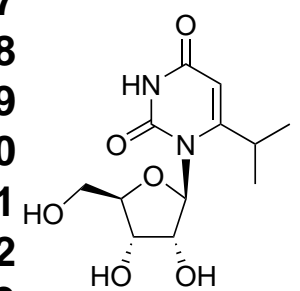

30

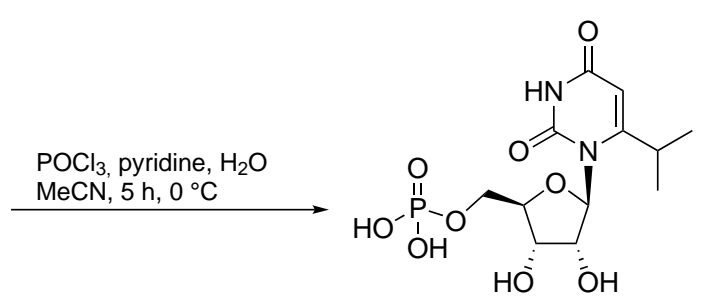

9

$\mathrm{M}: 286.3 \mathrm{~g} / \mathrm{mol}$

$\mathrm{M}: 366.3 \mathrm{~g} / \mathrm{mol}$

$\mathrm{POCl}_{3}$ (189 $\mu \mathrm{L}, 2.06 \mathrm{mmol}, 4.4$ eq.) was dissolved in MeCN (1 mL) and the solution was cooled to $0{ }^{\circ} \mathrm{C}$. Pyridine $(186 \mu \mathrm{L}, 2.30 \mathrm{mmol}, 4.4 \mathrm{eq}$.) and water $(23.0 \mu \mathrm{L}$, $1.30 \mathrm{mmol}, 2.2$ eq.) were added and the solution was stirred at $0{ }^{\circ} \mathrm{C}$ for $3 \mathrm{~min} .30$ (138 mg, $481 \mu \mathrm{mol}, 1.0 \mathrm{eq}$.) was added and the resulting suspension was stirred at $0{ }^{\circ} \mathrm{C}$ for $5 \mathrm{~h}$. Ice cold water $(20 \mathrm{~mL})$ was added and the solution was stirred for $30 \mathrm{~min}$. The solvents were evaporated in vacuo and the crude product was purified by ion exchange HPLC using a linear gradient of TEAA in water at $\mathrm{pH} 7$. The product (9) was obtained as the triethylammonium salt.

MS (ESI): $\mathbf{m} / \mathbf{z}(\%)=365.1(100)[\mathrm{M}-\mathrm{H}]^{-}$.

HRMS: $m / z$ calc. for $\mathrm{C}_{12} \mathrm{H}_{18} \mathrm{~N}_{2} \mathrm{O}_{9} \mathrm{P}[\mathrm{M}-\mathrm{H}]^{-}:$365.0755, found: 365.0746 . 


\subsubsection{5'-Tertbutyldimethylsilyl-2',3'-isopropylidene- dithioorotidinebenzylester (35)}

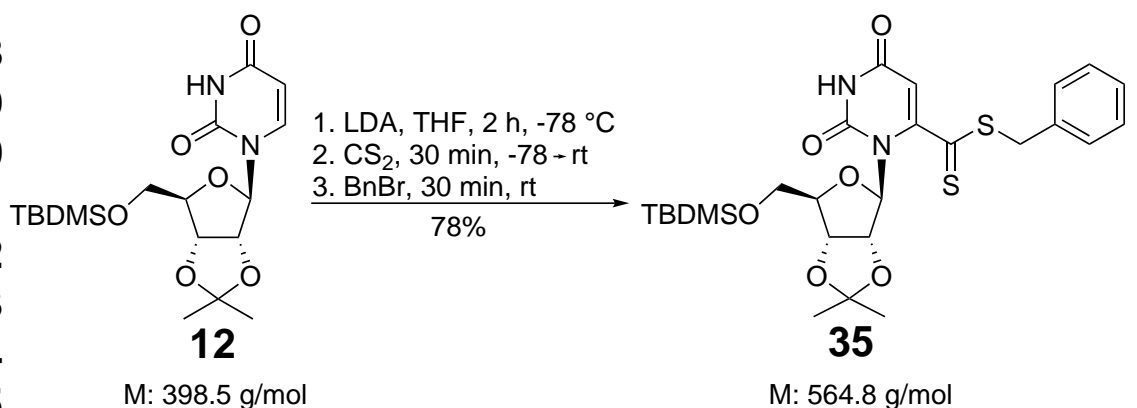

Under an argon atmosphere, $12(1.0 \mathrm{~g}, 2.5 \mathrm{mmol}, 1.0 \mathrm{eq}$ ) $)$ was dissolved in dry THF (15 mL) and the solution was cooled to $-78{ }^{\circ} \mathrm{C}$. LDA solution (2 $\mathrm{M}$ in THF, $3.13 \mathrm{~mL}, 6.25 \mathrm{mmol}, 2.5$ eq.) was added dropwise. The resulting brownish solution was stirred at $-78{ }^{\circ} \mathrm{C}$ for $30 \mathrm{~min}$. $\mathrm{CS}_{2}(166 \mu \mathrm{L}, 209 \mathrm{mg}, 2.75 \mathrm{mmol}, 1.1$ eq.) was added dropwise at $-78{ }^{\circ} \mathrm{C}$ and the red solution was stirred for $30 \mathrm{~min}$, while the solution was warmed to ambient temperature. $\mathrm{BnBr}(326 \mu \mathrm{L}, 470 \mathrm{mg}, 2.75 \mathrm{mmol}, 1.1$ eq.) was added and the solution was stirred for $30 \mathrm{~min}$. The mixture was quenched by the addition of $\mathrm{HOAc}(1 \mathrm{~mL})$ and the solvent was evaporated in vacuo. The crude product was purified by column chromatography on silica gel using DCM/MeOH 95:5. The desired product (35) $(1.1 \mathrm{~g}, 1.95 \mathrm{mmol}, 78 \%)$ was obtained as an orange solid.

${ }^{1} \mathrm{H}-\mathrm{NMR}\left(300 \mathrm{MHz}, \mathrm{CD}_{3} \mathrm{OD}\right): \delta=7.45-7.16(\mathrm{~m}, 5 \mathrm{H}$, Phenyl-H), $5.64(\mathrm{~s}, 1 \mathrm{H}, \mathrm{H}-5)$, $5.63\left(\mathrm{~d}, J=1.3 \mathrm{~Hz}, 1 \mathrm{H}, \mathrm{H}-1^{\prime}\right), 5.21\left(\mathrm{dd}, J=6.4,1.3 \mathrm{~Hz}, 1 \mathrm{H}, \mathrm{H}-2^{\prime}\right), 4.76$ (dd, $J=6.4$, $4.3 \mathrm{~Hz}, 1 \mathrm{H}, \mathrm{H}-3^{\prime}$ ), 4.65 (s, $2 \mathrm{H}, \mathrm{CH}_{2}$ ), 4.01 (td, J = 6.4, 4.3 Hz, $1 \mathrm{H}, \mathrm{H}-4$ '), 3.80 (dd, $J=6.4,2.0 \mathrm{~Hz}, 2 \mathrm{H}, \mathrm{H}-5$ ) $), 1.42\left(\mathrm{~s}, 3 \mathrm{H}, \mathrm{CH}_{3}\right), 1.30\left(\mathrm{~s}, 3 \mathrm{H}, \mathrm{CH}_{3}\right), 0.89(\mathrm{~s}, 9 \mathrm{H}$, $\left.\mathrm{SiC}\left(\mathrm{CH}_{3}\right)_{3}\right), 0.05\left(\mathrm{~s}, 3 \mathrm{H}, \mathrm{Si}\left(\mathrm{CH}_{3}\right)_{2}\right)$ ppm.

${ }^{13}$ C-NMR (125 MHz, CD $\left.{ }_{3} \mathrm{OD}\right): \delta=218.8$ (CSSR), 164.5 (C-4), $163.2(\mathrm{COOH})$,

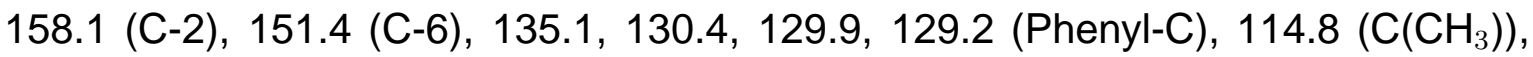
101.5 (C-5), 94.2 (C-1'), 90.9 (C-4'), 85.7 (C-2'), 83.5 (C-3'), 65.3 (C-5'), 42.3 $\left(\mathrm{CH}_{2}\right), 27.6\left(\mathrm{CH}_{3}\right), 26.4\left(\mathrm{SiC}\left(\mathrm{CH}_{3}\right)_{3}\right), 25.6\left(\mathrm{CH}_{3}\right), 19.2\left(\mathrm{SiC}\left(\mathrm{CH}_{3}\right)_{3}\right),-4.9 \mathrm{Si}\left(\mathrm{CH}_{3}\right)$, $-5.1 \mathrm{Si}\left(\mathrm{CH}_{3}\right) \mathrm{ppm}$.

MS (ESI): $\mathbf{m} / \mathbf{z}(\%)=587.2(100)[\mathrm{M}+\mathrm{Na}]^{+}, 1151.4(90)[2 \mathrm{M}+\mathrm{Na}]^{+}, 563.2(100)$ $[\mathrm{M}-\mathrm{H}]^{-}$. 
3. Experimental section

HRMS: $m / z$ calc. for $\mathrm{C}_{26} \mathrm{H}_{36} \mathrm{~N}_{2} \mathrm{O}_{6} \mathrm{~S}_{2} \mathrm{SiNa}[\mathrm{M}+\mathrm{Na}]^{+}:$587.1676, found: 587.1669 . 


\subsubsection{Dithioorotidinebenzylester (36)}

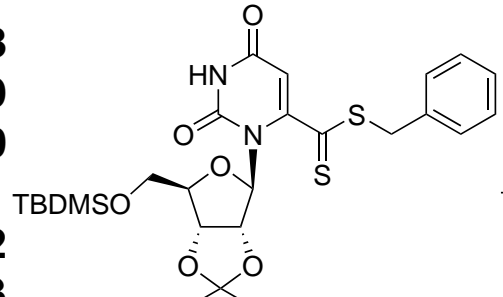

35

TFA/ $/ \mathrm{H}_{2} \mathrm{O}$ v/v 50:50

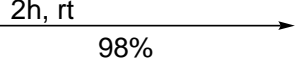

M: $564.8 \mathrm{~g} / \mathrm{mol}$

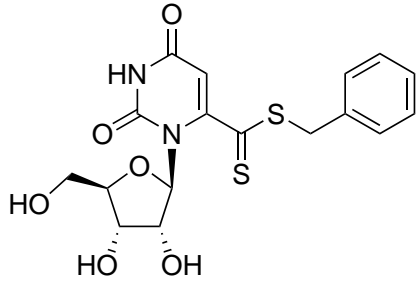

36

M: $410.5 \mathrm{~g} / \mathrm{mol}$

35 (696 mg, $1.23 \mathrm{mmol}, 1.0$ eq.) was dissolved in $\mathrm{TFA} / \mathrm{H}_{2} \mathrm{O}(50: 50 \mathrm{v} / \mathrm{v}, 20 \mathrm{~mL})$ and the solution was stirred at ambient temperature for $30 \mathrm{~min}$. The solvents were evaporated in vacuo. The desired product (36) $(500 \mathrm{mg}, 1.21 \mathrm{mmol}, 98 \%)$ was obtained as an orange solid.

${ }^{1} \mathrm{H}-N M R\left(300 \mathrm{MHz}, \mathrm{CD}_{3} \mathrm{OD}\right): \delta=7.43-7.27(\mathrm{~m}, 5 \mathrm{H}$, Phenyl-H), $5.64(\mathrm{~s}, 1 \mathrm{H}, \mathrm{H}-$ 5), $5.46\left(\mathrm{~d}, J=3.5 \mathrm{~Hz}, 1 \mathrm{H}, \mathrm{H}-1^{\prime}\right.$ ), 4.71 (dd, J = 6.2, $3.5 \mathrm{~Hz}, 1 \mathrm{H}, \mathrm{H}-2$ '), 4.64 (d, $J=2.2 \mathrm{~Hz}, 2 \mathrm{H}, \mathrm{CH}_{2}$ ), 4.33 (t, J = 6.2 Hz, $1 \mathrm{H}, \mathrm{H}-3$ '), 3.85-3.60 (m, $\left.3 \mathrm{H}, \mathrm{H}-4^{\prime}, \mathrm{H}-5^{\prime}\right)$ ppm.

MS (ESI): m/z (\%) = $433.1(80)[\mathrm{M}+\mathrm{Na}]^{+}, 409.0(50)[\mathrm{M}-\mathrm{H}]^{-}$.

HRMS: $m / z$ calc. for $\mathrm{C}_{17} \mathrm{H}_{18} \mathrm{~N}_{2} \mathrm{O}_{6} \mathrm{~S}_{2} \mathrm{Na}[\mathrm{M}+\mathrm{Na}]^{+}:$:33.0498, found: 433.0492 . 


\subsubsection{Dithioorotidine-5'-monophosphatebenzylester (37)}<smiles>O=C(SCc1ccccc1)c1cc(=O)[nH]c(=O)n1C1OC(CO)C(O)C1O</smiles>

36
$\mathrm{POCl}_{3},(\mathrm{MeO})_{3} \mathrm{PO}$

$6 \mathrm{~h}, \mathrm{rt}$<smiles>O=c1cc(C(=S)SCc2ccccc2)n(C2OC(COP(=O)(O)O)C(O)C2O)c(=O)[nH]1</smiles>

37

M: $410.5 \mathrm{~g} / \mathrm{mol}$

Under an argon atmosphere, 36 (200 mg, $487 \mu \mathrm{mol}, 1.0$ eq.) was suspended in dry trimethylphosphate $(2.5 \mathrm{~mL})$ and was cooled to $0{ }^{\circ} \mathrm{C}$. Phosphoroxychloride (89 $\mu \mathrm{L}, 149 \mathrm{mg} 974 \mu \mathrm{mol}, 2.0$ eq.) was added dropwise and the resulting solution was stirred at $0{ }^{\circ} \mathrm{C}$ for $4 \mathrm{~h}$ and at ambient temperature for $20 \mathrm{~h}$. The mixture was quenched by the addition of aqueous $\mathrm{NaHCO}_{3}$ solution $(6 \%, 1 \mathrm{~mL})$ and the solvent was evaporated in vacuo. The crude product was purified by ion exchange HPLC using a linear gradient of TEAA in water at $\mathrm{pH}$ 7. The product (37) was obtained as the triethylammonium salt.

MS (ESI): m/z (\%) = $489.0(100)[\mathrm{M}-\mathrm{H}]^{-}$.

HRMS: $m / z$ calc. for $\mathrm{C}_{17} \mathrm{H}_{19} \mathrm{~N}_{2} \mathrm{O}_{9} \mathrm{~S}_{2} \mathrm{P}[\mathrm{M}-\mathrm{H}]^{-}:$489.0197, found: 489.0196 . 


\subsection{Synthesis of queuine}

\subsubsection{Methyl-6-deoxy-6-iodo-3,4-O-isopropylidene- $\alpha$-D- galactopyranoside (139)}

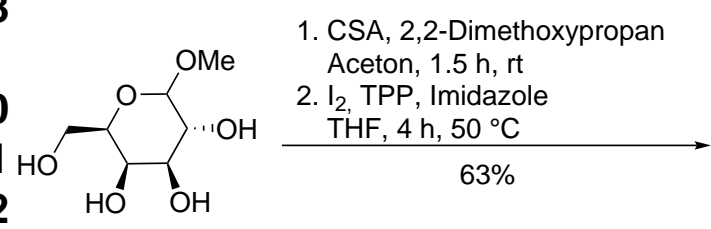

137

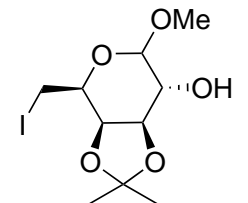

139

$\mathrm{M}: 428.4 \mathrm{~g} / \mathrm{mol}$

$\mathrm{M}: 344.1 \mathrm{~g} / \mathrm{mol}$

To a stirred suspension of methyl $\alpha$-D-galactopyranoside $137(25 \mathrm{~g}, 129 \mathrm{mmol}$, 1.0 eq.) in acetone ( $450 \mathrm{~mL})$ 2,2-dimethoxypropane (39,5 mL, $233 \mathrm{mmol}, 2.5$ eq.) and camphor sulfonic acid ( $5 \mathrm{~mol} \%, 1.5 \mathrm{~g}, 6.45 \mathrm{mmol}$ ) were added and the resulting solution was stirred for $2 \mathrm{~h}$ at ambient temperature. After addition of $\mathrm{NEt}_{3}(3 \mathrm{~mL})$ the mixture was evaporated in vacuo and the resulting residue was redissolved in THF (900 mL). Triphenylphosphine $(50.75 \mathrm{~g}, 194 \mathrm{mmol}, 1.5 \mathrm{eq}$.) and imidazole (17.6 g, $258 \mathrm{mmol}, 2.0$ eq.) were added and the solution was heated to $50{ }^{\circ} \mathrm{C}$. Subsequently a solution of iodine $(49.2 \mathrm{~g}, 194 \mathrm{mmol}, 1.5 \mathrm{eq}$.) in THF (180 mL) was added dropwise and the solution was stirred for $2.5 \mathrm{~h}$ at $50{ }^{\circ} \mathrm{C}$. The solution was cooled to ambient temperature and quenched with aqueous $\mathrm{Na}_{2} \mathrm{~S}_{2} \mathrm{O}_{3}$ solution $(10 \%$, $600 \mathrm{~mL}$ ). The layers were separated, and the aqueous layer was extracted with EtOAc $(3 \times 200 \mathrm{~mL})$. The combined organic layers were washed with sat. aqueous $\mathrm{NaCl}$ solution $(2 \times 200 \mathrm{~mL})$, dried over $\mathrm{MgSO}_{4}$ and the solvents were evaporated in vacuo. The crude product was purified by column chromatography on silica gel using pentane/EtOAc 1:1. The desired product $139(27.9 \mathrm{~g}, 81.1 \mathrm{mmol}, 63 \%$ over two steps) was obtained as a white solid.

${ }^{1} \mathrm{H}-N M R\left(300 \mathrm{MHz}, \mathrm{CDCl}_{3}\right): \delta=4.68(\mathrm{~d}, J=3.9 \mathrm{~Hz}, 1 \mathrm{H}, \mathrm{H}-1), 4.25-4.17(\mathrm{~m}, 2 \mathrm{H}$, $\mathrm{H}-3, \mathrm{H}-4), 4.08-4.00(\mathrm{~m}, 1 \mathrm{H}, \mathrm{H}-5), 3.81-3.75(\mathrm{~m}, 1 \mathrm{H}, \mathrm{H}-2), 3.43\left(\mathrm{~s}, 3 \mathrm{H}, \mathrm{OCH}_{3}\right)$, 3.30-3.17 (m, $\left.2 \mathrm{H}, \mathrm{H}-6, \mathrm{H}-6^{\prime}\right), 1.40\left(\mathrm{~s}, 3 \mathrm{H}, \mathrm{C}\left(\mathrm{CH}_{3}\right)_{2}\right), 1.26\left(\mathrm{~s}, 3 \mathrm{H}, \mathrm{C}\left(\mathrm{CH}_{3}\right)_{2}\right) \mathrm{ppm}$.

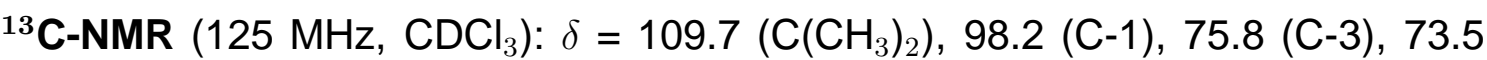
(C-4), $69.4(\mathrm{C}-5), 68.6(\mathrm{C}-2), 55.6\left(\mathrm{OCH}_{3}\right), 27.4\left(\mathrm{C}\left(\mathrm{CH}_{3}\right)_{2}\right), 25.7\left(\mathrm{C}\left(\mathrm{CH}_{3}\right)_{2}\right), 2.8(\mathrm{C}-6)$ ppm. 
3. Experimental section

MS (ESI): $\mathbf{m} / \mathbf{z}(\%)=367.0(100)[\mathrm{M}+\mathrm{Na}]^{+}$.

HRMS: $\mathrm{m} / z$ calc. for $\mathrm{C}_{10} \mathrm{H}_{17} \mathrm{OO}_{5} \mathrm{Na}[\mathrm{M}+\mathrm{Na}]^{+}: 367.0013$, found 367.0017 . 


\subsubsection{Methyl-6-deoxy-6-iodo-3,4-O-isopropylidene-2-O- tertbutyldimethylsilyl- $\alpha$-D-galactopyranoside (140)}

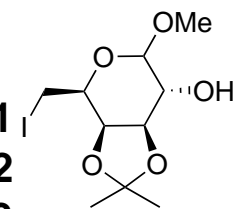

139

$\mathrm{M}: 344.1 \mathrm{~g} / \mathrm{mol}$

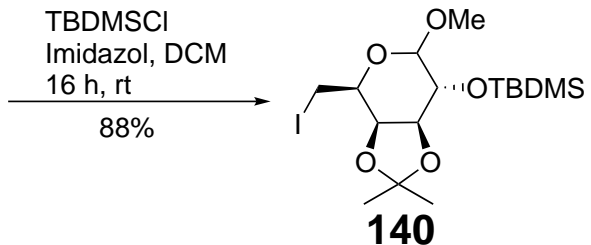

M: $428.3 \mathrm{~g} / \mathrm{mol}$

Under argon atmosphere, iodide 139 (10.0 g, $29.1 \mathrm{mmol}, 1.0$ eq.), imidazole (2.38 g, $34.9 \mathrm{mmol}, 1.2 \mathrm{eq}$ ) and TBDMSCl (5.26 g, $34.9 \mathrm{mmol}, 1.2 \mathrm{eq}$.) were dissolved in dry DCM $(120 \mathrm{~mL})$ and the solution was stirred for $16 \mathrm{~h}$ at ambient temperature. The reaction was quenched with water $(100 \mathrm{~mL})$. The layers were separated and the organic layer was washed with water $(2 \times 60 \mathrm{~mL})$ and sat. aqueous $\mathrm{NaCl}$ solution $(60 \mathrm{~mL})$, dried over $\mathrm{MgSO}_{4}$ and the solvents were evaporated in vacuo. The crude product was purified by column chromatography on silica gel using pentane/EtOAc 95:5. The desired product 140 (11.35 g, $24.8 \mathrm{mmol}, 85 \%)$ was obtained as clear oil.

${ }^{1} \mathrm{H}-\mathrm{NMR}\left(300 \mathrm{MHz}, \mathrm{CDCl}_{3}\right): \delta=4.59(\mathrm{~d}, J=3.6 \mathrm{~Hz}, 1 \mathrm{H}, \mathrm{H}-1), 4.29(\mathrm{dd}, J=5.7$, $2.4 \mathrm{~Hz}, 1 \mathrm{H}, \mathrm{H}-4)$, 4.19-4.08 (m, $2 \mathrm{H}, 3 \mathrm{H}, \mathrm{H}-3), 3.74(\mathrm{dd}, J=7.2,3.6 \mathrm{~Hz}, 1 \mathrm{H}$, $\mathrm{H}-2$ ), 3.44 (s, $3 \mathrm{H}, \mathrm{OCH}_{3}$ ), 3.41-3.29 (m, $2 \mathrm{H}, \mathrm{H}-6, \mathrm{H}-6$ '), 1.48 (s, $\left.3 \mathrm{H}, \mathrm{C}\left(\mathrm{CH}_{3}\right)_{2}\right), 1.34$ (s, $\left.3 \mathrm{H}, \mathrm{C}\left(\mathrm{CH}_{3}\right)_{2}\right), 0.98$ (s, $\left.9 \mathrm{H}, \mathrm{SiC}\left(\mathrm{CH}_{3}\right)_{3}\right), 0.10$ (s, $\left.3 \mathrm{H}, \mathrm{Si}\left(\mathrm{CH}_{3}\right)_{2}\right), 0.08$ (s, $3 \mathrm{H}$, $\left.\mathrm{Si}\left(\mathrm{CH}_{3}\right)_{2}\right)$ ppm.

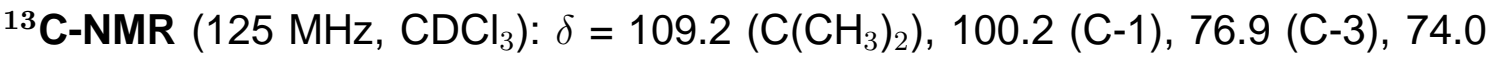
(C-4), $71.2(\mathrm{C}-2), 68.6(\mathrm{C}-5), 55.8\left(\mathrm{OCH}_{3}\right), 28.1\left(\mathrm{C}_{\left.\left(\mathrm{CH}_{3}\right)_{2}\right),} 26.2\left(\mathrm{C}_{\left.\left(\mathrm{CH}_{3}\right)_{2}\right),}\right) 25.8\right.$ $\left(\mathrm{SiC}\left(\mathrm{CH}_{3}\right)_{3}\right), 18.1\left(\mathrm{SiC}\left(\mathrm{CH}_{3}\right)_{3}\right), 2.85(\mathrm{C}-6), 0.58\left(\mathrm{Si}\left(\mathrm{CH}_{3}\right)_{2}\right), 0.75\left(\mathrm{Si}\left(\mathrm{CH}_{3}\right)_{2}\right)$ ppm.

MS (ESI): m/z (\%) = $481.1(100)[\mathrm{M}+\mathrm{Na}]^{+}$.

HRMS: $m / z$ calc. for $\mathrm{C}_{16} \mathrm{H}_{31} \mathrm{IO}_{5} \mathrm{SiNa}[\mathrm{M}+\mathrm{Na}]^{+}:$481.0878, found 481.0878. 


\subsection{3. (2R,3S,4S)-3,4-O-Isopropylidene-2-O- tertbutyldimethylsilyl-hex-5-en-1-al (141)}

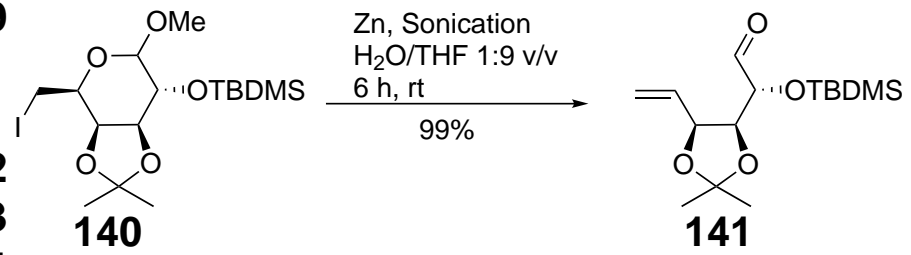

$\mathrm{M}: 428.3 \mathrm{~g} / \mathrm{mol}$
M: $300.5 \mathrm{~g} / \mathrm{mol}$

Galactopyranoside 140 (32.6 g, $71.2 \mathrm{mmol}, 1.0$ eq.) and was dissolved in $\mathrm{THF} / \mathrm{H}_{2} \mathrm{O}$ $(9: 1, \mathrm{v} / \mathrm{v}, 600 \mathrm{~mL})$ and zinc powder $(46.5 \mathrm{~g}, 710 \mathrm{mmol}, 10.0$ eq.) was added. The suspension was stirred at $50{ }^{\circ} \mathrm{C}$ for $6 \mathrm{~h}$. After cooling to ambient temperature, the suspension was filtered through a silica plug and washed with $\mathrm{Et}_{2} \mathrm{O}(300 \mathrm{~mL})$. The organic layer was washed with water $(200 \mathrm{~mL})$, sat. aqueous $\mathrm{NaHCO}_{3}$ solution $(200 \mathrm{~mL})$ and sat. aqueous $\mathrm{NaCl}$ solution $(200 \mathrm{~mL})$, dried over $\mathrm{MgSO}_{4}$ and the solvents were evaporated in vacuo to give the desired product $141(21.2 \mathrm{~g}, 70.6 \mathrm{mmol}$, $99 \%$ ) as yellowish oil.

${ }^{1} \mathrm{H}-\mathrm{NMR}\left(300 \mathrm{MHz}, \mathrm{CDCl}_{3}\right): \delta=9.67(\mathrm{~d}, J=0.9 \mathrm{~Hz}, 1 \mathrm{H}, \mathrm{CHO}), 5.92$ (ddd, $J=17.3,10.4,6.8 \mathrm{~Hz}, 1 \mathrm{H}, \mathrm{H}-5$ ), 5.35, (dt, $J=17.3,1.5 \mathrm{~Hz}, 1 \mathrm{H}, \mathrm{H}-6), 5.21$ (dt, $\left.J=10.4,1.5 \mathrm{~Hz}, 1 \mathrm{H}, \mathrm{H}-6^{\prime}\right), 4.72(\mathrm{t}, J=6.8 \mathrm{~Hz}, 1 \mathrm{H}, \mathrm{H}-4), 4.32$ (dd, $J=6.8,5.3 \mathrm{~Hz}$, $1 \mathrm{H}, \mathrm{H}-3), 4.07$ (dd, $J=5.3,0.9 \mathrm{~Hz}, 1 \mathrm{H}, \mathrm{H}-2), 1.51\left(\mathrm{~s}, 3 \mathrm{H}, \mathrm{C}\left(\mathrm{CH}_{3}\right)_{2}\right), 1.35(\mathrm{~s}, 1 \mathrm{H}$, $\left.\mathrm{C}\left(\mathrm{CH}_{3}\right)_{2}\right), 0.92\left(\mathrm{~s}, 9 \mathrm{H}, \mathrm{SiC}\left(\mathrm{CH}_{3}\right)_{3}\right), 0.09\left(\mathrm{~d}, J=1.8 \mathrm{~Hz}, 6 \mathrm{H}, \mathrm{Si}\left(\mathrm{CH}_{3}\right)_{2}\right) \mathrm{ppm}$.

${ }^{13}$ C-NMR $\left(125 \mathrm{MHz}, \mathrm{CDCl}_{3}\right): \delta=201.8(\mathrm{CHO}), 133.8(\mathrm{C}-5), 118.9(\mathrm{C}-6), 109.2$

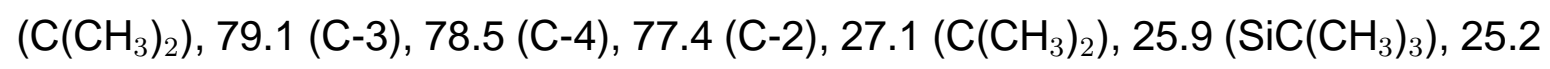
$\left(\mathrm{C}\left(\mathrm{CH}_{3}\right)_{2}\right), 18.4\left(\mathrm{SiC}\left(\mathrm{CH}_{3}\right)_{3}\right),-4.4\left(\mathrm{Si}\left(\mathrm{CH}_{3}\right)_{2}\right),-4.7\left(\mathrm{Si}\left(\mathrm{CH}_{3}\right)_{2}\right)$ ppm.

MS (ESI): $\mathbf{m} / \mathbf{z}(\%)=323.2(0.5)[\mathrm{M}+\mathrm{Na}]^{+}$.

HRMS: $m / z$ calc. for $\mathrm{C}_{15} \mathrm{H}_{28} \mathrm{O}_{4} \mathrm{SiNa}[\mathrm{M}+\mathrm{Na}]^{+}:$323.1649, found 323.1648. 


\subsection{4. (2R,3S,4S)-3,4-O-Isopropylidene-2-O- tertbutyldimethylsilyl-hepta-1,5-diene (142)}

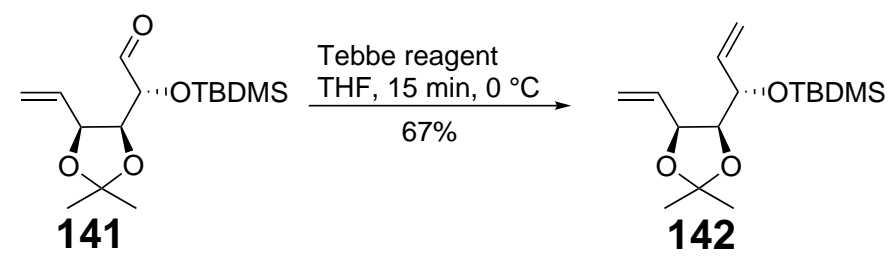

M: $300.5 \mathrm{~g} / \mathrm{mol}$

$\mathrm{M}: 398.5 \mathrm{~g} / \mathrm{mol}$

Under an argon atmosphere, aldehyde 141 (21.2 g, $70.6 \mathrm{mmol}, 1.0$ eq.) was dissolved in dry THF $(200 \mathrm{~mL})$ and the solution was cooled to $0{ }^{\circ} \mathrm{C}$. TeBBE REAGENT $(0.5 \mathrm{M}$ in toluene, $200 \mathrm{~mL}, 100 \mathrm{mmol}, 1.4 \mathrm{eq}$.) was added dropwise and the resulting solution was stirred at $0{ }^{\circ} \mathrm{C}$ for $30 \mathrm{~min}$. Subsequently, $\mathrm{Et}_{2} \mathrm{O}(200 \mathrm{~mL})$ was added and water (12 $\mathrm{mL}$ ) was added dropwise. The resulting suspension was dried over $\mathrm{MgSO}_{4}$, filtered and the residue was washed with $\mathrm{Et}_{2} \mathrm{O}(100 \mathrm{~mL})$. The solvents of the combined organic layers were evaporated in vacuo and the resulting crude product was purified by column chromatography on silica gel using pentane/EtOAc 95:5. The desired product $142(14.1 \mathrm{~g}, 47.1 \mathrm{mmol}, 67 \%)$ was obtained as an orange oil.

${ }^{1}$ H-NMR $\left(300 \mathrm{MHz}, \mathrm{CDCl}_{3}\right): \delta=6.04-5.80(\mathrm{~m}, 2 \mathrm{H}, \mathrm{H}-2, \mathrm{H}-6), 5.41-5.12(\mathrm{~m}, 4 \mathrm{H}$, $\mathrm{H}-1, \mathrm{H}-7), 4.48-4.41(\mathrm{~m}, 1 \mathrm{H}, \mathrm{H}-5), 4.22-4.14(\mathrm{~m}, 1 \mathrm{H}, \mathrm{H}-4), 4.02-3.95(\mathrm{~m}, 1 \mathrm{H}, \mathrm{H}-$

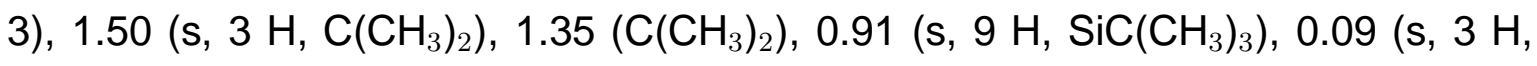
$\left.\mathrm{Si}\left(\mathrm{CH}_{3}\right)_{2}\right), 0.07\left(\mathrm{~s}, 3 \mathrm{H}, \mathrm{Si}\left(\mathrm{CH}_{3}\right)_{2}\right) \mathrm{ppm}$.

${ }^{13} \mathrm{C}-N M R\left(125 \mathrm{MHz}, \mathrm{CDCl}_{3}\right): \delta=136.9$ (C-2), 134.8 (C-6), 118.7 (C-7), 116.6

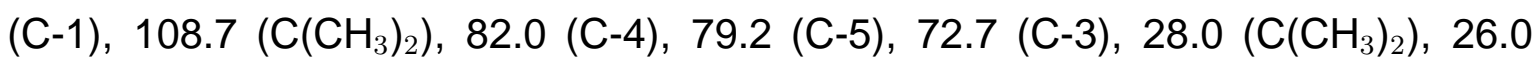

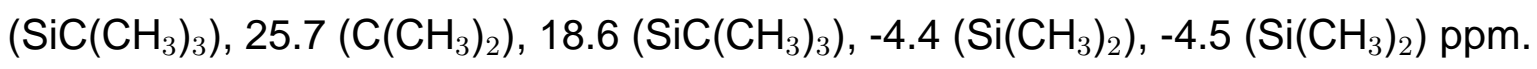

MS (ESI): $\mathbf{m} / \mathbf{z}(\%)=321.2(14)[\mathrm{M}+\mathrm{Na}]^{+}$.

HRMS: $m / z$ calc. for $\mathrm{C}_{16} \mathrm{H}_{30} \mathrm{O}_{3} \mathrm{SiNa}[\mathrm{M}+\mathrm{Na}]^{+}: 321.1856$, found 321.1854 . 


\subsection{5. (1S,2S,3S)-1-O-tertbutyldimethylsilyl-2,3-O- isopropylidene-cyclopent-4-ene (145)}

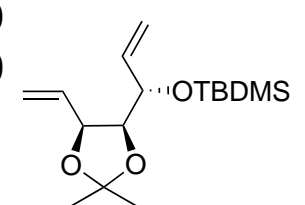

142

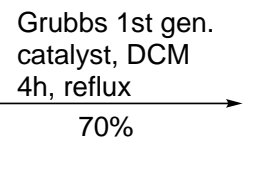

M: $928.5 \mathrm{~g} / \mathrm{mol}$

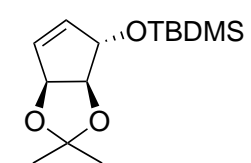

145

M: $270.4 \mathrm{~g} / \mathrm{mol}$

Under an argon atmosphere, diene 142 (942 mg, $3.10 \mathrm{mmol}, 1.0$ eq.) and GRUBBS CATALYST, 1 ST GEN. $(2.5 \mathrm{~mol} \%, 877.5 \mu \mathrm{mol}, 64 \mathrm{mg})$ were dissolved in dry DCM $(10 \mathrm{~mL})$ and the solution was stirred under reflux for $4 \mathrm{~h}$. After cooling to ambient temperature, the solvent was evaporated in vacuo and the resulting crude product was purified by column chromatography on silica gel using pentane/EtOAc 3:1. The desired product 145 (587 mg, $2.17 \mathrm{mmol}, 70 \%$ ) was obtained as brown oil.

${ }^{1} \mathrm{H}-\mathrm{NMR}\left(300 \mathrm{MHz}, \mathrm{CDCl}_{3}\right): \delta=6.00(\mathrm{~d}, J=5.7 \mathrm{~Hz}, 1 \mathrm{H}, \mathrm{H}-1), 5.88(\mathrm{dd}, J=5.7$, $2.0 \mathrm{~Hz}, 1 \mathrm{H}, \mathrm{H}-4), 5.27$ (dd, J = 5.6, $1.0 \mathrm{~Hz}, 1 \mathrm{H}, \mathrm{H}-3), 4.76(\mathrm{~s}, 1 \mathrm{H}, \mathrm{H}-2), 4.49$ (d, $J=5.6 \mathrm{~Hz}, 1 \mathrm{H}, \mathrm{H}-5), 1.38\left(\mathrm{~s}, 3 \mathrm{H}, \mathrm{C}\left(\mathrm{CH}_{3}\right)_{2}\right), 1.33\left(\mathrm{~s}, 3 \mathrm{H}, \mathrm{C}\left(\mathrm{CH}_{3}\right)_{2}\right), 0.90(\mathrm{~s}, 9 \mathrm{H}$, $\left.\mathrm{SiC}\left(\mathrm{CH}_{3}\right)_{3}\right), 0.08\left(\mathrm{~s}, 3 \mathrm{H}, \mathrm{Si}\left(\mathrm{CH}_{3}\right)_{2}\right), 0.06\left(\mathrm{~s}, 3 \mathrm{H}, \mathrm{Si}\left(\mathrm{CH}_{3}\right)_{2}\right) \mathrm{ppm}$.

${ }^{13}$ C-NMR $\left(125 \mathrm{MHz}, \mathrm{CDCl}_{3}\right): \delta=135.5(\mathrm{C}-5), 134.8(\mathrm{C}-4), 111.8\left(\mathrm{C}_{\left.\left(\mathrm{CH}_{3}\right)_{2}\right), 86.0}\right.$ (C-3), $84.4(\mathrm{C}-2), 81.1(\mathrm{C}-1), 27.4\left(\mathrm{C}\left(\mathrm{CH}_{3}\right)_{2}\right), 25.8\left(\mathrm{C}\left(\mathrm{CH}_{3}\right)_{2}\right), 18.6\left(\mathrm{SiC}\left(\mathrm{CH}_{3}\right)_{3}\right),-4.4$ $\left(\mathrm{Si}\left(\mathrm{CH}_{3}\right)_{2}\right),-4.5\left(\mathrm{Si}\left(\mathrm{CH}_{3}\right)_{2}\right)$ ppm.

MS (ESI): $\mathbf{m} / \mathbf{z}(\%)=315.2(4)[\mathrm{M}+\mathrm{HCOO}]^{-}$.

HRMS: $m / z$ calc. for $\mathrm{C}_{14} \mathrm{H}_{26} \mathrm{O}_{3} \mathrm{SiHCOOa}[\mathrm{M}+\mathrm{HCOO}]^{-}: 315.1640$, found 315.1633 . 


\subsection{6. (2R,3S,4S)-2-Hydroxy-3,4-O-isopropylidene-hepta-1,5- diene (143)}

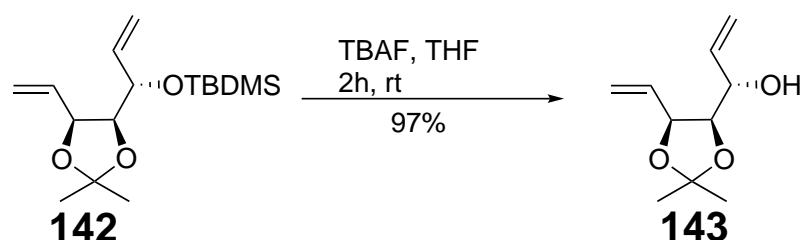

M: $298.5 \mathrm{~g} / \mathrm{mol}$

M: $184.2 \mathrm{~g} / \mathrm{mol}$

Diene 142 (13.6 g, $45.6 \mathrm{mmol}, 1.0$ eq.) was dissolved in THF (500 mL) and a solution of TBAF.3 $\mathrm{H}_{2} \mathrm{O}$ (28.8 g, $91.2 \mathrm{mmol}, 2.0$ eq.) in THF (100 mL) was added dropwise. The solution was stirred for $2.5 \mathrm{~h}$ at ambient temperature. The solvent was evaporated in vacuo and the resulting crude product was purified by column chromatography on silica gel using pentane/EtOAc 5:1. The desired product 143 (8.12 g, $44.1 \mathrm{mmol}, 97 \%$ ) was obtained as yellow oil.

${ }^{1} \mathrm{H}-\mathrm{NMR}\left(300 \mathrm{MHz}, \mathrm{CDCl}_{3}\right): \delta=6.07-5.93(\mathrm{~m}, 1 \mathrm{H}, \mathrm{H}-2), 5.90-5.77(\mathrm{~m}, 1 \mathrm{H}, \mathrm{H}-6)$, 5.44-5.17 (m, $4 \mathrm{H}, \mathrm{H}-1, \mathrm{H}-7)$, 4.63-4.55 (m, $1 \mathrm{H}, \mathrm{H} 5)$, 4.16-4.04 (m, $2 \mathrm{H}, \mathrm{H}-4, \mathrm{H}-3)$, $1.52\left(\mathrm{~s}, 3 \mathrm{H}, \mathrm{C}\left(\mathrm{CH}_{3}\right)_{2}\right), 1.38\left(\mathrm{~s}, 3 \mathrm{H}, \mathrm{C}\left(\mathrm{CH}_{3}\right)_{2}\right) \mathrm{ppm}$.

${ }^{13}$ C-NMR (125 MHz, $\left.\mathrm{CDCl}_{3}\right): \delta=136.8$ (C-2), 134.1 (C-6), 119.5 (C-7), 117.2 (C-1), $108.1\left(\mathrm{C}_{\left.\left(\mathrm{CH}_{3}\right)_{2}\right),} 80.8(\mathrm{C}-4), 79.7(\mathrm{C}-5), 70.7(\mathrm{C}-3), 27.5\left(\mathrm{C}_{\left.\left(\mathrm{CH}_{3}\right)_{2}\right), 25.1}\right.\right.$ $\left(\mathrm{C}\left(\mathrm{CH}_{3}\right)_{2}\right)$ ppm.

MS (ESI): $\mathbf{m} / \mathbf{z}(\%)=207.1(7)[\mathrm{M}+\mathrm{Na}]^{+}$.

HRMS: $m / z$ calc. for $\mathrm{C}_{10} \mathrm{H}_{16} \mathrm{O}_{3} \mathrm{Na}[\mathrm{M}+\mathrm{Na}]^{+}:$207.0992, found 207.0992. 


\subsection{7. (1S,2S,3S)-1-Hydroxy-2,3-O-isopropylidene-cyclopent-4- ene (130)}

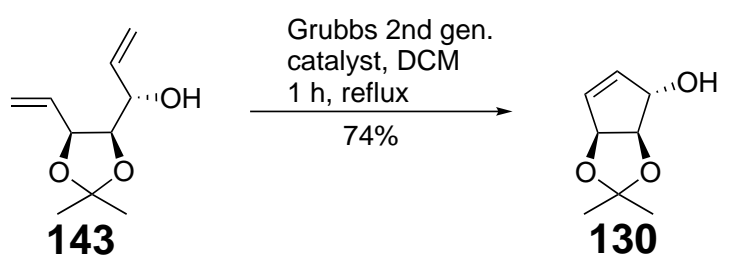

M: $184.2 \mathrm{~g} / \mathrm{mol}$

M: $156.2 \mathrm{~g} / \mathrm{mol}$

Under an argon atmosphere, diene 143 (8.12 g, $44.1 \mathrm{mmol}, 1.0 \mathrm{eq}$.) and GRUBBS CATALYST, 2ND GEN. (2.3 mol\%, $848 \mathrm{mg}, 1.0$ eq.) were dissolved in dry DCM $(200 \mathrm{~mL})$ and the solution was stirred under reflux for $1 \mathrm{~h}$. After cooling to ambient temperature, the solvent was evaporated in vacuo and the resulting crude product was purified by column chromatography on silica gel using pentane/EtOAc 2:1. The desired product 130 (5.2 g, $32.7 \mathrm{mmol}, 74 \%$ ) was obtained as brown oil.

${ }^{1} \mathrm{H}-\mathrm{NMR}\left(300 \mathrm{MHz}, \mathrm{CDCl}_{3}\right): \delta=6.00(\mathrm{~d}, J=5.7 \mathrm{~Hz}, 1 \mathrm{H}, \mathrm{H}-1), 5.88(\mathrm{dd}, J=5.7$, $2.0 \mathrm{~Hz}, 1 \mathrm{H}, \mathrm{H}-4), 5.27$ (dd, J = 5.6, $1.0 \mathrm{~Hz}, 1 \mathrm{H}, \mathrm{H}-3), 4.76(\mathrm{~s}, 1 \mathrm{H}, \mathrm{H}-2), 4.49$ (d, $J=5.6 \mathrm{~Hz}, 1 \mathrm{H}, \mathrm{H}-5), 1.38\left(\mathrm{~s}, 3 \mathrm{H}, \mathrm{C}\left(\mathrm{CH}_{3}\right)_{2}\right), 1.33\left(\mathrm{~s}, 3 \mathrm{H}, \mathrm{C}\left(\mathrm{CH}_{3}\right)_{2}\right) \mathrm{ppm}$.

${ }^{13} \mathrm{C}$-NMR (125 MHz, CDCl 3 ): $\delta=135.5(\mathrm{C}-5), 134.8(\mathrm{C}-4), 111.8\left(\mathrm{C}_{\left.\left(\mathrm{CH}_{3}\right)_{2}\right), 86.0}\right.$ (C-3), $84.4(\mathrm{C}-2), 81.1(\mathrm{C}-1), 27.4\left(\mathrm{C}\left(\mathrm{CH}_{3}\right)_{2}\right), 25.8\left(\mathrm{C}_{\left.\left(\mathrm{CH}_{3}\right)_{2}\right) \mathrm{ppm} .}\right.$

MS $(E S I): \mathbf{m} / \mathbf{z}(\%)=179.1(4)[\mathrm{M}+\mathrm{Na}]^{+}$.

HRMS: $\mathrm{m} / z$ calc. for $\mathrm{C}_{8} \mathrm{H}_{12} \mathrm{O}_{3} \mathrm{Na}[\mathrm{M}+\mathrm{Na}]^{+}:$179.0679, found 179.0678 . 


\subsection{8. (1R,2S,3S)-1-Bromo-2,3-O-isopropylidene-cyclopent-4- ene (122)}

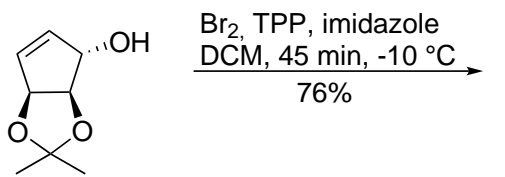

130

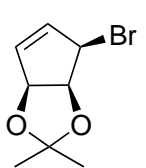

122

Triphenylphosphine (16.1 g, $61.4 \mathrm{mmol}, 2.0$ eq.) was dissolved in DCM (300 mL) and cooled to $-10^{\circ} \mathrm{C}$. A solution of bromine $(3.1 \mathrm{~mL}, 61.4 \mathrm{mmol}, 2.0$ eq.) in DCM $(20 \mathrm{~mL})$ was added dropwise. The resulting solution was added slowly to a solution of alcohol 130 (4.8 g, $30.7 \mathrm{mmol}, 1.0$ eq.) and imidazole $(2.3 \mathrm{~g}, 33.8 \mathrm{mmol}$, 1.1 eq.) in $\mathrm{DCM}(150 \mathrm{~mL})$ at $-10^{\circ} \mathrm{C}$. The reaction mixture was stirred at $-10{ }^{\circ} \mathrm{C}$ for $45 \mathrm{~min}$, then allowed to reach ambient temperature and $\mathrm{Et}_{2} \mathrm{O}(300 \mathrm{~mL})$ was added. The resulting organic solution was washed with water $(2 \times 300 \mathrm{~mL})$ and sat. aqueous $\mathrm{NaCl}$ solution $\left(300 \mathrm{~mL}\right.$ ), dried over $\mathrm{MgSO}_{4}$ and the solvents were evaporated in vacuo. The residue was dissolved in DCM $(10 \mathrm{~mL})$ and hexane $(500 \mathrm{~mL})$ was added. The resulting suspension was filtered, and the filtrate was concentrated in vacuo. The residue was suspended in hexane $(150 \mathrm{~mL})$ and filtered. The filtrate was concentrated in vacuo and the resulting crude product purified by column chromatography on silica gel using pentane/EtOAc 95:5. The desired product $122(5.1 \mathrm{~g}$, $23.3 \mathrm{mmol}, 76 \%$ ) was obtained as colorless oil.

${ }^{1}$ H-NMR $\left(300 \mathrm{MHz}, \mathrm{CDCl}_{3}\right): \delta=6.01-5.97(\mathrm{~m}, 1 \mathrm{H}, \mathrm{H}-5), 5.97-5.93(\mathrm{~m}, 1 \mathrm{H}, \mathrm{H}-4)$, $5.32(\mathrm{~d}, J=5.4 \mathrm{~Hz}, 1 \mathrm{H}, \mathrm{H}-3), 4.96(\mathrm{~d}, J=5.4 \mathrm{~Hz}, 1 \mathrm{H}, \mathrm{H}-2), 4.86-4.82(\mathrm{~m}, 1 \mathrm{H}$, $\mathrm{H}-1), 1.38\left(\mathrm{~s}, 3 \mathrm{H}, \mathrm{C}\left(\mathrm{CH}_{3}\right)_{2}\right), 1.34\left(\mathrm{~s}, 3 \mathrm{H}, \mathrm{C}\left(\mathrm{CH}_{3}\right)_{2}\right) \mathrm{ppm}$.

${ }^{13}$ C-NMR $\left(125 \mathrm{MHz}, \mathrm{CDCl}_{3}\right): \delta=135.1(\mathrm{C}-5), 134.2(\mathrm{C}-4), 112.2\left(\mathrm{C}_{\left.\left(\mathrm{CH}_{3}\right)_{2}\right), 86.0}\right.$ (C-3), $84.1(\mathrm{C}-2), 54.5(\mathrm{C}-1), 27.5\left(\mathrm{C}\left(\mathrm{CH}_{3}\right)_{2}\right), 26.3\left(\mathrm{C}_{(}\left(\mathrm{CH}_{3}\right)_{2}\right)$ ppm.

MS $(E S I): \mathbf{m} / \mathbf{z}(\%)=241.0(7)[\mathrm{M}+\mathrm{Na}]^{+}$.

HRMS: $m / z$ calc. for $\mathrm{C}_{8} \mathrm{H}_{11} \mathrm{O}_{2} \mathrm{BrNa}[\mathrm{M}+\mathrm{Na}]^{+}: 240.9835$, found 240.9833 . 


\subsubsection{2',3'-O-Isopropylidene-queuine (144)}

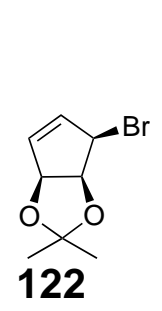

M: $219.1 \mathrm{~g} / \mathrm{mol}$

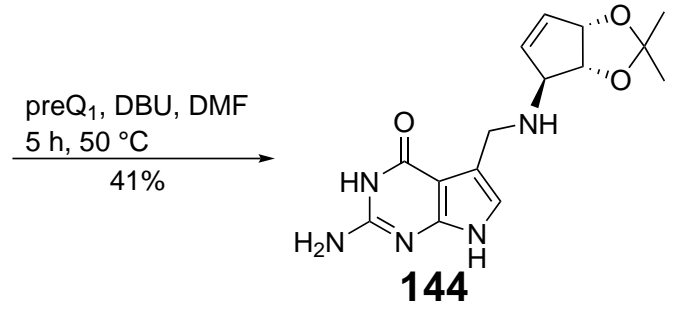

M: $317.3 \mathrm{~g} / \mathrm{mol}$

Under an argon atmosphere, preQ $_{1}(\mathbf{5 8})(1.0 \mathrm{~g}, 4.0 \mathrm{mmol}, 1.0$ eq.) was dissolved in DMF (15 mL). DBU (6.0 mL, $40.0 \mathrm{mmol}, 10.0$ eq.) was added and the solution was stirred at $50{ }^{\circ} \mathrm{C}$ for $15 \mathrm{~min}$. A solution of bromocyclopentene $122(1.1 \mathrm{~g}$, $4.8 \mathrm{mmol}, 1.2$ eq.) in DMF ( $3 \mathrm{~mL})$ was added dropwise and the solution was stirred at $50{ }^{\circ} \mathrm{C}$ for $5 \mathrm{~h}$. After cooling to ambient temperature, the solvent was evaporated in vacuo and the residue was purified by column chromatography on silica gel using EtOAc/MeOH/NEt 3 3:1:0.1. The resulting crude product was suspended in $\mathrm{CHCl}_{3}$ $(100 \mathrm{~mL})$ and stirred for $10 \mathrm{~min}$. The solid components were separated by filtration and suspended in methanol $(30 \mathrm{~mL})$. The suspension was filtered, and the filtrate was concentrated in vacuo to yield the desired product $144(581 \mathrm{mg}, 1.64 \mathrm{mmol}$, $41 \%)$ as a slightly yellow solid.

${ }^{1} \mathrm{H}-\mathrm{NMR}\left(300 \mathrm{MHz}, \mathrm{CD}_{3} \mathrm{OD}\right): \delta=6.90(\mathrm{~s}, 1 \mathrm{H}, \mathrm{H}-8), 6.30(\mathrm{dt}, J=5.9,1.7 \mathrm{~Hz}$, $\left.1 \mathrm{H}, \mathrm{H}-5^{\prime}\right), 6.01\left(\mathrm{~d}, J=5.9 \mathrm{~Hz}, 1 \mathrm{H}, \mathrm{H}-4^{\prime}\right), 5.36\left(\mathrm{~d}, J=5.8 \mathrm{~Hz}, 1 \mathrm{H}, \mathrm{H}-3^{\prime}\right), 4.94(\mathrm{~d}$, $J=5.7 \mathrm{~Hz}, 1 \mathrm{H}, \mathrm{H}-2)$, 4.49-4.29 (m, $3 \mathrm{H}, \mathrm{H}-1$ ', $\left.\mathrm{H}_{2}-10\right), 1.37\left(\mathrm{~s}, 3 \mathrm{H}, \mathrm{C}\left(\mathrm{CH}_{3}\right)_{2}\right), 1.36$ (s, $\left.3 \mathrm{H}, \mathrm{C}\left(\mathrm{CH}_{3}\right)_{2}\right)$ ppm.

MS (ESI): m/z (\%) = $318.2(100)[\mathrm{M}+\mathrm{H}]^{+}, 340.2(4)[\mathrm{M}+\mathrm{Na}]^{+}$.

HRMS: $\mathrm{m} / z$ calc. for $\mathrm{C}_{15} \mathrm{H}_{20} \mathrm{~N}_{5} \mathrm{O}_{3} \mathrm{Na}[\mathrm{M}+\mathrm{Na}]^{+}: 318.1561$, found 318.1562 . 


\subsubsection{Queuine (95)}

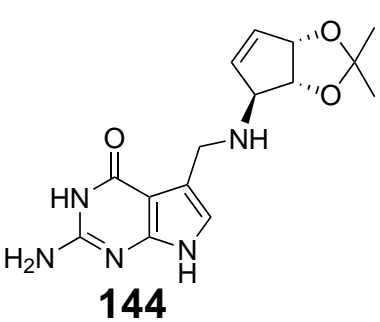

M: $317.3 \mathrm{~g} / \mathrm{mol}$

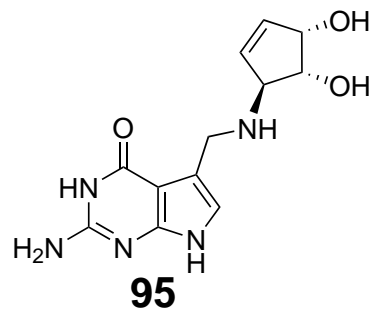

M: $277.3 \mathrm{~g} / \mathrm{mol}$

2',3'-O-Isopropylidene-queuine (144) (581 mg, $1.64 \mathrm{mmol}, 1.0$ eq.) was dissolved in methanol $(60 \mathrm{~mL})$ and conc. $\mathrm{HCl}$ solution $(5 \mathrm{~mL})$ was added. The solution was stirred under reflux for $2 \mathrm{~h}$. After cooling to ambient temperature, the resulting suspension was concentrated in vacuo to yield queuine (95) (544 mg, $1.57 \mathrm{mmol}, 96 \%)$ as a slightly yellow solid.

${ }^{1} \mathrm{H}-N M R\left(300 \mathrm{MHz}, \mathrm{CD}_{3} \mathrm{OD}\right): \delta=7.04(\mathrm{~s}, 1 \mathrm{H}, \mathrm{H}-8), 6.28(\mathrm{dt}, J=6.3,2.2 \mathrm{~Hz}, 1 \mathrm{H}$, H-5'), 6.10 (dd, J = 6.3, 1.7 Hz, $\left.1 \mathrm{H}, \mathrm{H}-4^{\prime}\right), 4.71-4.65$ (m, $1 \mathrm{H}, \mathrm{H}-3$ ') , 4.55-4.25 (m, $4 \mathrm{H}, \mathrm{H}-2$ ', H-1', $\left.\mathrm{H}_{2}-10\right)$ ppm.

${ }^{13}$ C-NMR (125 MHz, CD $\left.{ }_{3} \mathrm{OD}\right): \delta=161.8(\mathrm{C}-6), 152.6$ (C-2), 146.6 (C-4), 138.9 (C-4'), 129.8 (C-5'), 121.0 (C-7), 109.8 (C-8), 99.9 (C-5), 74.7 (C-3'), 74.0 (C-2'), $87.8\left(\mathrm{C}-1^{\prime}\right), 42.6(\mathrm{C}-10) \mathrm{ppm}$.

MS (ESI): m/z (\%) = $278.1(95)[\mathrm{M}+\mathrm{H}]^{+}, 276.1(100)[\mathrm{M}-\mathrm{H}]^{-}, 312.1(75)[\mathrm{M}+\mathrm{Cl}]^{-}$.

HRMS: $m / z$ calc. for $\mathrm{C}_{12} \mathrm{H}_{15} \mathrm{~N}_{5} \mathrm{O}_{3} \mathrm{Na}[\mathrm{M}+\mathrm{Na}]^{+}: 300.1067$, found 300.1063. 


\subsubsection{Benzyl- $\beta$-D-galactopyranoside (132)}

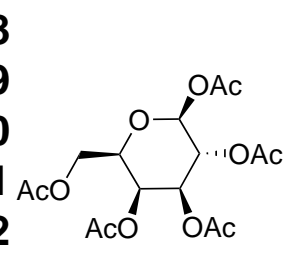

131

1. $\mathrm{BF}_{3} \cdot \mathrm{OEt}_{2}$ $\mathrm{BnOH}$, molecular sieves $\mathrm{DCM}, 20 \mathrm{~h}, \mathrm{rt}$ 2. $\mathrm{NaOMe}, \mathrm{MeOH}$ $20 \mathrm{~h}, \mathrm{rt}$

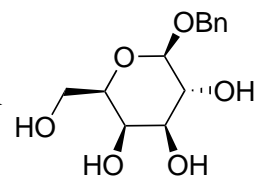

132

$\beta$-D-Galactose-pentaacetate (131) (10.0 g, $25.4 \mathrm{mmol}, 1.0$ eq.) was dissolved in DCM (100 mL) and benzylalcohol (3.5 mL, $33.2 \mathrm{mmol}, 1.3 \mathrm{eq}$.) and molecular sieves (4 Å, $10.0 \mathrm{~g}$ ) were added. Subsequently, $\mathrm{BF}_{3} \cdot \mathrm{OEt}_{2}(6.5 \mathrm{~mL}, 51.0 \mathrm{mmol}, 2.0$ eq.) was added dropwise at $0{ }^{\circ} \mathrm{C}$. The solution was stirred for $20 \mathrm{~h}$ at ambient temperature and neutralized with $\mathrm{NEt}_{3}$. The organic solution was washed with water $(3 \times 70 \mathrm{~mL})$ dried over $\mathrm{MgSO}_{4}$ and the solvent was evaporated in vacuo. The crude residue was redissolved in methanol $(300 \mathrm{~mL})$ and $\mathrm{NaOMe}(2.0 \mathrm{~g})$ was added. The solution was stirred for $20 \mathrm{~h}$ at ambient temperature and neutralized with DOWEX $50 \mathrm{~W}$. The solids were filtered off and the solvent was evaporated in vacuo. The resulting crude product was purified by column chromatography on silica gel using DCM/MeOH 9:1. The desired product 132 (3.72 g, $13.8 \mathrm{mmol}, 54 \%)$ was obtained as an orange resin.

${ }^{1} \mathrm{H}-N M R\left(300 \mathrm{MHz}\right.$, DMSO-d $\left.\mathrm{d}_{6}\right): \delta=7.43-7.20(\mathrm{~m}, 5 \mathrm{H}, \mathrm{Ph}), 4.82(\mathrm{~d}, \mathrm{~J}=12.3 \mathrm{~Hz}$, $1 \mathrm{H}, \mathrm{CH}_{2} \mathrm{Ph}$ ), 4.85 (d, J = $\left.12.3 \mathrm{~Hz}, 1 \mathrm{H}, \mathrm{CH}_{2} \mathrm{Ph}\right), 4.21$ (d, $J=7.5 \mathrm{~Hz}, 1 \mathrm{H}, \mathrm{H}-1$ ), 3.68 (d, J = 3.2 Hz, $1 \mathrm{H}, \mathrm{H}-4), 3.58\left(\mathrm{~d}, J=2.2 \mathrm{~Hz}, 1 \mathrm{H}, \mathrm{H}-6_{a}\right), 3.56(\mathrm{~d}, J=2.2 \mathrm{~Hz}, 1 \mathrm{H}$, $\left.\mathrm{H}-6_{b}\right)$, 3.45-3.27 (m, $\left.3 \mathrm{H}, \mathrm{H}-5, \mathrm{H}-3, \mathrm{H}-2\right) \mathrm{ppm}$.

${ }^{13}$ C-NMR (125 MHz, DMSO-d $\left.\mathrm{d}_{6}\right): \delta=138.3,128.2,127.2,127.4(\mathrm{Ph}), 102.8(\mathrm{C}-1)$, 75.4 (C-3), 73.6 (C-2), 70.8 (C-5), $69.6\left(\mathrm{CH}_{2} \mathrm{Ph}\right), 68.3$ (C-4), 60.7 (C-6) ppm.

MS (ESI): m/z $(\%)=293.2(100)[\mathrm{M}+\mathrm{Na}]^{+}$.

HRMS: $m / z$ calc. for $\mathrm{C}_{13} \mathrm{H}_{18} \mathrm{O}_{6} \mathrm{Na}[\mathrm{M}+\mathrm{Na}]^{+}:$293.0996, found 293.0996. 


\subsubsection{Benzyl-6-O-tertbutyldimethylsilyl- $\beta$-D- galactopyranoside (133)}

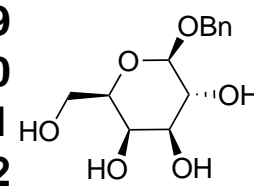

132

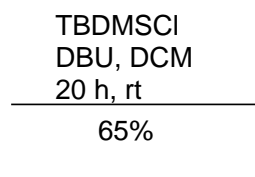

M: $270.3 \mathrm{~g} / \mathrm{mol}$

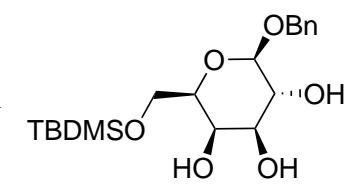

133

$\mathrm{M}: 384.5 \mathrm{~g} / \mathrm{mol}$

132 (3.72 g, $13.8 \mathrm{mmol}, 1.0$ eq.) and TBDMSCl (2,29 g, $15.2 \mathrm{mmol}, 1.1$ eq.) were suspended in DCM $(90 \mathrm{~mL})$ and stirred for $30 \mathrm{~min}$ at ambient temperature. The suspension was cooled to $0{ }^{\circ} \mathrm{C}$ and $\mathrm{DBU}(2.7 \mathrm{~mL}, 15.2 \mathrm{mmol}, 1.1$ eq.) in DCM $(15 \mathrm{~mL})$ was added dropwise. The resulting solution was stirred for $20 \mathrm{~h}$ at ambient temperature. The solvent was evaporated in vacuo and the resulting crude product was purified by column chromatography on silica gel using DCM/MeOH 95:5. The desired product 133 (3.46 g, $9.01 \mathrm{mmol}, 65 \%)$ was obtained as a white sticky solid.

${ }^{1}$ H-NMR $\left(300 \mathrm{MHz}, \mathrm{CDCl}_{3}\right): \delta=7.37-7.21(\mathrm{~m}, 5 \mathrm{H}, \mathrm{Ph}), 4.85(\mathrm{~d}, J=11.7 \mathrm{~Hz}, 1 \mathrm{H}$, $\left.\mathrm{CH}_{2} \mathrm{Ph}\right), 4.56\left(\mathrm{~d}, J=11.7 \mathrm{~Hz}, 1 \mathrm{H}, \mathrm{CH}_{2} \mathrm{Ph}\right), 4.23(\mathrm{~d}, J=7.8 \mathrm{~Hz}, 1 \mathrm{H}, \mathrm{H}-1), 3.90-3.77$ ( $\left.\mathrm{m}, J=3.2 \mathrm{~Hz}, 2 \mathrm{H}, \mathrm{H}-4, \mathrm{H}-6_{a}\right), 3.69$ (dd, $\left.J=9.6,7.8 \mathrm{~Hz}, 1 \mathrm{H}, \mathrm{H}-6_{b}\right), 3.47-3.31$ (m, $3 \mathrm{H}, \mathrm{H}-5, \mathrm{H}-3, \mathrm{H}-2), 0.89\left(\mathrm{~s}, 9 \mathrm{H}, \mathrm{C}\left(\mathrm{CH}_{3}\right)_{2}\right), 0.07\left(\mathrm{~s}, 6 \mathrm{H}, \mathrm{Si}\left(\mathrm{CH}_{3}\right)_{2}\right) \mathrm{ppm}$.

${ }^{13} \mathrm{C}-\mathrm{NMR}\left(125 \mathrm{MHz}, \mathrm{CDCl}_{3}\right): \delta=137.2,128.6,128.5,128.0(\mathrm{Ph}), 102.0(\mathrm{C}-$ 1), 75.0 (C-3), 73.8 (C-2), 71.8 (C-5), $70.9\left(\mathrm{CH}_{2} \mathrm{Ph}\right), 69.1$ (C-4), 62.7 (C-6), 26.0

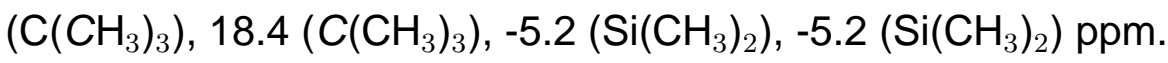

MS (ESI): $\mathbf{m} / \mathbf{z}(\%)=407.3(100)[\mathrm{M}+\mathrm{H}]^{+}$.

HRMS: $m / z$ calc. for $\mathrm{C}_{19} \mathrm{H}_{32} \mathrm{O}_{6} \mathrm{SiNa}[\mathrm{M}+\mathrm{Na}]^{+}:$407.1869, found 407.1860. 



\section{Bibliography}

[1] H. R. Horten, L. A. Moran, K. G. Scrimgeor, M. D. Perry, J. D. Rawn, Biochemie, 4th Aufl., Pearson Studium, 2008.

[2] Http://theconversation.com/dna-dating-how-molecular-clocks-are-refininghuman-evolutions-timeline-65606 (06.08.2018).

[3] O. Avery, C. MacLeod, M. McCarty, J. Exp. Med. 1944, 79, 137-158.

[4] J. D. Watson, F. H. Crick, Nature 1953, 171, 737-738.

[5] D. Voet, J. G. Voet, Biochemistry, 3. Aufl., J. Wiley and Sons, 2004.

[6] Http://dnacamp.cgrb.oregonstate.edu/w1d5_930.html (17.07.2018).

[7] J. Bernal, D. Crowfoot, Nature 1934, 133, 794-795.

[8] L. Pauling, R. B. Corey, H. R. Branson, Proc. Natl. Acad. Sci. 1951, 37, 235240.

[9] A. M. Gero, W. J. O’Sullivan, Blood Cells 1990, 16, 467.

[10] A. van Kuilenburg, H. van Lenthe, M. Loeffler, A. H. van Gennip, Clinical Chemistry 2004, 50, 2117-2124.

[11] T. Appleby, C. Kinsland, T. P. Begley, S. E. Ealick, Proc. Natl. Acad. Sci. USA 2000, 97, 2005-2010.

[12] P. Harris, J. C. Navarro Poulsen, K. F. Jensen, S. Larsen, Biochemistry 2000, 39, 4217-4224.

[13] B. G. Miller, A. M. Hassell, R. Wolfenden, M. V. Milburn, S. A. Short, Proc. Natl. Acad. Sci. U.S.A. 2000, 97, 2011-2016.

[14] B. G. Miller, A. M. Hassell, M. V. Milburn, S. A. Short, Acta Crystallogr. D. Biol. Crystallogr. 2000, 56, 472-474. 
[15] J. Wittmann, D. Heinrich, K. Gasow, A. Frey, U. Diederichsen, M. G. Rudolph, Structure 2008, 16, 82-92.

[16] D. Heinrich, U. Diederichsen, M. G. Rudolph, Chemistry 2009, 15, 66196625.

[17] M. J. Yablonski, D. A. Pasek, B. D. Han, M. E. Jones, T. W. Traut, J. Biol. Chem. 1996, 271, 10704-10708.

[18] B. J. Desai, B. M. Wood, E. V. Federov, A. A. Federov, B. Goryanova, T. L. Aymes, J. P. Richard, S. C. Almo, J. A. Gerlt, Biochemistry 2012, 51, 86658678.

[19] D. W. Banner, A. C. Bloomer, G. A. Petsko, D. C. Phillips, I. A. Wilson, Biochem. Biophys. Res. Commun. 1976, 72, 146-155.

[20] J. A. Smiley, M. E. Jones, Biochemistry 1992, 31, 12162-12168.

[21] J. A. Smiley, L. Saleh, Bioorg. Chem. 1999, 27, 297-306.

[22] J. B. Bell, M. E. Jones, J. Biol. Chem. 1991, 266, 12662-12667.

[23] K. Toth, T. L. Amyes, B. M. Wood, K. K. Chan, A. Shabila, J. A. Gerlt, J. P. Richard, Biochemistry 2009, 48, 8006-8013.

[24] S. Rindfleisch, Dissertation, Georg-August-Universität Göttingen, 2018.

[25] S. Hur, T. C. Bruice, Proc. Natl. Acad. Sci. USA 2002, 99, 9668-9673.

[26] P. Harris, J. C. Poulsen, K. F. Jensen, S. Larson, J. Mol. Biol. 2002, 318, 1019-1029.

[27] B. G. Miller, M. J. Snider, R. Wolfenden, S. A. Short, J. Biol. Chem. 2001, 276, 15174-15176.

[28] J. K. Lee, Orotidine Monophosphate Decarboxylase. A Mechanistic Dialogue, Springer Verlag, 2004.

[29] M. E. Meza-Avina, L. Wie, M. G. Buhendwa, E. Poduch, A. M. Bello, E. F. Pai, L. P. Kotra, Mini-Reviews in Medicinal Chemistry 2008, 8, 239-247.

[30] M. Fujihashi, L. Wei, L. P. Kotra, E. F. Pai, Journal of Molecular Biology 2009, 387, 1199-1210. 
[31] M. Fujihashi, T. Ishida, S. Kuroda, L. P. Kotra, E. F. Pai, K. Miki, J. Am. Chem. Soc. 2013, 135, 17432-17443.

[32] N. Wu, W. Gillon, E. F. Pai, Biochemistry 2002, 41, 4002-4011.

[33] N. Wu, Y. Mo, J. Gao, E. F. Pai, Proc. Natl. Acad. Sci. USA 2000, 97, 20172022.

[34] K. Tokuoka, Y. Kusakari, S. R. Krungkrai, H. Matsumura, Y. Kai, J. Krunkrai, T. Horii, T. Inoue, J. Biochem. 2008, 143, 69-78.

[35] K. K. Chan, B. M. Wood, A. A. Fedorov, E. V. Fedorov, H. J. Imker, T. L. Amyes, J. P. Richard, S. C. Almo, J. A. Gerlt, Biochemistry 2009, 48, 5518-5531.

[36] B. G. Miller, M. J. Snider, R. Wolfenden, S. A. Short, Biochemistry 2000, 39, 8113-8118.

[37] B. G. Miller, G. L. Butterfoss, S. A. Short, R. Wolfenden, Biochemistry 2001, $40,6227-6232$.

[38] J. K. Lee, K. N. Houk, Science 1997, 276, 942-945.

[39] B. G. Miller, R. Wolfenden, Annu. Rev. Biochem. 2002, 71, 847-885.

[40] B. P. Callahan, B. G. Miller, Bioorg. Chem. 2007, 35, 465-469.

[41] B. P. Callahan, A. F. Bell, P. J. Tonge, R. Wolfenden, Bioorg. Chem. 2006, 34, 59-65.

[42] R. B. Silverman, M. P. Groziak, J. Am. Soc. 1982, 104, 6434-6439.

[43] P. Beak, B. Siegel, J. Am. Soc. 1976, 98, 3601-3606.

[44] T. S. Lee, L. T. Chong, J. D. Chodera, P. A. Kollmann, J. Am. Chem. Soc. 2001, 123, 12837-12848.

[45] S. Mundra, L. P. Kotra, Future Med. Chem. 2014, 6, 165-177.

[46] C. L. Stanton, I.-F. W. Kuo, C. J. Mundy, T. Laino, K. N. Houk, J. Phys. Chem. B. 2007, 111, 12573-12581.

[47] P. Beak, B. Siegel, J. Am. Soc. 1973, 95, 7919.

[48] K. Shostak, M. E. Jones, Biochemistry 1992, 31, 12155-12161. 
[49] C. A. Lewis Jr., R. Wolfenden, Biochemistry 2007, 46, 13331-13343.

[50] D. Heinrich, Dissertation, Georg-August-Universität Göttingen, 2008.

[51] J. A. Smiley, P. Paneth, M. H. O’Leary, J. B. Bell, M. E. Jones, Biochemistry 1991, 30, 6216-6223.

[52] S. A. Acheson, J. B. Bell, M. E. Jones, R. Wolfenden, Biochemistry 1990, 29, 3198-3202.

[53] J. I. Ehrlich, C. C. Hwang, P. F. Cook, J. S. Blanchard, J. Am. Chem. Soc. 1999, 121, 6966-6967.

[54] T. L. Amyes, J. Richard, J. Tait, J. Am. Chem. Soc. 2005, 127, 15708-15709.

[55] A. Sievers, R. Wolfenden, Bioorg. Chem. 2004, 33, 45-52.

[56] A. Frey, Examensarbeit, Georg-August-Universität Göttingen, 2006.

[57] H. Vorbrüggen, C. Ruh-Pohlenz, Synthesis Of Nucleosides, American Cancer Society, 2004, 1-630.

[58] Y.-C. Shih, Y.-Y. Yang, C.-C. Lin, T.-C. Chien, J. Org. Chem. 2013, 78, 40274036.

[59] M. Fujihashi, A. M. Bello, E. Poduch, L. Wei, S. C. Anmedi, E. F. Pai, L. Kotra, J. Am. Chem. Soc. 2005, 127, 15048-15050.

[60] P. F. Torrence, B. Bhoosahn, J. Med. Chem. 1977, 20, 974-976.

[61] A. Patchornik, B. Amit, R. B. Woodward, J. Am. Chem. Soc. 1970, 92, 63336335.

[62] J. Strohmeier, Dissertation, Georg-August-Universität Göttingen, 2012.

[63] C. A. Cupas, R. L. Pearson, J. Am. Chem. Soc. 1968, 90, 4742.

[64] G. K. Prakash, T. Mathew, Angew. Chem. Int. Ed. 2010, 49, 1726-1728.

[65] P. Natarajan, R. Chaudhary, P. Venugopalan, J. Org. Chem. 2015, 80, 1049810504.

[66] J. P. Das, P. Sinha, S. Roy, Org. Lett. 2002, 18, 3055-3058.

[67] J. Wittmann, M. G. Rudolph, Acta Cryst. 2007, 63, 744-749. 
[68] B. W. Potvin, H. J. Stern, S. R. May, G. F. Lam, R. S. Krooth, Biochem. Pharmacol. 1978, 27, 655-665.

[69] H. L. Levine, R. S. Brody, F. H. Westheimer, Biochemistry 1980, 19, 49934999.

[70] M. U. Schmidt, J. Bruning, J. Glinnemann, M. W. Hutzler, P. Morschel, S. N. Ivashevskaya, J. van de Streek, D. Braga, L. Maini, M. R. Chierotti, R. Gobetto, Angew. Chem. Int. Ed. Engl. 2011, 50, 7924-7926.

[71] R. E. Handschuhmacher, J. Biol. Chem. 1960, 235, 2917-2919.

[72] R. S. Brody, F. H. Westheimer, J. Biol. Chem. 1979, 254, 4238-4244.

[73] M. A. Rishavy, W. W. Cleland, Biochemistry 2000, 39, 4569-4574.

[74] W.-Y. Tsang, F. M. Wood, B. McK. Wong, W. Wu, J. A. Gerlt, T. L. Amyes, J. P. Richard, J. Am. Chem. Soc. 2012, 134, 14580-14594.

[75] T. L. Amyes, B. M. Wood, K. Chan, J. A. Gerlt, J. P. Richard, J. Am. Chem. Soc. 2008, 130, 1574-1575.

[76] K. Toth, T. L. Amyes, B. M. Wood, K. K. Chan, J. A. Gerlt, J. P. Richard, J. Am. Chem. Soc. 2007, 129, 12946-12947.

[77] J. L. Van Vleet, L. A. Reinhardt, B. G. Miller, A. Sievers, W. W. Cleland, Biochemistry 2008, 47, 798-803.

[78] A. Vardi-Kilsthain, D. Doron, D. T. Major, Biochemistry 2013, 52, 4382-4390.

[79] R. Kluger, S. Rathgeber, FEBS J 2008, 275, 6089-6100.

[80] J. Gao, S. Ma, D. T. Major, K. Nam, J. Pu, D. G. Truhlar, Chem. Rev. 2006, 106, 3188-3209.

[81] G. W. Howe, R. Kluger, J. Org. Chem. 2014, 79, 10972-10980.

[82] E. S. Polovnikova, M. J. McLeish, E. A. Sergienko, J. T. Burgner, N. L. Anderson, A. K. Bera, F. Jordan, G. L. Kenyon, M. S. Hasson, Biochemistry 2003, $42,1820-1830$.

[83] A. Yep, G. L. Kenyon, M. J. McLeish, Proc. Natl. Acad. Sci. USA 2008, 105, 5733-5738. 
[84] R. Kluger, K. Tittmann, Chem. Rev. 2008, 108, 1797-1833.

[85] D. J. T. Porter, S. A. Short, Biochemistry 2000, 39, 11788-11800.

[86] F. R. Traube, T. Carell, RNA Biology 2017, 14, 1099-1107.

[87] S. Kumar, X. Cheng, S. Klimasauksas, S. Mi, J. Postfai, R. J. Roberts, G. Wilson, Nucleic Acids Res. 1993, 22.

[88] S. Feng, S. J. Cokus, X. Zhang, P.-Y. Chen, M. Bostick, M. G. Goll, J. Hetzel, J. Jain, S. H. Strauss, M. E. Halpern, C. Ukomadu, K. C. Sadler, S. Pradhan, M. Pellegrini, S. E. Jacobsen, PNAS 2010, 107, 8689-8694.

[89] K. W. Jair, K. E. Bachmann, H. Suzuki, A. H. Ting, I. Rhee, R. W. Yen, K. E. Baylin, S. B. Scuebel, Cancer Research 2006, 66, 682-692.

[90] A. Jeltsch, W. Nellen, F. Lyko, Trends Biochem. Sci. 2006, 6, 306-308.

[91] M. G. Goll, F. Kirpekar, K. A. Maggert, J. A. Yoder, C. L. Hsieh, K. G. Zhang, S. E. Jacobsen, T. H. Bestor, Science 2006, 5759, 395-398.

[92] M. Muller, M. Hartmann, I. Schuster, S. Bender, K. L. Thuring, M. Helm, J. R. Katze, W. Nellen, F. Lyko, A. E. Ehrenhofer-Murray, Nucleic Acids Res. 2015, 43, 10952-10962.

[93] R. L. Hurto, Adv. Exp. Med. Biol. 2011, 722, 137-155.

[94] T. P. Jurkowski, A. Jeltsch, PLoS One 2011, 6.

[95] T. P. Jurkowski, M. Meusburger, S. Phalke, M. Helm, W. Nellen, G. Reuter, A. Jeltsch, RNA 2008, 14, 1663-1670.

[96] E. C. Schulz, H. M. Roth, S. Ankri, R. Ficner, PLoS One 2012, 7, e3872.

[97] N. Okada, S. Noguchi, H. Kasai, N. Shindo-Okada, T. Ohgi, T. Goto, S. Nishimura, J. Biol. Chem. 1979, 8, 3067-3073.

[98] D. Dowling, Z. D Miles, C. Kohrer, S. J Maiocco, S. J Elliott, V. Bandarian, C. L Drennan, Nucleic acids research 2016, 44, 3067-3073.

[99] H. Kasai, Z. Ohashi, F. Harada, S. Nishimura, N. J. Oppenheimer, P. F. Crain, J. G. Liehr, D. L. Von Minden, J. A. McCloskey, Biochemistry 1975, 14, 198208. 
[100] T. Ohgi, T. Kondo, T. Goto, J. Am. Chem. Soc. 1979, 101, 3629-3633.

[101] T. Kondo, T. Ohgi, T. Goto, Agric. Biol. Chem. 1977, 41, 1501-1507.

[102] T. Kondo, K. Okamoto, T. Ohgi, T. Goto, Tetrahedron 1986, 42, 207-213.

[103] H. Akimoto, E. Imamiya, T. Hitaka, H. Nomura, J. CHEM SOC. PERKIN TRANS. 1988, 1, 1637-1644.

[104] C. J. Barnett, L. Grubb, Tetrahedron 2000, 56, 9221-9225.

[105] S. M. Ali, K. Ramesh, R. T. Borchardt, Tetrahedron Lett. 1990, 31, 1509-1512.

[106] B. M. Trost, M. T. Sorum, Org. Proc. Res. and Dev. 2003, 7, 432-435.

[107] H. Ovaa, J. D. C. Codee, B. Lastdrager, H. S. Overkleeft, G. A. van der Marel, J. H. van Boom, Tetrahedron Lett. 1998, 39, 7987-7990.

[108] D. Volanthen, C. J. Leumann, Synthesis 2003, 7, 1087-1090.

[109] H.-D. Gerber, G. Klebe, Org. Biomol. Chem. 2012, 10, 8660-8668.

[110] S. Brass, H.-D. Gerber, S. Dörr, W. E. Diederich, Tetrahedron 2006, 62, 17771786.

[111] R. L. Lehtilä, J. O. Lehtilä, M. U. Roslund, R. Leino, Tetrahedron 2004, 60, 3653-3661.

[112] G. Catelani, F. Collona, A. Marra, Carbohydrate Research 1988, 182, 297300.

[113] P. R. Skaaderup, L. Hyldtoft, R. Madsen, Monatshefte für Chemie 2002, 133, 467-472.

[114] L. Moynihan, R. Chadda, M. P., P. V. Murphy, Organic Letters 2015, 17, 62266229.

[115] M. A. Fernandez-Herrera, H. Lopez-Munos, J. M. V. Hernandez-Vazques, M. Lopez-Davila, J. Sandoval-Ramirez, Eur. J. Med. Chem. 2011, 46, 38773886.

[116] A. B. Smith, J. B. Sperry, Q. Han, J. Org. Chem. 2007, 72, 6891-6900.

[117] D. L. Wright, Curr. Org. Chem. 1999, 3. 
[118] S. Johansson, P. Neumann, A. Wulf, L. M. Welp, H.-D. Gerber, M. Krull, U. Diederichsen, H. Urlaub, R. Ficner, Scientific Reports 2018, 8:8880.

[119] G. L. Igloi, H. Kossel, Nucleic Acids Res 1985, 13, 6881-6898.

[120] C. M. Porter, B. G. Miller, Bioorg Chem 2012, 43, 44-50. 


\section{Appendix}

\section{A. Abbreviations}

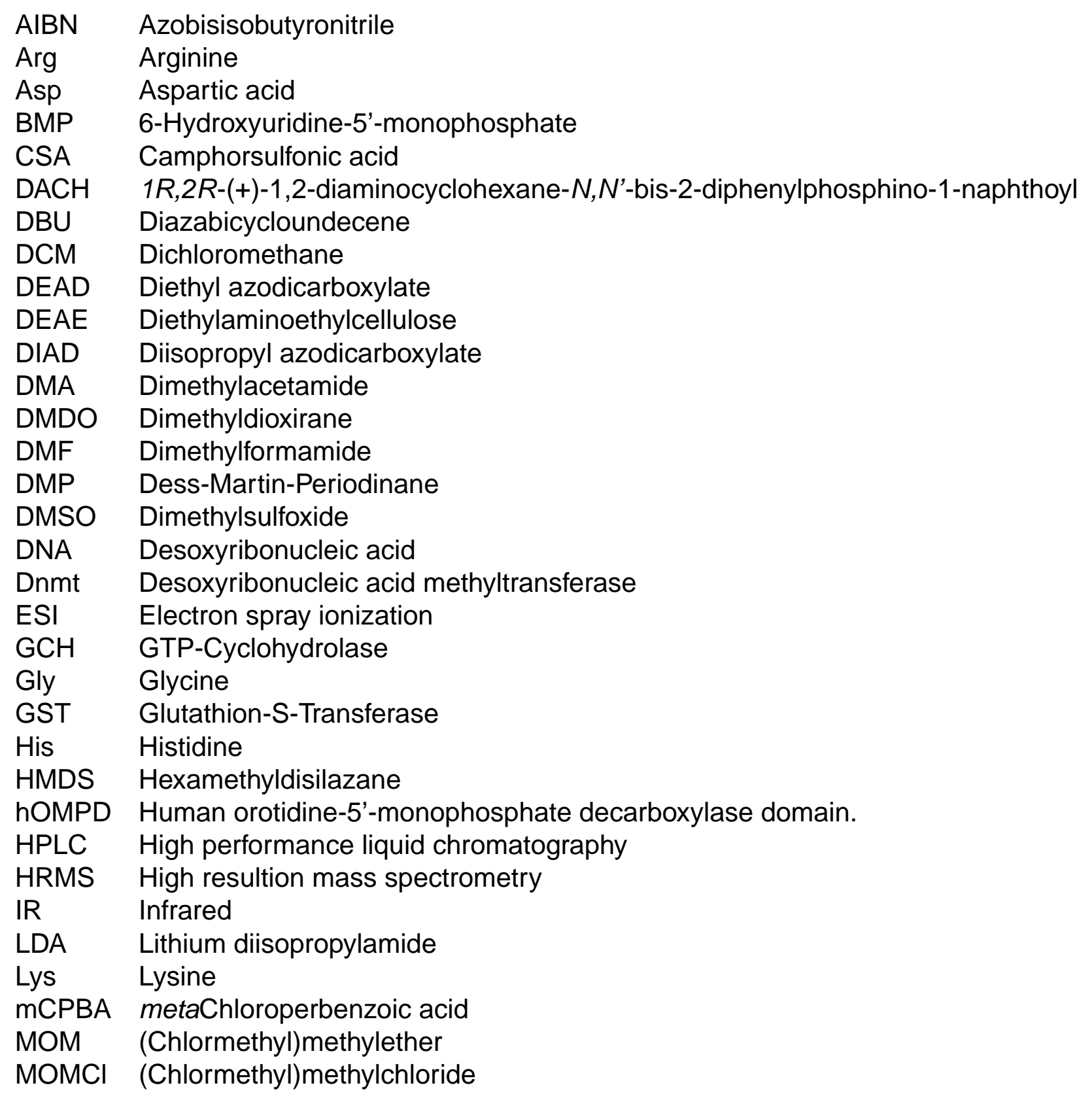




$\begin{array}{ll}\text { mRNA } & \text { messenger ribonucleic acid } \\ \text { MS } & \text { Mass spectrometry } \\ \text { NBS } & \text { N-Bromosuccinimide } \\ \text { NIS } & \text { N-lodosuccinimide } \\ \text { NMR } & \text { Nuclear magnetic resonance } \\ \text { OMP } & \text { Orotidine-5'monophosphate } \\ \text { OMPD } & \text { Orotidine-5'monophosphate decarboxylase } \\ \text { PCC } & \text { Pyridiniumchlorochromate } \\ \text { PDB } & \text { Protein data bank } \\ \text { PNBA } & \text { paraNitrobenzylalcohol } \\ \text { RNA } & \text { ribonucleic acid } \\ \text { SAH } & \text { S-Adenosyl methionine } \\ \text { SAM } & \text { S-Adenosyl methionine } \\ \text { Ser } & \text { Serine } \\ \text { TAT } & \text { Tyrosine aminotransferase } \\ \text { TBAF } & \text { Tetrabutylammoniumfluoride } \\ \text { TBDMSCl } & \text { Tertbutyldimethylsilylchlorid } \\ \text { TBHP } & \text { Tertbutylhydroxyperoxide } \\ \text { TEA } & \text { Trietylamine } \\ \text { TEAA } & \text { Triethylammonium acetate } \\ \text { TEMPO } & \text { (2,2,6,6-tetramethylpiperidin-1-yl)oxidanyl } \\ \text { TES } & \text { Triethylsilyl } \\ \text { TFA } & \text { Trifluoroacetic acid } \\ \text { TFAA } & \text { Trifluoroacetic anhydride } \\ \text { TGT } & \text { tRNA guanine transglycosylase } \\ \text { THF } & \text { Tetrahydrofurane } \\ \text { Thr } & \text { Threonine } \\ \text { TIM } & \text { Triosephosphate isomerase } \\ \text { TLC } & \text { Thin layer chromatographie } \\ \text { TMS } & \text { Trimethylsilyl } \\ \text { TMSCl } & \text { Trimethylsilylchlorid } \\ \text { TPP } & \text { Triphenylphosphine } \\ \text { tRNA } & \text { transfer ribonucleic acid } \\ \text { Tyr } & \text { Tyrosine } \\ \text { UMP } & \text { Uridine-5'-monophosphate } \\ \text { UMPS } & \text { Uridine-5'-monophosphate synthase } \\ \text { UV } & \text { Ultraviolett } \\ \text { wt } & \text { wild type } \\ & \end{array}$




\section{B. Crystal data collection and refinement data}

\begin{tabular}{|l|l|}
\hline \multicolumn{2}{|c|}{ Data collection of hOMPD $_{\mathrm{wt}}$ crystals in complex with BMP } \\
\hline Wavelength $(\AA)$ & 0.7563 \\
\hline Resolution range $(\AA)$ & $30.3-0.95(0.984-0.95)$ \\
\hline Space group & C222 1 \\
\hline Unit cell $(\AA) /\left({ }^{\circ}\right)$ & $77.896116 .42561 .968 / 909090$ \\
\hline Total reflections & $619037(52593)$ \\
\hline Unique reflections & $171326(17215)$ \\
\hline Multiplicity & $3.6(3.1)$ \\
\hline Completeness $(\%)$ & $97.14(98.27)$ \\
\hline Mean $I / \sigma(I)$ & $17.94(2.12)$ \\
\hline Wilson B-factor & 8.26 \\
\hline R-merge & $0.03575(0.5231)$ \\
\hline R-meas & $0.04123(0.632)$ \\
\hline R-pim & $0.01988(0.3475)$ \\
\hline CC $_{1 / 2}$ & $0.999(0.76)$ \\
\hline CC* & $1(0.929)$ \\
\hline
\end{tabular}




\begin{tabular}{l|l|}
\multicolumn{2}{c}{ Model refinement of $\boldsymbol{h O M P D}_{\mathrm{wt}}$-BMP-complex data } \\
\hline Reflections used in refinement & 171183 (17204) \\
\hline Reflections used for R-free & 8468 (905) \\
\hline R-work & 0.0992 (0.3037) \\
\hline R-free & 0.1121 (0.3217) \\
\hline CC(work) & 0.966 (0.859) \\
\hline CC(free) & $0.957(0.867)$ \\
\hline Number of non-hydrogen atoms & 3527 \\
\hline macromolecules & 2957 \\
\hline ligands & 50 \\
\hline solvent & 520 \\
\hline Protein residues & 257 \\
\hline RMS(bonds) $(\AA)$ & 0.001 \\
\hline RMS(angles) $\left({ }^{\circ}\right)$ & 1.62 \\
\hline Ramachandran favored $(\%)$ & 98.81 \\
\hline Ramachandran allowed $(\%)$ & 1.19 \\
\hline Ramachandran outliers $(\%)$ & 0.00 \\
\hline Rotamer outliers $(\%)$ & 4.04 \\
\hline Clashscore & 10.63 \\
\hline Average B-factor & 11.61 \\
\hline macromolecules & 9.52 \\
\hline ligands & 17.92 \\
\hline solvent & 22.88 \\
\hline
\end{tabular}


Data collection of $h \mathrm{OMPD}_{\mathrm{wt}}$ crystals in complex with 6-aza-UMP

\begin{tabular}{|l|l|}
\hline Wavelength $(\AA)$ & 0.7293 \\
\hline Resolution range $(\AA)$ & $42.46-1.0(1.036-1.0)$ \\
\hline Space group & C222 1 \\
\hline Unit cell $(\AA) /\left({ }^{\circ}\right)$ & 77.67116 .57261 .97 / 909090 \\
\hline Total reflections & $568265(56287)$ \\
\hline Unique reflections & $147558(14770)$ \\
\hline Multiplicity & $3.9(3.8)$ \\
\hline Completeness $(\%)$ & $97.69(98.79)$ \\
\hline Mean $I / \sigma(I)$ & $15.19(1.59)$ \\
\hline Wilson B-factor & 9.09 \\
\hline R-merge & $0.04599(0.8464)$ \\
\hline R-meas & $0.05267(0.9766)$ \\
\hline R-pim & $0.02484(0.4715)$ \\
\hline CC $_{1 / 2}$ & $1(0.59)$ \\
\hline CC $^{*}$ & $1(0.861)$ \\
\hline
\end{tabular}




\begin{tabular}{l|l|}
\hline \multicolumn{2}{l}{ Model refinement of hOMPD $_{\mathrm{wt}}$-6-aza-UMP-complex data } \\
\hline Reflections used in refinement & $147554(14767)$ \\
\hline Reflections used for R-free & $7260(718)$ \\
\hline R-work & $0.1140(0.2930)$ \\
\hline R-free & $0.1321(0.3012)$ \\
\hline CC(work) & $0.978(0.804)$ \\
\hline CC(free) & $0.972(0.778)$ \\
\hline Number of non-hydrogen atoms & 2881 \\
\hline macromolecules & 2452 \\
\hline ligands & 42 \\
\hline solvent & 387 \\
\hline Protein residues & 258 \\
\hline RMS(bonds) $(\AA)$ & 0.012 \\
\hline RMS(angles) $\left({ }^{\circ}\right)$ & 1.70 \\
\hline Ramachandran favored $(\%)$ & 98.81 \\
\hline Ramachandran allowed (\%) & 1.19 \\
\hline Ramachandran outliers $(\%)$ & 0.00 \\
\hline Rotamer outliers $(\%)$ & 0.37 \\
\hline Clashscore & 4.36 \\
\hline Average B-factor & 13.03 \\
\hline macromolecules & 10.80 \\
\hline ligands & 17.57 \\
\hline solvent & 26.69 \\
\hline
\end{tabular}


Data collection of $h \mathrm{OMPD}_{\mathrm{wt}}$ crystals in complex with 6-amido-UMP

\begin{tabular}{|l|l|}
\hline Wavelength $(\AA)$ & 0.9763 \\
\hline Resolution range $(\AA)$ & $42.47-1.2(1.243-1.2)$ \\
\hline Space group & C222 1 \\
\hline Unit cell $(\AA) /\left({ }^{\circ}\right)$ & 77.735116 .30262 .174 / 909090 \\
\hline Total reflections & $569885(46920)$ \\
\hline Unique reflections & $85218(7891)$ \\
\hline Multiplicity & $6.7(5.9)$ \\
\hline Completeness $(\%)$ & $96.80(90.55)$ \\
\hline Mean $I / \sigma(I)$ & $13.40(1.80)$ \\
\hline Wilson B-factor & 12.47 \\
\hline R-merge & $0.07651(0.9925)$ \\
\hline R-meas & $0.08301(1.088)$ \\
\hline R-pim & $0.0318(0.4362)$ \\
\hline CC $_{1 / 2}$ & $0.999(0.668)$ \\
\hline CC $^{*}$ & $1(0.895)$ \\
\hline
\end{tabular}




\begin{tabular}{|c|c|}
\hline Reflections used in refinement & 85217 (7891) \\
\hline Reflections used for R-free & $4164(386)$ \\
\hline R-work & $0.1212(0.2844)$ \\
\hline R-free & $0.1456(0.2976)$ \\
\hline CC(work) & $0.972(0.734)$ \\
\hline $\mathrm{CC}($ free $)$ & $0.966(0.662)$ \\
\hline Number of non-hydrogen atoms & 2615 \\
\hline macromolecules & 2222 \\
\hline ligands & 32 \\
\hline solvent & 361 \\
\hline Protein residues & 257 \\
\hline RMS(bonds) ( $\AA$ ) & 0.012 \\
\hline RMS(angles) $\left(^{\circ}\right)$ & 1.69 \\
\hline Ramachandran favored (\%) & 98.41 \\
\hline Ramachandran allowed (\%) & 1.59 \\
\hline Ramachandran outliers (\%) & 0.00 \\
\hline Rotamer outliers (\%) & 1.64 \\
\hline Clashscore & 3.49 \\
\hline Average B-factor & 16.22 \\
\hline macromolecules & 13.74 \\
\hline ligands & 16.61 \\
\hline solvent & 31.41 \\
\hline
\end{tabular}




Data collection of $h \mathrm{OMPD}_{\mathrm{wt}}$ crystals in complex with 6-thioamido-UMP
\begin{tabular}{|l|l|}
\hline Wavelength $(\AA)$ & 0.9763 \\
\hline Resolution range $(\AA)$ & $42.42-1.124(1.164-1.124)$ \\
\hline Space group & $\mathrm{C} 222_{1}$ \\
\hline Unit cell $(\AA) /\left(^{\circ}\right)$ & 77.461116 .10562 .13 / 909090 \\
\hline Total reflections & $636400(26827)$ \\
\hline Unique reflections & $102727(7283)$ \\
\hline Multiplicity & $6.2(3.7)$ \\
\hline Completeness $(\%)$ & $96.66(69.28)$ \\
\hline Mean $I / \sigma(I)$ & $13.58(1.60)$ \\
\hline Wilson B-factor & 11.61 \\
\hline R-merge & $0.07188(0.7435)$ \\
\hline R-meas & $0.07837(0.8666)$ \\
\hline R-pim & $0.03074(0.4303)$ \\
\hline CC & $0.999(0.673)$ \\
\hline CC & $1(0.897)$ \\
\hline
\end{tabular}


Model refinement of $h O M P D_{w t}-6$-thioamido-UMP-complex data

\begin{tabular}{|c|c|}
\hline Reflections used in refinement & $102725(7283)$ \\
\hline Reflections used for R-free & $5044(360)$ \\
\hline R-work & $0.1252(0.3236)$ \\
\hline R-free & $0.1519(0.3443)$ \\
\hline CC(work) & $0.972(0.784)$ \\
\hline CC(free) & $0.963(0.715)$ \\
\hline Number of non-hydrogen atoms & 2641 \\
\hline macromolecules & 2269 \\
\hline ligands & 43 \\
\hline solvent & 329 \\
\hline Protein residues & 257 \\
\hline RMS(bonds) $(\AA)$ & 0.012 \\
\hline RMS(angles) $\left(^{\circ}\right)$ & 1.71 \\
\hline Ramachandran favored (\%) & 98.81 \\
\hline Ramachandran allowed (\%) & 1.19 \\
\hline Ramachandran outliers (\%) & 0.00 \\
\hline Rotamer outliers (\%) & 0.78 \\
\hline Clashscore & 4.86 \\
\hline Average B-factor & 15.53 \\
\hline macromolecules & 13.39 \\
\hline ligands & 19.98 \\
\hline solvent & 29.76 \\
\hline
\end{tabular}


Data collection of $h^{O M P D_{w t}}$ crystals in complex with 6-methyl-UMP

\begin{tabular}{|l|l|}
\hline Wavelength $(\AA)$ & \\
\hline Resolution range $(\AA)$ & $42.5-1.122(1.162-1.122)$ \\
\hline Space group & C222 1 \\
\hline Unit cell $(\AA) /\left({ }^{\circ}\right)$ & 77.375116 .68762 .027 / 909090 \\
\hline Total reflections & $618960(24690)$ \\
\hline Unique reflections & $104066(7617)$ \\
\hline Multiplicity & $5.9(3.2)$ \\
\hline Completeness $(\%)$ & $97.07(71.93)$ \\
\hline Mean $I / \sigma(I)$ & $12.34(1.54)$ \\
\hline Wilson B-factor & 13.21 \\
\hline R-merge & $0.06168(0.5737)$ \\
\hline R-meas & $0.06729(0.6806)$ \\
\hline R-pim & $0.02652(0.3563)$ \\
\hline CC $_{1 / 2}$ & $0.999(0.797)$ \\
\hline CC $^{*}$ & $1(0.942)$ \\
\hline
\end{tabular}


Model refinement of $h \mathrm{OMPD}_{\mathrm{wt}}-6$-methyl-UMP-complex data

\begin{tabular}{|l|l|}
\hline Reflections used in refinement & 104065 (7617) \\
\hline Reflections used for R-free & 5183 (379) \\
\hline R-work & 0.1269 (0.3332) \\
\hline R-free & 0.1458 (0.3075) \\
\hline CC(work) & 0.970 (0.741) \\
\hline CC(free) & 0.967 (0.788) \\
\hline Number of non-hydrogen atoms & 2466 \\
\hline macromolecules & 2146 \\
\hline ligands & 43 \\
\hline solvent & 277 \\
\hline Protein residues & 257 \\
\hline RMS(bonds) (̊̊) & 0.014 \\
\hline RMS(angles) ( $\left.{ }^{\circ}\right)$ & 1.85 \\
\hline Ramachandran favored (\%) & 98.81 \\
\hline Ramachandran allowed (\%) & 1.19 \\
\hline Ramachandran outliers (\%) & 0.00 \\
\hline Rotamer outliers (\%) & 0.43 \\
\hline Clashscore & 2.51 \\
\hline Average B-factor & 17.00 \\
\hline macromolecules & 15.19 \\
\hline ligands & 24.67 \\
\hline solvent & 29.84 \\
\hline
\end{tabular}


Data collection of $h O M P D_{w t}$ crystals in complex with 6-isopropyl-UMP

\begin{tabular}{|l|l|}
\hline Wavelength $(\AA)$ & 0.9763 \\
\hline Resolution range $(\AA)$ & 64.52 - 1.3 (1.346 - 1.3) \\
\hline Space group & C222 1 \\
\hline Unit cell $(\AA) /\left({ }^{\circ}\right)$ & 77.562116 .2862 .075 / 909090 \\
\hline Total reflections & $447839(44961)$ \\
\hline Unique reflections & $69057(6840)$ \\
\hline Multiplicity & $6.5(6.6)$ \\
\hline Completeness $(\%)$ & $99.75(99.50)$ \\
\hline Mean $I / \sigma(I)$ & $11.21(0.70)$ \\
\hline Wilson B-factor & 18.52 \\
\hline R-merge & $0.08549(2.165)$ \\
\hline R-meas & $0.09297(2.35)$ \\
\hline R-pim & $0.03613(0.9043)$ \\
\hline CC $_{1 / 2}$ & $0.998(0.433)$ \\
\hline CC $^{*}$ & $1(0.778)$ \\
\hline
\end{tabular}


Model refinement of $h O M P D_{w t}$-6-isopropyl-UMP-complex data

\begin{tabular}{|c|c|}
\hline Reflections used in refinement & $69056(6821)$ \\
\hline Reflections used for R-free & 3344 (332) \\
\hline R-work & $0.1417(0.5017)$ \\
\hline R-free & $0.1730(0.4634)$ \\
\hline CC(work) & $0.978(0.643)$ \\
\hline $\mathrm{CC}($ free $)$ & $0.971(0.647)$ \\
\hline Number of non-hydrogen atoms & 2639 \\
\hline macromolecules & 2259 \\
\hline ligands & 45 \\
\hline solvent & 335 \\
\hline Protein residues & 256 \\
\hline RMS(bonds) $(\AA)$ & 0.091 \\
\hline RMS(angles) $\left(^{\circ}\right.$ ) & 3.35 \\
\hline Ramachandran favored (\%) & 98.01 \\
\hline Ramachandran allowed (\%) & 1.99 \\
\hline Ramachandran outliers (\%) & 0.00 \\
\hline Rotamer outliers (\%) & 0.41 \\
\hline Clashscore & 2.80 \\
\hline Average B-factor & 18.97 \\
\hline macromolecules & 16.64 \\
\hline ligands & 21.99 \\
\hline solvent & 34.29 \\
\hline
\end{tabular}


Data collection of $h \mathrm{OMPD}_{\mathrm{wt}}$ crystals in complex with 6-isopropenyl-UMP

\begin{tabular}{|l|l|}
\hline Resolution range $(\AA)$ & $44.97-1.15(1.191-1.15)$ \\
\hline Space group & $\mathrm{P} 12_{1} 1$ \\
\hline Unit cell $(\AA ̊) /\left({ }^{\circ}\right)$ & 70.77261 .97269 .464 / 90112.57890 \\
\hline Total reflections & $668931(66385)$ \\
\hline Unique reflections & $192202(19047)$ \\
\hline Multiplicity & $3.5(3.5)$ \\
\hline Completeness (\%) & $97.86(97.51)$ \\
\hline Mean $I / \sigma(I)$ & $14.84(1.25)$ \\
\hline Wilson B-factor & 16.66 \\
\hline R-merge & $0.03648(1.137)$ \\
\hline R-meas & $0.04338(1.343)$ \\
\hline R-pim & $0.02318(0.7065)$ \\
\hline CC $_{1 / 2}$ & $0.999(0.503)$ \\
\hline CC $^{*}$ & $1(0.818)$ \\
\hline
\end{tabular}


Model refinement of $h O \mathrm{MPD}_{\mathrm{wt}}$-6-isopropenyl-UMP-complex data

\begin{tabular}{|c|c|}
\hline Reflections used in refinement & $192186(19047)$ \\
\hline Reflections used for R-free & $9755(931)$ \\
\hline R-work & $0.1356(0.3424)$ \\
\hline R-free & $0.1573(0.3467)$ \\
\hline CC(work) & $0.962(0.634)$ \\
\hline CC(free) & $0.960(0.624)$ \\
\hline Number of non-hydrogen atoms & 4729 \\
\hline macromolecules & 4136 \\
\hline ligands & 101 \\
\hline solvent & 492 \\
\hline Protein residues & 514 \\
\hline RMS(bonds) $(\AA)$ & 0.018 \\
\hline RMS(angles) $\left(^{\circ}\right)$ & 2.11 \\
\hline Ramachandran favored (\%) & 97.82 \\
\hline Ramachandran allowed (\%) & 2.18 \\
\hline Ramachandran outliers (\%) & 0.00 \\
\hline Rotamer outliers (\%) & 0.00 \\
\hline Clashscore & 8.13 \\
\hline Average B-factor & 22.71 \\
\hline macromolecules & 21.28 \\
\hline ligands & 16.84 \\
\hline solvent & 35.90 \\
\hline
\end{tabular}


Data collection of $h \mathrm{OMPD}_{314 \mathrm{AcK}}$ crystals in complex with OMP

\begin{tabular}{|l|l|}
\hline Wavelength $(\AA)$ & 0.8266 \\
\hline Resolution range $(\AA)$ & 44.67 - 1.2 (1.243 - 1.2) \\
\hline Space group & C222 1 \\
\hline Unit cell $(\AA) /\left({ }^{\circ}\right)$ & 77.285116 .81961 .951 / 909090 \\
\hline Total reflections & $596481(59213)$ \\
\hline Unique reflections & $87507(8673)$ \\
\hline Multiplicity & $6.8(6.8)$ \\
\hline Completeness $(\%)$ & $99.85(99.88)$ \\
\hline Mean $I / \sigma(I)$ & $14.57(1.41)$ \\
\hline Wilson B-factor & 12.66 \\
\hline R-merge & $0.08955(1.6)$ \\
\hline R-meas & $0.09694(1.731)$ \\
\hline R-pim & $0.03677(0.6548)$ \\
\hline CC $_{1 / 2}$ & $0.999(0.587)$ \\
\hline CC & $1(0.86)$ \\
\hline
\end{tabular}




\begin{tabular}{|c|c|}
\hline \multicolumn{2}{|c|}{ Model refinement of $h \mathrm{OMPD}_{314 \mathrm{AcK}}-\mathrm{OMP}$-complex data } \\
\hline Reflections used in refinement & $87501(8672)$ \\
\hline Reflections used for R-free & $4273(433)$ \\
\hline R-work & $0.1315(0.3388)$ \\
\hline R-free & $0.1576(0.3412)$ \\
\hline CC(work) & $0.974(0.799)$ \\
\hline $\mathrm{CC}$ (free) & $0.971(0.727)$ \\
\hline Number of non-hydrogen atoms & 2782 \\
\hline macromolecules & 2387 \\
\hline ligands & 67 \\
\hline solvent & 328 \\
\hline Protein residues & 256 \\
\hline RMS(bonds) $(\AA)$ & 0.013 \\
\hline RMS(angles) $\left(^{\circ}\right)$ & 1.78 \\
\hline Ramachandran favored (\%) & 98.79 \\
\hline Ramachandran allowed (\%) & 1.21 \\
\hline Ramachandran outliers (\%) & 0.00 \\
\hline Rotamer outliers (\%) & 0.77 \\
\hline Clashscore & 4.46 \\
\hline Average B-factor & 16.93 \\
\hline macromolecules & 14.82 \\
\hline ligands & 24.49 \\
\hline solvent & 30.80 \\
\hline
\end{tabular}


Data collection of $\boldsymbol{h O M P D}_{314 \mathrm{AcK}}$ crystals in complex with BMP

\begin{tabular}{|l|l|}
\hline Wavelength $(\AA)$ & \\
\hline Resolution range $(\AA)$ & $44.72-1.1(1.139-1.1)$ \\
\hline Space group & C222 1 \\
\hline Unit cell $(\AA) /\left({ }^{\circ}\right)$ & $77.386116 .83862 .036 / 909090$ \\
\hline Total reflections & $766064(74211)$ \\
\hline Unique reflections & $113656(11263)$ \\
\hline Multiplicity & $6.7(6.6)$ \\
\hline Completeness $(\%)$ & $99.88(99.90)$ \\
\hline Mean $I / \sigma(I)$ & $17.26(2.72)$ \\
\hline Wilson B-factor & 10.63 \\
\hline R-merge & $0.05806(0.7654)$ \\
\hline R-meas & $0.06293(0.8309)$ \\
\hline R-pim & $0.02403(0.32)$ \\
\hline CC $_{1 / 2}$ & $0.999(0.842)$ \\
\hline CC $^{*}$ & $1(0.956)$ \\
\hline
\end{tabular}




\begin{tabular}{l|l|}
\multicolumn{1}{l}{ Model refinement of hOMPD $_{314 \text { AcK }}$-BMP-complex data } \\
\hline Reflections used in refinement & $113650(11261)$ \\
\hline Reflections used for R-free & $5781(550)$ \\
\hline R-work & $0.1072(0.2308)$ \\
\hline R-free & $0.1244(0.2380)$ \\
\hline CC(work) & $0.971(0.700)$ \\
\hline CC(free) & $0.962(0.649)$ \\
\hline Number of non-hydrogen atoms & 2757 \\
\hline macromolecules & 2377 \\
\hline ligands & 56 \\
\hline solvent & 324 \\
\hline Protein residues & 256 \\
\hline RMS(bonds) $(\AA)$ & 0.012 \\
\hline RMS(angles) $\left({ }^{\circ}\right)$ & 1.77 \\
\hline Ramachandran favored $(\%)$ & 98.79 \\
\hline Ramachandran allowed $(\%)$ & 1.21 \\
\hline Ramachandran outliers $(\%)$ & 0.00 \\
\hline Rotamer outliers $(\%)$ & 0.77 \\
\hline Clashscore & 5.50 \\
\hline Average B-factor & 14.50 \\
\hline macromolecules & 12.39 \\
\hline ligands & 14.34 \\
\hline solvent & 30.02 \\
\hline
\end{tabular}




\section{Acknowledgments}

First and foremost I would like to thank Prof. Dr. Ulf Diederichsen for giving me the opportunity to work on these highly interesting research topics at the interface of organic chemistry and biology. Thank you for the academic freedom and all the great support.

Thank you to Prof. Dr. Kai Tittmann for being part of the thesis committee and acting as second referee. Your knowledge in the field of enzymology and crystallography were very helpful and I enjoyed our discussion on the sometimes confusing data.

Moreover, I would like to thank the further members of the examination board Prof. Dr. Manuel Alcarazo, Prof. Dr. Claudia Steinem, Dr. Sebastian Kruss and Dr. Michael John.

Sören thank you for the close cooperation on the OMPD project. You made it always possible to measure new inhibitor samples even on the tightest schedules and the structure resolution was always impressing. Sven thank you for your patience during the queuine synthesis.

I thank my Bachelor student Marcel and my lab intern Isabelle for the support on the inhibitor synthesis. You did excellent work.

Thank you to the Central Analytics team for the measurement of a multitude of mass spectra and to the NMR facility for the acquisition of NMR spectra.

To all members of the Diederichsen group, especially to my colleagues from lab 106, Patrick Menzel, Dr. Stephen Middel, Nils Frederik Meyer, Lina Kopp, Lucas Hensen, Simon Pottgießer and Manuel Müller, thank you for the great time. I always enjoyed being part of this group, the kicker competitions and our funny coffee breaks. To Patrick, Tobi, Pira and Markus, you made fantasy football great again.

A big thank you goes to the proofreaders of this thesis. Mike, Patrick, Tobi and Pira your comments were highly appreciated. 
Furthermore, I would like to thank Angela Heinemann and Aiofe Neville for all the organizational support. The office was always a helpful place. And to "Mrs. Heinemann" thank you for a little "kick in the ass" when necessary.

Most notably I would like to thank my parents for all their moral and financial support from the start of my Bachelor studies to the last line of this thesis. Without you none of this would have been achievable.

Carina you helped me through the hardest times of this work and built me up, when I wanted to quit. You make my life brighter and I am glad your are always by my side.

And last but not least I would like to thank all my family and friends for the great time. I am fortunate to have you around me. 